\title{
Spaces of Co-existence: \\ The Processes and Prospects of Living with Endangered Species
}

\author{
By \\ John Wall \\ Bachelor of Arts, Memorial University of Newfoundland, 1992 \\ Master of Science, University of Guelph, 1999
}

A dissertation submitted to the Faculty of Graduate and Postdoctoral Affairs in partial fulfilment of the requirements for the degree of

Doctor of Philosophy

in

Geography

Carleton University

Ottawa, Ontario

(C) 2011, John Wall 


\section{Library and Archives \\ Canada}

Published Heritage Branch

395 Wellington Street

Ottawa ON K1A ON4

Canada
Bibliotheqque et

Archives Canada

Direction du

Patrimoine de l'édition

395, rue Wellington

Ottawa ON K1A ON4

Canada
Your file Votre référence

ISBN: 978-0-494-81555-7

Our file Notre référence

ISBN: $978-0-494-81555-7$
NOTICE:

The author has granted a nonexclusive license allowing Library and Archives Canada to reproduce, publish, archive, preserve, conserve, communicate to the public by telecommunication or on the Internet, loan, distribute and sell theses worldwide, for commercial or noncommercial purposes, in microform, paper, electronic and/or any other formats.

The author retains copyright ownership and moral rights in this thesis. Neither the thesis nor substantial extracts from it may be printed or otherwise reproduced without the author's permission.

\section{AVIS:}

L'auteur a accordé une licence non exclusive permettant à la Bibliothèque et Archives Canada de reproduire, publier, archiver, sauvegarder, conserver, transmettre au public par télécommunication ou par l'Internet, prêter, distribuer et vendre des thèses partout dans le monde, à des fins commerciales ou autres, sur support microforme, papier, électronique et/ou autres formats.

L'auteur conserve la propriété du droit d'auteur et des droits moraux qui protège cette thèse. $\mathrm{Ni}$ la thèse ni des extraits substantiels de celle-ci ne doivent être imprimés ou autrement reproduits sans son autorisation.
In compliance with the Canadian Privacy Act some supporting forms may have been removed from this thesis.

While these forms may be included in the document page count, their removal does not represent any loss of content from the thesis.
Conformément à la loi canadienne sur la protection de la vie privée, quelques formulaires secondaires ont été enlevés de cette thèse.

Bien que ces formulaires aient inclus dans la pagination, il n'y aura aucun contenu manquant.

\section{Canadä}




\section{Abstract}

As humans alter the world ever more dramatically, the possibility of successful futures for other species declines. Current extinctions are driven by human impacts - namely conversion of plant and animal habitat for human use, overexploitation of marine and terrestrial plants and animals, pollution that reduces reproductive success, as well as the effects of anthropogenic climate change. Governments and conservationists respond to species loss by trying to understand anthropogenic impacts on other species and to control adverse human behaviour. However, the multiple conditions and sites of co-existence between humans and wild animals offer a fertile space for geographic inquiry that explores the nature of space shared between humans and others, and similarities and differences among places and species. Approaches to separating humans and other species in the interest of biodiversity protection appear to be failing. Future efforts will depend on a new understanding of shared space and co-existence between humans and other species.

Using an animal geography approach and qualitative methods this research examines the shared physical, discursive, and political spaces of humans and grizzly bears (Ursus arctos) in the Bow Valley, Alberta, humans and eastern wolves (Canis lycaon) in the Ottawa Valley, Ontario, and humans and North Atlantic right whales (Eubalaena glacialis) in the Bay of Fundy, New Brunswick. In these cases, animal subjectivity, compatible lifeways between humans and other species, human orientation toward the other, and mutuality in relationship with were found to correlate with successful co-existence. The prospects for successful coexistence are heavily conditioned by these four enabling conditions. 


\section{Dedication}

To Mom and Dad, Barbara, Patricia and Ismo, Hope, Lachlan, and Skylar;

and,

in alphabetical order:

Bear 66, Delilah, Isabelle Dubé, and McDonald 4.

Your deaths have saved many lives. You've made a different future possible. 


\section{Acknowledgements}

This dissertation would not be possible without the love, support and encouragement of my wife Barbara Cartwright. Her patience and generosity allowed me to undertake the work and challenged me to extend my ideas. I am ever grateful. My children, Lachlan and Skylar, tolerated many absences and much distractedness, but encouraged me to carry on. Hope sacrificed many walks and much attention over four and a half years. My parents, parents-in-law, brother and sisters were constantly encouraging, and I particularly appreciate Patricia and Ismo Haaka for making time and space for me to write, and Marie Wall for coaching and support.

Dr. Iain Wallace welcomed me into both the Carleton Geography and Environmental Studies Department and disciplinary geography, encouraged me into the deep end of the pool, and patiently took no for an answer when I ignored his excellent advice, which was often. My committee members Drs. Nancy Doubleday, Derek Smith and Julie Urbanik each challenged me and contributed incisively to shape this dissertation. Dr. Graham Smart introduced me to the wonders of discourse analysis; CU Library Geography Specialist Susan Tudin was a geography literature guardian angel; Darin Bagshaw was a committed and relentless research assistant; Chris Czerwinski went above and beyond the call of cartographic duty. Thank you all.

Thanks as well to the many generous citizens of the Bow Valley, Ottawa Valley and the Bay of Fundy who welcomed me into their lives and the researchers who shared their expertise. This research was made possible by financial assistance from the Social Science and Humanities Research Council of Canada, Carleton University and the Department of Geography and Environmental Studies. 


\section{Table of contents}

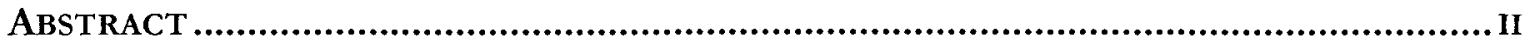

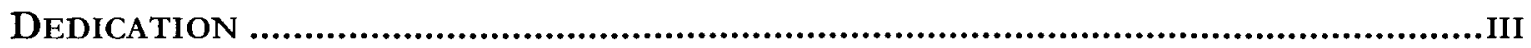

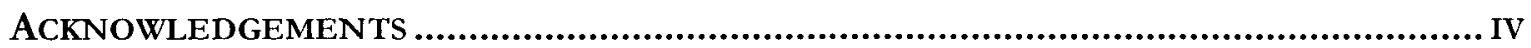

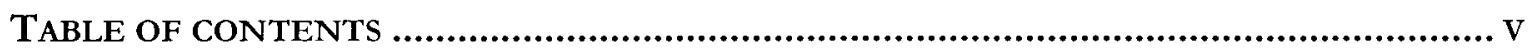

LIST OF TABLES ..................................................................................... VII

LIST OF FIGURES .......................................................................................... IX

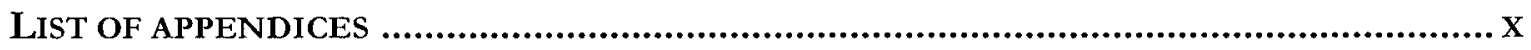

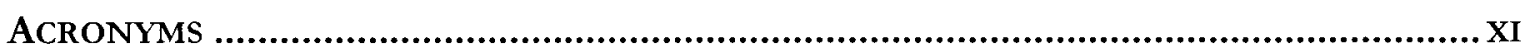

TOWARD SPACES OF CO-EXISTENCE: AN INTRODUCTION ......................................1

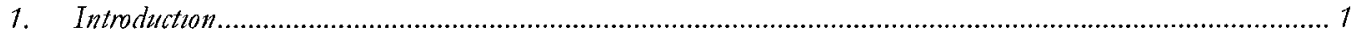

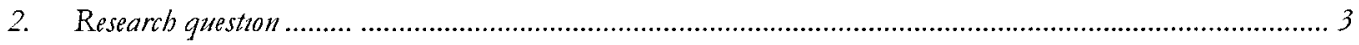

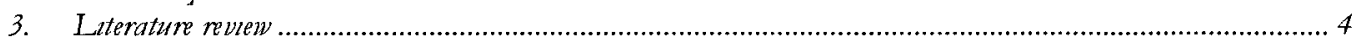

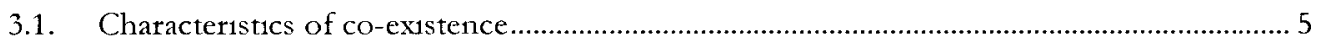

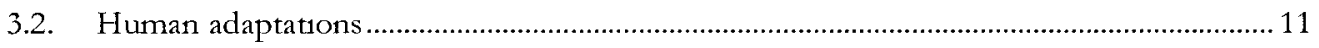

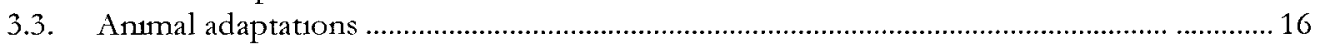

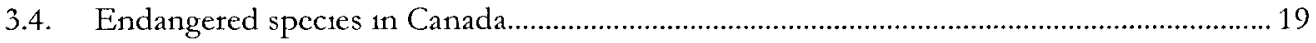

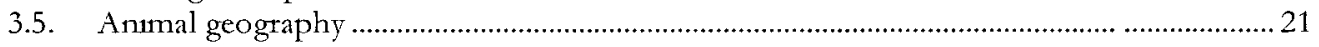

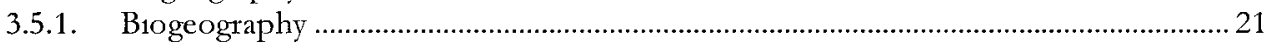

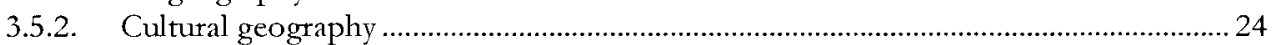

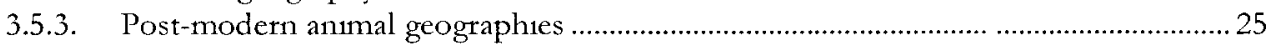

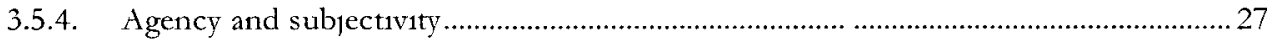

3.5.5. Human-environment relationships and values of nature ......................................... 31

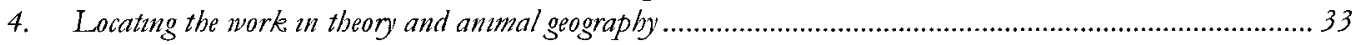

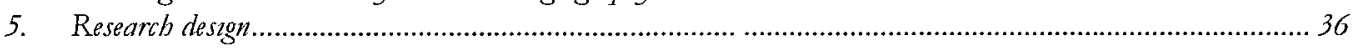

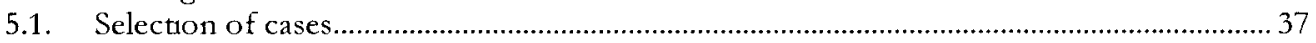

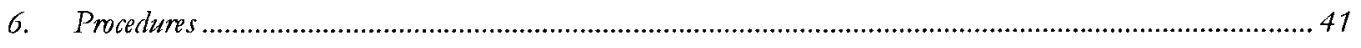

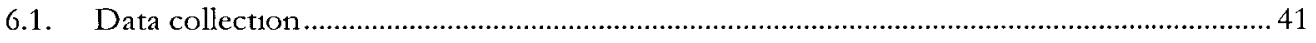

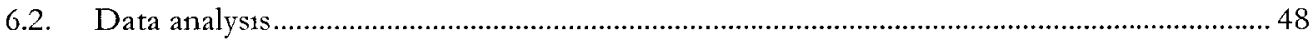

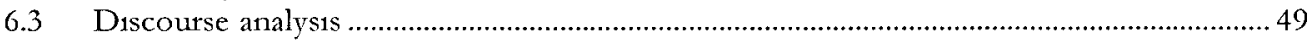

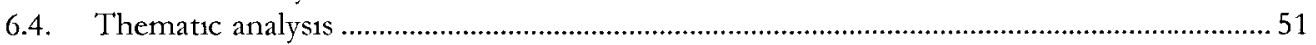

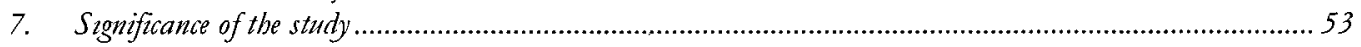

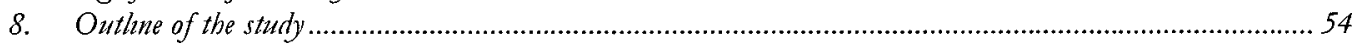

PEOPLE AND GRIZZLY BEARS IN THE BOW VALLEY .............................................56

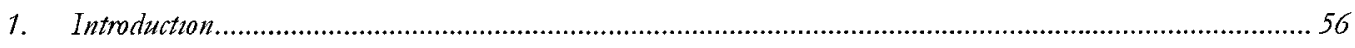

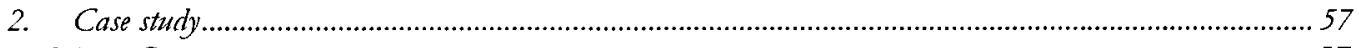

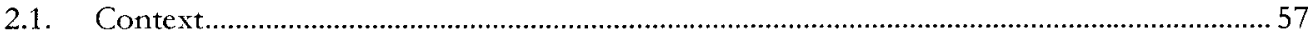

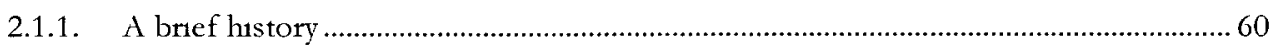

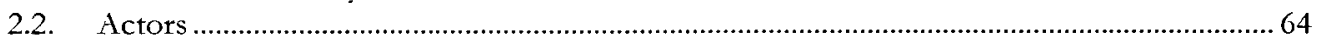

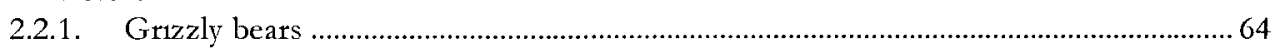

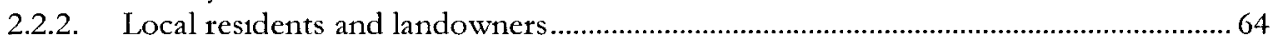

2.2.3. Provincial government ................................................................................................ 66

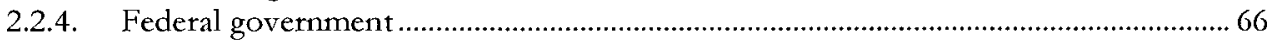

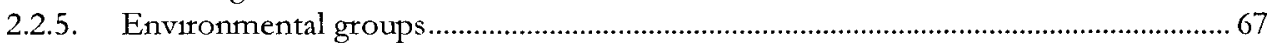

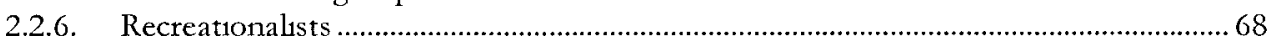

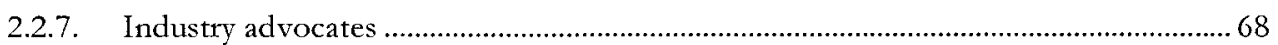

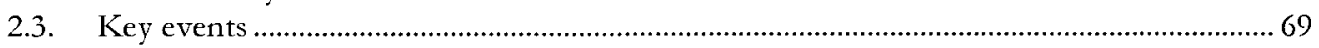

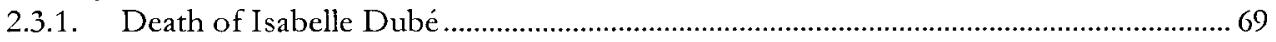

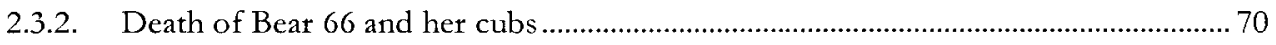

2.3.3. Bear hunt moratorium and DNA population study ……........................................ 71

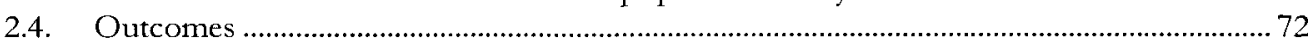

2.4.1. Public education and conflict mitgation efforts.......................................................... 72

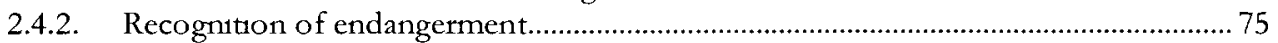




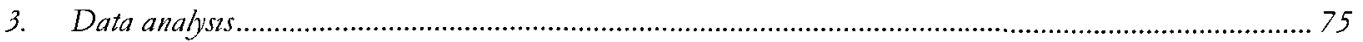

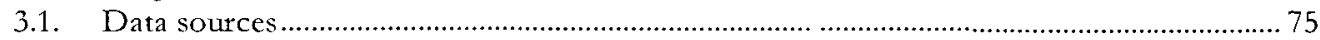

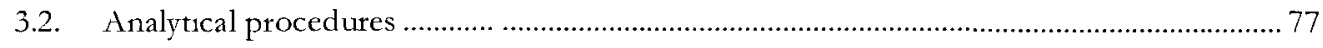

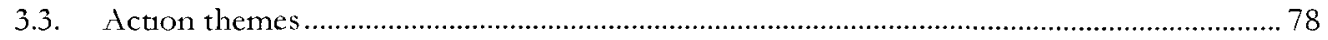

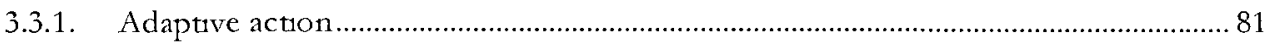

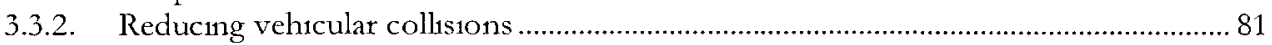

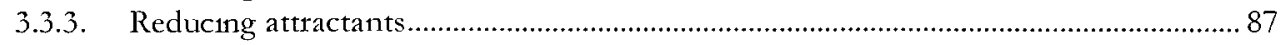

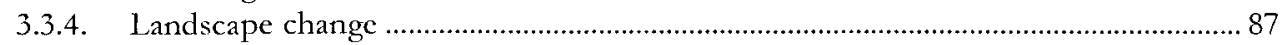

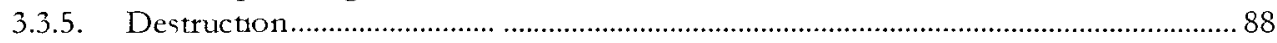

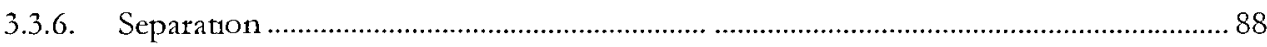

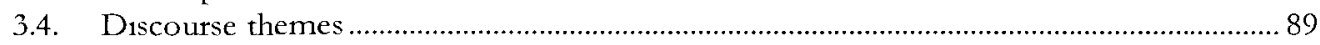

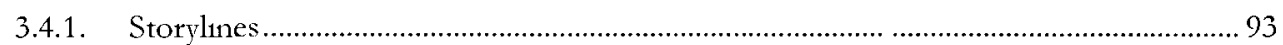

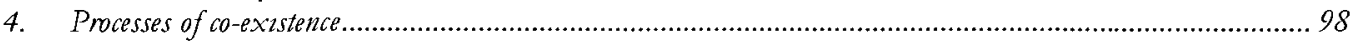

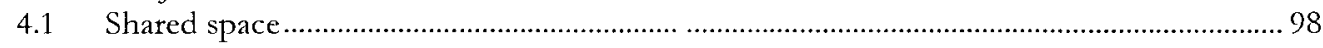

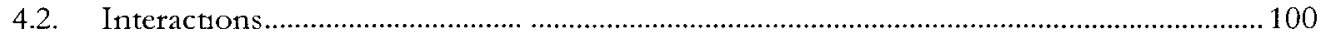

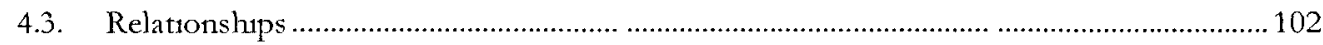

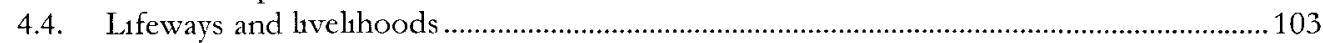

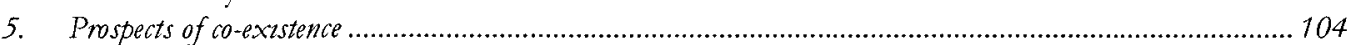

People and eastern wolves in the OTtawa Valley ....................................... 108

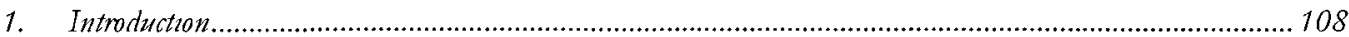

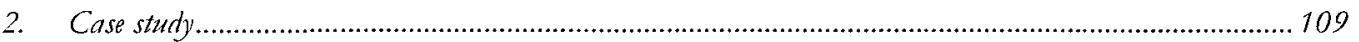

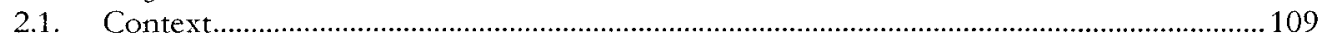

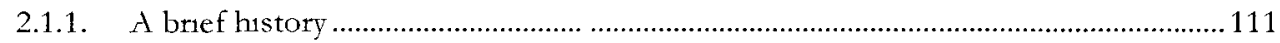

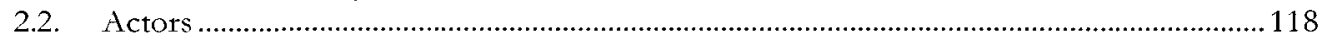

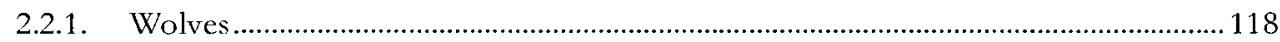

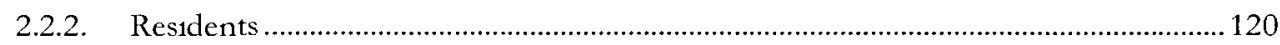

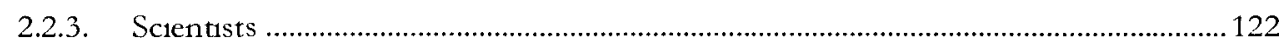

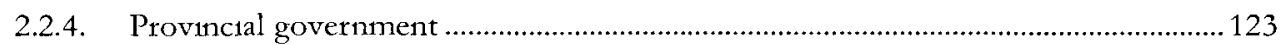

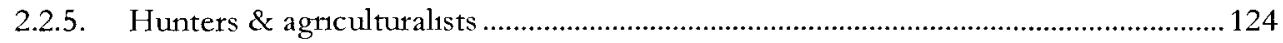

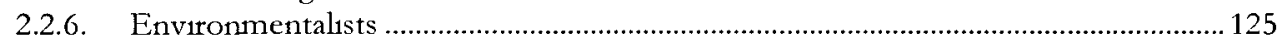

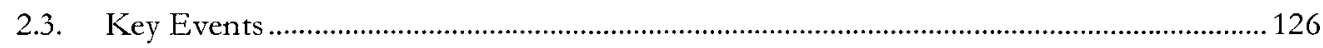

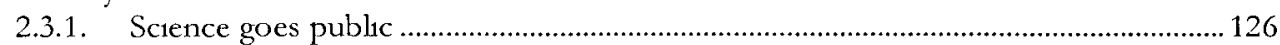

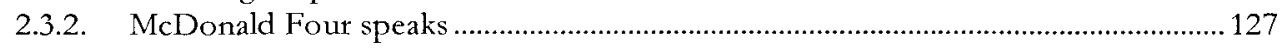

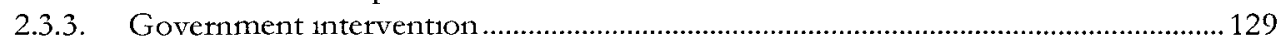

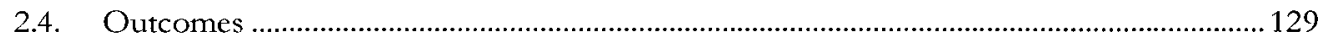

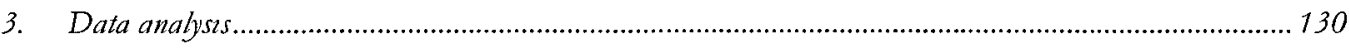

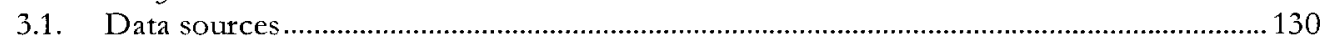

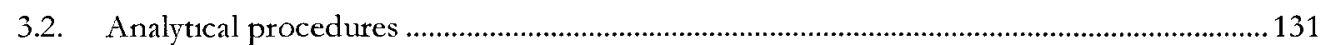

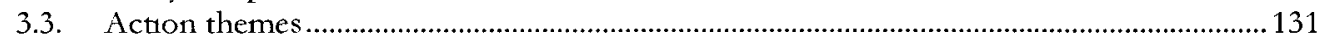

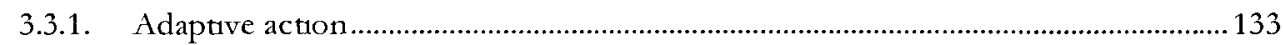

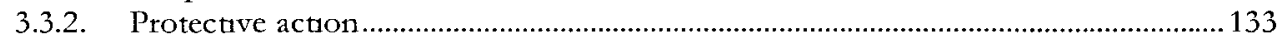

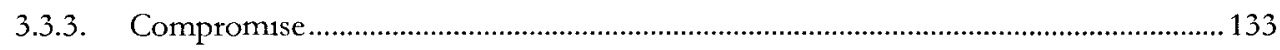

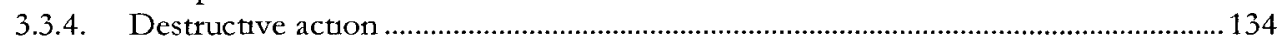

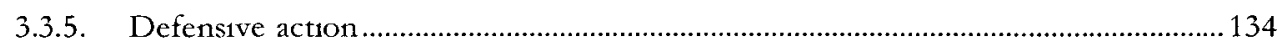

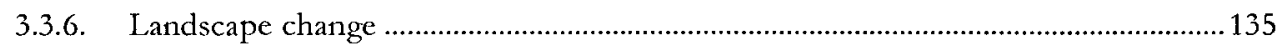

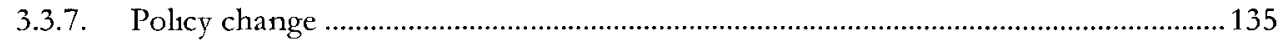

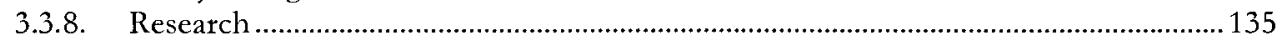

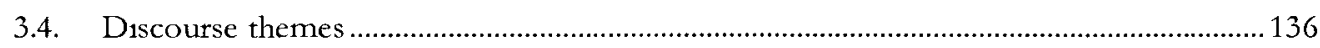

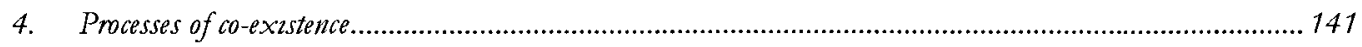

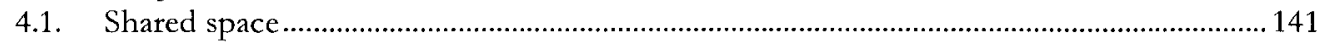

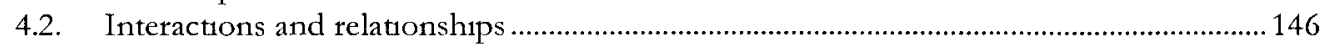

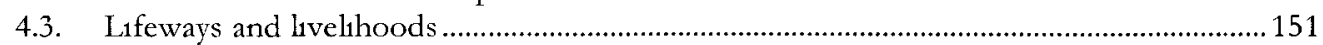

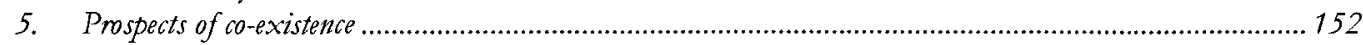

PEOPLE AND RIGHT WHALES IN THE BAY OF FUNDY ........................................ 153

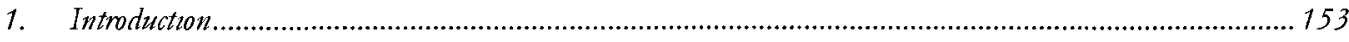

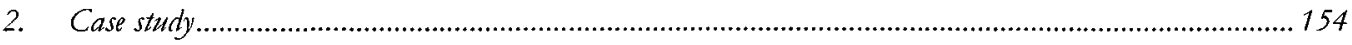

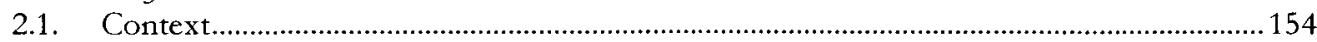




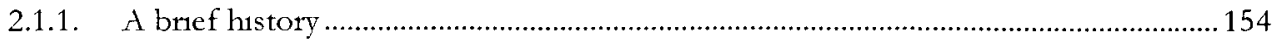

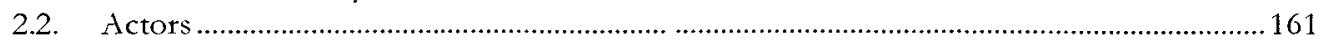

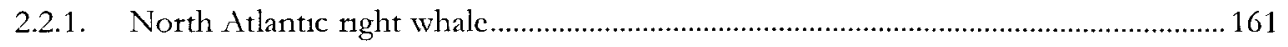

22.2 Department of Fisheries and Oceans ............................................................... 164

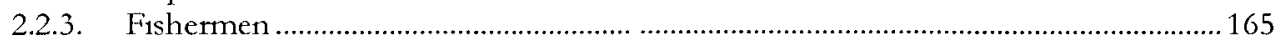

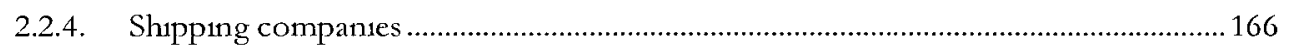

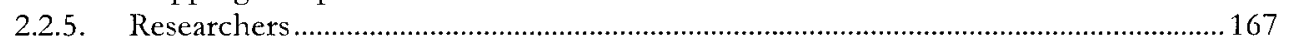

2.2.6. Liquefied natural gas proponents ........................................................................... 168

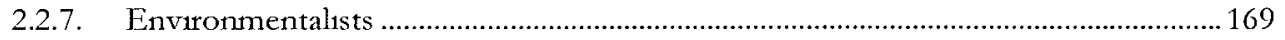

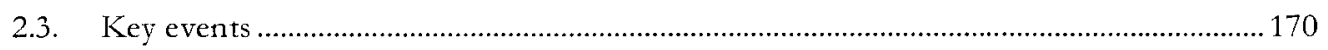

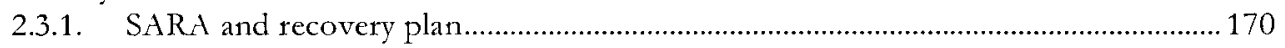

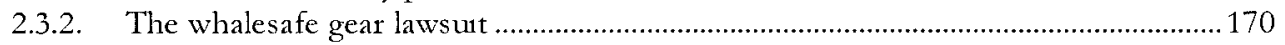

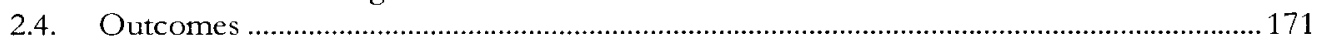

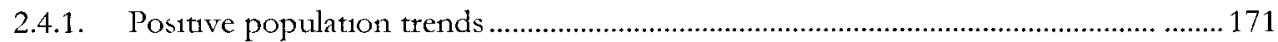

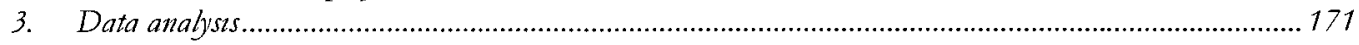

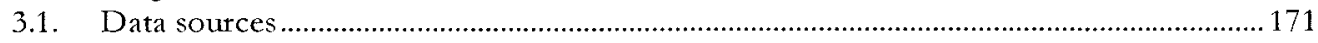

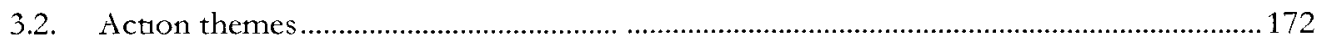

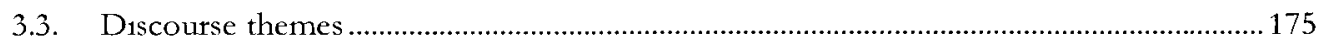

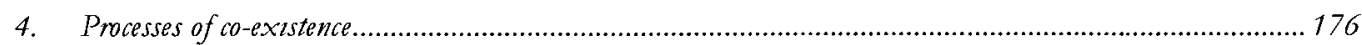

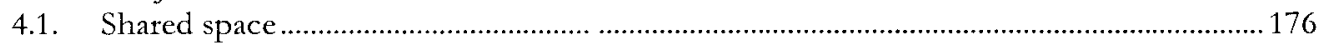

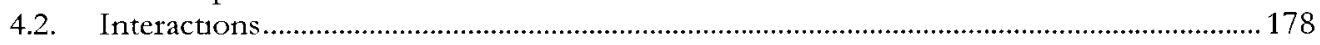

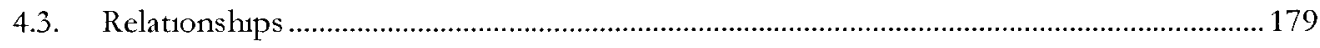

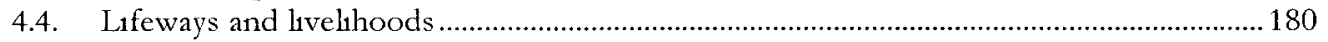

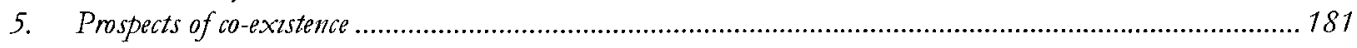

MOVING TOWARD SPACES OF CO-EXISTENCE ................................................... 185

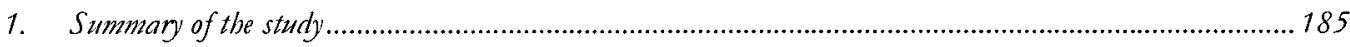

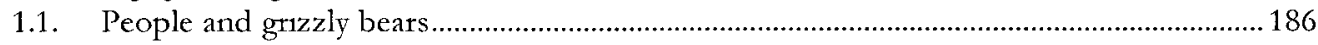

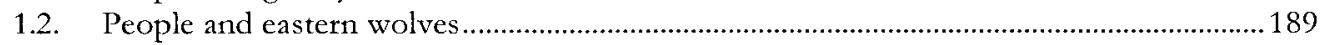

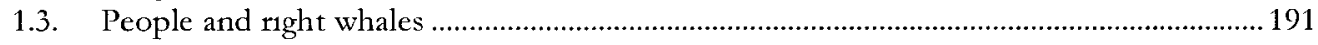

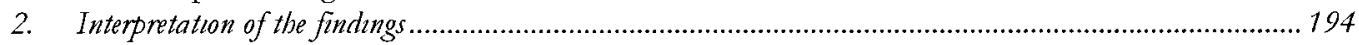

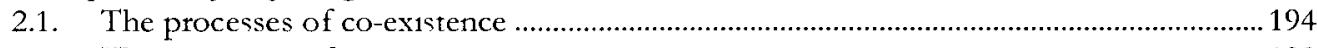

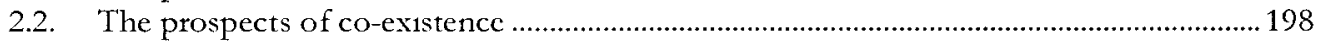

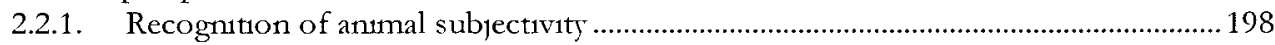

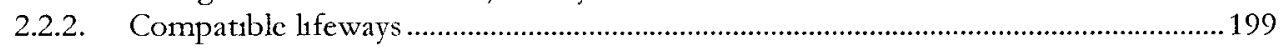

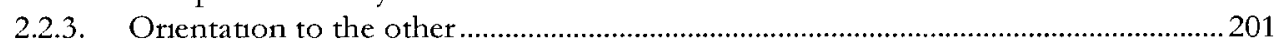

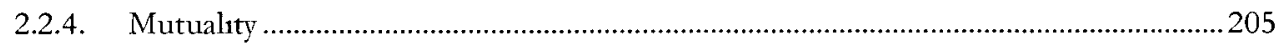

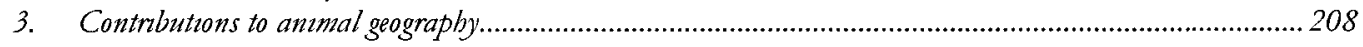

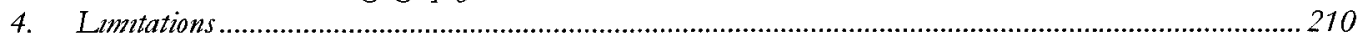

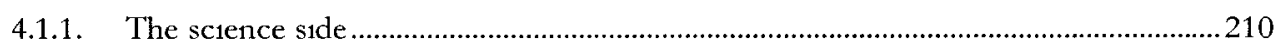

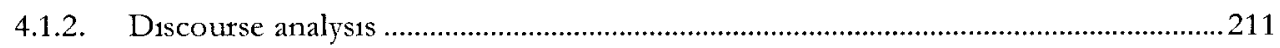

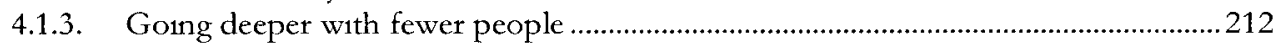

4.1.4. Dealing more extensively with difference ...........................................................2 212

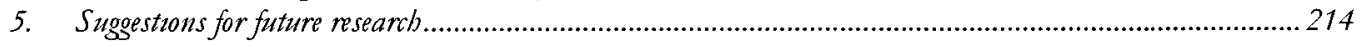

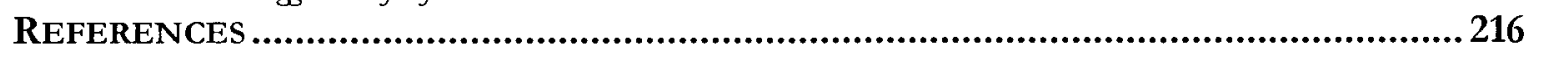




\section{List of tables}

Table 1: Modes of co-existence and related actions .............................................................................19

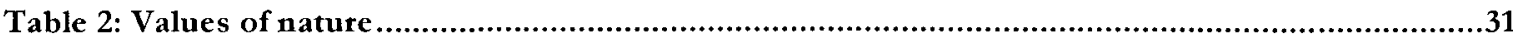

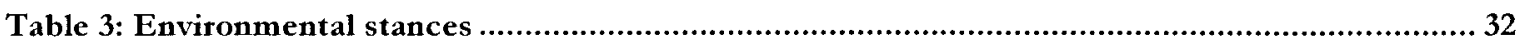

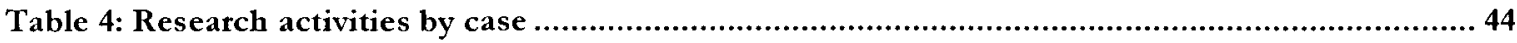

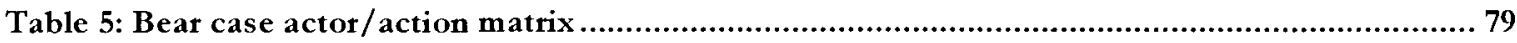

Table 6: Causes of beat mortality, 2000-2009, after Alberta (2010) ....................................................81

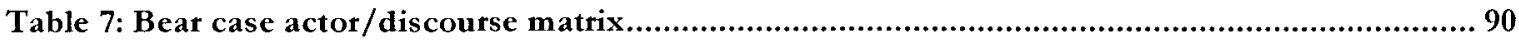

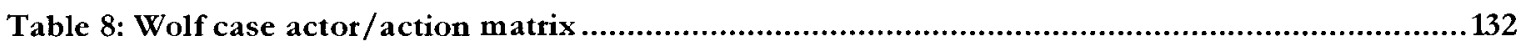

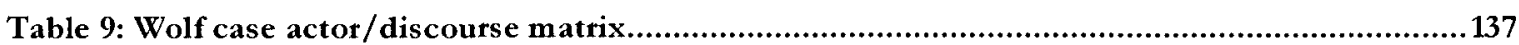

Table 10: Wolf case discourse coalitions and storylines, c. 1998.....................................................140

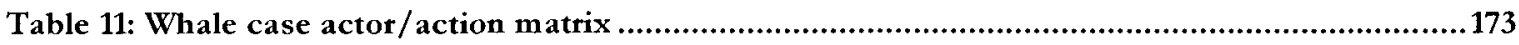

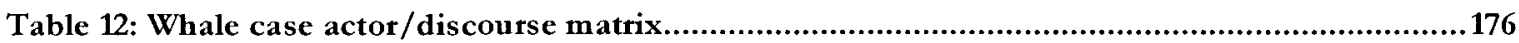

Table 13: Case summary of construction and impact on co-existence ..............................................196 


\section{List of figures}

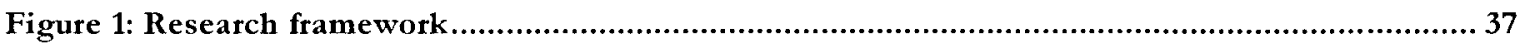

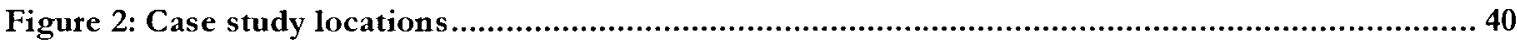

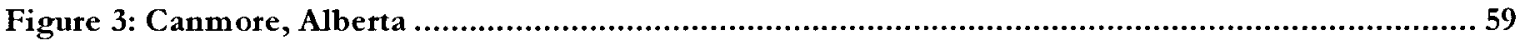

Figure 4: Timeline of human-bear co-existence in the Bow Valley ..........................................60

Figure 5: WildSmart Table Talker - Rocky Mountain Ski Lodge, August 2009 ............................ 95

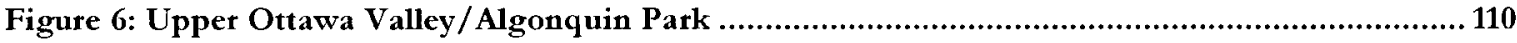

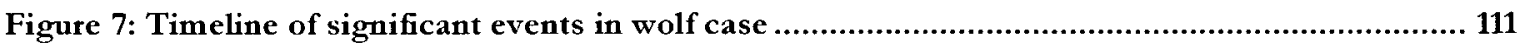

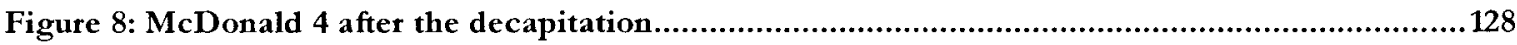

Figure 9: Visitors of all ages preparing for interpretive talk, Algonquin Park Public Wolf Howl, August $20,2009$.

Figure 10: Approximately 2000 people silently waiting for Park Naturalists to induce wild wolves to howl, illuminated by a passing truck, August 20, 2009...............................................149

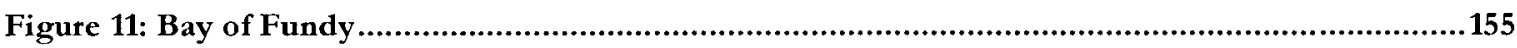

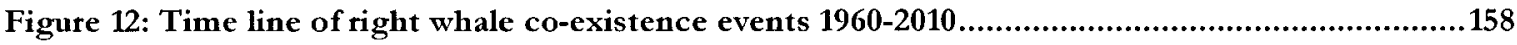

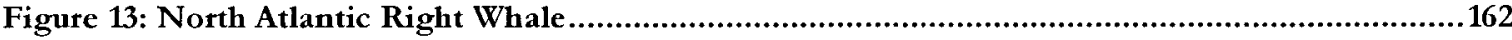

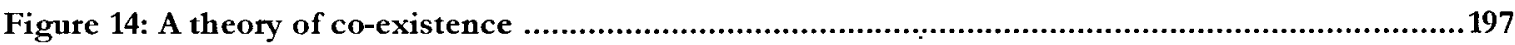




\section{List of appendices}

APPENDIX A: INFORMED CONSENT DOCUMENTATION ....................................229

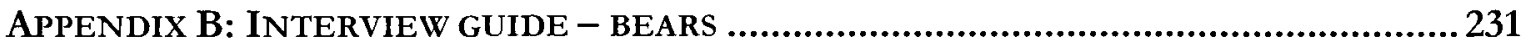

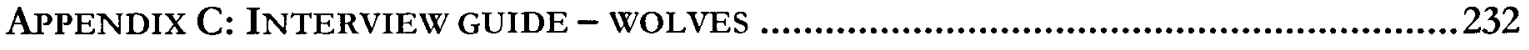

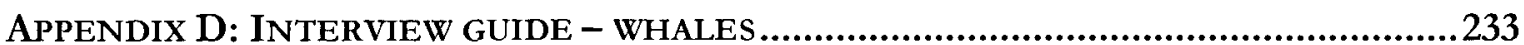

APPENDIX E: INFORMANTS CONTEXT/REFERENCE SHEET ..................................234 


\section{Acronyms}

AMPPE - Association for Mountain Parks Protection and Enjoyment

AWAG - Algonquin Wolf Advisory Group

DFO - Department of Fisheries and Oceans

ESA - US Endangered Species Act (1973)

ESGBP - Eastern Slopes Grizzly Bear Project

FRIGBP - Foothills Research Institute Grizzly Bear Project

HWCR - Human-wildlife conflict resolution

LNG - Liquefied Natural Gas

MNR - Ontario Ministry of Natural Resources

$\mathrm{NGO}$ - Non-governmental organization

NMFS - US National Marine Fisheries Service

OFAH - Ontario Federation of Anglers and Hunters

PHVA - Population and Habitat Viability Assessment

SARA - Species at Risk Act (2002)

SRD - Alberta Sustainable Resource Development

TEK - Traditional environmental knowledge 


\section{Toward spaces of co-existence: an introduction}

Informant $A^{7}:$ We grew up here on the ranch with the bears and the bears taught us. We didn't really know it at the time, but they taught us a lot about themselves just by the way they behaved.

$J W:$ What are some things that stand out in that vein, things that you learned from bears?

Informant A: Do you want to... do you want to blow your mind? JW: Sure. Absolutely.

Interview excerpt September 1, 2009

\section{Introduction}

As humans alter the world ever more dramatically, the possibility of successful futures for other species declines. Observers argue that species are going extinct at a rate 1,000 to 10,000 times faster than the historic rate inferred from the fossil record (Singh, 2002; Stork, 2010). There have been swift and cataclysmic extinctions in earth's history, but human impacts are driving the current extinction event by conversion of plant and animal habitat, overexploitation of plants and animals, pollution that reduces reproductive success, as well as the effects of anthropogenic climate change (Clark, 1999; Hunter, et al., 2010; Stork, 2010). The limiting of possible futures for other species corresponds with an erasure of their space.

${ }^{1}$ As part of the research ethics and informed consent process, informants contributed on the understanding that their contributions would be confidential. In Appendix E, there is a list of informants whose comments are cited within the text with basic but non-identifying information to provide context. Informants are listed in the Appendix in the order which their comments appear in the text. 
Responses to species loss by governments and conservationists include trying to understand the anthropogenic impact on other species and to control harmful human behaviour. This general mechanism has developed into the academic and field discipline of conservation biology, a mission- and crisis-oriented discipline in which scientists attempt to intervene to alter an all-but-certain trajectory of extinction for species (Groom, Meffe, \& Carroll, 2006; Hambler, 2004; Hunter, 1996; Soulé, 1985). Since 'conservation biology' was introduced as a concept in the 1980 s, its language and practitioners have taken a leading role in debates and decision-making related to species survival. Geography is well represented in conventional species protection today, largely through the technical contributions of GIScience, mapping, and techniques of spatial analysis. However, geography has engaged with animals in many ways over the decades. An early preoccupation of geographers was the differences in location, range and evolution of species (Wallace, 1876). This was the foundation of the biogeographic sub-discipline, to which the label of "animal geography" was first applied in the $20^{\text {th }}$ century (Larson, 1986; Newbigin, 1913). Human geography has contributed to understandings of human-animal relationships in terms of the shaping of landscape (Sauer, 1952a, 1952b) and in commenting on the motivations and power structures within those relationships (Tuan, 1984). On the other hand, while the concept of social nature represents a leap in recognizing the co-constructedness of what had once been taken unproblematically as the non-human world, geographers have not tended to apply these insights to the conditions and the bodies of species at risk (Castree, 2005). Because of their integration in the network of human affairs, domesticated animals and urban wildlife are more easily incorporated in explorations of social nature - the 'wild' category is more difficult to engage. So, while the history of animal endangerment and conservation is well trodden ground, a crucial question remains: whether "things (like bodies and natures) do not 
simply have a contested history but also a complex present, in which their identities are fragile and may differ between sites" (Mol, 2002, p. 43, cited in Hinchliffe, 2007, p. 47). The multiple conditions and sites of co-existence between humans and wild animals offer a fertile space for geographic inquiry that explores the nature of space shared between humans and others.

\section{Research question}

In this dissertation, I set out to explore the processes of co-existence between people and endangered species, and the spaces they share. Initially the scope included the physical, political and discursive spaces shared by humans and non-human others. This grew to include a more expansive view of space, and particularly the relational ontologies that enable the co-construction of space by human and non-human actors. An additional goal was that the research would influence thought and practice on endangered species protection.

To meet these purposes, I set the following questions:

- How do humans and non-human animals adapt to each other's presence?

- What does this tell us about the prospects for successful long-term coexistence of humans and endangered species?

To put these 'grand tour' questions into an actionable form, I applied following subquestions to three different cases of human-other co-existence in Canada:

- in a given ecosystem, what are the spatial and inter-species dynamics between humans and endangered species?

- what ethological, biological, traditional and other knowledge can be deployed to understand the 'animal side' of the inter-species equation? 
- how do people react to the knowledge that they share their lifespace with rare animals, or animals that are perceived (locally, regionally or at larger scales) as threatened?

- what knowledge, attitudes and behaviour on the part of human residents have had an impact on the endangered species, to what effect? And, to the extent it is possible to answer, vice-versa.

\section{Literature review}

This research lies at the intersection of four bodies of knowledge:

1. the relations and co-existence of humans and non-humans,

2. human adaptations to living with animals,

3. animal adaptation to living with humans, and

4. the context of endangered species in Canada.

In addition, this research is rooted in the tradition of new or post-modern animal geography, so to contextualize the research and relate it the existing body of work, I also

5. review animals in geography, and locate the present work within that tradition.

There are many other literatures that touch on or relate to aspects of the study. The review acknowledges these fields, while maintaining focus on the five main topics of the research. 


\subsection{Characteristics of co-existence}

The intertwining of human and non-human lives is ubiquitous but often unremarked. Just over 100 kilograms of meat per Canadian were available for consumption in 2008, representing 23.8 million pigs, 3.25 million cows and 623 million chickens (Canadian Meat Council, n.d.; Statistics Canada, 2010). According to a study for the Canadian Veterinary Medical Association there are an average of 1.76 cats per household and 1.38 dogs, for a total of 14.5 million companion animals in the country (Perrin, 2009). More than 5,200 establishments engage in commercial hunting, fishing and trapping, contributing $\$ 1.2$ billion to GDP (Industry Canada, 2010). The last comprehensive statistics for hunting nation-wide showed that $5 \%$ of the population engaged in hunting for recreation or personal use (Environment Canada, 1999).

Dependence on animals and their products is deeply embedded in human society and culture. For example, the agricultural revolution that began approximately 10,000 years ago and enabled the creation of large-scale human settlements was based in part on the creation of animal agriculture (Seger \& Van Beek, 1996). The unfolding of this concept and its impact on landscape was a theme in the cultural geography of the Berkeley School in the 1950s (Sauer, 1952a, 1952b) which dwelt on the interaction between human action and environment. Sauer saw the history of domestication as one by which 'natural landscapes' were converted into 'cultural landscapes' (Wolch, Emel, \& Wilbert, 2003).

Domestication is a focal point in the study of human-animal relationships and one that remains a contested area of study. Conventional accounts of domestication as emerging as a side effect of crop tending in the transition from hunting and gathering have been challenged by views of domestication as a cultural and religious phenomenon. Zeuner (1963) 
argued that social relationships between humans and non-humans formed a basis for domestication, while Sauer (1952b) contended that cultural (and especially religious) practices preceded agricultural ones in promoting domestication. These arguments have been rehearsed in archaeology, anthropology and geography, with evidence-based studies leaning toward more materialist explanations of domestication (Rodrigue, 1992). Since the cultural may leave less evidence than the material for archaeologists to study, these questions may never be resolved definitively, but regardless of the practices of human domestication of other species, an often-overlooked aspect is its impact on human culture and settlements.

Kay Anderson (1997) tackles domestication with a post-structural account that considers how animal evolution was reorganized so that the natural state of 'useful' animals became one of co-existence with humans. As this happened, humans became more secure, settled and sedentary - they became domesticated or 'domus-centred'. This process had several significant effects. It was a process in which 'Man' overcame 'His' animal nature and becoming 'civilized'. Rationality was exalted and "improvement" valorised, setting the stage for gendering of the domus, enlivening colonialism, and drawing the dividing line between humans and animals ever more boldly. Anderson describes this as "transcending the wild" (p.471)

The narrative of humans re-shaping the world to meet human needs has been challenged from other quarters. Budiansky (1995) has argued that associating with humans was a successful survival strategy adopted by certain animals, a position bolstered by evidence of sociality in wild canids corresponding to other dog-like traits, suggesting the possibility of self-domestication (Hare \& Tomasello, 2005; Trut, 1999). O’Connor (1997) used the example of the relationship between certain ants and aphids to demonstrate an alternate version of "domestication". Ants can corral colonies of aphids by biting off their 
wings and herding them near ant colonies in order to feed on a sugary secretion that the aphids produce, and sometimes on the aphids themselves (Offenberg, 2001). These examples lay the groundwork for an exploration of agency in human-animal relationships that challenges traditional views of human agency, making space for consideration of animal agency.

Kay Anderson's observations of the interplay between material re-shaping of animal lives and the construction of human-animal relationships provide an entrée to the principles and philosophy of co-existence. Non-humans have been positioned as "the ultimate Other" (Birke \& Hubbard, 1995) and in playing that contrasting role have contributed to the making of Homo sapiens as humans. The question of the correct relationship between humans and these Others animates discussion of animal practices of use, protection, husbandry and coexistence (Pluhar, 1995; Shepard, 1996).

Plumbing the human-animal relationship as a forum for othering is problematic in that humans - Homo sapiens - are animals too. As material beings, biology is a foundation for everything else that we are. The dividing line between us and them, or between culture as a human realm and nature as a non-human realm is neither fixed nor universal. The Old Testament creation story gave 'Man' dominion over all the earth's creatures as well as instructions to replenish and subdue the earth. These and other elements have been used to underpin both endorsements of the Judeo-Christian ethic as based in stewardship, and to critique it as exploitative (Bourdeau, 2004; Nash, 1989). This dividing line was highlighted boldly in the Enlightenment, particularly by Descartes (1637/1993). Searching for a firm basis for inquiry, his philosophy exalted reason above all and derived moral value and truth from that base. Lacking reason, animals fell outside the moral universe and humans owed 
them no duty at all; cruelty should be avoided only because it could lead to cruelty towards humans.

If the circle of moral concern excludes animals, there are no strictures on how they might be used or treated. This argument does not end with Descartes, but is carried into current debates on animal treatment by authors like R.G. Frey (1980). Frey argues that morality is rooted in symbolic interaction, and that since animals lack language, the ability to reflect on suffering, or to have desires, they can have no interests or rights. Therefore humans cannot have duties toward them. This is a tradition of what Mary Midgely calls "absolute dismissal". She notes, however, that this is a position "oftener professed than held. It is more obscure and harder to maintain than it first appears... About the treatment of animals, most people do in fact draw the line somewhere" (Midgley, 1983, p. 17).

This argument has been challenged along several lines in recent decades. Peter Singer's landmark Animal Liberation espoused a utilitarian approach to animal interests (Singer, 2002). Utilitarianism views the satisfaction of desire as the basis of good. If human use denies an animal its future good, then this is a moral wrong, and species difference is not a basis for withholding moral concern. Tom Regan (1983) developed a rights based approach that argues all mammals above a certain age are 'subjects of a life' and that this alone entitles them to basic rights. A third approach to appropriate treatment of other species is that of capabilities. Widely used in welfare economics in relation to humans, capabilities are those functionings that represent choice and capacity to achieve. In relation to other species, Nature being neither just nor nice, humans can safeguard other species' capabilities through intervention (Nussbaum, 2006). 
Scully (2002) approaches this issue from a different direction. As opposed to developing rights for animals from a philosophical viewpoint, he examines the responsibilities of people based on the attributes of reason and mercy that other commentators use to more sharply draw the line between humans and others. Rather than see the different capacities of humans and non-humans as a reason to disregard animal interests, Scully argues that these capacities call humans to act humanely and justly towards other creatures.

Each of these approaches applies different standards and precepts to questions of appropriate treatment of animals. An alternative is to weigh human values toward other species under the rubric of biophilia, which is defined as the inherent tendency of humans to associate with life and life-like processes (Kellert, 1996; Kellert \& Wilson, 1993). Stephen Kellert (1996) sees a range of values which humans can bring to the human-nature relationship (including with non-human animals), ranging from utilitarian values (valuing for food, fabric and fibre) to spiritual ones (symbolic and religious value). These include negativistic values - fear and aversion - which would provide an evolutionary advantage to those members of the species avoiding dangerous animals. In this system, aversion and affection towards other species both have value and form components within a range of possible stances toward the Other.

These different stances inform differences in action toward members of other species. The consumption of animal products, keeping of pets, hunting, and acceptance of adverse impacts on wild animals and their habitat (discussed below in Endangered Species in Canada) suggest that the use, harm, killing of animals and even loss of species are broadly acceptable to humans. These consequences, however, are moderated by law - animal cruelty laws, prohibitions on harassing wildlife, and endangered species laws regulate the use and 
treatment of animals. Notably, criminal law related to animals in Canada is contained in the Part XI of the Criminal Code, which deals with wilful damage to property - at the federal level, unowned animals (strays and wildlife) cannot be considered victims of cruelty ("Criminal Code," 1985). The basis of this assessment, dating from the Victorian era and reconfirmed in a 2008 amendment to the Criminal Code is that people are naturally interested in protecting their property and would not harm it.

The ontological implications of this situation are that non-humans are not only qualitatively different from humans, but categorically different. Humans can generally use other species as they wish, but this is moderated by some considerations of decency (echoing prohibitions against animal harm because it may lead to human harm) or biodiversity protection, recognizing that species should not be wholly destroyed. The tenor of the relationship is forbearance - humans could do anything to non-humans, but we hold back from the extremes of this behaviour. There is a space of contradiction between our capacities and acts with regards to other species, which is easier to ignore than confront. As Midgely put it:

A sense of unreality often blocks our attempts to understand our moral relations with animals. The whole question is hard to fit into our ethical system. Arguments for taking it seriously tend to be dismissed rather than met, to be stigmatized wholesale as perverse, sentimental, emotive, childish, impractical, superstitious, insincere - somehow not solid. They do not, however, go away; if anything they become more pressing. Now this kind of upsetting clash always deserves serious attention. The first thing to be said about such clashes is that they arise on plenty of other topics as well as about animals. We get a similar unnerving sense of double vision, of hovering between dream and reality, whenever we are confronted with any unsatisfactory and difficult corner of our moral scene. It happens both when principles collide, and when principle merely collides with practice. Ethics is practical. If standards conflict, or if they are 
so high and so general that we cannot see easily how we could act on them, we feel dazed (Midgley, 1983, p. 9).

This dazedness is a reason that the moral dimension of human-animal co-existence is only rarely made explicit in human-wildlife conflict resolution and in dealing with situations of shared space. It is a reason that animal geographers' efforts to examine non-humans as a radically different social group rather than as categorically different 'things' is a fruitful line of inquiry and why the process of othering non-humans is a reflex for many people. The following section explores the ways that humans and other species share space.

\subsection{Human adaptations}

The ways in which people live with non-humans can also be interpreted through the lens of value orientation. Although the problems of essentializing human culture are vast, as with Kellert's values of nature, Kluckhorn and Strodtbeck (1961) argued that each culture develops particular responses and adaptations to a limited number of human problems for which all people must find solutions. They claimed that "this is the universal aspect of value orientations because the common human problems to be treated arise inevitably out of the human condition" (p.10). One of these problems is the question of the relationship between humans and nature.

Kluckhorn and Strodtbeck proffer three orientations between human cultures and nature, which they use in an unreconstructed sense of 'the non-human world'. These orientations are societies that are subjugated to nature, that live in harmony with nature, or achieve mastery over nature. More recent approaches to nature (particularly social nature) read this dualistic construction of human and non-human as vastly oversimplified and blind to the social production of nature (Fitzsimmons, 1989). However, just as ethical stances toward non-humans discussed above inform human attitudes towards non-human others, it 
is useful to consider the position of societies and cultures in relation to the non-human world. Kellert and Wilson studied the cross-cultural applicability of values toward nature (Kellert, 1996; Kellert \& Wilson, 1993). They found a commonality of specific landscape preferences (open fields, water features, specific arrangements of plants and trees) suggesting a range of universal values that supported the biophilia hypotheses. More recently Dayer, Stinchfield and Manfredo (2007) have developed a research instrument to measure crosscultural dimensions of wildlife value orientations.

The sense of subjugation of humans to nature, or more specifically to non-human animals, can be seen in the field of human-wildlife conflict resolution (HWCR). Humanwildlife conflict is generated both from animal incursions in human affairs, particularly by crop raiding and livestock predation, and from encroachment of humans on wildlife by habitat fragmentation, hunting and increased traffic in habitat areas (Sillero-Zubiri \& Switzer, 2001). Historically, killing the offending animals or further transforming wild habitats has resolved the situations (Treves, Wallace, Naughton-Treves, \& Morales, 2006). This response is emblematic of a shift from subjugation to nature to mastery of nature as the earth is transformed into humanised landscapes.

Efforts in human-wildlife conflict resolution have often been led by conservation organizations or initiatives. These have stemmed from recognition of the needs of people who live with and near wildlife, and a pragmatic approach to reversing a trend of habitat conversion (Hughes \& Flintan, 2001). Along with a principle of conservation as "the management of human use of organisms or ecosystems to ensure such use is sustainable" (IUCN, 1980, p. 1), human-wildlife conflict resolution is a tool to permit co-existence while recognizing realities of human transformation of ecosystems. This represents an area of conflict between managing consumption and protecting wildlife. Campbell (2000) found that 
marine turtle specialists recognized sustainable use as a conservation strategy but that they were reluctant to accept indigenous or traditional approaches to separation, protection and use. Critiques of current efforts to engage local people in conservation argue that these efforts are often insincere or at least incomplete (Chapin, 2004). The core of the problem centres on whether sustainable use is a goal in itself or a strategy for species survival. This difference sets the stage for misunderstanding between conservationists and development advocates.

These mainstream approaches stand in contrast to views on cultures that approach 'harmony with nature'. In environmental management and in research, the domain that touches this position most closely is that of traditional ecological knowledge. Traditional ecological knowledge (TEK) is defined in different ways, including as local knowledge, indigenous traditional knowledge, Inuit Qaujimajatuqangit, and others (Berkes, 1993; Pauktuutit Inuit Women of Canada, 2006). The concept is that there is particularity in context and that the cultures and societies constructed in these contexts develop deep, observational knowledge of the ecologies and ecosystems in which they are co-constituted. TEK includes both knowledge and ways of knowing, capturing the concept of difference in worldviews. This can include 'cautionary knowledge' of co-existence with dangerous animals such as elephants (Moore, 2009) and patterns of knowledge and appropriate behaviour that guide interactions with animals, as described by Clarke and Slocombe (2009) in their analysis of Aboriginal respect for grizzly bears.

Lorimer (2006) deploys a concept from Deleuze and Guattari to explore biodiversity as a "discursive and material outcome of a socio-material assemblage of people, practices, technologies and other non-humans" (p. 540). Considering humans, non-humans, things and activities as an assemblage could be considered a post-modern re-visitation of earlier 
Sauerian concepts of cultural landscape - in this case it is not only landscape that is transformed, but society and culture as well. If we count animals as a radically different social group (as animal geographers often do) then transformations among non-humans generated in relationship with humans become a part of a rich and reciprocal shared landscape. This type of complexity may make up part of what is now considered traditional ecological knowledge. There are many examples of this type of assemblage which represent a sort of reciprocity between the construction of nature by the application of concepts and perceptions by a society, but which are in turn shaped by their relationship to and use of landscape and resources. Nietschmann (1973) described this situation among the Miskito Indians of Nicaragua, whose coastal society was heavily dependent on, and cultural identity shaped by, relations with the green sea turtle. A non-Indigenous example can be found in the whaling culture and society that developed in Nantucket among Quakers in the $18^{\text {th }}$ and $19^{\text {th }}$ century (Armstrong, 2004; Philbrick, 2000).

Historic and recent work in human geography and adjacent fields has challenged naive views of an essentialized non-human natural world and strictly social human world. Cronon's (1996) chapter on "getting back to the wrong nature" recounts his earlier work in environmental history that examined the ways that Aboriginal people in North America reshaped their landscapes, only to have subsequent geographies of colonialism and alienation 'write out' this contribution. The preoccupation of geographers with the humanenvironment interface is of long standing. In 1966, J.D. Chapman wrote in his Canadian Association of Geographers Presidential Address:

In my view the time has come to make explicit once again our concern with the environment, for, as Rostlund observed, we have long concerned ourselves "with the study of nature on the one hand and culture on the other" but the interrelations between the two have in large measure been sidestepped 
probably because no acceptable methods were available. I would claim that acceptable methods and techniques are now available to geographers which, coupled with the explication of the terms and concepts concerning the environment and the environed to be found in a wide range of social and physical science literature, give us the opportunity to face this matter again. (Chapman, 1966, p. 140).

At that point, in the early days of modern environmentalism, the interface was still the point of interest. By the 1980s, the idea of the environment, or of nature, as something external to society began to be problematized (Smith, 1984), and this set the stage for a sustained debate between realists and post-modernists on the nature of nature. By 1989, the concept of social nature as "the geographical and historical dialectic between societies and their material environments" (Fitzsimmons, 1989, p. 106) had emerged. The object of study now was no longer the interface between discrete worlds of humans and environment, but instead co-constituting relationships.

In light of these developments, 1960s-era views of 'harmony with nature' cultures are oversimplified and even naive. In a review article, Hames (2007) analyzes what he calls the "ecologically noble savage concept" and argues that anthropologists and ethnographers have documented native peoples' possession of a deep understanding of local ecosystems for many years. At the same time, this TEK is not always teamed with a realistic knowledge of the presence or causes of resource depletion (Smith, 2001). Sometimes particular worldviews, hunting techniques, or both required 'overkill' or killing more prey animals than could be used. In the case of buffalo hunts, no animals could be allowed to escape from a kill site because "the same buffalo could never be taken a second time and...they would also make known to the others the deception that had been practiced upon them" (Brink, 2008, p. 157). As in many other areas, these examples problematize essentialization of human acceptance of, and adaptability to, living with wildlife. 


\subsection{Animal adaptations}

A typical narrative in environmental discourse is that of the overwhelming negative influence of human expansion on other species Undoubtedly, evidence of a biodiversity crisis, while contested, is pervasive and convincing (T W Clark, 1999, Singh, 2002, Stork, 2010), and the role of humans in species loss is clear (Butchart, et al , 2010) However, just as human relations with nature are a "problem which must be answered by all cultures", how to persist and co-exist with humans and their influences is a question that must be answered by all species Those that persist in the face of human pressures must have some answers to this question

Some non-humans not only survive with humans, but thrive Obvious examples are those animals that people intentionally bring into their homes as companions, the most numerous of which are dogs and cats A mainstream interpretation of the archacology of domestication is that domestication of canines was an early innovation by Paleolithic huntergatherers (around 14,000 B P) that corresponded with the development of hunting at a distance with arrows and other ranged weapons This innovation was facilitated by dogs' ability to track prey and bring down wounded anımals (Clutton-Brock, 1995) This may have made the dog the only species to be domesticated by hunter-gatherers rather than settling agriculturalısts, which may have given the dog a 4,000 year lead in joining humans and households While this is mentioned above in the context of human agency, experimental evidence suggests that the agentic picture may be more complex

A mult1-decadal experiment in Siberia bred 35 generations of foxes (Vulpes vulpes) by selection for behavioural traits of tamability (Trut, 1999) In each generation, the animals that were calmest with human researchers were permitted to breed By the tenth generation, 
the foxes had changed their morphology to include drooping ears, fallen tail, and piebald coloration, much like dogs and similar to other domesticated species. In the wild, the process may have emerged as a survival strategy in which the calmest and least human-averse wolves may have become camp followers, feasting on scraps, providing de facto guard services, and gradually becoming friendly toward hunter-gatherer communities. In subsequent generations, this may have led to domestication as we know it. This experiment lends support to the self-domestication theory (Budiansky, 1995).

Other species succeed in human-modified environments without the relational aspects of pet-keeping or sharing households. Synanthropes are species that benefit from human presence, even becoming dependent on humans for at least part of their life cycle (Johnson \& Klemens, 2005). Examples include house mice (Mus musculus), Norway rats (Rattus novegicus), house sparrows (Passer domesticus), and rock pigeons (Columba livia) (p.213). Human contributions to these species include habitat improvements, food, and assistance with dispersal. There is a range of possible beneficial interactions for the synanthropic species, ranging from nesting sites for hawks and falcons, to supplemental feeding for gulls, to outright dependence for some species of lice. An extreme example is that of the American crow (Comus bracbyrbynchos) which has spread across North America in tandem with agricultural transformation and urban development. The crow has largely replaced ravens (Corvus corax), which are dependent on wilderness and displaced by anthropogenic transformation (Gade, 2010).

This mutualism or parasitism that leads to success for some species is relatively rare. There are many species, sometimes termed "urban-sensitive" that require large range areas, have easily disrupted reproductive patterns, or have very particular habitat or food requirements. Johnson and Klemens (2005) generalize that long-lived species with delayed 
breeding and low reproductive rates "are less likely to do well in disturbed environments" than short-lived species with high reproductive rates (p. 214). This generalization illustrates a pattern in which deer do relatively well in suburbia compared to moose, as do raccoons and coyotes compared to wolves. In some cases, species' longevity and fecundity are altered in response to human populations.

These examples of alternative life histories, evolutionary strategies that respond to human change, and new narratives of 'self-domestication' support a vigorous reading of animal agency. Human and other species' lifeways ${ }^{2}$ are altered in response to each other. This reading problematizes a dominant narrative of a one-way relationship in which humans manage other species. However, loss of biodiversity is increasingly evident, and the human response to this loss includes the protection of species at risk of extinction. The next section reviews literature on endangered species, focusing on species at risk in Canada.

These types of relationships suggest possible modes of co-existence between humans and wild animals and introduce an aspect of time geography in the use of space. Specifically, non-threatening synanthropes and humans can share space at the same time, for example, squirrels in front yard trees, raccoons and groundhogs nesting in green spaces lining highways, and urban birds are often so commonplace as not even to draw notice from city residents. This is a relationship of truce that can easily deteriorate - crows, for example, can roost in groups of up to 100,000 and cities that host such roosts have considerable disturbance and property damage ("Residents asked to do their part against crows," 2010). Adaptive change that reduces contact and conflict in this situation is a possibility - both for humans and animals. Large and potentially dangerous animals like bears and wolves can

2 I use 'lifeways' as a concept that includes the way of life - niche, needs, interests and economic geography - both of humans and other species. 
share space with humans, but not often at the same time. Area closures by season or based on observations of animal presence can foster co-existence by preventing contact between humans and others, even as they share a landscape. Alternatively, permanent separation, by fencing, removal of the animal, or as a side effect of destructive action (killing, habitat destruction) is a mode of non-co-existence. The opposite, protective action, can promote species survival or recovery in the face of species loss. These modes of co-existence provide a heuristic by which to examine human-wildlife interaction in the research. Table 1 presents a matrix of these modes, which formed an early basis for a coding and analytical structure in the research.

\begin{tabular}{|l|l|l|l|l|}
\hline & \multicolumn{1}{|c|}{ Adaptive } & \multicolumn{1}{|c|}{ Separative } & \multicolumn{1}{|c|}{ Destructive } & \multicolumn{1}{|c|}{ Protective } \\
\hline Human Action & $\begin{array}{l}\text { Reduce harm, } \\
\text { accept risks }\end{array}$ & $\begin{array}{l}\text { Avoid non- } \\
\text { human in space } \\
\text { and time }\end{array}$ & $\begin{array}{l}\text { Intentional or } \\
\text { unintentional } \\
\text { destruction of } \\
\text { non-humans }\end{array}$ & $\begin{array}{l}\text { Protected areas, } \\
\text { harm reduction }\end{array}$ \\
\hline $\begin{array}{l}\text { Non-human } \\
\text { behaviour }\end{array}$ & Synanthropy & Aversion & $\begin{array}{l}\text { Human-wildlife } \\
\text { conflict }\end{array}$ & $\begin{array}{l}\text { Guarding/defending } \\
\text { behaviour }\end{array}$ \\
\hline $\begin{array}{l}\text { Possible } \\
\text { outcomes }\end{array}$ & Co-existence & $\begin{array}{l}\text { Separate } \\
\text { spaces }\end{array}$ & Dis-integration & $\begin{array}{l}\text { Possible co- } \\
\text { existence }\end{array}$ \\
\hline
\end{tabular}

Table 1: Modes of co-existence and related actions

\subsection{Endangered species in Canada}

Endangerment is typically interpreted like a biological status - species that are at risk of extirpation or extinction are in danger. It matters, however, whether this danger derives from human action or inexorable processes of natural selection. Extinction is a part of evolution, and it is estimated that 99 per cent of all species that have ever existed are now extinct (Raup, 1986). Hunting or other overexploitation, habitat destruction or disturbance, and diffuse changes such as those affecting climate are sources of anthropogenic endangerment, and these are often the focus of today's species survival efforts (HiltonTaylor, et al., 2009). 
In Canadian law, there is a separation between the scientific investigation of a species' status, which is the responsibility of the Committee on the Status of Endangered Wildlife in Canada, and the actual listing of species, which is a political decision by the federal cabinet. This process "separates the scientific assessment process from the listing decision, ensuring that scientists can provide fully independent recommendations and that decisions affecting Canadians are made by elected officials who can be held accountable for those decisions" (Canada, 2007, p. 3). It also includes socioeconomic considerations as part of the listing of a species, making it a political act and making 'endangered' a political rather than biological label.

'The biological concept that applies to species at risk of extinction is 'rarity'. Species can be or become rare based on small population sizes, restricted habitats, or both (Gaston, 1994). Some species' reproductive strategy, range, feeding requirements, or other biological limitations restrict them to small population sizes - they are specialists and they may never be numerous or widespread, even in the absence of human disturbance. There is an ongoing tension between inclusion of political and social considerations in the listing process and adhering strictly to biological criteria. Ilical and Harrison (2007) examine this tension in the context of Canadian and US endangered species regulations. They explain that, under the US Endangered Species Act, listing is based on technical criteria (science concerning endangered species) and the enforcement regime is highly regulatory. Disputes among the federal government and landowners, environmentalists or other stakeholders are resolved in the adversarial court system. Canada's Species at Risk Act (SARA), on the other hand, includes socioeconomic criteria and is implemented through Recovery Plans and Recovery Teams that are largely associational and voluntary, with a dimension of flexibility and compensated stewardship. The Canadian system is also highly deferent to the provinces, reflecting the 
greater control over natural resources assigned to the Canadian provinces in comparison to US states, and the fact that SARA applies only to federal lands Eight provinces also have endangered species legislation, and in practice the recovery plans for listed species are led by either federal or provincial agencies in a partnership arrangement (Illical \& Harrison, 2007)

\subsection{Anımal geograpby}

Animal-related research has been present in geography since the earliest days of the discipline The approaches to this reseaich have followed the preoccupations and methods of academic geography and geographers, mirroring the discipline as a whole Post-modern and post-structural approaches to the 'animal question' since the mid-1990s have led to a burst of research and publications in the sub-field In "Reanimatıng Cultural Geography" Wolch, Emel and Wilbert (2003) provide a thorough review of animal geography and note that in the 20th century an "active if small portion of the discipline" included a zoogeography of animal distribution and a cultural geography of animals with a focus on domestication After a gap in interest in animal geography in the second half of the twentieth century, a third approach emerged as part of the process of rethinkıng culture, subjectivity and nature that has marked cultural geography in recent decades The following sections will look at each of the three phases they describe, zoogeography, cultural geography and the new animal geographies, with attention to the study of wild anımals in geography

\subsubsection{Biogeography}

The earliest geographic approach to studying anımals is biogeography or, more

specifically, zoogeography (Beddard, 1895, He1prin, 1887, Larson, 1986, Wallace, 1876) Today most zoogeographers are to be found in the fields of evolutionary and conservation biology - biogeographers in geography departments tend to study distributions of plants 
While a conventional view of this field suggests the object of study (plant or animal) is considered a biotic component of the physical environment, biogeographers have often considered human impacts on animal distributions and how species adapted to human habitats can invade and disrupt geographically restricted native species (see, for example, McKinney \& Lockwood, 1999). Recent accounts have also included the biogeography of humans (Lomolino, Riddle, \& Brown, 2006b). Also, the study of the spread of place-specific breeds of domestic animals shows continuity with biogeographic methods. For example, (Yarwood \& Evans, 2000; Yarwood \& Evans, 2003) have examined the distribution of regional breeds now considered 'rare' and examined the cultural and economic dimensions of these breeds within the context of globalization. This should not be considered merely an early phase of development that was replaced by the later development of cultural animal geography, but as a continuing foundation for which most responsibility has been adopted by neighbouring disciplines of biology and ecology.

Wolch, Emel and Wilbert (2003) begin their review with Marion Newbigin's Animal Geography in 1913, which applied approaches that had been successfully applied to plants. This included a physical and climatic description of the world's biomes followed by the plant-animal complexes supported by each. Newbigin explains that "we may study the animals of the natural regions of the globe as forming a part of the features of those regions, and in this case attention is directed rather to the adaptations displayed by the animals, than to their zoological relationship" (Newbigin, 1913, p. 10). This reflects the physical, areal, and deterministic thinking current in geography at that time.

Newbigin's work is an important one, and in it she recognizes earlier advances in plant biogeography, and the contributions of Darwin and Wallace in understanding animal distributions. In fact, animal geographies extend back to at least 1778, with Eberhard 
Zimmermann's Geographische Geschichte [Ger. geographical history]. This work looked at the distribution patterns of mammals by analyzing the general physical and historical determinants underlying observable patterns of distribution, an inventory of the habitats of known mammals, and a theoretical discussion of the system of distribution derived from studies of physical determinants and actual pattems of distribution (Larson, 1986). Other milestones in the field include Geograpbical Distribution of Animals (Wallace, 1876), The Geograpbical and Geological Distribution of Animals (Heilprin, 1887) and A Text-book of Zoögeography (Beddard, 1895).

The study of the distribution of animals had considerable social and political impact, inasmuch as it was implicated in the erosion of 19 th century biological, geographical and theological assumptions. The European 'discovery' of South America had sown early seeds of what would become biogeography - whereas faunal differences between Europe and Africa could be explained away by climate and latitude, the vast differences between South America and Africa were harder to address. Furthermore, the vast number of species identified in South America raised the question of how so many different animals could fit in Noah's Ark (George, 1993). These early questions foreshadowed the controversies that erupted after the publication of the theory of natural selection by Charles Darwin and Alfred Russell Wallace in 1858.

In the 20th century the acceptance of plate tectonics, new phylogenetic methods, new techniques in ecological biogeography and investigations of the mechanisms that limit animal distributions have calmed many of the controversies from the early days of the field of biogeography. These included the centres of origin for species, the mechanisms of evolution and dispersal, and the creation of barriers that separated species and set the stage for speciation (Lomolino, Riddle, \& Brown, 2006a). The net result of these developments 
has been increasing sophistication in the explanatory power of biogeography since many descriptive aspects of the field were already accomplished in the 19th century.

\subsubsection{Cultural geography}

There were a handful of early explorations in anthropogenic impacts on animals, but the first cultural geography of animals developed in the 1950s when landscape geography initiated inquiries into domestication and agricultural landscapes (Sauer, 1952a, 1952b). This followed in a French tradition of Paul Vidal de la Blache, who considered domesticated animals and agricultural landscapes in his theories of 'gente de vie' (Vidal de la Blache, 1956). In the Anglophone tradition, the thrust of landscape geography related to domestication was that animal practices had a role in the conversion of 'natural landscapes' into 'cultural landscapes'(Wolch, et al., 2003). By the early 1960s interest was growing in an animal geography of domestication, human-animal interaction and human impacts on animals. In 1960 Charles Bennett proposed a formal cultural animal geography, to "encompass those aspects of animal geography which accumulate, analyze, and systematize data relevant to the interactions of animals and human cultures" (Bennett, 1960, p. 13). Bennett's proposals "dovetailed with cultural ecology, already emerging in both North America and Europe, which focuses on the origins of animal domestication... and... was characterized by attention to place, region and above all landscape" (Wolch, et al., 2003, p. 186). Through these proposals Bennett was trying to bring the geography back in to animal geography, considering that the field of the time was dominated by "faunistic, historical and ecological" foci that geographers were pleased to leave to specialists in biology, palaeontology and ecology respectively. 


\subsubsection{Post-modern animal geographies}

Bennett's approach to systematizing data on animal-human interaction was in the areal, positivistic tradition that, over time, became a target of critique as atheoretical and overly descriptive (Benko \& Strohmayer, 2004). The mid-century approaches to animal geography were varied, but in many ways they harkened back to Hartshorne's (1939) inclusion of animal geography as a sub-field of the discipline that would contribute to a regional geography. As that mode of regional geography lost ground in the $198.0 \mathrm{~s}$ and $90 \mathrm{~s}$, inquiries on identity, culture, representation and discourse began to assume greater interest in the discipline (Benko \& Strohmayer, 2004). By the mid-1990s a 'new' animal geography began to interrogate issues far from the distribution and domestication subjects of the previous generation. By 2000, Sarah Whatmore was able to write in the Dictionary of Human Geography that "animal geography is a newly coined term in human geography which has taken shape since the mid-1990s and is concerned with the material well-being and cultural meaning of non-human animals in the geography of social life" (Whatmore, 2000, p. 25). Today the term 'new animal geography' is still heard but 'animal geography', referring to the post-modern variety, is widely accepted. In 2009, the formation of an Animal Geography Specialty Group within the American Association of Geographers, which includes prominent advocates of the 'new animal geography', marked the recognition of post-modern animal geography as a sub-discipline within cultural geography.

A milestone in the development of post-modern animal geography was a thematic issue of Society and Space in 1995 organized by Jennifer Wolch and Jody Emel, later published as the edited volume Animal geographies: place, politics and identity in nature-culture borderlands. This book was intended to "contribute to (a) fundamental rethinking of animals and suggest how, by looking through geographical lenses, we may be able to bring animals into clearer focus 
and back into our understanding of social life" (Wolch \& Emel, 1998, p. xii). The essays centre on the "issue of human-animal relations", or what Wolch and Emel term "the animal question". The editors argue that the study of nature-culture relations and geographical social theory that had developed since the 1970 s is illuminating when applied to relations between human and non-human animals. They note that conservation of natural species and traditional cultures for their intrinsic value have been associated with the political right, and that only some strands of leftist scholarship include animal welfare as part of their concerns for revaluing the marginalized. Most leftist analysis “interpret(s) a focus on animals as an attempt to regain some pre-modern, spiritual or animistic stance" (xii). This leads the authors to the question, "is it possible to construct a democratic, non-racist, non-sexist politics that embraces an animated and embodied nature?" and they respond that their project is "the creation of many forms of shared space" (xii). This might include ways of putting ideas derived from blurring the line between human and non-human animals and deconstructing convenient binaries between urban and rural, humans and others. These are the sorts of issues dealt with in much of the recent literature.

Philo and Wilbert (2000) introduce Animal spaces, beastly places by describing animal geographies that follow how animals have been socially defined and represented, exploring non-human agency, and querying whether a 'real' geography of animals can be developed rather than an anthropocentric geography of humans in relation to animals. This last dimension is particularly relevant in considering the cultural geography of wild animals and animal agency. In Hybrid geographies: natures cultures spaces, Sarah Whatmore (2002) applies actor network theory to wildlife. Whatmore (2002) uses actor-network theory to explore hybridity - de-centring social agency in favour of an achievement "spun between social actors rather than a manifestation of unitary intent” (p. 10) and decoupling from subject-object binaries. 
Her case studies, however, such as comparing the extensive trade networks providing animals for ancient Rome's Coliseum to the data networks that connect modern zoos in conservation breeding programs focus on anımals that are thoroughly caught up in human networks (being traded, relocated, held in captivity, and sometumes kulled for entertainment) She argues that all animals are caught up in such networks, if only by living in territory that has been defined, bounded and managed by humans (Whatmore \& Thorne, 1998) While a reasonable observation, it glosses over considerable diffeıences between wildlife in human custody and the largely autonomous lives of wild animals in rural and remote regions, which this work attempts, in part, to bridge by addressing wild animals in contact with humans but not bound entirely in human networks

New geographies of anımals in rural/wild settings include studies of how anımals become symbols and focal points in conflict, especially when endangered species legislation protects habitat in economically vulnerable areas (Procto1, 2000) or when individual animals are harmed by human actions (Michel, 2000) Bovenkerk and colleagues take up this topic in some detail in considering the ethical dimension of rehabilitation and care of injured seals in the Netherlands (Bovenkerk, Stafleu, Tramper, Vorstenbosch, \& Brom, 2003) Overall, however, the geographies of wild anımals in the new tradition are quite limited

\subsubsection{Agency and subjectivity}

In recent years anımal geographers have rased questions of how anımals participate in and shape their futures This typically falls under the discourse of animal agency and animal subjectivity Agency is defined as capacity to effect change, and it is often used in relationship to structure, "basıc, enduring and determinative patterns in social life" ("Social structure," 2002) Structure has been called "fossillzed agency" in which powerful actors have enshrined (in social practice, law, tradition) discrete ways of actung 
Claims for animal agency have been contentious, turning on the extent to which intentionality and choice figure in the agency of autonomous beings. Dismissers of animal significance (of both the absolute and relative varieties) tend to de-emphasize animals' scope of conscious action and of choice (Frey, 1980). However, their actions clearly matteranimals alter their landscape by digging dens and treading paths, rolling rocks and wrecking trees. They also pollinate plants and spread seeds, contributing to ecosystem diversity. Their predator-prey relationships influence ecology and populations - of their own and other species. Only careful observation and guidance from ethology (the study of animal behaviour) can tell how choice enters into these actions.

A traditional view of structure was that these behaviours were simple and largely instinctual. Higher thought, planning, tool-making and communication were reserved to Homo sapiens. Scientists noticed complex communication patterns rooted in gesture, coloration, and scents but linguistic abilities (speech and language) were regarded as the benchmark for communication, and in this way the human/non-human line was justified and supported (Cohen, 1986). Beyond communication, animal tradition and even culture were noted and theorized through the latter part of the $20^{\text {th }}$ and early $21^{\text {st }}$ centuries. In these cases, chimpanzees from different study areas were noted to use different tools and practices, and these practices were not based on survival necessities or strict environmental determination. While chimpanzees in the Ivory Coast would crack nuts, chimpanzees in Tanzania would not. The ones in Tanzania would fish termites from a mound and put them in their mouths, the ones in Ivory Coast would swipe them off their 'rod' and into their mouths in a single handful. While at least 38 tools have been observed in the chimpanzee repertoire, at most any one group uses 23 - and almost all groups have customary 
behaviours that are specific to their group. The transmission of knowledge of these tools was not genetic or instinctual, but based on local culture (Whiten, et al., 1999).

Many scientists find the word 'culture' for non-humans problematic and prefer to reserve its use for human traits and complexes (Abner, 2005). However, even these authors rely on the concept of 'tradition' to explain why some groups of animals behave in consistent but not predetermined or survival-required ways. These traditions are communicated between generations by various means. Fledgling birds will imprint upon star patterns during their months in the nest, and these appear to set their navigation systems for a lifetime of migration and travel patterns. These systems are site-specific: for example, salmon use the distinct scents of their birth rivers to target them for return when they are ready to spawn (Hauser, 2001). Mammals like wolves and right whales learn specific patterns of travel and behaviour through their year or more of constant travel with their packs or mothers. Right whales mother/calf pairs have been noted visiting every likely feeding site between the calving grounds and summer feeding grounds, even if the potential sites are "out of season". In subsequent years, the calves have been observed returning to the mother-approved sites but have not often been found to extend their range to potential feeding sites outside the ones they were brought to as calves (Informant B). It is a certainty that the young of many species learn from their conspecifics, particularly their mothers.

If the animals can learn, can they also plan or intend? What can be said about the nature of animal agency compared to that of humans? Anthony Giddens (1987) addressed the subject in this way:

What is it about agents which differentiates them from objects or the operation of impersonal forces in the world of nature? What distinguishes human agents from other beings to which agency might reasonably be attributed - that is to 
non-human animals? With due recognition of the complexity of the issues involved, the following answers might be given briefly. Agency is a manifestation of an organism, which therefore possesses a body, that body being capable of intervening causally in the stream of events that constitutes its environment of behaviour. Agency hence presumes a 'motor of events', that is the agent. But it also entails that such a 'motor' is a concept-bearing being, whose concepts are employed to organize activities that modify the stream of events in the world. Agency, to put it another way, presumes the capability of 'acting otherwise'. We can suppose that the higher animals are concept-bearing beings, and are thus agents in this sense. Human beings differ from the animals since they possess syntactically differentiated languages. The range of conceptual operations they are able to carry on whether embedded in the practical content of what they do, or formulated discursively - is immensely larger than that available to non-human animals. Human beings have an understanding of themselves as agents, thus allowing for a reflexive appropriation of knowledge denied to non-human animals. They are also able conceptually to 'bracket' time and space, connecting future and past in a manner not open to the remainder of the animal kingdom. There is no reason to doubt that the behaviour of animal agents is purposive. But in the case of human agents purposiveness is integrated with a continuous reflexive monitoring of what the actor does, intrinsic to what 'doing' is (216).

Giddens appears to recognize that animals are not 'locked in' to patterns of behaviour, and therefore have the capacity to 'act otherwise'. This is borne out by the studies of wolves, whales and bears reviewed in this dissertation in which their capacity to choose courses of action and take initiative is more substantial than might be assumed by social scientists theorizing about animal capacities and action while distant from that action. Animal actions also interface with human economic, social and political realities, contributing to change in human affairs. Taken together, these conditions recommend an expansive reading of animal agency. 


\subsubsection{Human-environment relationships and values of nature}

Although human values - the principles, standards and judgments of importance are highly individual and contextual, there are certain dimensions of relationship between humans and the world around them that transcend the particular. The study of 'values of nature' (described below and summarized in Table 2) has found that there is a variety of positions or stances on the non-human world that share dimensions across cultures.

Different cultures, and different individuals and groups within a culture, have different values; however the range of possible stances is finite.

\begin{tabular}{|c|c|c|}
\hline Summary & Nature Value & Definition \\
\hline \multirow{3}{*}{ 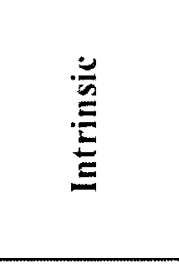 } & Aesthetic & Reflects the physical attraction and appeal of nature \\
\hline & Humanistic & $\begin{array}{l}\text { Emphasizes strong affection and emotional attachment } \\
\text { for nature }\end{array}$ \\
\hline & Naturalistic & $\begin{array}{l}\text { Expresses desire for close contact and immersion in } \\
\text { nature }\end{array}$ \\
\hline \multirow{5}{*}{ 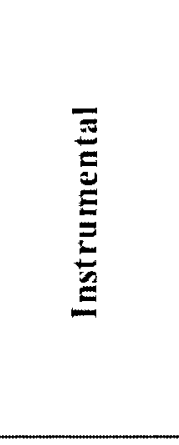 } & Moralistic & Reflects an ethical and spiritual affinity for nature \\
\hline & Dominionistic & Reflects the urge to master and control nature \\
\hline & Scientific & $\begin{array}{l}\text { Emphasizes the empirical and systematic study and } \\
\text { understanding of nature }\end{array}$ \\
\hline & Symbolic & Source of language and imagination \\
\hline & Utilitarian & $\begin{array}{l}\text { Reflects the material and commodity attraction of the } \\
\text { natural world }\end{array}$ \\
\hline$\underset{z}{Z}$ & Negativistic & Reflects the avoidance, fear and rejection of nature \\
\hline
\end{tabular}

\section{Table 2: Values of nature} after Kellert (1996)

A second dimension of analysis is the environmental position of an actor. There are few self-identified "non-environmentalists" in the landscape of ideas. However, what falls under the definition of environmental behaviour ranges widely. O'Riordan (1989) examined this issue under the rubric of green politics and modern environmental conceptions. Table 3 
presents a schematic of O'Riordan's analysis that provides a framework for understanding different environmentalisms. It is a system of analysis that categorizes action and belief to analyze and predict appropriate action by a partıcular actor.

\begin{tabular}{|c|c|c|c|}
\hline \multicolumn{2}{|c|}{ Ecocentrism } & \multicolumn{2}{|c|}{ Technocentrism } \\
\hline Gaianism & Jom & commod & Inten \\
\hline $\begin{array}{c}\text { Falth in the nights of } \\
\text { nature } \\
\text { Essential need for } \\
\text { co-evolution of } \\
\text { human natural ethics }\end{array}$ & $\begin{array}{c}\text { Farth in the } \\
\text { cooperative } \\
\text { capabilities of } \\
\text { societies to be self- } \\
\text { reliant } \\
\text { Renewable } \\
\text { resources } \\
\text { Appropriate } \\
\text { technologies }\end{array}$ & $\begin{array}{c}\text { Faith in the } \\
\text { adaptability of } \\
\text { existıng institutions } \\
\text { Current system can } \\
\text { accommodate } \\
\text { environmenta! } \\
\text { demands }\end{array}$ & $\begin{array}{c}\text { Faith in the } \\
\text { application of } \\
\text { science, market } \\
\text { forces and } \\
\text { managerial ingenuty } \\
\text { to intervene in nature } \\
\text { Economic growth } \\
\text { Overcome } \\
\text { environmental } \\
\text { problems }\end{array}$ \\
\hline \multicolumn{2}{|c|}{$\begin{array}{c}\text { Demand for redistribution of power towards } \\
\text { decentralized, federated economy with more } \\
\text { emphasis on informal socio-economic interactions } \\
\text { and participatory justice }\end{array}$} & \multicolumn{2}{|c|}{$\begin{array}{l}\text { Belief in the retention of the status quo in the } \\
\text { existing structure of economic and poitical power, } \\
\text { but a demand for more responsiveness and } \\
\text { accountability in political regulatory, planning and } \\
\text { educational institutions }\end{array}$} \\
\hline
\end{tabular}

Table 3: Environmental stances after O'Riordan (1989) and "Environmentalism" Dictionary of Human Geography, 2000

These, and any, heuristic devices are simplifications of reality, and indeed, simplifying the human-nature nexus is sometimes desirable. However, much work in human geography in recent decades has been about unsettling easy and superficial conceptions about land, landscape and space as mere platforms upon which actions happen and place is made (Bordessa, 1993; Soja, 1999). Approaching nature as a co-constructed concept is a radical challenge for those at the interface - rural residents, conservation officers, wildlife managers, rangers and others. This leads to somewhat unreflective practice in human-environment relationships. The present research posits that overlaying a framework of 
'environmentalisms' on events and narratives as they unfold can enrich this situation. In the cases detailed in chapters 2,3 , and 4 , a narrative account is followed by a thematic and discursive analysis, leading to an examination of the prospects of a co-existence recognizing the active nature and agency of the non-human participants. This approach enables a reflective, and hopefully successful, approach to human-other relationships.

\section{Locating the work in theory and animal geography}

This research is attempting to flesh out a politics of nature that is inclusive of animal others, specifically species at risk of extinction or extirpation. In the tradition of animal geography, I accept animals as active co-constructors of their world. This depends on a relational ontology that differs from a fixed ontology in which nature is 'a given'. However, legal responsibility for moderating human-wildlife conflict and protecting species at risk in Canada falls to government agencies. Typically, these are provincial authorities for terrestrial species and the federal Department of Fisheries and Oceans for marine species. The professional tradition that these efforts fall under is that of wildlife management, joined in recent years by conservation biology. Dating from the late $19^{\text {th }}$ century conservation movement, wildlife management is an interventionist tradition to protect and improve nature with a focus on human use and enjoyment. As one text puts it, "wildlife management is the manipulation and protection of a population to achieve a goal" (Caughley \& Sinclair, 1994, p. 1).

The practice of wildlife management is rooted in a positivist and utilitarian tradition, and its goals can include wildlife-related tourism and recreation, human-wildlife conflict reduction, prevention of the spread of wildlife disease and environmental sustainability, among others (Manfredo, 2008). The achievement of these goals brings "the public" into the 
ambit of wildlife managers, often trained in biology but needing to relate to human values and motivations to understand and influence human-wildlife interactions. This need has encouraged the integration of social science in wildlife management, typically under the umbrella of 'human dimensions of wildlife' (Manfredo, 2008; Treves, et al., 2006). The scientific approach and the ontology of the world as a manageable but external realm limit the possibility of seeing the wildlife as co-constructors and active agents. The focus is on populations as opposed to individuals (Dyke, 2008), and the distinction between humans and non-humans is clear and bright.

Critical geographers, on the other hand, have not only attempted to blur this line but sometimes to erase it. Sarah Whatmore has used actor-network theory to interrogate relationships with wild animals. In Whatmore and Thorne (1998) the authors describe "wildlife' as a relational achievement spun between people and animals, plants and soils, documents and devices, in heterogeneous social networks that are performed in and through multiple places and fluid ecologies" (p. 437). David Demeritt's work on global warming and forest resources (Demeritt, 2001a, 2001b) applies different but related approaches to deconstruct binaries of social and natural, "insisting that nature is not simply natural: ... in both discourse and practice it is socially made, not ontologically given" (Castree, 2003, p. 205). Castree argues that animal geography can bypass a lack of interest in ecocentric thinking - associated with naturalism and 'left behind' by social nature - by considering the political status of nature, environment and the non-human. "These geographers propose to move beyond dualism in order to rethink who the subjects of politics might be now" (Castree, 2003, p. 207).

In this research, I draw from writings and interviews with biologists and wildlife managers and from interviews and media accounts with citizens affected by and interested in 
living with wildlife. The relationality of living with the other comes through in some of these sources, but the tendency is not to be overly reflective about the co-constructed nature of shared space. Therefore, this work is attempting to build a bridge between the positivist tradition and a relational ontology. Observations are considered in terms of their material, discursive and constructive content. The challenge of the subject matter is reproduced in the research process - recognizing the construction of knowledge and the social process of research and theorizing, the object of study becomes a substrate upon which can be layered interpretations and constructions that themselves are more changeable and more transitive than a putative underlying reality (Forsyth, 2001; Sayer, 1992, 2000). This belief in a reality that can be agreed upon and a series of signifiers and constructions through which that reality can be understood, deconstructed and discussed belongs to the tradition of critical realism.

A critical realist approach occupies a centre line in the 'science wars' (see, for example, Kwan \& Tsang, 2001 for a typology and reconciliation of realism and constructivism under the critical realist banner). While in a positivist worldview facts can speak for themselves, discourse analysts and post-structuralists find facts in the symbolic interaction of the co-constructor; therefore, nature does not pre-exist discourse of nature. This position was attacked by environmental and conservation advocates who claimed that this 'intellectual tinkering' was 'just as destructive to nature as bulldozers and chainsaws' (Soulé \& Lease, 1995 cited in Whatmore, 2002, p. 10). Critical realists posit a relatively intransitive ontology that is mediated by transitive epistemology, a flawed but gradually and partially perfectible set of assumptions, perceptions and perspectives (Sayer, 1992).

Within the context of animal geography as a sub-discipline, this work draws inspiration from efforts such as Gullo, Lassiter and Wolch's “A Cougar's Tale" (1998) which 
drew from scientific literature on cougars and other cats as a point of comparison with cougar behaviour in areas of recent human settlement, drawing inferences about the resulting relationships that emerged. This two pronged approach of examining "human-side" and "animal-side" of a relational space may make a contribution to Philo and Wilbert's (2000) call for a 'real' geography of animals. At the same time, it is grounded in an empirical and pragmatic effort to connect the progressive strains of relationality in animal geography with the practical and positivist work generally found in conservation biology and wildlife management.

\section{Research design}

Within the processes by which humans and non-humans adapt to each other and permit each other's continued existence (or fail to do so), numerous variables and dimensions come into play: biological, economic, social, moral and historical among them. Also, each site or space of co-existence and species in the study is context-laden. The spaces in the study require careful substantive and contextual review. This set of conditions suggested a qualitative paradigm and case study strategy. Figure 1 is a schematic diagram of the relationships between questions and methods which is elaborated below. 


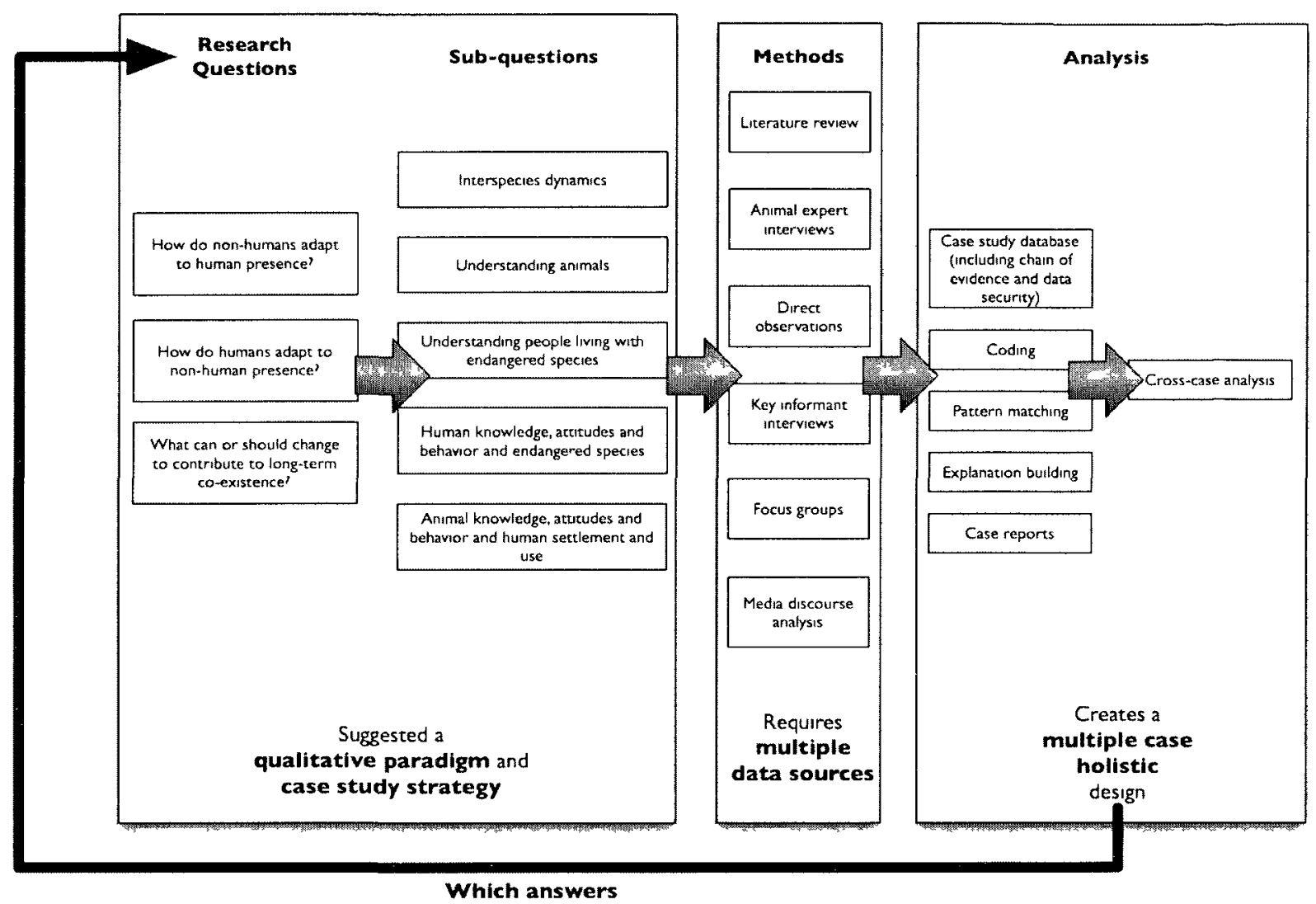

\section{Figure 1: Research framework}

Case studies are in-depth explorations of an activity or process, bounded by time and activity, in which "researchers collect detailed information using a variety of data collection procedures" (Creswell, 2002, p. 15). Each study is an empirical inquiry that investigates a contemporary phenomenon within its real-life context, especially when the boundaries between phenomenon and context are not clearly evident (Yin, 2009).

\subsection{Selection of cases}

In order to focus questions of shared space and interacting with other species, I scanned situations of co-existence and conflict between people and large, predatory or competitive species in Canada. These species can be seen as competing with humans for 
land or resources or as causing a major impact on human activities Endangerment was defined as being listed on the federal Species at Rish registry

I read widely on conservation issues and situations of human-wildlife conflict, sought out organized programs or activities that support successful co-existence, and consulted key informants on pressing situations of endangerment in Canada Following Yin's (2009) approach to case study selection, I sought to examme different perspectrves and insights on a single phenomenon I also considered regional and urban/rural diversity and the construction of endangerment - the biological, social and political dimensions of how a species comes to be listed as endangered This led me to the selection of the following cases fot examination (see figure 2 for locations and index to larger scale maps)

An exploration of the wolves of the Ottawa Valley and Algonquin Park In the 1990s, the k1lling of wolves in the border regions outsıde Algonquin Park, Ontario became a contentious public issue This situation came to light as the result of a research project in the park that was subsequently criticized for 1ts principal researcher being "too activist" However, since then wolf protection measures have been put in place in all townships surrounding Algonquin Park, pleasing conservatıonısts and angering many local residents

\section{An analysis of the status and prospects of the North Atlantic Right Whale}

Although nobody knows the historic number of North Atlantic Right Whales, it is clear that substantal numbers were killed from the early 1500 s until they were legally protected in 1937 Today fewer than 400 remain, and they migrate from the coastal regions around Florida and the Gulf of Mexico in winter to the Bay of Fundy and Scotia Shelf in summer As they are critically endangered, a range of protective measures have been taken in the Bay of Fundy, including moving shipping lanes and forming a whale rescue team to disentangle 
whales from fishing gear. This study addresses human adaptations to the presence of endangered species, ecosystem degradation and species decline

\section{A study focused on the present and future of grizzly bears in the Bow Valley}

of Alberta. Canmore is a desirable destination in fast-growing Alberta. At the edge of the Rocky Mountains and on the border of Banff National Park, it is noted for its beauty, recreational opportunities and especially wildlife. Canmore's population has grown from 5,600 in 1991 to over 12,800 in 2006 (Statistics Canada, 1996, 2006). This rapid growth has converted a considerable area of habitat to residential land, and seen a large number of people move into bear country. The provincial and municipal governments have instituted a series of programs to ensure that "living in Canmore means living with wildlife as well" (Alberta, n.d.). This case provides an opportunity to explore how newcomers who knowingly move into wildlife habitat adjust. The bears of this region of the Bow Valley are well studied, which provides information on how bears have adapted to the large influx of people into the region. 


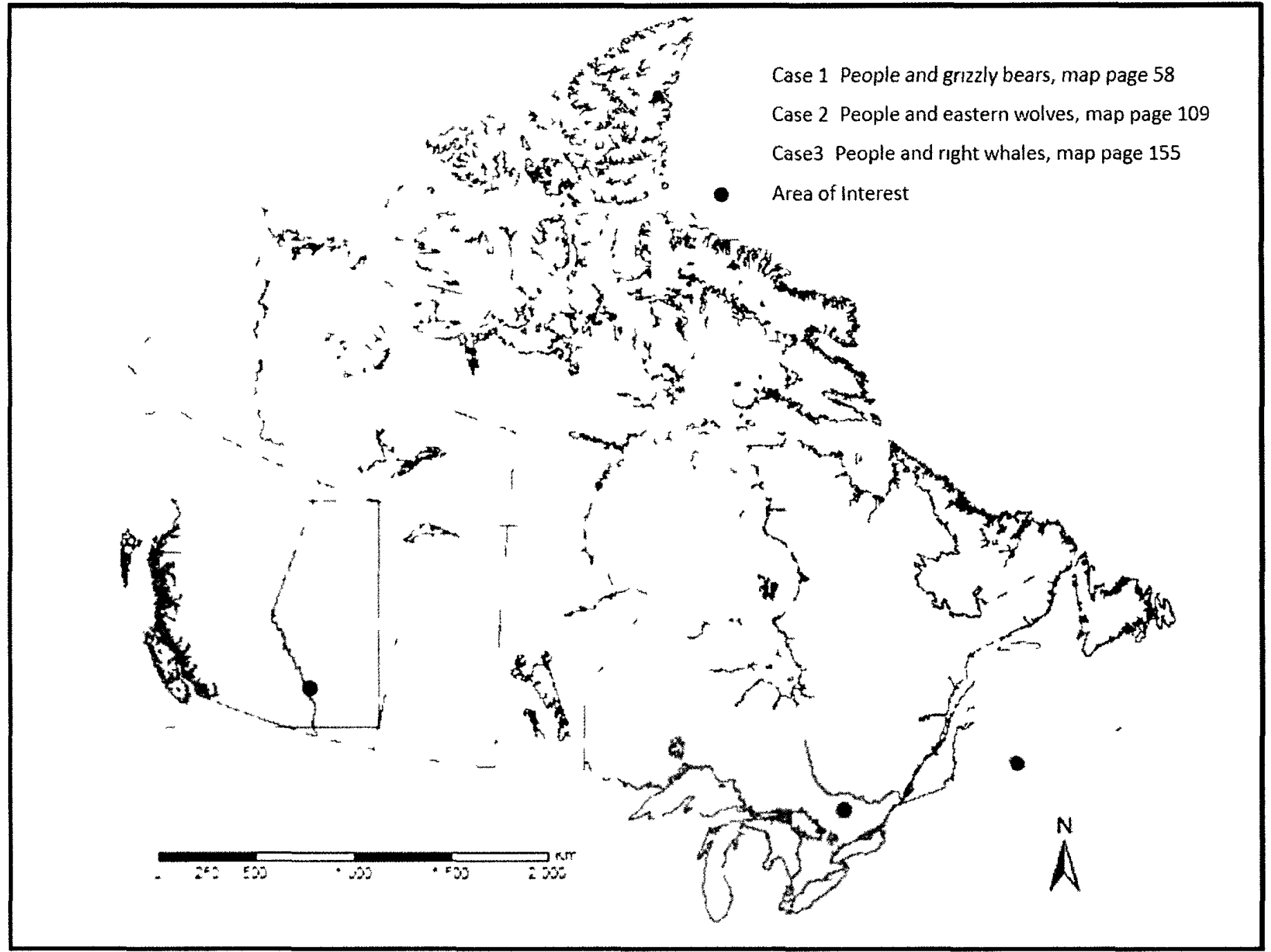

Figure 2: Case study locations

Map by: Christopher J. Czerwinski/John Wall 


\section{Procedures}

\subsection{Data collection}

Between January 2009 and 2010 I conducted research from Ottawa and during site visits to the Ottawa Valley, Bay of Fundy and Bow Valley. The research effort was twopronged. I wanted to gather information about how people in each study area understood and adapted to the presence of the focal species, and in turn, how the focal species adapted to changes in human presence and land use.

There were several challenges to account for in the research. As a geographical study, I was able to draw on a body of social science methods, notably interviewing and media discourse analysis to develop a framework for understanding human perceptions and attitudes related to the focal species. These methods also allowed me to compile a narrative of key events in the recent history of the human-animal relationship, and to note 'critical discourse moments' when relationships and understanding of those relationships changed. At the same time, this gathering of viewpoints was not exhaustive or statistical, leaving a compilation of respondents' views as a continuing challenge of interpretation. Although I sought and often found contrary viewpoints, the theme of co-existence may have discouraged participants who do not agree that co-existence is a worthwhile goal, and so the informant pool may be too shallow to be conclusive. At the same time, letters to the editor in local papers and media reports do offer insight into a range of viewpoints that may not have been directly accessible to me as a researcher.

To evaluate these media reports, I conducted a media discourse analysis. Media reports offer a narrative of relevant events and a generalized view of the way residents of each case area conceive of and position themselves toward the species in question. Media 
coverage represents events in the world by setting up identities for those involved in the story and by taking a stance in the reporter-audience relationship (Fairclough, 1995). Each case included the analysis of local and regional newspaper coverage for the 10 years preceding the research, generally 1999-2009. The research included a textual analysis which looks at the themes and topics of coverage and the language, rhetoric and discursive strategies and processes in that coverage (after Carvalho, 2000).

On the animal front, the challenge of understanding an animal view of humans or human action is more fundamental than social science methods that can be fortified by triangulation and verification. Biologists have been authorized as the voices of animals in natural history and management, and biological views tend to prioritize the population over the individual. I depended on interviews with and the published work of those who have spent extended periods with the animals to interpret how changing circumstance influences their behaviour.

In both the 'people-' and the 'animal-' related interviews, I used the approach recommended by Holstein and Gubrum's (1995) Active Interview. The authors argue that interviews are "interpretively active, implicating meaning-making practices on the part of both interviewers and respondents" (p. 5). The authors argue that all interviews are constructed and discursive, whether recognized or not, and the conscious and conscientious analysis of interviews in this light is more positive and effective than introducing methodological constraints that attempt to remove the "interactional ingredients" of the interview. The authors posit that these attempts assume that participants have a store of knowledge at the ready and the researcher's role is to allow them to utter their knowledge without interference. That the interview is instead part of the participants' process of making 
meaning was vindicated by the frequent expression of statements in this research like, "that's a good question" and "I've never thought about it that way before".

To encourage consistency between cases, I developed a case study protocol after Yin (2009) to codify the purpose and procedures of the study. I used this in planning each case study and site visit, and developed an interview protocol sheet for each case. This sheet included an informed consent form for the interviewee (a copy was also left with each interviewee), a list of questions and space for note taking and observations. In practice, the questions served as a guide, since each interviewee had individual areas of interest and expertise which provided the opportunity to delve more deeply into some topics than others. These guides are available in Appendices B, C and D of this dissertation. Ordinatily the interviews were recorded and transcribed in their entirety, with some exceptions as described below.

Table 4 is a summary of the research activities for each case: 
Table 4: Research activities by case

\begin{tabular}{|c|c|c|c|c|c|}
\hline & $\begin{array}{c}\text { Media Sources } \\
\text { Analysed }\end{array}$ & $\begin{array}{c}\text { Key } \\
\text { Informant } \\
\text { Interviews }\end{array}$ & $\begin{array}{c}\text { Public } \\
\text { Consultation }\end{array}$ & $\begin{array}{l}\text { Science } \\
\text { Interview }\end{array}$ & Site Visit \\
\hline Ottawa Valley & $\begin{array}{l}\text { Globe and Mail } \\
\text { Pembroke } \\
\text { Observer } \\
\text { North Bay } \\
\text { Nugget }\end{array}$ & 12 & $\begin{array}{l}\text { Focus Group/ } \\
\text { Ads in } \\
\text { Pembroke } \\
\text { Observer and } \\
\text { Barry's Bay } \\
\text { This } \\
\text { Week/Posters }\end{array}$ & $\checkmark$ & $\begin{array}{l}\text { Jan 27-30; } \\
\text { May 11- } \\
13 ; \text { May } \\
26-28 \\
2009\end{array}$ \\
\hline Bay of Fundy & $\begin{array}{l}\text { Saint John } \\
\text { Telegraph- } \\
\text { Journal }\end{array}$ & 6 & $\begin{array}{l}\text { Toll free } \\
\text { number with } \\
\text { posters }\end{array}$ & $\checkmark$ & $\begin{array}{l}\text { July 4-18, } \\
2009\end{array}$ \\
\hline Bow Valley & $\begin{array}{l}\text { Calgary Herald } \\
\text { Canmore } \\
\text { Leader } \\
\text { Rocky Mountain } \\
\text { Outlook }\end{array}$ & 10 & $\begin{array}{l}\text { Toll free } \\
\text { number with } \\
\text { ads in Canmore } \\
\text { Leader and } \\
\text { Rocky } \\
\text { Mountain } \\
\text { Outlook/Posters }\end{array}$ & $\bar{\checkmark}$ & $\begin{array}{l}\text { Aug 11-23; } \\
\text { Nov 14-18, } \\
2009\end{array}$ \\
\hline
\end{tabular}

In the paragraphs that follow I outline the activities for each case.

People and Wolves in the Ottawa Valley - In January 2009, I began to make contact with individuals who I identified through media reports and a snowball sample who had an interest in or involvement with Ottawa Valley wolves. I developed initial contacts through organizations including the Amprior and Area Naturalists Club, the Pembroke Outdoor Sportsmen Club, and the Friends of Bonnechere Park. I also began making contacts with members of the Algonquin Wolf Advisory Group, a consultative body formed by the Ontario government to advise the Minister of Natural Resources on wolf management and protection. Through these initial contacts I developed a list of potential participants, and of those who agreed to be interviewed I would ask for further recommendations for contacts. I conducted the first of these interviews by phone and in person in January 2009. 
This method of snowball sampling (non-probability referrals of informants with an interest or knowledge of the topic) did generate leads and suggestions for further interviews; however, I became aware of a constraint of 'filtering' by which interviewees' selection of potential informants narrowed the pool in a way that was possibly restricting the range of views that I was receiving. To open up the process, I moved forward with planned focus groups and launched a new 'public' dimension of the process. I established a toll-free telephone line with a message service and a special e-mail account. Beginning on February 27, 2009 I publicized the line and e-mail with ads in local papers and posters on community bulletin boards. This allowed local residents to contribute to the research without being selected by me or other interviewees.

On May 12 and 14, 2009 I scheduled focus groups in the public libraries of Pembroke and Barry's Bay, two larger communities in the study area. I invited callers to the 1-800 line to participate in the focus groups but found the numbers were sub-optimal, so began to invite participants who had been recommended by other participants. In spite of this recruiting method, only 3 participants attended the Pembroke focus group and I cancelled Barry's Bay due to a lack of participants. Of the participants in Pembroke, all three could be considered to have ecocentric viewpoints. Based on this experience and advice from other rural area researchers, I decided to abandon the focus group method because the public nature of the forum combined with the inability to find informants who did not know each other well, and the sometimes contentious nature of the topic made it a poor fit for my target communities. For the subsequent cases, I decided to focus on the snowball sampling and public appeal for participation.

In addition to these interviews and focus groups I conducted a media discourse analysis of the Globe and Mail, for a provincial perspective, and the Pembroke Observer and 
North Bay Nugget for a regional perspective. These papers were the geographically closest media outlets for which the period of interest (1999-2009, with some reference to the early 1990s) was available indexed and digitized.

In August 2009, I attended, recorded and photographed an Algonquin Park Public Wolf Howl which, from media reports and interviews I had already begun to observe, was influential in shaping public opinions about the wolves and the situation of co-existence far beyond the regional boundaries.

People and the Right Whales of the Bay of Fundy - Having completed the pilot study in the Ottawa Valley, I refined the case study protocol and planned a two-week site visit to Campobello Island, Grand Manan Island, and Saint Andrews, New Brunswick to conduct the case study of people and right whales between July 4 and 18, 2009. The right whales tend to summer in the deep waters of the Bay of Fundy, and the fishers of Grand Manan have the most contact with the whales. The island is also the site of the Grand Manan Whale and Seabird Research Station. Campobello is the home of the Campobello Whale Rescue Team, the members of which have extensive direct experience of right whales and one of their key threats, fishing gear entanglements, and is joined by bridge to Lubec, Maine, the base of the New England Aquarium right whale researchers. Saint Andrews is the site of the Department of Fisheries and Oceans Biological Research Station.

Interviewing people for this case study was both challenging and rewarding. While interviewing 'formal' informants like government and agency representatives was similar to the Ontario process, individuals were less likely to submit to a formal interview. I was advised to avoid the focus group method. At the same time those participants who did agree to be interviewed would spend large amounts of time with me, often at their place of work 
(on their boat or at the wharf). A trusted local would introduce interviewees to me and then they would talk as they worked. This made the procedure of reading the informed consent form and recording the interview difficult. Instead, I would describe the project and ask for their consent verbally, and then write notes up periodically during the visit. The data collection was more closely related to participant observation than interviewing. I spent more than eight hours with some respondents.

This process was enriching in that it gave me a deeper comprehension of the viewpoints and challenges faced by fishers in the region, but it also gave a more restricted range of viewpoints. Later, I made a purposive effort to add alternative viewpoints and extend my understanding of the situation but was reassured by triangulating the views of fishers with the input of other informants and media outlets.

This case also included consultation with scientific and regulatory informants.

\section{People and Grizzly Bears in the Bow Valley - From August 11 to 23, 2009 I} visited Canmore, Alberta. This period was more intense than the Ontario research in that I conducted a similar amount of work that I had done there over several months in less than two weeks. It was also more organized than the Bay of Fundy - government offices, coffee shops and local businesses were easily accessible to arrange interviews, and scientists, regulators and concerned citizens lived and worked within a few minutes of my research base at the Rocky Mountain Chalets. The process of simultaneous snowball sampling with soliciting public participation with ads and posters was relatively seamless by this point and I collected considerable amounts of data, while observing sites of human-bear conflict and real estate and tourism development that play a role in the human-wildlife relationship in the region. 
In November, I returned to the region to attend the Third People-Bear Conflict Workshop, a gathering of approximately 200 bear researchers and managers at which I presented a poster of my preliminary research. This was an enriching experience in that all possible scientific informants were gathered in one place, and I was able to take part in three days of up-to-the-minute discussions of research and policy. I recorded the information from the conference and included the relevant portions in my analysis.

\subsection{Data analysis}

The research resulted in a large volume of data in different formats. The main outputs were recordings and transcriptions of interviews and the focus group, digital files of media coverage, photocopies and digital files of book chapters and journal articles on my focal species, photographs from my site visits and photographs and audio recordings from the Algonquin Park Public Wolf Howl.

The first step in the analysis was to collect the data in analyzable formats, which for me was largely textual. I had three ways of recording interviews. With the consent of my informants, I used a small digital voice recorder during in-person interviews. On the telephone, I used an adapter to connect the recorder so that I could also create digital audio files. Finally, I used a web-based voice over IP system (Skype) with a software package called Call Recorder to accept toll-free phone calls and conduct interviews directly on my computer. I then used file conversion software (iTunes, Switch, or MovieTools) to convert these files to $\mathrm{mp} 3$ format for ease of transcription, as the different recording tools produced recordings in different file formats. However, I saved the original recordings in each case for data verification and to resolve subsequent problems with file formats or audibility. 
News articles were collected from the Proquest Current Newsstand electronic database This provided articles from regional and national newspapers that were digitized and indexed, which facilitated the location and analysis of relevant articles, but also limited the selection of data sources (to get non-digitized news articles from local papers I used the microfilm records of the National Library of Canada, which was enormously time consuming)

Interviews were transcribed in their enturety and coded on paper with colour coding to identify interviewees, and with marginal labels to identifv themes The coding was done by the constant comparison method (Glaser \& Strauss, 1967, Lincoln \& Guba, 1985, Merriam, 1998) in which simular statements are coded with meaningful labels, and theses labels become an abstract unit of analysis The original statements are retained and are used to 'ground' results, providing a "chain of evidence" linking data to analysed results (Yin, 2009) This is discussed in more detail in the Thematic Analysis section below

\subsection{Discourse analysis}

Anımal geography and some other human-anımal studies have included some discourse analysis (Gibson-Graham, 2002, Wolch \& Emel, 1998, Wolch, et al , 2003) Jepson (2008) used discourse analysis to examine how humans perform the 'skilled mental slight of hand' ( $\mathrm{p}$ 128) required to sanction the killing of nonhuman anımals, for instance Other discourse-oriented work has included how language contributes to the exploitation of domesticated animals (Stibbe, 2001) and how foxes were represented in the campangn to end fox huntıng in the United Kingdom (Woods, 2000) Discourse analysis offers a powerful tool to consider the range of positions extant in situations of human-wildife conflict and to understand the relationship between discourse and policy action 
Anabela Carvalho (2000) innovated a method of longitudinal discourse analysis of newspaper texts on a single topic as part of her doctoral research on media coverage of the politics of the greenhouse effect over a fifteen-year period (Carvalho, 2005). Carvalho borrows from three traditions to develop her method: Van Dijk's cognitive-structural model (van Dijk, 1980, 1985, 1988a, 1988b,) is concerned with "theme structure", the hierarchical structure of topics in

a text and how these topics are semantically related; frame analysis [articulated by Gamson, Croteau, Hoynes, \& Sasson (1992), and Muscovici (1984)] which looks at how disparate bits of information are fit into familiar plots or storylines, thus making sense of complex realities; and narrative analysis. Narrative analysis is similar to literary analysis, in that it examines the "story" and how the story is told. This approach addresses characters, sequence of events, storylines and outcomes. It may seem surprising that this approach is applied to ostensibly "factual" text like media articles; however reporters have to choose the details to include and omit in a story, the sources that they consider relevant and authoritative, and string story elements together in a coherent fashion. How these moves are accomplished, is informative about the substance of the issue to be covered and about the way this knowledge is produced and consumed.

Carvalho's method is applied through a two-stage process of textual and contextual analysis. Textual analysis means that the articles collected on a given topic are studied in their own right, looking at a range of factors from surface descriptors and organization, themes, actors, languages, discursive strategies (the way the piece is put together) and ideological standpoints of the actors. Contextual analysis includes analyzing each news story in light of how other media outlets have covered the same story, and in light of how the issue has been covered subsequently. This approach depends on a range of positions in different media 
outlets, which was moie the situation in the wolf case than the others in the present research

The task of reading media reports (and language in general) as more than "a neutral system of signs that describe the world" is one that has been taken up by Maarten Hajer (1993, p 44) He introduces two key concepts that feature in the analysis of the media coverage of Algonquin wolves, that of discourse coalitions and storylines Hajer argues that in public policy there are various ways of constructung the world For example, he looks at large groups of dead trees - while the trees are not socially constructed, the idea of them (as dead due to natural causes versus victims of acid rain) is This idea then has implications about the society that kills them and permits them to be killed, among others Hajer labels a group of people who share the same construct "discourse coalitions" Members of discourse coalitions may or may not be in contact or communication with each other, but because they share ideas and ways of seeing the world, they also communicate along simular lines These lines of convergence are called "storylmes"

\subsection{Thematic analysis}

One of the challenges of qualitative research is parsing, making meaning from and presenting significant elements of the often vast amounts of data collected that can span transcrupts, media reports, images and other sources This can be almost paradoxical, because one of the strengths of the qualitative paradigm is its aspiration to holism and context, reduction of data to make it more manageable can work against these goals

The process of data analysis that helps bridge the gap between the richness of qualitative data and the necessity of concise presentation and theory bulding is thematic analysis, the 1dentification and linking of patterns within a set of texts This process includes 
the collection of data and transformation for coding (in this case by transcription), classification of meaningful statements and identification of statements by giving each meaning unit an identifying code, and the combination and cataloguing of repeated patterns into themes (Aronson, 1994). These individual statements and patterns are units of analysis, defined as "a concept, idea or action that illuminates the significant features of the data to permit answering the research question" (Foss \& Waters, 2007, pp. 185-186). Since these were indicated by the question, I began with a priori codes of the actors, actions, attitudes and behaviours of people and animals in the cases. These were extended as novel concepts and objects emerged in the research to include 127 codes covering a full range of the human and animal dimensions of the research.

The coding process includes a close reading of the text and the identification of units of meaning, which in this case were indicated within the digital file in "Text Analysis Markup System" which is a syntax similar to HTML that inserts 'tags' within text. These tags can later be used to retrieve relevant passage from the whole dissertation database or any subset of articles or transcripts. This permits 'at a glance' summaries of actors and action types that can be analyzed in various ways or exported into spreadsheets or tables for presentation. The program that facilitates coding, searching codes and presenting data is called TAMSAnalyzer (Text Analysis Markup System, http://tamsys.sourceforge.net/).

For presenting the data, I turned to recommendations from Miles and Huberman (1994) who often recommend matrices as means of summarizing and presenting complex data. This became a useful tool for framing 'actor-action' and 'actor-discourse' summaries in the cases in the form of tables, and these are used in the presentation of each case. The columns of the tables represent the themes that were derived from the literature and refined from the data itself; the rows represent the actors in each case; and the contents of the cells 
are summary statements of the actions or discursive elements relevant to each case. With TAMSAnalyzer I can go back to the coded passages to verify evidence, which grounds the summaries and resulting theory in the data.

\section{Significance of the study}

A geographic study of the intentional creation of lasting spaces of co-existence is an innovative and useful contribution to the field of animal geography. Conceptually, it extends the contemporary literature on social nature and animal geographies into a so-far neglected milieu. In practical terms, it provides a bridge between conservation biology and other branches of science with social science and communication. It has long been recognized that most wildlife problems are people problems, but insights from inquiry into social nature and human-environment relationships have not been translated into practical terms to support positive action (Jacobson \& McDuff, 1998; Madden, 2004).

Animal geographers have identified the questions and possibilities of creating a 'true animal geography' (Philo \& Wilbert, 2000) and seeing animals as a profoundly different social group as opposed to a qualitatively different entity when it comes to human relations (Wolch \& Emel, 1998). However, animal geography studies have tended to focus on those animals whose lives are most entangled with humans - domesticated, agricultural and captive. While wild animals are not absent from the new animal geography, they hold a minor role. Considering wild animals in their own terms as well as in their relations with humans fills a significant gap.

The role of social science in conservation has long been recognized. However, the form of inquiry that this label represents is circumscribed in what is typically called "human dimensions of wildlife". Typical areas of interest are values and attitudes toward nature and 
how to influence human action (see, for example, Manfredo, 2008). Geographers, meanwhile, have become deeply engaged in questions of the social construction of nature and the mutual constitution of nature and society, problematizing even the term "nature" (Castree, 2005), while anthropologists have engaged with humans and wildlife from the perspective of social conflict (Knight, 2000). This work is disciplinarily specific in many ways, and perhaps is not communicated or shared with the biologists and wildlife managers who grapple with resolving human-wildlife conflict on a routine basis. While some of this work may be too esoteric or theoretical to be of daily use, re-examining the intellectual underpinnings of human-wildlife relationships is a worthwhile enterprise that may make a contribution to practice.

The approach to the research was three-pronged. There was a discourse analysis of media and a thematic analysis of reflections and commentaries by key actors; and a review of the literature and interviews related to animal behaviour and changing use of space. These multiple approaches were directly aimed at responding to the research questions above, specifically an examination of how humans and non-humans adapt to each other's presence, and what this process indicates for successful long-term co-existence.

\section{Outline of the study}

Chapter 1 has introduced the study and explored the literature related to the four main concepts and the academic discipline that are most relevant to this research: coexistence, human adaptations to living with animals, animal adaptations to living with humans and the context of endangered species in Canada; and an overview of the field of animal geography. Chapters 2 through 4 are case study reports of co-existence, namely between people and bears (chapter 2), people and wolves (chapter 3) and people and whales 
(chapter 4). Each chapter provides an overview of the case, a narrative of the incidents and changes in the case over the study period, typically 10-20 years, and an analysis of the actors, actions, processes and prospects of co-existence. Chapter 5 is a concluding chapter that provides a cross-case analysis and develops themes of agency, mutuality, discourse and a summary statement on animal geographies in cases of co-existence. 


\section{People and grizzly bears in the Bow Valley}

Lower elevation habitat has always been a part of the grizily bear's breadbox. That is where their year begins when they come out of their dens. The more bears you have and the greater diversity and distribution, the better off they are genetically.

Brian Horejsi, Wildlife Biologist, 2000

\section{Introduction}

The Bow Valley of Alberta is a remarkable landscape. One of the major mountain passes that traverse the Rocky Mountains, it is a key transportation link across the continental divide, for humans and for the many other species that live within and on both sides of the nearly 78,000 square kilometres of mountains, valleys and foothills that separate the interior of British Columbia and the prairies of central Alberta. It is a resource-rich region, with oil and gas deposits, rich forests, ranch lands and many mineral seams, particularly of coal. It is also one of Canada's premier tourist destinations, including the Canadian Rocky Mountain Parks World Heritage site, which encompasses Banff, Jasper, Kootenay and Yoho National Parks and Mount Robson, Mount Assiniboine and Hambler Provincial Parks. Also adjacent and contiguous to the World Heritage Site are nine Alberta provincial parks. These protected areas include nearly inaccessible reserves, low impact/backcountry camping, a busy section of the Trans-Canada Highway, elaborate hotel complexes and tourism-oriented townsites. 


\section{Case study}

\subsection{Context}

Near the gates of Banff National Park is the Town of Canmore, a former coalmining community that has seen tremendous growth largely as a second home and recreational destination since its last coal mine closed in 1979. The human population of Canmore has grown from about 1,000 at that time to approximately 16,000 today (including seasonal residents), and the wildlife management unit that includes Canmore is home to approximately 99 grizzly bears. The combination of highway traffic, rail transport, rapid urbanization, industrial development and human population growth create a charged context for co-existence.

Mining and other resource-dependent communities are often thought of as part of the periphery - in Canmore's case a resource frontier adjacent to and dependent on the nearby Calgary metropole. This is significant because conflict and co-existence with wildlife are typically issues of the rural periphery. Canmore's transformation to a recreational destination represents a different sort of economic geography from traditional centreperiphery relations. Sandilands (2002) writes about globalization as a process in which wilderness changes from a standing reserve of raw materials in the periphery to stands of materialized rawness, preserved as recentered chunks of the core. Tim Luke describes this as a "shift from an extractive to an attractive model of development, which is, in turn, a response to other extensive changes in commodity production, urban growth and the quality of life" (Luke, 2002, p. 92). 
This transformation operates on many levels; a shift in economic structure from primary to tertiary activities is an obvious one. The way that people use the land and change the landscape is key, however.

In the former mining town of Canmore (see figure 3), real estate development sprawled through the valley bottom and tony bistros and shops now line the main street. At the same time, fleece-covered bikers and hikers are heavy users of trails and recreation areas that cross and surround the town and extend to the south and to the adjacent provincial and national parks. These changes represent economic and social transformation within the town and an ecological transformation surrounding it. The human changes have been recorded and critiqued by long-time residents who deplore the shift and are, in fact, being pushed out of the town by gentrification (Sandford, 2008). The effects on grizzly bears have also been carefully studied and documented, and they are negative (Herrero, 2005). This research attempts to locate these changes within the human-bear relationship to each set of actors and to their shared landscape. 


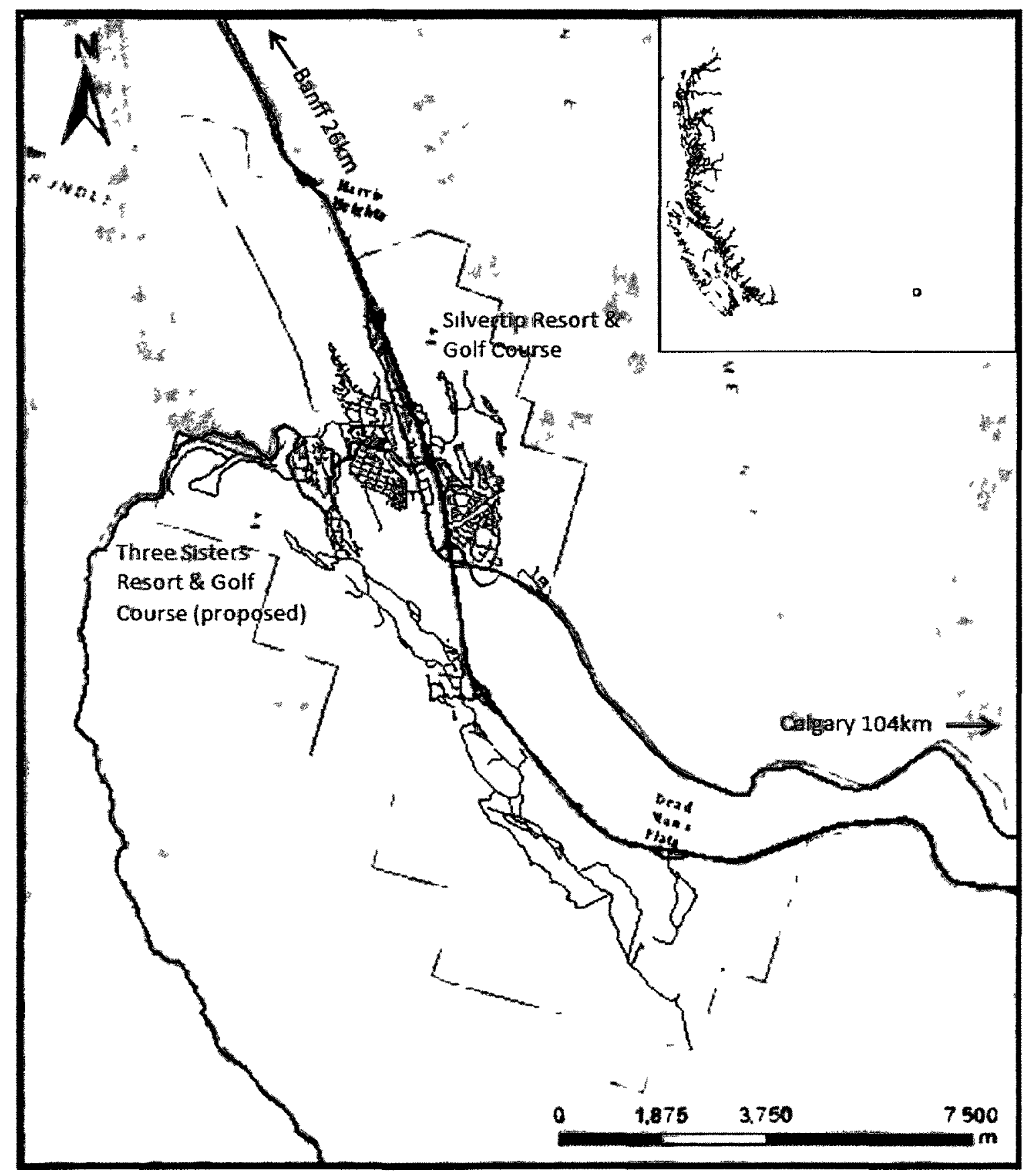

Figure 3: Canmore, Alberta

Map by: Christopher J. Czerwinski/John Wall 
2.1.1. A brief history

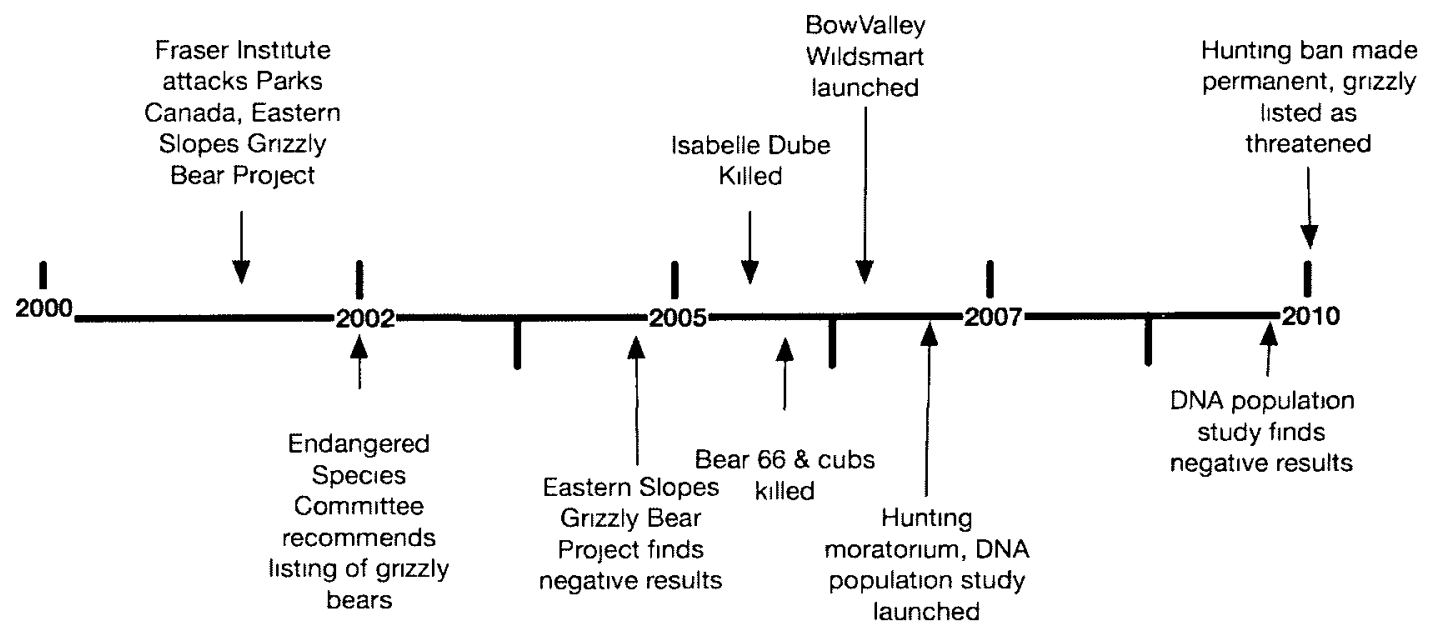

Figure 4: Timeline of human-bear co-existence in the Bow Valley

As the ranch lands of the Alberta prairie give way to the Rocky Mountain foothills and then to the dramatic passes and valleys of Canada's Rocky Mountain Parks, the sense of slipping into the frontier is palpable. Today this frontier ethos is moderated and conditioned by access to both backcountry adventure and urban style in the Canmore and Banff townsites. The changes that have been seen in this area as Alberta has grown as an economic and energy powerhouse are reflected in people's perception of the grizzly bears (Ursus artos) over the years. A menace to ranchers and annoyance to miners has become an emblem of rugged mountain vistas and values. No fewer than three larger-than-life grizzly bears greet the motorist driving from Calgary to Banff National Park, advertising accommodations and a casino.

In the era of European settlement, grizzly bears were common on the prairie and on the Pacific coast, but not extensive in the mountain region, which is relatively poorer habitat (Herrero, 2005; Mattson \& Merrill, 2002). The advent of extensive agriculture, including 
road building, ploughing of grasslands, and a frontier ethos of clearance and civilization eliminated the prairie grizzly populations by the early $20^{\text {th }}$ century, and in 2009 Environment Canada found that the habitat was so transformed that no effort at recovering the prairie population was feasible (Environment Canada, 2009).

As the prairies ceased to provide safe and productive habitat for grizzlies, the marginal lands of the foothills, mountains and valleys of the Rocky Mountains became a refuge, and the grizzly bear population of Alberta is found only in the western reaches of the province. Human-wildlife conflict was and is common in the ranching country of the foothills, from Peace River country in the province's north to the US/BC border adjacent to Waterton National Park and the Flathead Basin, a heavily forested and largely undisturbed region in the south of the province. Up until 1972 there were very few controls on how ranchers could deal with grizzly bears on their property or that were considered threatening, leading to substantially unregulated hunting or 'defence of life and property kills' on grizzly bears. That year, provincial policy changed to require provincial officials to respond to 'problem animals' except in cases of emergency (personal communication, Informant A) and subsequently an increasing range of non-lethal measures have been adopted by the Alberta government to reduce conflict (Festa-Blanchet, 2010; personal communication, Informants A \& C).

Such measures are relatively easy in the less populated, and less touristed, regions of the province where agriculture and natural resource extraction dominate the economy. In Central Rockies region of the Bow Valley the situation is different. Before 1979, coal mining was the dominant industry in the region, and the area outside Banff National Park (and to some extent, within it), extractive industry was not generally perceived as problematic. In 1979 the last coal mine in Canmore was closed and the population of 1,000 people was 
facing an uncertain future. The tourism engendered by nearby Banff clearly pointed toward opportunities lacking for the many other single-industry towns in the province. In 1978 the Government of Alberta had designated a tourism, recreation, and envitonmental protection plan in the Kananaskis Improvement District to the south, including the creation of the Kananaskis Village Area resort. Kananaskis Country has been called “Alberta's Banff” since it provides the province options for development and recreation that are outside its jurisdiction in the national parks. While this permitted the development of a wild space with primarily recreational values, Canmore's proximity to Calgary, location on the Trans-Canada Highway and adjacency to the Banff Park gate made it a desirable location for real estate development and re-shaping as a recreational landscape. The influx of people and resulting changes in the landscape sometimes encourage foraging by bears, and young and cub-raising bears sometimes use the human settlements to protect themselves from older, larger bears that are more sensitive to disturbance.

The changing landscapes, growing human population and increasing pressure on bears has contributed to increasing contact between bears and people, sometimes leading to conflict. A dramatic case occurred in 2006 when a Canmore schoolteacher was killed on a recreational trail adjacent to a golf course. She was killed by a bear that had been relocated about 100 kilometres to a distant portion of his likely home range the previous week because he was behaving unusually in the town. The bear returned and had several encounters with humans before the attack. This incident dramatically raised the profile of the issues related to the experience of a community living with bears and spawned initiatives to help reduce the risk of future conflicts.

In the meantime a debate had been taking place about the status of the bears in the province. In 2002 the Alberta Endangered Species Conservation Committee recommended 
that grizzly bears be listed as threatened. Instead the province listed them as 'may be at risk' and deferred a decision on further protection for the bear (Alberta, 2010a). The Alberta Government was reluctant to extend protection to grizzly bears, but eventually did so in 2010. By 2005 the 11-year University of Calgary-based Eastern Slopes Grizaly Bear Project (ESBGBP) was reporting that a mortality rate of $9 \%$ or less was necessary to keep the population stable (Herrero, 2005). Parks Canada research, and particularly the collaring program, showed that there were approximately 60 bears in the National Parks area of the valley, and that $14 \%$ of the population had been removed (from all causes, including relocation) in 2005 (Bertch \& Gibeau, 2009). In the light of this information, the profile of the issue and the continuing state of ignorance on the number of bears in the province, the province introduced a bear hunt moratorium in 2006 , coincident with a three-year, provincewide 'gold standard' DNA-based population assessment. By 2009 the study was not finished and the moratorium continued until 2010, when the study was released. It showed 651 bears in the province outside of National Parks, and an additional 159 in those parks (Boulanger \& Stenhouse, 2010). This was substantially lower than the historic 'rule of thumb' number of 1000 bears in the province that the government had used for many years, and on which it had implicitly based bear management policies. The study showed the densest and healthiest bear populations to be in the northern area of the Rocky Mountain chain that had the least roads and industrial development, lending credence to environmentalist calls for more attention in grizzly bear management to securing undisturbed habitat. It also rebutted claims by the Alberta Fish and Game Association and its members that there were more grizzly bears than ever and that the hunt could not make a substantial dent in the bear population (Semmens, 2005). 
Hikers and trail runners had become used to taking advantage of the trails along the northern slope of town. These trails were closed in 2006 after the death of Isabelle Dubé in the area. Alberta Parks, responsible for the trails, stated that the timing was an unfortunate coincidence and that a study had been underway on the risks posed by the trail system. This closure became part of subsequent debates over co-existence measures. See figure 4 for a timeline representation of key events in the case.

\subsection{Actors}

\subsubsection{Grizzly bears}

Between 2006 and 2009, a rigorous grizzly bear census was conducted by the Government of Alberta through the Foothills Research Institute. This study showed that there were approximately 800 grizzly bears in the province and about 100 in the Bow Valley and Kananaskis County (Boulanger \& Stenhouse, 2010). About half the bears are in the more remote and less disturbed northern reaches of the province. The mortality and natality of the Bow Valley bears is finely balanced and it is estimated that the survival rate of grizzlies in the area needs to be $91 \%$ or higher for the population to remain stable (Garshelis, Gibeau, \& Herrero, 2005).

\subsubsection{Local residents and landowners}

Canmore has a population of about 16,000 permanent and seasonal residents, while Kananaskis Country has a population of about 400. The economy of Canmore has a higher proportion of economic activity related to tourism and services than the provincial economy as a whole. The value of real estate in the town has increased dramatically over the past 30 years and tradeoffs between the use of land for development or for conservation value (such as wildlife corridors) have serious economic implications. 
As the town grew, the first set of new arrivals were outdoors lovers interested in the mountain lifestyle and the sense of community in Canmore. As the community's attractiveness grew during rapid growth in the oil industry through the 1990 s and 2000 s, luxury real estate, condominiums and second homes became a more dominant part of the real estate market. By the early 2000 s long-time residents and some early immigrants reported that they felt either priced out of town by gentrification, or locked into town by the real estate market. "(If you live in Canmore today) everybody guesses oh, you must have a lot of money. Only if I sell and move to, I don't know, some place in Prince Rupert. I hear that real estate is still reasonable in Prince Rupert (British Columbia)" (Informant C).

The changes in real estate development had at least three effects. The growing footprint of the town edged into the planned corridor spaces that had been intended to serve as wildlife corridors. Open fields in these spaces, particularly golf courses, provided enhanced habitat for bears; and the growing population and changing norms of residents meant that there were more attractants within the town, notably garbage, fruit trees and bird feeders. It was not simply that humans were expanding into bear habitat, but that they were in fact creating bear habitat and engendering behavioural changes on the part of bears that promoted contact and conflict with the bears.

As this contact promoted conflict, human action was altered. In 1999 Canmore shifted from household pickup to a closed garbage system. Each neighbourhood had a bear proof container installed, and residents would bring their household garbage there for pick up. This reduced attractants in the town and brought about a corresponding decrease in conflict (Bow Valley WildSmart, n.d.). A public campaign to reduce other attractants on private land was launched in 2006 under the auspices of Bow Valley WildSmart, discussed below. 


\subsubsection{Provincial government}

Alberta Sustainable Resource Development (SRD) is the provincial department responsible for wildlife management and Crown lands in Alberta. SRD has the most prominent role in human-bear contact and conflict in the region, but other provincial bodies, including Alberta Parks (which is responsible for trails and recreational land around the town and the Canmore Nordic Center properties). SRD is also responsible for provincial land use planning policy which, although adjusted in 2008 as part of a Land Use Framework, was considered by many residents as partially responsible for unsound development, including expansion into corridors and wildlife habitat areas.

SRD is the first line of contact for area residents who see bears and in responding to incidents of human-wildlife conflict. Historically, this type of incident fell under the jurisdiction of a structure with SRD called the Problem Wildlife Committee, and was responded to by SRD Fish and Wildlife Officers. In a restructuring, this was re-framed as a Human-Wildlife Conflict Reduction unit. This renaming reflected a re-orientation of the work of the department to focus on the causes of conflict rather than on the animals involved in particular incidents (personal communication, Informant D).

\subsubsection{Federal government}

Immediately adjacent to Canmore is Banff National Park and the divisions between park and town, provincial and federal land are artificial ones from the bears' point of view. Parks Canada is a frequent subject and its staff often commentators on topics related to bear research, conflict reduction measures within the parks, major research initiatives that involve parks staff or support such as the Eastern Slopes Grizzly Bear Project. In the 321 newspaper articles examined in the research, Parks Canada is mentioned 259 times in ten years. Although they do not have a direct role in managing the bears in the Canmore area, their 
high profile, research capacity and trustworthiness from the public point of view means that they have a considerable influence on the public discourse on bears and people.

\subsubsection{Environmental groups}

There is a range of environmental groups active on bear issues in the Bow Valley. Most of these organizations are rooted in the local community, with some that are based in Calgary. Prominent organizations include the Alberta Wilderness Association, Bow Valley Naturalists, Banff Environmental Action and Research Society, Bragg Creek Environmental Coalition, Canadian Parks and Wilderness Society, the Bow Valley Grizzly Bear Alliance, and Defenders of Wildlife. Over the decade of the case study data different organizations become more or less prominent in the debate, suggesting there is change and renewal within the sector, but the storylines tend to have continuity (as discussed below).

The discursive landscape relating to grizzly bears is an active one, with more than a dozen environmental groups active in commenting on and advocating positions. These organizations point out flaws in management systems and expose government reticence to increase protection. The situation is quite contentious, with development advocates and environmental spokespeople in frequent conflict. These organizations communicate about the negative impacts of land use change on the bears, the threats to bears, somewhat about how to handle oneself in bear country, and ask the provincial government to instigate policy changes that will contribute to bear survival. They range from membership organizations like the Alberta Wilderness Association with more than 5,000 members and a broad mandate to advocacy organizations like Defenders of Wildlife which were not membership based but active in the conservation arena with 57 media appearances between 2004 and 2009. A summary of the statements and positions of these organizations can be found below in Table 7, a matrix of actors and their discourse in the case (page 90). 


\subsubsection{Recreationalists}

Recreational facility users, notably the Bow Valley Mountain Bike Association, have often felt unfaurly constrained by regulations related to area closures and use restrictions (Doyle, 2005, Shutıak, 1999) Use restrıctions include no bıkıng, minımum sızes of hıkıng groups in certain areas, and area closures The recreational groups tend to promote compromise - increase use of potentially shared space, while educating users on bear-smart behaviour such as warning sounds and bear defences Some commentators argue that the restrictions are justified because the quietness and speed of bikes make it easy to surprise a bear, and then after passing a bear (feeding on the side of a tratl for example) the bikes speed away, possibly triggering a predatory response from the bear (personal communication, Informant A)

\subsubsection{Industry advocates}

The Association for Mountain Parks Protection and Enjoyment (AMPPE) is the most vocal pro-tourism voice and often communicates to counter the proposals of environmental advocates There are other industry associations like the Alberta Motor Transport Association that comment on particular issues related to their industry Individual companies like CP Ratl (whose trains are responsible for ralway collisions with bears) also are also part of action and communication related to bears, both in destructive action and in attempting to mitigate the risks of collision by attempting to clean the tracks of fallen grain and to maintain grain carrier cars to prevent grain spills

The types of changes that come in for criticism from industry advocates tend to be preventative and pre-emptive ones When protection advocates recommended that tourism on Lake Louse ski hills be eliminated to avo1d harassing summering bears, local tourist 
operators called the research "pseudo science" and presented a recurring storyline that "parks are to be protected, yes, but for people as well as animals" (Locke, 1999, p. A23).

AMPPE differs from CP Rail in that the rail company's statements indicate that they believe the collisions with bears are an unfortunate and largely unavoidable consequence of rail transport, that they work hard to reduce collisions, and that they are doing all they can to do so (Marr, 2005; Williams, 1999). The tourism operators, on the other hand, often oppose protective measures and argue that grizzly bear protection is causing conflict rather than being necessary due to expanded human activity (Stolte, 2005). Generally, the industry voice is pro-status quo and against protective action, particularly if this action is pre-emptory.

\subsection{Key events}

Within a particular discourse there may be long periods of 'normal' time during which discursive positions are more or less recurrent. These periods are punctuated by what Carvalho calls critical discourse moments, "periods that involve specific happenings which may lead to a challenge to the 'established' discursive positions" (Carvalho, 2000, p. 5). This section examines important events that shifted the debate and the trajectory of action in this case.

\subsubsection{Death of Isabelle Dubé}

During Canmore's rapid expansion, the desire to accommodate growth and the high value of area real estate led to the acceptance of "compatible" human uses within the wildlife corridors intended to remain to the north and south of the town. Golf courses, recreation trails and other facilities were permitted within the ostensible corridors (Jacob Herrero Environmental Consulting, 2000). As bears became habituated to human presence in these areas, even raising cubs within town limits (personal communication, Informant $C$ ), they lost 
wariness and tended to eventually get into conflict situations. In 2005 Isabelle Dubé, a popular Canmore schoolteacher, was killed by a bear on a trail adjacent to the Silvertip golf course. The bear was Bear 99, who had had several non-threatening but anomalous encounters with humans over the previous several days. Provincial wildlife authorities relocated Bear 99 to Lake Minnewanka (about $25 \mathrm{~km}$ north, within Banff National Park) but eight days later he returned to the golf course and the fatal encounter.

One of the key dimensions of the death of Isabelle Dubé which attracted much attention and criticism was the known presence of a bear that had been acting strangely, some said aggressively, which was not communicated to area residents and recreationalists. Silvertip Golf Course staff had used water sprinklers and noisemakers to haze Bear 99 from the course at approximately 9:30 am on June 5, 2005 and encountered Dubé and two friends running on a nearby trail less than an hour later. An Alberta Parks staff member had met the three runners, but did not know that there was a bear in the area, although Alberta Sustainable Resource Development (SRD) staff had collared the bear before releasing it on June 2. A resident that I interviewed reported that the trail was marked with an out-of-date and widely disregarded 'bear in area' notice (personal communication, Informant C).

\subsubsection{Death of Bear 66 and her cubs}

Three months later, a well-known bear named Bear 66 became a focus of the human-bear relationship. In 2005 Bear 66 was a frequent visitor to the tourist facilities around Banff townsite. In 2004, she had caused much excitement by walking down Banff Avenue (the town's main road), surprising park staff and tourists alike. Her presence was tolerated in and around the townsite as part of a policy to maintain bears in the landscape, while using noisemakers, rubber bullets and bear dogs in an 'aversive conditioning program' 
to train the bear to stay out of human areas. In 2005 she was raising three cubs around the townsite, and was being carefully monitored by park staff. However, on August 19, the mother was killed by a train while feeding on berries adjacent to the track Her three cubs were judged to be poor candidates for rehabilitation and release, so were left to attempt to survive their first fall and winter without their mother's guidance and protection. Experts gave them a $5-10 \%$ chance of survival, but two of the three were killed by cars while crossing the Trans-Canada Highway on September 9. The third cub was captured by Park staff and transferred to the Calgary Zoo since there was no realistic chance of survival on her own.

As will be discussed in the discourse and thematic analyses below, reactions to both these events were strong. The death of Dubé generated a spike in warnings about risks from bears, criticism of government for not sharing enough information about bear locations, and some soul-searching about whether humans safety was adequately considered along with protection of bears. The death of Bear 66 and her cubs a month later generated considerable media attention and the fact that Bear 66 was a sort of town celebrity magnified attention paid to the situation. While the first incident empowered conservation critics, the second mobilized protection advocates. Cooperative solutions emerged over time, but the atmosphere was charged and attention paid to conservation issues elevated during this period.

\subsubsection{Bear hunt moratorium and DNA population study}

These events and the passions they aroused crystallized the issues and actions related to separating humans and grizzly bears and trade-offs between conservation and development. While these two sets of events were the most dramatic, there were also four non-fatal bear attacks and one other grizzly bear cub killed by a train in 2005 . There was a 
substantive debate in the media about whether bears were at risk of extinction, an excessive threat to humans, or both. An important part of this debate was whether the provincial government would cancel the annual grizzly bear hunt (Cooper, 2005; Ellis, 2005). In 2005 the province permitted the hunt and 73 licenses were issued but only 10 bears killed. Together with the fatal and non-fatal bear attacks and highly visible bear deaths, this put the issue of grizzly bear status and the future of human-wildlife conflict on the front pages of local and regional newspapers.

In 2006, the province declared a three-year moratorium on bear hunting in conjunction with a population study to confirm the numbers of bears in the province (D'Aliesio, 2006). This was the first time ever that the bear hunt had been cancelled in Alberta and the announcement came with an acknowledgement that the province had been operating with insufficient information about the population. The new research program that would census the animals was a DNA-based system of identifying individual animals, with a sampling system that would place barbed wire hair snags in random locations on a 1 $\mathrm{km}$ by $1 \mathrm{~km}$ grid, covering the entire western portion of the province. This study was undertaken over the following three years.

The five years after 2005 were busy ones for innovation and adaptation in creating the conditions for co-existence. The following section examines some of the results of this process.

\subsection{Outcomes}

\subsubsection{Public education and conflict mitigation efforts}

Dubé's widower, the two friends who were running with her on June 5 and local supporters launched a website called trailex.org to record bear sightings and post or e-mail 
them to area recreationalists. Modelled on the Canadian Avalanche Association's warning system for backcountry travellers, it was thought that information of this sort might have prevented the encounter of June 5 (Remington, 2006). Although Parks Canada or Alberta Sustainable Resource Development staff and independent researchers had radio collared many bears, the information on their whereabouts was not communicated, to avoid inciting wildlife watchers to approach the bears and to avoid creating unreasonable fears in visitors and residents (D'Aliesio, 2007; personal communication Informant E). Trailex, in contrast, was meant to collect and share information among wild area users.

At the same time, a conversation was beginning between government authorities at all levels, proponents of real estate development, and environmentalists on how people living in close proximity to wildlife can and must modify their behaviour to reduce risk to both people and animals. This took place in a series of 'roundtable' meetings in Canmore that brought together environmental, development and governmental groups as well as members of the public. While the town had moved earlier to a 'closed' garbage collection system to reduce the risk of bears feeding from residential garbage, there was a sense from all parties that more could be done to promote successful co-existence (personal communication, Informants F \& G). Bow Valley WildSmart was a result of this conversation. A non-profit coalition, WildSmart educates people on responsible and safe behaviour in wildlife habitat, promotes attractant management to reduce synanthropic behaviour by bears, elk and cougars, and promotes aversive conditioning to discourage bears from frequenting human use areas ("Bow Valley WildSmart - Living with Bears, Cougars and Wildlife in the Bow Valley," 2011). By 2007 the reporting function of trailex.org was taken over by WildSmart, which produces a web-based weekly or monthly summary (depending on 
the season) of government information and unconfirmed sighting reports, along with information on attractants and feeding patterns that suggest caution by wild area users

In addition to efforts led by civil society organizations, federal and provincial governments contunued, added or enhanced programs to e1ther separate humans or bears, or to promote adaptive behaviour on the parts of humans and bears Alberta SRD continued their Karelian Bear Dog Program, in which Fish and Wildlfe Officers use 'wildlife service dogs' for, among other tasks, aversive conditioning of wildlife to encourage them to avord humans and human use areas (Alberta, 2009) WildSmart and SRD stepped up efforts to receive wildlife sighting reports and to consolidate these reports for public information The province closed 1,100 hectares of areas served by tralls near Canmore and instituted a more rigorous and timely program of area closures to reduce contacts Parks Canada continued a decade-old 'Bear Guardian' program that has interpreters patrollıng Banff National Park to break up 'bear jams' of cars stopping to look at bears (thought to promote habituation and risk contact) and to educate visitors about bears and bear safety

In the immediate aftermath of Dube's death, there was alarmism about the presence and threat of grizzly bears which was countered by recognition of the risks inherent in living in the mountains For many recent arrivals (including Dubé) the mountain town values, wilderness, and outdoor recreation were a fundamental part of living in the region, including recognition of the risks that this entalls This shared ethic transcended newcomer/long timer or environmentalist/developer fault lines that otherwise formed part of the co-exustence discourse in the region When calls for action to prevent conflict were amplified in the summer of 2005 there was considerable cooperation in advancing an agenda, which contributed to the rapid development of WildSmart, which was operational in the winter of 2006 (personal communication, Informants E \& G) 


\subsubsection{Recognition of endangerment}

One area of intersection between civil society organizations and the provincial

government that also was prevalent in 2005 was that of the grizzly bear hunt. Environmental organizations had campaigned for years to have the hunt cancelled; arguing that increasing human impact and a lack of coherent information on the state of the species required the province to adopt a precautionary approach. The province was reluctant to accept the 2002 recommendation to list the species as threatened but in 2006 acknowledged that the population estimates were inadequate. Pro-protection advocates lobbied hard against continuing the bear hunt between 2002 and 2006, and the continuation of the bear hunt became a major point of contention during this period. In 2009 and 2010 when the results were released by the province the results were more negative than the province and pro-use advocates had been presenting, which finally led to a permanent moratorium on the hunt and listing of the bears as threatened.

\section{Data analysis}

\subsection{Data sources}

In August 2009 I used the Canadian Newsstand Database to search for newspaper articles that included the terms Canmore, Bow Valley, and Grizzly Bear and gathered 336 potential articles from 1999 to 2009 from the Rocky Mountain Outlook and the Calgary Herald. Since the same newspaper company owns these newspapers, the Herald often reprinted articles directly from the Outlook. Also, some of these articles were not related or only tangentially related to human-bear co-existence or related topics, and some of these were subsequently excluded from the research. Later, I used the archive tool of the Canmore Leader 
website (which is not included in Canadian Newsstand) to conduct a similar search and downloaded 220 articles from 2002 to 2008 that related to my research.

Both sets of articles were prepared for analysis by formatting them as 'rtf' files and naming them with the case study code (be), the date, and the newspaper source. After deleting duplicate files and screening out irrelevant articles, there were 321 articles remaining for analysis. These were loaded into TAMSAnalyzer, a qualitative data analysis system, to code and present the data.

I conducted nine formal interviews, received four anonymous submissions, and recorded two days of 'state of the field' bear research reports at the Human-Bear Conflict Workshop in Canmore in 2009. The interviews were transcribed and loaded into TAMSAnalyzer. The anonymous submissions were recorded in my notes, and the recording and proceedings of the Workshop were reviewed as in a literature review covering topics such as attractant removal, aversive conditioning, and research methods.

I interviewed two researchers on the situation of human-bear co-existence in the Bow Valley and relied upon three reports: The Eastern Slopes Grizzly Bear Project (Herrero, 2005); the Foothills Research Institute 2004-2010 research reports on grizzly bear population in Alberta (Boulanger \& Stenhouse, 2010 and related documents from DNA population study); ${ }^{3}$ and the Proceedings of the 2010 Human-Bear Conflict Workshop (Matt, 2009). These reports address the most recent knowledge on human-bear relationships in general and in the Bow Valley in particular. I used the publications in these three data sets to address questions of how human presence is affecting bears.

3 This report and the related annual reports that are sub-regional in nature are available at http://www.srd.alberta.ca/ManagingPrograms/FishWildlifeManagement/BearManagement/Grizzly Bears/GrizzlyBears.aspx. 


\subsection{Analytical procedures}

The analysis consisted of a close reading of the articles. With the first dozen, I examined the topics and characteristics of the articles, comparing them to the a prioricodes that I had derived from the research. I looked for 'actors' which included general categories of actors (environmentalists, federal government, individual human) and organization names (Bow Valley Naturalists, Parks Canada, 'a Quebec man'); and 'actions' which corresponded to the four categories of action that I had derived from the literature and reflection on modes of co-existence: adaptive, separative, destructive and protective - see Table 1). Where bear behaviour was covered by the media source, I also coded for the type of behaviour the bear exhibited: aversive, curious, defensive attack, feeding, predatory and synanthropic. My goal with this approach was to identify actors and actions on both human and bear sides to examine processes of co-existence.

It became apparent as the early coding proceeded that there were a range of possible actions that fell outside the a priori coding system. Also, in the pre-coding process I had considered communication as an action, thus linking action and discourse conceptually. However, the organizations with the resources and mandate to act on bear issues and conflict were generally governmental and the organizations that were most active in media discourse were primarily environmental organizations and bear advocates. These differences meant that a consideration of action and discourse could be fruitfully done as separate but linked analysis (requiring separate coding for discourse/communication and action). I attempted to focus the coding on my research questions exclusively, but there were some necessary additions which I tried to capture under general themes such as "SAR" for references to species at risk legislation or research or "Quotable Quotes" for salient summaries or other points that deserved particular analysis. Once the basic structure was set, 
the remaining articles were analyzed generally sticking with the code set but making additions if necessary. The result was 127 codes which, as the structure solidified, I defined so as to avoid ambiguity or duplication.

Once the articles were coded I used the search tools in TAMSAnalyzer to call up all the 'action' passages, all the 'communication' passages, all the 'organization' codes and used these to prepare two tables, one of actors and actions and one of actors and communication topics. I created additional tables of evidence associated with each line in each table to ground the summaries featured in the main tables. These summaries of actors, action and discourse provide the basis for the happenings in the case study report.

\subsection{Action themes}

In this case, actors undertook the full range of actions related to co-existence. The primary and most diverse actors were the government agencies who are challenged to manage wildlife for a range of objectives including use, conservation, recreation and public safety. Government is also not monolithic, and with multiple agencies engaged with bears and through change over time there is a range of actions that they undertook. In the environmental community there was a range of action. In some cases, this was of a 'compromise' nature which includes trading off competing interests and in other efforts to force government action, such as using the legal system or new technology to effect change on the part of government. Table 5 presents a matrix of actors and actions to support the subsequent thematic breakdown of actions in the case. 
Table 5: Bear case actor/action matrix

\begin{tabular}{|c|c|c|c|c|c|c|c|c|c|}
\hline & Adaptive & Separative & Protective & Compromise & Destructive & Defensive & $\begin{array}{l}\text { Landscape } \\
\text { Change }\end{array}$ & Policy Change & Research \\
\hline $\begin{array}{l}\text { Sustainable } \\
\text { Resource } \\
\text { Development }\end{array}$ & $\begin{array}{l}\text { Monitoring and } \\
\text { trackıng } \\
\text { Individuals }\end{array}$ & $\begin{array}{l}\text { Aversive } \\
\text { conditıonıng, } \\
\text { relocatıng } \\
\text { Individuals }\end{array}$ & Reduce huntıng & & $\begin{array}{l}\text { Permıt huntıng } \\
\text { (pre-2006), } \\
\text { destroy problem } \\
\text { bears }\end{array}$ & Publıc safety kılls & & $\begin{array}{l}\text { Hunt moratorium } \\
\text { and cancellation }\end{array}$ & Bear Numbers \\
\hline Alberta Parks & Garbage control & $\begin{array}{l}\text { Protected area } \\
\text { management }\end{array}$ & & $\begin{array}{l}\text { Managıng } \\
\text { sporting events } \\
\text { w/I parks (Incl. } \\
\text { Canmore Nordıc } \\
\text { Centre) }\end{array}$ & & & Proscribed burns & & $\begin{array}{l}\text { Impact of human } \\
\text { use structures }\end{array}$ \\
\hline Parks Canada & $\begin{array}{l}\text { Highway crossing } \\
\text { structures; } \\
\text { fencing roads, } \\
\text { monitoring } \\
\text { individuals, } \\
\text { manage bears in } \\
\text { place; area } \\
\text { closures; garbage } \\
\text { control }\end{array}$ & $\begin{array}{l}\text { Protected area } \\
\text { management, } \\
\text { Lımitıng access } \\
\text { to bear } \\
\text { watchıng/bear } \\
\text { jams }\end{array}$ & $\begin{array}{l}\text { Reduce speed on } \\
\text { highway }\end{array}$ & $\begin{array}{l}\text { Contested: } \\
\text { viewing of bears } \\
\text { on Lake Loulse } \\
\text { skı slopes }\end{array}$ & $\begin{array}{l}\text { Highway twınnıng } \\
\text { (increase traffic) }\end{array}$ & Publıc safety kılls & & $\begin{array}{l}\text { Ecological } \\
\text { Integrity; user } \\
\text { experience }\end{array}$ & $\begin{array}{l}\text { Bear numbers, } \\
\text { mortality, use of } \\
\text { crossıng } \\
\text { structures, bear } \\
\text { ecology }\end{array}$ \\
\hline $\begin{array}{l}\text { Bow Valley } \\
\text { Naturalists }\end{array}$ & & & $\begin{array}{l}\text { Legal action } \\
\text { against real } \\
\text { estate } \\
\text { development }\end{array}$ & & & & & & \\
\hline $\begin{array}{l}\text { Banff } \\
\text { Environmental } \\
\text { Action and } \\
\text { Research } \\
\text { (BEAR) Snrietv }\end{array}$ & & & & & & & & & Corridors \\
\hline $\begin{array}{l}\text { Bow Valley } \\
\text { Mountain Bike } \\
\text { Alliance }\end{array}$ & $\begin{array}{l}\text { Communication } \\
\text { with members }\end{array}$ & & & $\begin{array}{l}\text { Pro use in bear } \\
\text { areas }\end{array}$ & & & & & \\
\hline $\begin{array}{l}\text { Eastern Slopes } \\
\text { Grizzly Bear } \\
\text { Project }\end{array}$ & & & & & & & & & $\begin{array}{l}\text { Ecology, human } \\
\text { Impact, range, } \\
\text { mortality }\end{array}$ \\
\hline
\end{tabular}




\section{Adaptive \\ Separative}

Purchasing and

Purchasing and

Nature

managing land managıng land

Conservar

Bow Valley

WildSmart

Bear aware,

attractant

removal, social

marketıng

\section{Trailex.org}

\section{Grizzly Bear}

Recovery Team

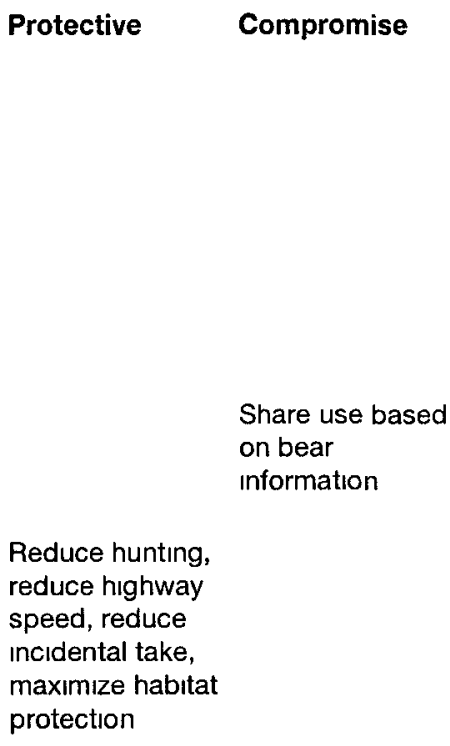

Protective

Compromise

Share use based

on bear

information

Reduce hunting

reduce highway

speed, reduce

incidental take,

maximize habitat

protection

Destructive

Defensive

Landscape

Change

Landscape scale conservation plan
Mortality,

ecology, recovery
Public attitudes

and action 


\subsubsection{Adaptive action}

Adaptive action is something that either one or more humans or one or more nonhumans do in order to accommodate the other. There were seven types of actions that could be considered human action to accommodate bears, generally corresponding to the highest risk factors for grizzly bears that human use introduced to the area. Table 6 shows the causes of known bear deaths in Alberta between 2000 and 2009 (Alberta, 2010b).

Humans caused $93 \%$ of the known bear deaths. Noting that natural deaths and predation (usually by other bears) could easily go unrecorded by managers and researchers, human-caused mortalities are still an overwhelming issue for the species. Reducing these mortality rates is key to securing the demographic future of the populations (Bertch \& Gibeau, 2009; Herrero, 2005). This section on adaptive action focuses on the unintentional human-cased deaths - the intentional killing is dealt with in the section on destructive actions below.

Table 6: Causes of bear mortality, 2000-2009, after Alberta (2010b)

\begin{tabular}{|c|c|c|c|c|c|c|c|c|c|c|c|}
\hline Year & 2000 & 2001 & 2002 & 2003 & 2004 & 2005 & 2006 & 2007 & 2008 & 2009 & Total \\
\hline Hunting licences allocated & 145 & 122 & 130 & 101 & 73 & 73 & 0 & 0 & 0 & 0 & 644 \\
\hline Total grizzlies taken during legal hunt & 19 & 17 & 15 & 18 & 6 & 10 & $N / A$ & $N / A$ & N/A & $N / A$ & 85 \\
\hline Illegal kill & 9 & 5 & 7 & 5 & 1 & 6 & 2 & 3 & 1 & 6 & 45 \\
\hline Self defence & 3 & 3 & 2 & 7 & 3 & 1 & 5 & 4 & 6 & 0 & 34 \\
\hline Destroyed - problem bears & 0 & 1 & 0 & 0 & 1 & 3 & 1 & 2 & 6 & 0 & 14 \\
\hline Aboriginal (subsistence harvest) & 3 & 0 & 4 & 0 & 0 & 1 & 0 & 0 & 2 & 3 & 13 \\
\hline Accidental (human-related e.g. road kills) & 0 & 0 & 1 & 2 & 0 & 0 & 1 & 0 & 4 & 5 & 13 \\
\hline Unknown & 0 & 1 & 2 & 4 & 1 & 0 & 2 & 0 & 1 & 1 & 12 \\
\hline Mistaken for black bear & 1 & 1 & 2 & 1 & 0 & 0 & 2 & 0 & 0 & 3 & 10 \\
\hline Research-related & 0 & 0 & 1 & 3 & 0 & 2 & 1 & 0 & 0 & 0 & 7 \\
\hline Killed by predation & 0 & 0 & 0 & 0 & 1 & 1 & 0 & 0 & 0 & 3 & 5 \\
\hline Total known human-caused grizzly mortalities & 35 & 27 & 32 & 36 & 11 & 23 & 12 & 9 & 19 & 17 & 221 \\
\hline Total mortalities & 35 & 28 & 34 & 40 & 13 & 24 & 14 & 9 & 20 & 21 & 238 \\
\hline
\end{tabular}

\subsubsection{Reducing vehicular collisions}

Thirteen bears were killed in accidents between 2000 and 2009, generally in collisions with motor vehicles or trains. This issue is extremely topical in the Bow Valley, which channels the CPR main line and the main route of the Trans-Canada Highway westward from Calgary through the relatively narrow corridor. Between 1990 and 2008 Parks Canada 
reports that 15 grizzly bears were killed in the Mountain Parks by vehicles and 14 by trains. CP Rail has undertaken a series of protective measures, including a $\$ 20$ million refit of federally owned grain hopper cars to reduce spillage and the operation of a vacuum car that attempts to remove spilled grain from railway tracks. In 2010 they committed to a continued program of research to identify additional means of avoiding collisions (CP Rail, 2010). Within the parks efforts have been made to reduce collisions by installing 22 underpasses and 3 overpasses and fencing most of the rest of the highway. This program began in the mid-1990s and early reports included concerns that larger animals were not using the passages, however by the time of writing, the crossing structures were considered a "runaway success" with four more overpasses and six underpasses (plus additional culverts for smaller animals) being built in the continuing process of highway expansion in the park (Remington, 2010).

Outside the park, these types of measures are more challenging to implement, as conservation values and the costs they entail are less dominant. However, an August 26, 2006 article in the Calgary Herald noted that an underpass in Canmore had been used about 900 times by animals crossing the Trans-Canada Highway in just two years since construction. An additional measure lobbied for by environmental groups both inside and outside the park was a reduction of speed limits. Later in 2006 , especially in the period after the death of the cubs of Bear 66, there were loud calls for changes to the speed limits.

This issue particularly highlights the conflicting interests of different actors. For example, in 1999 a spokesperson for Bow Valley Naturalists was quoted as saying, "there have been some well-intentioned efforts to reduce the animal mortality but clearly more has to be done. I can't accept that this is an insurmountable problem." This was countered by the president of the Association of Mountain Parks Protection and Enjoyment (AMPPE), an 
organization of park business owners, who said, "I don't think that there's a workable solution. The question is whether national park values should be applied to the national transportation corridor. I don't think that's possible, quite frankly" and the Alberta Trucking Association, which said that 70 kilometers per hour "would be a difficult speed to maintain". The AMPPE President stated that "people that want to take a leisurely drive can take the (Bow Valley Parkway)" a scenic branch of the TCH with a speed limit of 60 kilometers an hour (Dawson, 1999). Here the question of whether bears need people to slow down to avoid being killed is subverted to the question of whether people want to "take a leisurely drive". It also illustrates the differences in rationale and value of animal accommodation for truckers, for whom time is money, and tourists for whom wildlife values are presumably higher.

Another dimension of adaptive measures to reduce highway deaths is similar to one related to the protection of migration corridors - the ability to maintain the measures over time. In 2004, a wildlife corridor was completed to the east of Canmore as a legacy project of the G-8 Summit that took place in Kananaskis in 2003. A month later the Municipal District of Bighorn approved a plan to build 70 houses, 30 townhouses and a business park 100 meters from the corridor. This was controversial because proponents argued it would undermine the conservation value of the corridor, while the developer reduced the development's scope considerably and had a design that would meet most existing guidelines (Semmens, 2004). This is an example of an attempted adaptive move that I call 'compromise' or 'splitting the difference'. A 2002 study outlined the biologically optimal route for a corridor, and in 2003 the federal government paid $\$ 1.6$ million for the underpass to facilitate the corridor. In 2004 the real estate development compromise proposed a significant development directly adjacent to the corridor, near the northern entrance to the 
underpass This seems reasonable - the wildlife gets a corridor and the landowner gets to develop the land What is not clear (although numerous presentations to the Municipal District of Bighorn Council argued negatively) is whether the development undermines the purpose of the corridor and the underpass The Deputy Reeve of the District was quoted after the decision as saying, "I think the people that have opposed this over the years can claim a victory because they have substantially reduced its footprint Obviously some people will only be satisfied when there is absolutely nothing, but 1t's not their land" (Semmens, 2004) This type of false compromise is often seen as a common sense solution proposed by politicians and development advocates but draws fire from biologists and environmentalists because (they contend) it compromises the basic requirements of the species in question ${ }^{4}$

\section{Area closures and warnings}

Area closures and 'bear in area' warnings can be considered as separative actions at the local scale but adaptive measures at the regional or landscape scale, in that they facilitate people and bears to co-exist in the landscape - albeit not at the same location and time The issue of closures and warnings has been active for some time, but came to a new level of prominence after the death of Isabelle Dubé She was kiled in an area where a grizzly that had recently been relocated to the periphery of his territory (outside of the town of Canmore) The bear was collared and was being tracked by wildlife managers at the time, but no notice or information was avalable to recreationalists

${ }^{4}$ The development was approved in 2004, followed by a tentative plan of subdivision in 2005 This plan lapsed and was replaced in 2009 with a Concept Plan which outlines the proposed development, site plan, and design standards This plan was approved As of 2010 no building was underway on the site 
Both in the Alberta jurisdiction (Canmore, Kananaskis Country) and in federal jurisdiction (mountain parks), human access is controlled in the interest of reducing encounters - "Mike Gibeau, lead researcher for the Eastern Slopes Grizzly Bear Project, said grizzly bears continue to be put under pressure from humans in the park, but if administrators leam more about how park users behave, the chances of reducing encounters are improved" (Babin, 2000). This concept of managing people and bears is mirrored in the work and organization of the Alberta government department responsible for wildlife.

Alberta Sustainable Resource Development (SRD) has shifted its focus and organizational structure from a Problem Wildlife unit to a Human Wildlife Conflict Prevention unit, a move that "is essential in the organization to get away from terminology that predetermines where the problem lies" (Informant D). The unit's major focus is on identifying attractants or behavioural patterns that lead to conflict, and responses include closing areas seasonally or when a bear is in an area.

A tension emerges from how that changed access differentially affects users. After the death of Dubé, the province closed approximately 1,100 hectares of land in Kananaskis Country that had been served by wilderness trails, and set the trails to grow over. This raised the ire of many backcountry travellers. Dubé's widower, Heath McCroy, said the teacher, "who was an active trail user, would be opposed to permanent closures of trails in wildlife corridors, except during times of heightened animal activity. 'It makes sense to close trails when there is bear activity to reduce fatalities and reduce injuries. But we are pushing to keep trails open for public use while keeping people safe,"” (Remington, 2006). 
McCroy acted on this conviction by helping lead the creation of trailex.org, a 'crowdsourcing' website which would collect observations of grizzly bears and other wildlife and post them for a broad public, and disseminate them by e-mail. There were reservations about this approach on the part of provincial authorities. One position was that these reports would give a false sense of being "real-time". McCroy stated, "Of course, it won't actually be real time because bears can move 20 kilometers in an hour-and-a-half, but it will give people a real-time perspective that bears are in the area so they can have a sense of awareness and use caution, like taking bear spray and not wearing earphones" (Remington, 2006). However, the professional sentiment was that people in bear country should do that all the time, and that people would believe that if there were no sightings in an area, they would expect that there would be no bears. By 2007 the bear status updates were compiled weekly (or monthly, depending on the season) from government and independent sightings, and included an overview of feeding and behavioural conditions that indicated where extra caution should be shown. This bulletin became more generalized, moved away from the 'real time' presentation that McCroy had envisioned, and became the responsibility of the Bow Valley WildSmart Program in 2007.

The need to do something about the state of communications and warnings was amplified immediately after Dubé's death with statements such as this one being common: "There is no way, of course, that Fish and Wildlife managers could have predicted that the three-to-four-year-old bear would return just over a week later to kill Dubé, a popular athlete, schoolteacher and mother. Yet, Canmore residents have every right to demand answers - and much better information - about the predators in their midst" (Remington,

\footnotetext{
${ }^{5}$ Crowdsourcing is a term applied to group efforts, primarily in Internet and other digital
} applications, to deploy the work of many people on a particular task. 
2005). Some comments were a good deal stronger and a 'pro-human' storyline that

conservation measures had been too successful began to take hold, such as this one from a representative of the Association for Mountain Parks Protection and Enjoyment (a tourism industry group):

She points to Herrero's findings that the grizzly population on the Eastern Slopes increased slightly between 1994 and 2002 , and suggests any increase in bear-human conflicts is caused by an increase in grizzlies.

"Why else would there be such confrontation?" she says. "If there was a shortage of bears, why are we seeing them more?

Why are we having conflict issues?"

Bogdane says too much focus is put on the grizzly's mortality rate and not enough on its birth rate. She says the public needs to look at the number of bears in the Bow Valley. "How many bears do we want? At what point in time does the public start to get concerned on the other side, that there will be too many bears and that there are more conflict issues?" (Williamson, 2005)

This is one of the currents that underpin the debate between pro-use and proprotection advocates in this case - when 'enough is enough' and how recreation areas (including parks) are meant to be used by people

\subsubsection{Reducing attractants}

Reducing attractants is an adaptive action. Some of the mechanisms by which this is done were outlined in the narrative section above: limiting access to garbage through closed systems or clean campground programs; removal of plants, trees, birdfeeders and other human-placed attractions, and clearing plants like buffalo berries away from town sites and heavily used human areas.

\subsubsection{Landscape change}

The two most dramatic aspects of landscape change in the case study area are conversion of forest and uncleared land for settlement, and the subdivision of that land for 
building, which I have called real estate development. This has direct and indirect impacts on wildlife. As the use of the space changes from wildlife habitat to human settlement, there is a direct effect on wildlife. For bears, which range widely, this is not as severe an impact as it might be for animals with smaller ranges whose ecosystem might be entirely reshaped or lost. However, there is another dimension to the conversion, which is increased presence (noise and activity), which leads to disturbance. Species and individuals that are highly sensitive to disturbance would likely do poorly (reduced fertility, for example) compared to others. In this case we also have a situation in which bears that are temperamentally suited to co-exist with people might derive benefits from synanthropic behaviour, namely access to human attractants and protection for more skittish bears.

\subsubsection{Destruction}

I coded passages as destructive actions if they destroy bears or the conditions they require for success, and this certainly overlaps with habitat loss mentioned above. This may be contested in different ways, as in a set of arguments in the hunting debate that suggested that bear hunting helped keep bears wild and was a net contributor to the ecology. Without getting into the merits of that argument, the intentional result of the activity is to kill a bear; so hunting is included as a destructive action in this case. Destructive actions are overviewed in, but can be summarized as train and vehicle collisions, hunting, defence of life and property, and habitat loss.

\subsubsection{Separation}

An altemative to adaptive and destructive action is separation. The goal here is to keep the bears and the people apart. Effective wildlife corridors and closing areas to recreation or other use are methods of keeping bears and humans from encountering each other while sharing the same landscape. Fences and road traverses, discussed above as 
adaptive measures, are also separative Relocating bears that have come into conflict with humans is another Hazing and aversive conditioning can be separative inasmuch as they try to associate negative sentiments for human use areas with bears and thus encourage them to stay away The challenge here is that the geography of the Bow Valley and the sprawl of urbanization across it militates against there being 'an animal space' Secondly, the synanthropy of the bears is underestimated This was most clearly lllustrated in the change of bear behaviour in the 1990s when the Town of Canmore moved to a closed garbage system The bears are close to people often because of benefits that they derive from the relationship The designation of "people space" and "bear space" is impractical because their convergence can benefit as well as harm the bears How bears react in this situation and the effect of urbanization on them will be discussed in the following section

\subsection{Discourse themes}

The discourse in this case is adversarial, with environmental organizations and prouse organization competing in the discursive realm for influence on government decision makers and agents who can take action to protect bears or to permit human activity that might be destructive to bears 
Table 7: Bear case actor/discourse matrix

\section{Informing \\ Bear Smart \\ Obfuscation}

Bear habits biology

Sustainable Resourc

Development

\section{Alberta Parks}

\section{Parks Canada}

\section{Alberta Wilderness}

Association

\section{Bow Valley Naturalists Bear habits, biology}

Brochures, one-on-one, media

Brochures, one-on-one, media
Delay release of

information/research

\section{Pro-protection Advocacy}

\section{Anti-protection Advocacy \\ Area closure \\ Area closure \\ Area closure}

Reduce speed/road \&

rail mortality; reduce

real estate

development; SARA

listing; suspend/end

hunt; recovery plan

Speed limits/road \&

rail mortality; reduce

real estate

development;

functional corridors

Association of

Mountain Parks

Protection and

Enjoyment

Maintain speeds

promote

compromise actions;

less focus on

ecological integrity 
Action and Research

(BEAR) Society

\section{Bragg Creek}

Environmental Coalition

Bow Valley Mountain

Bike Alliance

\section{Canadian Parks and}

Wilderness Society

\section{Fraser Institute}

\section{Eastern Slopes Grizzly}

Bear Project

\section{Alberta Motor Transport}

Association

\section{Informing}

\section{Bear Smart}

Risks to bears,

profile raising

(Vigil)

Obfuscation

\section{Pro-protection}

Advocacy

road \& rail mortality

reduce real estate

development

\section{Biking regulations Communication with members, supportive of Trailex}

Concerned about trail closures, prejudice against mountain bikers

Increase protected areas; stronger protection within protected areas; listing Alberta grizzly bears

Attacks Parks

Canada on

ecological integrity policy

Contested: Higher than acceptable mortality threatens grizzly bear populations 
Informing

Bear Smart

Alliance

\section{Defenders of Wildlife}

Risks to bears

Alberta Fish and Game

Association

\section{Calgary Area Outdoor Council}

Bow Valley WildSmart

Bear risks, bear habits and

biology, bear sightings and risks

Trailex.org
Bear sightings

\section{Obfuscation}

Pro-protection

Advocacy

SAR listing; improved

management; stronger

protection within

protected areas

SAR listing; improved

management; stronger

protection within

protected areas;

opposition to

government position

functional corridors,

reduce real estate

development

\section{Anti-protection}

Advocacy

Warning
Opposed to hunting

reductions
Public meetings

Brochures, signage, one-

on-one, media 


\subsubsection{Storylines}

The term storylines, from discourse analysis, sometimes raises concerns when applied to fact-based media and reportage because such reports, especially from the news media, are merely reported, not 'made up' as most stories are. At the same time, reporters and editors select stories to be told; they must be coherent to the reader; reporters select facts and authoritative voices to include (and therefore others to exclude); and there are not an infinite number of positions on any particular issue. Therefore, there are particular ways of viewing a situation and narratives that express those ways, and these repeated narrative threads can be considered storylines.

In the bear case, I identified six storylines from the media reports:

\subsubsection{Informing}

Governments, NGOs and wilderness user groups engaged in communicative discourse, sharing information with residents, recreationalists and group members about bear behaviour and biology, regulations on wilderness use related to reducing risk from bear contact, and on risks to bears from human activity and disturbance. Also Trailex attempted to communicate bear sighting information to help avoid contact and conflict.

\subsubsection{Bear smart}

This is a particular type of informing - information about how to behave in bear habitat, to alert bears to your presence and avoid attracting bears, and how to respond in the case of contact with bears. The first is communication about bears and risk management. Messages on bear safety and encounters were printed in the Calgary Herald twelve times and the Canmore Leader five times in the 2000 s. They are also distributed by WildSmart and in 
"You are entering bear country" brochures distributed by Bow Valley WildSmart and Parks Canada respectively.

The problem of being aware of bears in a given area described above also applied, it was felt, to general knowledge of bear habits and safety as well. At the time of Dubés death it was noted that:

there is no formal program to educate residents to the precautions needed in bear country. Banff National Park posts advisories or closures as needed. In contrast, signage around Canmore does little to warn people that they are in grizzly country. Defenders of Wildlife Canada expect that the town, developers, realtors, media and others will play key roles in developing a public education program. But lead responsibility rests with the province. When will the province launch a meaningful and effective education, notification and enforcement program to help Bow Valley residents co-exist with carnivores? (Pissot, 2005)

Bow Valley WildSmart was the outcome of such appeals, but it was largely driven by civil society within the Canmore region, with some support and advice from provincial and federal authorities. At the time of the research (2008-2009) the provincial BearSmart program had somewhat tenuous contacts with the Bow Valley WildSmart but the essence of the organization appeared to be a roundtable of environmental, wilderness users, developers and the municipal government to coordinate constructive action and education on wildlife issues. Figure 5 shows an educational piece placed in hotel rooms to educate visitors about the area's wildlife. 


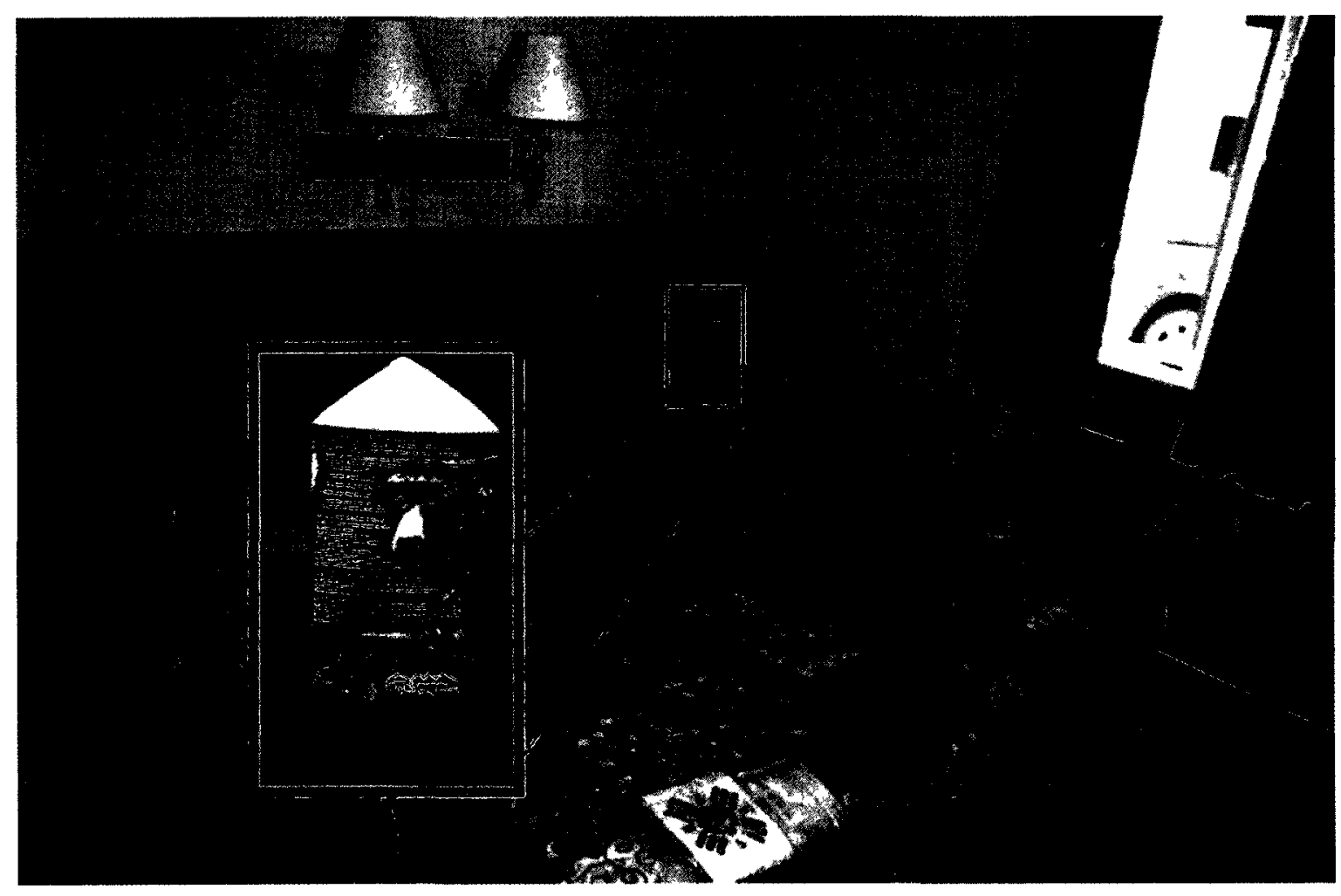

Figure 5: WildSmart Table Talker - Rocky Mountain Ski Lodge, August 2009 Photograph: John Wall

\subsubsection{Obfuscation}

The Government of Alberta showed a pattem of reluctance to engage seriously in considering the endangerment of grizzly bears during the study period. Although the government refuted this, reports on the bear status and recommendations to government were often delayed or avoided. After the Endangered Species Conservation Committee recommended threatened status for the bears, four years passed before action was taken. In 2006 a three-year study was commissioned to provide a 'gold standard' bear census. The study was not completed until 2009 and the results not released until 2010. During that period the Alberta Fish and Game Association conducted a bear census by asking its members how many bears they thought there were in their part of the province. The Minister of Sustainable Resource Development then instructed his department to consider 
this evidence along with their own DNA-based research in the major research process (Henton, 2009).

The government's position tended to be that there was not enough known about the bears to act on bear protection, but when more knowledge was developed it was often delayed or otherwise hidden. Anti-protection advocates also confused the issues. One of the reasons for the rigour and comprehensive nature of the Foothills research was because earlier research, the Eastern Slopes Grizzly Bear Project (ESGBP), was attacked by the conservative Fraser Institute for being run by environmentalists, including Parks Canada, which was said to be in the thrall of extreme environmentalists and dedicated to keeping humans out of the national parks (Cooper, Hayes, \& LeRoy, 2002). They claimed the data analysis was not done correctly and that the research was not peer reviewed, inciting Parks Canada to institute a peer review process. The peer review and subsequent research, notably the Foothills-led DNA study, found that the 2005 ESGBP findings were actually somewhat optimistic compared to the 2009 results. The Alberta Fish and Game Association and Association of Mountain Parks Protection and Enjoyment both put forward arguments that increased human-bear conflict was the result of rising bear populations rather than increased human disturbance, a contention that was not borne out by the biological research.

\subsubsection{Pro-protection advocacy}

The advocacy role of environmental and bear-protection organizations tended to focus on encouraging government to enact policies that would reduce the major risks to bears. The messages link closely to the mortality factors reported by government: reducing road and rail mortality by reducing speeds on highways and creating over- and under-passes and protecting them from human use (i.e. avoiding pedestrian use of highway underpasses in 
the Canmore area), removing attractants, particularly spilled grain from the railway tracks, promoting functional wildlife corridors, typically by reducing or more carefully managing real estate development. At a more policy-oriented level, the protection advocates argued for listing of the bears as a threatened species.

\subsubsection{Anti-protection advocacy}

The anti-protection advocates tended to oppose measures proposed by the protection advocates. Often this was on practical grounds - the Alberta Motor Transit Association argued that lower speed limits on the Trans-Canada Highway would cost its commercial trucker members money by slowing transport of goods. The Alberta Fish and Game Association argued against hunting restrictions, countering that hunting bears reduces risks to bears and humans by increasing wariness among the bear population. In some cases recreationalists opposed protection measures, notably the Bow Valley Mountain Bike Association which argued that access restrictions were differentially applied unfairly to bikers.

\subsubsection{Warning}

Related again to the information and bear smart storylines, particular actors, notably government, made particular announcements related to the presence of bears and closed areas to human use to avoid contact and conflict. Initially, the government was reticent to provide information on bear locations, but gradually they were pushed into providing more information by public demand after the death of Isabelle Dube and by the creation of Trailex, which would have preferred to release official information and individual submissions but was prepared to publish without government contributions. The 
government has the responsibility and the power not only to publicize the location of a bear but also to close that area to human use and the means to haze the bear out of the area.

Warning is different from the information and bear-aware storylines in that the information is specific and associated with a temporary shift of the territory from human use to bear use, separative in the moment but adaptive in the sense of a time geography that incorporates change in a particular space.

\section{Processes of co-existence}

\subsection{Shared space}

The concept of risk acceptance is related to this theme of sharing space in this context. Wildlife is a fact of life in the mountains and continues to be so in spite of evidence of negative human impact. This position puts the onus of responsibility on the wilderness traveller to recognize the risks, take precautions and to know that outdoor activities still have an inherent risk.

Managing bears is not easy. Some Canmore residents say they should have been warned about the bear's return; others said it should have been shot. Environmentalists say the golf course is to blame and argue that bigger corridors and less development will reduce conflicts.

Both ignore one basic fact: no matter how much mitigation is put into effect, the government cannot save you from a bear. It cannot keep all of them out, it cannot adequately warn you of their presence, and neither can it keep every bear alive. Trail and backcountry users need to be "bear smart" but even that is no guarantee. (Remington, 2005)

A resident wrote in a letter to the editor: 
I am a resident of the Bow Valley and, as such, must be constantly aware of the potential for human-bear encounters. In choosing to call such a wonderful area "home" I must realize this is bear habitat. I count myself lucky to catch the occasional sighting of a grizzly from a distance, but also accept an inherent risk. (Hillary, 2005)

This is a key dimension of the role that grizzly bears and other wildlife play in the production of Canmore as a place and the mountains as a space. The presence of the animals is one of the elements of its identity and construction. The names of the very resorts and developments blamed for harming wildlife include "Silvertip" (another name for grizzly), "Cougar Creek", and "Elk Run". Sanitizing the area of wildlife or even bears would not be consistent with most residents' and visitors' view of what it means to be a mountain town. This is a key aspect of the animal geography of Canmore in this situation, namely that the grizzly bears partially enable the construction of Canmore as a post-modern mountain town, in which traditional activities of ranching and mining have been substantially replaced by recreation, shopping, and property development but the imagery and architecture of ruggedness and wildness have been retained.

The grizzly bears also offer a strong example of animal agency in the co-construction of nature. The bears need corridors 350 meters wide for successful avoidance of the human space in Canmore. Instead, at one point the corridor on the south side of the town is only 19 meters. The bears' needs are contributing to a physical constraint on the town's form. The way that habitat is used by bears and by people indicates that the conception of human space and bear space is flawed - there is an interpenetration of space that is emblematic of the relational ontologies and hybrid geographies considered in animal geography. 


\subsection{Interactions}

In an important but limited number of cases, bears become habituated or tolerant of human presence and remain in human use areas. The overall tendency, however, is avoidance. The Eastern Slope Grizzly Bear Project found that bears could be active either day or night (diurnal or crepuscular) but that there was a big difference in movement based on whether humans were active or not active (Gibeau \& Stevens, 2005). For bears that remained active when humans were also active, they tended to "not take advantage of higher quality habitats in the same manner that wary bears did" (Gibeau \& Stevens, 2005, p. 182). Wary bears tended to use higher quality habitat and move less than habituated bears. Using more energy to forage and feed (due to more movement) and accessing lower quality resources would tend to mean female bears would mature later, have lower body size, and have smaller litters.

The bears that tend to use the human use areas are adolescents - the least dominant age class in the bear social structure (cubs may be less dominant, but being with their mothers gives them status and protection from other bears). The best quality food resources in the landscape would typically be appropriated by dominant adults, increasing the risk of aggression and even predation for smaller and younger bears. Therefore some bears use humans as 'cover' to avoid adult bears while feeding and foraging, if they are tolerant enough of human activity. This could be considered synanthropic behaviour, in which the bear gains a survival advantage due to human activity and presence - if this advantage is not outweighed by increased risk of intentional or accidental killing. Gibeau (2000) found that habituation does not provide competitive advantage to individual bears, however, instead "grizzly bears are finding fewer and fewer opportunities to meet their needs without association with people" (p. 104). This has led to a significantly stressed bear population. 
Experiments in co-existence, such as tolerance of bears on golf courses within the intended wildlife corridors, have led to the deaths of female bears and cubs. All the bears who were tolerated in this way were ultimately killed by traffic, trains or management removals (personal communication, Informant C). On the other hand, bears who were subjected to consistent, intense aversive conditioning (chased by bear dogs, shot with rubber bullets and paintballs, air horns and other loud noises) in campgrounds and picnic areas produced second and third generation bears who avoided those areas, without directly being conditioned themselves (Matt, 2009, p. 16).

In North America, there is relatively little overlap between grizzly bear range and areas where human density is greater than $25 / \mathrm{km}^{2}$. Where grizzlies once ranged across the prairies and throughout California, they are now restricted to the Rocky Mountains, the west coast of North America and Alaska, with relatively large and sustainable populations in British Columbia and Alaska. The Bow Valley represents a special case where high human use and density not only overlaps bear range, but also creates the fragmentation and synanthropic behaviour that in turn leads to human-wildlife conflict. The range that remains is either sparsely populated or 'refugia' like the Mountain Parks that are actively managed as protected areas. A problem with this scenario is that attractive but economically marginal lands end up as refugia, meaning that a "species ends up, not in the habitat most favourable to it, but in the habitat least favourable to the agent of decline" (Caughley, 1994). Since 48\% of the Mountain Parks are inhospitable to grizzly bears because of slope, rock and ice cover, there is an obvious habitat problem, which can be moderated through 'safety areas' where bears can forage without contact by humans, buffer zones, and corridors. The ongoing pressure on all three types of space is at the root of the stress in the population. 
The Foothills Research Institute Grizzly Bear Program (FRIGBP), which included the province-wide DNA population study mentioned above, methodically sampled the western part of the province and used DNA gathered from hair snag traps (liquid bait stations surrounded by barbed wire lines) and collaring to count grizzly bears, including the re-capture rates and movement patterns over four years (sampling different Bear Management Units in each year). This process (detailed in Boulanger \& Stenhouse, 2010) gave a very strong description of bear mortality by age and sex, which is important since the survival of cub-rearing females is a key to species survival. While the scale of the analysis is too large to be definitive about population projects in specific areas, the evidence shows that survival rates go up linearly with increases in the percentage of the home range protected and cub survival decreases with increases in road density.

The FRIGBP found an annual survival rate of $95 \%$ for adult females in the Bow Valley and the ESGBP found a rate of $92 \%$. This is higher than average in the province. However, cub survival was lower than average and together the numbers suggest that the grizzly bear population was declining during the 2000s (Festa-Blanchet, 2010).

\subsection{Relationships}

Grizzly bears form a part of the geographical imagination of Canmore as a mountain town. They are frequently seen around the town, as some females have raised cubs within the area. Just prior to my fieldwork in 2009 a well known grizzly had been killed in a train collision, and interviewees referred to the bear by name and number - the bears are not anonymous or interchangeable but have individual histories and stories, which influences the way that people see them - often as neighbours rather than just motile pieces of 'environment'. 
Some informants shared stories of attaching deep meaning to seeing their first bear, a sense of awe and attachment that stayed with them for many years (personal communication, Informant $\mathrm{H}$ ). There was also a sense of spiritual dimension of bears echoing the presence of bears in myths and aboriginal knowledge (personal communication, Informant C).

\subsection{Lifeways and liveliboods}

The physical dangers presented by bears and the financial dangers resulting from land use controls and other regulation to protect bears are two major themes in the case. The expansion of use into planned wildlife corridors is a good example of how the value of the real estate trumped other criteria for decision-making. The activities and positions of the AMPPE and the advocacy role of the Fraser Institute in trying to discredit the Eastern Slope Grizzly Bear Project illustrate the economic competition that is caught up in the co-existence question.

As far as the bear economy goes, the bears respond, as one researcher put it, to fear and food in that order. The mountain bears are underweight and combative compared to the grizzly bears of the west coast who can profit from a bounty of spawning salmon most years. When the bears wake from hibernation in the spring they begin to work their way toward the valley bottoms that melt out earliest for food sources like roots, berries and ant larvae, and work their way up the slopes as the snow retreats and greenery blossoms. By late summer they are "eating machines" facing tremendous pressure to fatten up before reentering hibernation. This process of migration for food brings them into human use areas at some point each year. They have phenomenal memories and curiosity - an apple tree left 
to fruit once will attract a bear on an annual basis, and all the neighbours of the apple tree owner will be visited as well.

Two of the major threats to bears are collisions with cars and trucks and with trains. CP has spent some $\$ 20$ million dollars to refit grain carriers to avoid spilled grain on the tracks and also deploys a vacuum cleaner train car remove grain from the tracks. Environmental groups often criticize these efforts as too slow and insufficient. Within the Parks, Parks Canada has twinned the highway to facilitate transport between Alberta and British Columbia, and done innovative and successful work to create fencing and over- and underpasses to facilitate safe transit by bears and other animals. Outside the park, crossing structures have been found to be successful but may be compromised by human use, as an underpass in Canmore that is sometimes used as a short cut by pedestrians, compromising its wildlife function, or by land use change, as in real estate development adjacent to corridors as may be happening in Dead Man's Flats.

There were two conflictual dimensions in the case: bears' attraction to human properties, which can be reduced by attractant management and aversive conditioning; and conflict over value - the costs and opportunity costs of protecting bears. These illustrate a human-bear conflict, and a human-human conflict on the subject of bears, echoing a theme in the human dimensions of wildlife literature.

\section{Prospects of co-existence}

The essence of change in the Bow Valley is the conversion of a space of extraction to a space of attraction. This is a process described by Luke as the re-cycling of the periphery as re-centred chunks of the core (Luke, 2002). Certainly the bistros and boutiques of Canmore today would be profoundly out of place to the miners and railwaymen who 
peopled Main Street pre-1979. The 1980s saw a process of change by which early, outdoorsy migrants engaged with the mountain ethos and culture that made Canmore unique as a place. This in turn increased the desirability of the town as a destination. When the province opened surrounding Crown land for development, local landowners began to engage in the real estate market, and wealthy Calgary residents began to seek mountain retreats, the ethos and culture was put in retreat; early residents lost ground in being able to afford to live in the town. What was left behind is a community made up of approximately $30 \%$ 'part timers' and $60 \%$ 'newcomers'. The social fabric is profoundly changed and what is left is a post-modern interpretation of a mountain town built on the promise and premise of recreation and profitable real estate investment (Sandford, 2008).

The pressure for continued growth is strong, although the 2008 global economic downturn reduced the pressure considerably, at least at the time of writing (Gailus, 2009). There are physical and legal barriers to expansion - the steep slopes north and south of the town, the boundary of Banff National Park to the west, and the less desirable, flatter lands to the east. What happens inside the valley bottom is ultimately a trade off. Land set aside for wide, wild migration corridors is not available for real estate or recreation. Land built out as resorts, golf courses and trails are at best marginally functional as wildlife corridors (Heuer, 2009). This situation has evolved and will further develop in the future as a contest.

A pro-human coalition has put forward a position that conservation is important, bears should be protected, but that reason and fairness dictates that protection measures not impact negatively on human use. Too much protection results in too many bears, which cause conflict, they contend; hunting and hazing keep bears wild and restrictions on development and use are unreasonable and unfair. A pro-bear coalition has put forward a contrary view that endless expansion of Canmore is squeezing out wildlife, and that further 
destruction of bears and habitat undermines what Canmore is as a place. The contest is played out constantly, in the media, policy-making structures, public hearings and Town Council meetings, among others.

The bears are part of the contest. By their presence, they keep the issues in the public eye, as demonstrated by the tragic events of 2005 and their discursive aftermath. They use what humans make available to them - whether that is fruit trees, garbage, buffalo berries and other food on ski hill and golf course verges or valley bottoms, or protection from aggressive bears. As humans alter their response with aversive conditioning or attractant removal, the bears adapt. Because of the spatial limitations and their biology, they do not have the luxury of not feeding, of not following their food sources up and down the mountain altitudes according to the season, of transiting the valley. Their life cycles, particularly for the habituated bears, are caught up in the actions and processes of human land use and habitat change. The net effect on the bears is negative - increased mortality near roads, increased effort and often decreased habitat quality near human use areas, and decreased cub survival.

The prospects for co-existence for people and bears in the Bow Valley are cloudy. Measures taken in the distant and recent past (the end of bear hunting, which was done much earlier in this region that elsewhere in the province), efforts to increase the permeability of highways with crossing structures, attractant removal and increased bear awareness are all positive steps. At the same time, the population is balanced on a knife edge - survival rates of adult females are thought to be about 92\% (Festa-Blanchet, 2010) and the minimum survival rate for population stability was calculated at 91\% (Garshelis, et al., 2005). Recognizing the variability of estimates and methods between studies, these numbers should give pause and encourage caution in management. The trend at the moment in policy change 
is toward greater protection for bears and habitat. Sharp critiques of efforts like the Eastern Slopes Grizzly Bear Project in the early 2000s have been dulled by ever mounting evidence that previous estimates were too optimistic. If current efforts continue and a resurgent economy does not compromise the remaining security areas and corridors, and bear smart activities (attractant removal and recreationalist education) and hazing measures continue to reduce risk of human-bear conflict the continued and successful co-existence is a possibility.

Bear protection is in the ascendancy for now - the government has 'gone slow' on protection for a long time, but the 2010 decisions appear to recognize the fragility of the situation. Whether the bear population responds as predicted, and hoped by bear advocates, will only be seen in the years to come. 


\section{People and eastern wolves in the Ottawa Valley}

We are doing more in this work (of wolf control) than ever has been done before. There has been an impression that we are protecting wolves. We are not protecting wolves. Jack Shannon, Provincial Predator Control Officer announcing controlled wolf culling, quoted in the Toronto Globe and Mail, March 18, 1966

Wolves are an integral part of Algonquin's biodiversity, and the focus of the park's popular education and interpretive programs. By protecting wolves today, we're making sure future generations of Ontarians will be able to hear wolves bowl in Algonquin.

Minister of Natural Resources David Ramsey announcing a permanent moratorium on killing wolves in townships surrounding Algonquin Park, quoted in the

North Bay Nugget, May 31, 2004

\section{Introduction}

In Ontario, Canada a dramatic situation of human-wildlife conflict has played out over many decades. It has involved controversy over and eventual protection of eastern wolves (Canis lyacon) and it reflects and embodies changes in environmental thought and action over that period. Eastem wolves in the upper Ottawa Valley adjacent to Algonquin Park have been valorised on the one hand as symbols of the wild, and on the other attacked physically and symbolically as a tool of urban elites who do not bear the costs of coexistence with predators even while lobbying for their protection.

This conflict came to prominence in the media and in environmental and political circles in the early 1990 s as research on the wolves showed high mortality in a particular area just outside the border of Algonquin Park. The evidence showed that wolves, ordinarily resident in the park, were being killed just outside park boundaries. This raised questions about the distinction between protected space and protected animals; the arguments for killing predators to protect deer and livestock, and the contested relationships between research, advocacy and policy change. This case study reviews the situation and dynamics of 
people and wolves in the region with a focus on the processes of co-existence before, during and after this period.

\section{Case study}

\subsection{Context}

Algonquin Park (see figure 6) occupies a particular space in Canada's geographical imagination (Baker, 2002). A vast series of landscapes, this 7,630 square kilometre region marks a transition zone between the fertile soils, rolling landscapes and hardwood forests in the south and rocky coniferous forests in the north. The complex and varied landscape supports considerable biodiversity, including 53 species of mammals, 272 species of birds and approximately 7,000 species of insects (Friends of Algonquin Park, 2005). Only imagined as a pristine wilderness, this active, shared landscape incorporates commercial logging, backcountry camping, a busy highway corridor with a range of services and accommodation, and 92 nature reserves and wilderness zones. There is a history of human use of its territory stretching to well before its establishment as a park in 1893, and indeed into prehistory with the Aboriginal inhabitants whose name the park has taken. In its current complex arrangement, Algonquin Park is a good example of what Whatmore and Thorne call "a dense and energetic infrastructure of wilderness management" (Whatmore \& Thorne, 1998, p. 437).

Over its 116-year history, the competing uses of the park have engendered conflicts between area residents who depend on the carefully managed logging concessions within the park for economic livelihoods, and advocates of park protection and 'wild nature'. Rarely 


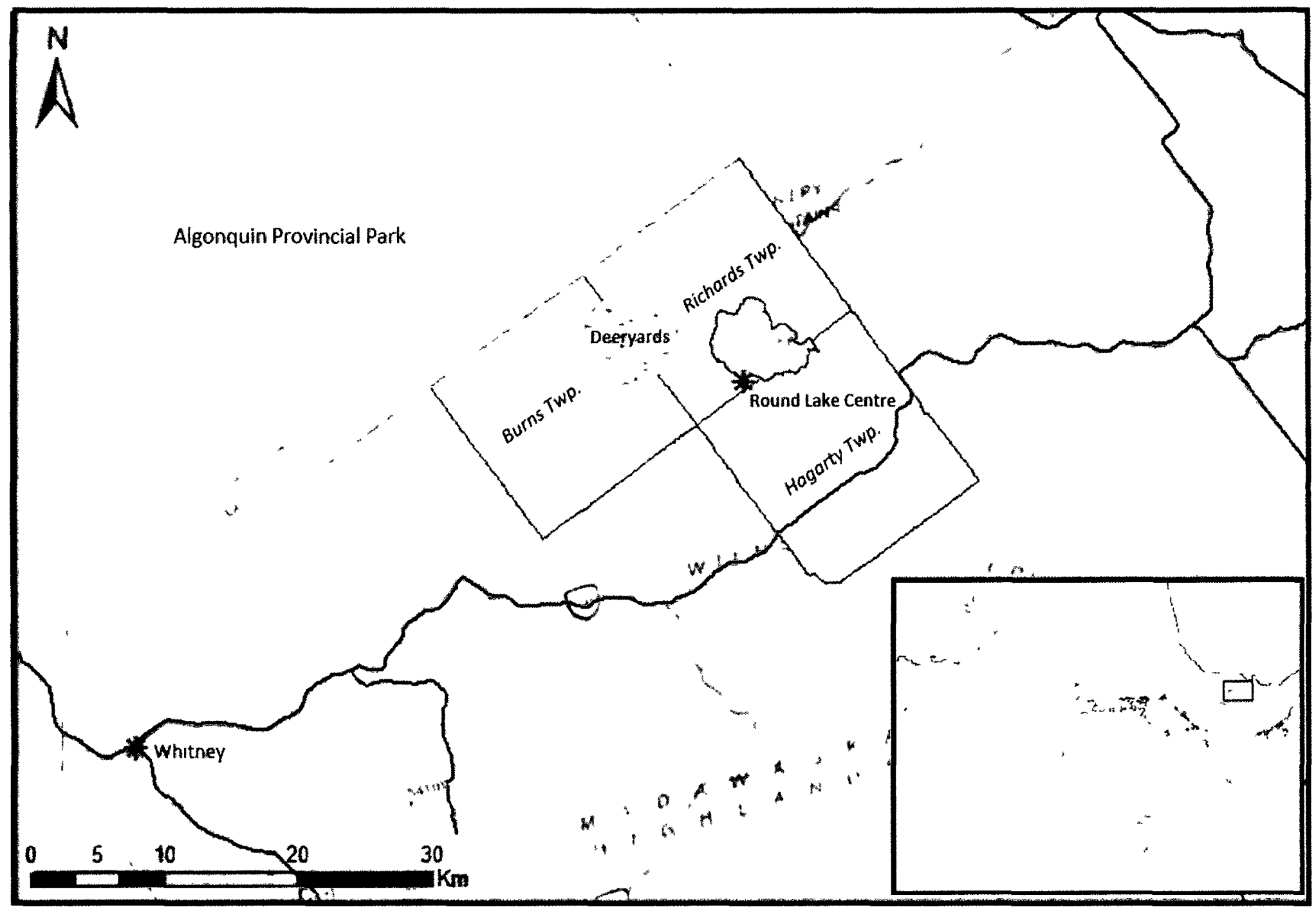

Figure 6: Upper Ottawa Valley/Algonquin Park

Map by Christopher J. Czerwinski/John Wall 
have these conflicts been as publicized and dramatic as those over the fate of 'Algonquin wolves' resident in the park and transiting its boundaries in the early 1990 s.

These debates, like many in human-wildlife conflicts, were between humans with competing views of a right relationship with the wolves - at times the wolves themselves all but disappeared from view. There are remarkably divergent positions within this debate, including which species of canid is involved, whether these canids are endangered, whether wolves as predators deserve protection, and which humans bear the costs and receive the benefits of wolf protection. On this latter point, the people-wolf controversy in the Ottawa Valley came to concretize more general debates about rural livelihoods and metropolitan control in Canada's most urban province. In this way, the story of the Algonquin wolves transcends its specifics and forms the basis of a broader consideration of co-existence processes and 'wildlife management' as a discursive and political field as well as a technical one.

\subsubsection{A brief history}

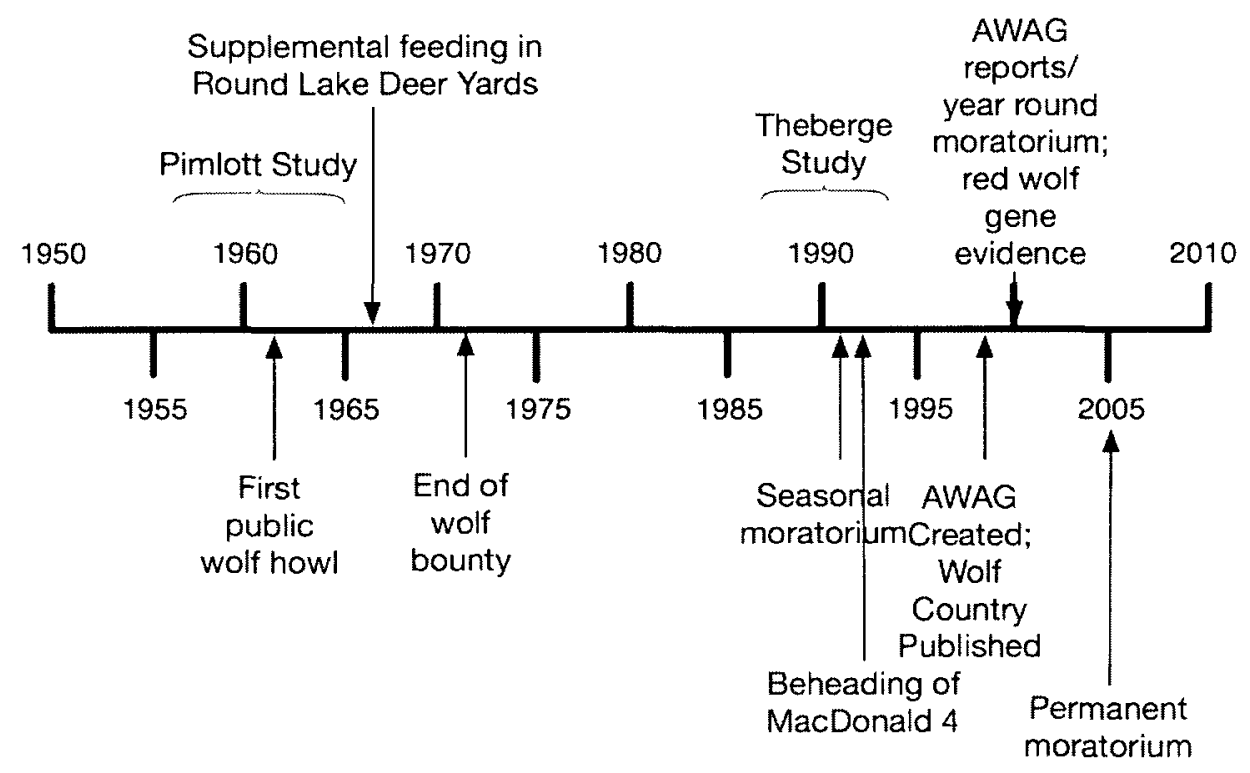

Figure 7: Timeline of significant events in wolf case 
The wolf has a long and complicated relationship with humans in Ontario. For much of the history of European settlers in the region, knowledge of wolves was experiential. The rural agriculturalists lived with wolves as a threat to livestock and trappers with wolves as a competitor for furbearers (Steed, 1988). Deer hunting as a livelihood activity and sport for regional residents, and deer as an iconic species for southern residents visiting the park, were thought by both groups to be imperilled by wolves. In fact, an embedded or cuitural dislike, even hatred, of wolves can be identified in media statements related to wolves in the study area.

Furthermore, Ontario was one of the first jurisdictions in North America to introduce a wolf bounty, in 1785, and one of the last to lift it, in 1972. Increased awareness of wolves as part of ecosystems, growing environmental awareness, and changing practices in wildlife management contributed to this policy change. However, until 2005, conservation of wolves or even consideration of them as fur-bearing animals was very limited. They were generally unregulated in the province and could be killed without a permit or reporting the kill until that year.

Prior to 1958 , in the early tradition of national park management, there was a focus on predator management and park improvement, reflecting an idea of nature in which human recreation was a priority and preservation of useful species and destruction of noxious ones essential. In this light, Algonquin Park rangers counted wolf control among their responsibilities until 1957, killing an average of 33 wolves each year from a typical annual population in the range of 200 . In preparation for the first comprehensive study of wolves in Ontario, Dr. Douglas Pimlott of the University of Toronto asked that the wolf culling be ended to facilitate the research, which began in 1958. For the following seven years a study of wolf ecology, predator-prey relationships, population numbers and health 
proceeded. One of the important methods that facilitated the research was a population census conducted by playing back recorded howls and later humans imitating wolf howls, which would generate a response and permit the counting of individual voices. In an era when radio collar telemetry was in its infancy, this method provided a key source of information. In 1963, this methodology was the basis for the first public wolf howl in Algonquin Park, which provided the public with direct engagement of the species both through naturalist talks and hearing the wolves speak in their own voices (Friends of Algonquin Park, n.d.; personal communication, Informant W).

Well into this period, historic attitudes towards wolves as dangerous, harmful to useful species like deer and livestock, and even as vermin continued in Ontario. As the government was attempting to put knowledge of wolves on a scientific basis through followups to the Pimlott study, an anti-wolf lobby was pressuring against research. A 1970 Globe and Mail column quoted the head of the Ontario Federation of Anglers and Hunters criticizing regulators and anti-wolf extremism saying:

We all know that wolves eat deer. We do not know whether the timberwolf exerts a limiting influence on the deer population.

Yet in the spring of 1969, the Department of Lands and Forests made it impossible for a reputable and established research program on timberwolves to be continued in Algonquin Park, which is the area where several years of the research has been carried out. The completion of this program, and it was in its final stages, may have supplied the answers to this problem. However, the complaints of a vocal minority were answered and research was stopped. The pressure group in this area, the Canadian Wolf Control Association, indicated to us that they are not interested in learning anything more about wolves and deer. They just want wolves exterminated. (Fife, 1970). 
In 1987 a second research project took place led by a student of Pimlott's, John Theberge. The Theberge study revisited Pimlott's research to examine change in wolf ecology and deer-wolf relationships over the preceding thirty years. Within a year, residents on the east side of the park were upset with the study and the scientists. This was in part because they believed any scientific study was necessarily pro-wolf and in part because they felt like they were being ignored by the researchers and the government (personal communication, Informants $\mathrm{H} \& \mathrm{I}$ ).

It was in this context that the high rate and significant total of human-caused mortality in the eastern boundary region of the park came to light. In 1992 researchers on this project noticed high mortality of radio-collared wolves at the park boundary. Most of these wolves were snared on trails leading out of the park into winter 'deer yards' which are favourable wintering and feeding areas in which deer tend to congregate. In 1993, 55\% of the radio-collared animals were killed by humans (Theberge \& Theberge, 2004). The researchers brought this information to public attention, which encouraged environmental groups to press for management changes to protect the wolves outside the park. In 1993 the province instituted a seasonal ban on wolf killing for five years in the three townships which contained the deer yards, causing considerable regional opposition (Theberge \& Theberge, 1998; personal communication, Informant I).

In 1998, the public-oriented book Wolf Country was released, in which Theberge presented a story of outreach, communicating with local community members and discussing as calmly as possible attitudes toward wolves and wolf-killing, even as he attempted to recover the radio-tracking collars from "park" wolf carcasses on the property of area farmers. In the present research, informants claimed the Theberge research featured a lack of respect or consideration for local people and their voices. Instead there was sense 
that "there was a thesis they were trying to prove...(and) they were dismissing anecdotal information that the local residents were willing to provide and therefore there was a conflict that was created that didn't necessarily need to happen" (personal communication, Informant I). This sense was reinforced in other interviews and also in media coverage during the events, and subsequently.

Some of the sense of exclusion that was described at the time and subsequently relate to a combination of a mistrust of outsiders and an existing anti-wolf sentiment within portions of the community. This mistrust is not strictly parochial, but is an instantiation of a defensive position in a community that often feels (not unreasonably) misunderstood and marginalized by the centre. The resource periphery that is Renfrew County depends on forestry (much of it in Algonquin Park) for economic security; its agricultural industry is diverse but challenged by soil conditions and climate. The sense that the rural residents must live with wolves and deal with their costs while urban elites benefit merely from the idea of wolves in "the north" causes great resentment, while attachment to Algonquin Park, the wolves that live there, and a construction of northerliness within the geographic imagination of southern publics contributed to the pro-protection discourse in the debates. These differences point out the different constructions of wolf that underpin political difference and potential action, and are considered in more detail in Chapter 5.

In August 1998, approximately the same time that Wolf Country was published, Theberge was charged with violating conditions of his scientific collector's permit. The charges were allegedly laid because the research team had not correctly labelled traps that were being used to humanely catch wolves for collaring, and because a student research team did not have a copy of their permit with them when they were questioned by a Conservation Officer (Honey, 1999). Seven months later the charges were dropped and Theberge claimed 
that this was because they were false and retaliatory. Media coverage of the dismissal of charges cast MNR in a negative light. The combination of the book's revelations and the Ministry's ham-handed response cast MNR as, at best, half-hearted about conservation of the wolves.

Later in 1998 the Minister for Natural Resources announced the creation of the Algonquin Wolf Advisory Group (AWAG), a twelve-member committee representing local citizens, government, trappers, hunters, conservation organizations and the science community (Algonquin Wolf Advisory Group, 2000). Between August 1999 and October 2000 the group held a series of meetings and a Population and Habitat Viability Assessment (PHVA) workshop - a type of experts' conference that has been used extensively around the world to do rapid assessments of populations of concern. The PHVA report was used by AWAG in preparing their recommendations, and the Algonquin Park Raven reported that one important result was that all participants agreed on the importance of maintaining the Algonquin wolf population, which was a radical departure from attitudes and opinions just a few decades earlier (Strickland, 2000).

By 2000 the mainstream media was reporting that, "the wolves in Ontario's Algonquin Provincial Park are not grey wolves but are instead closely related to the red wolf (Canis rufus), an animal with quite a different genetic makeup that points to an evolutionary link with coyotes. The connection, say researchers, is independent of the grey wolf, which cannot easily mate with the coyote. The red wolf, on the other hand, can" (O'Neill, 2000). The red wolf is included on the IUCN Red List of Threatened Species and was thought to be extirpated throughout North America except for pockets in the far south and west of the United States and Mexico (Kelly, Beyer, \& Philips, 2004). If the small, reddish wolves of Algonquin were in fact red wolves, not small timberwolves or timberwolf/coyote hybrids, 
and if they were different from the wolves in neighbouring areas, then their protection would become a matter of importance to preserving Canadian biodiversity.

AWAG recommended an adaptive management plan that upheld the winter hunting ban in the townships to the east of Algonquin Park and a closed season in the other townships surrounding the park. Instead, the minister introduced a ban on hunting wolves except to protect livestock in all the townships surrounding the park, initially for 30 months, and then permanently in 2005. Some felt that this undermined the AWAG process, and dissatisfaction with the decision was covered heavily in the Pembroke Observer, in which the Ontario Federation of Anglers and Hunters' representative on AWAG wrote a column and to which the same member frequently published letters to the editor. In one of these he wrote, "Instead of following the overwhelming majority-approved AWAG recommendation for prescribed wolf hunting and trapping seasons in select townships surrounding Algonquin Park, the Minister of Natural Resources elected to suspend this recommendation and replace it with a 30-month (proposed) wolf hunting and trapping moratorium, after being pressured by the World Wildlife Fund, Canadian Parks and Wilderness Society-Wildlands League and Prof. John Theberge. Your readers should understand that this ministerial proposal, if adopted, is arbitrary and literally makes a mockery of the enormous two-year workload his appointed advisory group endured" (Beck, 2001).

Obviously, the pro-protection Earthroots had a different perspective on the decision, and drew extensively from popular support to bolster their arguments. They publicized poll results that showed that $82 \%$ of Ontarians were opposed to snaring wolves and $75 \%$ opposed the lack of a management plan for wolves in the province (Brooks, 2001) and that 10,000 submissions had been received by Ontario's Environmental Bill of Rights Registry supporting increased protection and only two opposed ("Killing of wolves must 
stop, warns wilderness group," 2001). This appeal to public support was a rhetorical strategy that appears to have been effective in influencing government policy. In announcing the hunting bans that exceeded the AWAG recommendations the Minister of Natural Resources said, "there was significant support from the public for restrictions" ("Wolf hunting ban now in effect," 2002). See figure 7 for a timeline representation of significant events in the case.

\subsection{Actors}

\subsubsection{Wolves}

The eastern wolf is thought to range through central Ontario and west Quebec, numbering perhaps 2000 animals in 400 packs. Algonquin Park is the largest protected area in the range, and includes an average population of about 200 animals, varying yearly. Some of the elements of the wolves' numbers and species are debated or still being examined, as discussed below.

It is a mark of the complicated placement of the wolves of the upper Ottawa Valley and Algonquin Park that even their species identity has been hotly contested. In 1944 Young and Goldman's Wolves of North America listed 6 species of wolves and 14 sub-species. He identified the 'grey wolf' (Canis lupus) as the species endemic to the central Ontario region (Young \& Goldman, 1944). Standfield and Kolenosky, Ontario government scientists, published a typology of Ontario wolves in 1970 that noted that the wolves along the southern edge of the Canadian Shield were noticeably smaller than those in the north of the province, and argued that they were a previously unrecognized subspecies of the gray wolf (Kolenosky \& Standfield, 1975). In 1995 Ron Nowak identified 5 gray wolf subspecies in North America and identified the 'Algonquin Wolf' as Canis lupus lycaon (Algonquin Wolf Advisory Group, 2000). At around the same time, evidence emerged that this small, deer- 
eating wolf was actually either the same species or closely related to the red wolf (Canis rufus) - a critically endangered canid found only in the southern United States, primarily in captive breeding restoration programs (Wilson, et al., 2000). In common discourse the larger northern wolves were often called timber wolves and southern Ontario's coyotes called brush wolves, with the Algonquin wolves thought to be a hybrid or a transitional breed between the two territories.

Continuing research, and particularly the increasing availability of genetic testing on samples from live-trapped wolves as well as samples from wolves killed in earlier periods, extending back into the 1800 s (Wilson, Grewal, McFadden, Chambers, \& White, 2003), permitted researchers to identify that although red wolf and coyote genes were present in the 'Algonquin wolf' this was probably attributable to a common ancestor for both eastern wolves and red wolves as opposed to them being the same species (Wilson, et al., 2000). The question of hybridization played an important role in debates about management and protection of these wolves - their conservation value was much higher as "a red wolf...thought to live only in the United States" (Honey, 1998a) than as 'coy-dogs', common hybrids with no historic role in the ecosystem (O'Neill, 2000). By the early 2000s there was still some debate about the animals as subspecies Canis lupus lycaon or separate species Canis lycaon, but the latter, with the common name eastern wolf was becoming widely accepted (Grewal, et al., 2004). This was thought to be the species present in Algonquin Park and the Ottawa Valley, with range extending into Quebec and parts of northem Ontario, with a population of approximately 2,000 remaining (Species at Risk Public Registry, 2001; Wilson, et al., 2000).

In spite of continuing research with more advanced tracking technology and advances in genetic analysis, definitive scientific classification of these wolves remains 
elusive. One reason for this is that they challenge a principle of conservation biology that sees "reproductive isolation (as) a prerequisite for speciation" (Rutledge, Garoway, Loveless, \& Patterson, 2010, p. 1). Instead of seeing relatively cleanly defined lines between grey wolves in northem Ontario, eastern wolves in central Ontario and coyotes further south with some blurring along the boundaries, new research supports the concept of a "hybrid swarm" or syngameon in which eastern wolves, evolved in North America (like the red wolf), served as a "genetic bridge" between western coyotes (Canis latrans) immigrating from the south and Canis lupus in the north. The wild canids south east of Algonquin Provincial Park and extending into Atlantic Canada are offspring from this ancient hybridization event, and although the wolves of Algonquin Park include DNA from both grey wolves and coyotes, they remain a distinct genetic group (Rutledge, Garoway, et al., 2010). This is an important observation because in spite of their small numbers they might not be recognized as endangered without meeting conservation biology standards for being genetically distinct.

\subsubsection{Residents}

The focal region of this study is the northem part of Renfrew County between the Town of Renfrew and Algonquin Park. About 7,000 people live in the region and 97,000 in the county as a whole. Forestry, agriculture and tourism are major industries in the area.

This region has frontier characteristics, having been settled by Europeans in the late nineteenth century and being heavily dependent on natural resource industries. Interviews from the research presented deer hunting as an important economic and social activity, and wolf predation on livestock as extremely threatening, considering the challenges of successful agriculture on the marginal land of the region. There were also cultural dimensions related to the settlement of the area in a short period of time by Polish immigrants escaping German-occupied Kashubia in the mid-nineteenth century (Connolly, 
2005) Current residents described a cultural tradition of taming the wilderness, in which wolves were seen as materially and symbolically opposed to human livelihoods This may have formed the foundation of animosity that was rehearsed and expressed in the debates over protection in the 1990 s and 2000 s

While there can be no doubt that wolf predation was costly and harmful to individual farmers, and was sometimes blamed for the loss of small-scale anumal agriculture in the region, it is equally likely that restructuring of the industry and the lack of competitive advantage for animal agriculture in the region also played a role Government of Ontario insurance records for livestock predation show that Renfrew County as a whole ranked 32 out of 49 regions or counties in the province in the mid-2000s (Ontario Ministry of Agriculture Food and Rural Affarrs, 2009) This indicates that the problem of livestock predation in the region is real, but within the bounds of normal expectations in the province Considering that the county is heavily forested and agniculture largely gives way to forestry in the northern region, predation may be lower than might be expected

Culling of wolves to support the deer population and to reduce livestock predation seems to have been a common practice, with 'wolf shoot days' and shooting derbies continuming up to the present day (although outside the 'no-kill zone' surrounding Algonquin Park) (Al's Comer Store, 2010). The extent to which these types of actuvities were undertaken was unknown prior to the Theberge study Within a few years of tracking the wolves with radio collars, the researchers in the study noticed significant numbers of wolves being killed, largely by snares, just outsıde the park boundaries The wolves would follow wintering deer outside the park, and in the absence of legal protection, there was no limitation on their killing by human neighbours concerned about deer populations and livestock predation 


\subsubsection{Scientists}

Algonquin Park has been an important centre for wildlife research for many years and more than 16 theses and published papers have been produced from researched based at the Park's Wildlife Research Station, established in 1944. One of the early researchers who made an important contribution to public awareness of wolves in Ontario was Doug Pimlott, who led the 1957-1965 study and began a process of shifting attitudes about wolves in the province through public information and education.

Later John and Mary Theberge and their students identified the problem of humancaused wolf mortality and altered the discourse of wolf research and protection in the province. Theberge's 1998 book $W$ olf Country details efforts that the scientists made to elevate awareness of the threats to wolves and effect policy change. This has led to criticisms of the wolf research as "advocacy science" and pro-hunting commentators used this charge to attempt to impugn the research (Beck, 2001).

When the Algonquin Wolf Advisory Group (AWAG) was established it began operating on the principle of 'best available science' and the 'expert' members were primarily biologists and ecologists. Between August 1999 and October 2000 the group held a series of meetings and a Population and Habitat Viability Assessment (PHVA) workshop - a type of experts' conference that has been used extensively around the world to do rapid assessments of populations of concern.

The PHVA report found that the evidence on whether the human-caused mortality was a threat to the population was inconclusive, but that the high mortality in the east side of the park should not be extrapolated to the park as a whole. The mortality rate alone was not found to be as alarming as the Theberges and environmental groups had argued, but at the same time, the population appeared dependent on in-migration from outside the park 
(Ewins, de Almeida, Miller, \& Byers, 2000). In the post-AWAG era, the provincial government has stepped up its research capacity on wolves in the area and throughout the province. Tracking of the population has been improved, and new publications have provided fresh insight on the genetic status of the wolves, the pup mortality rate and the social structure (Rutledge, Garoway, et al., 2010; Rutledge, Patterson, et al., 2010; Wheeldon, Patterson, \& White, 2010).

\subsubsection{Provincial government}

The main provincial actor in this case is the Ministry of Natural Resources, but there are different segments of this Ministry that warrant consideration. Algonquin Park is part of Ontario Parks, an arms-length agency of the Ministry that has played a major role in educating Ontario residents and other visitors about the wolves in the area. Based on the innovation of wolf howling for research, in 1962 the park began offering a public wolf howl as an interpretive event. Since then more than 120,000 people have participated in an interpretive talk and roadside wolf howl in which up to 2,000 people drive to a pre-scouted location along the park's main highway, stand in silence and listen as park naturalists attempt to provoke a howl from one of the packs' rendezvous sites. The success rate overall is more than $70 \%$. This is one of the main ways that Ontarians have learned of and become attached to Algonquin wolves, which is a big departure from the 1950 s when the wolves were seen as a menace to the deer that were the park's main attraction.

Within the Ministry proper, there has long been a tension about whether the department is protecting wolves or protecting the livelihoods of rural residents of the province. This dynamic is highlighted on several occasions, for example when wolf killing was eliminated within Algonquin Park in 1957 and when the bounty on wolves was lifted in 1972. The overall framework for wildlife management in the province is one of sustainable 
use of resources and protection and promotion of the province's hunting heritage. Calls for the wolves to be protected because of their special status or on general principles did not find a sympathetic ear within the Ministry. At the same time, the province's capacity to judge the population and population risk was not strong during the 1990 s controversy, which more or less yielded the field to the Theberges. The Theberges were based at the University of Waterloo and their research was partially funded during some periods by the Ministry of Natural Resources but the most consistent funder was WWF-Canada (Theberge \& Theberge, 1998, 2004). When they then ignored the Theberge's recommendations, charged John Theberge with violating his research permit, and changed the terms of that permit midproject, the Ministry appeared to be openly hostile to the researchers and to wolf conservation.

The institution of AWAG helped deflect these criticisms, and the recommendations from the AWAG process (for which the MNR was the Secretariat) would have brought wolves in line with wildlife policy more generally in the province, based on a scientific assessment and sustainable use principles. However, the Minister of Natural Resources took a different position, which established protection for the wolves around the park and sustainable use elsewhere in the province. Subsequently the internal science capacity related to wolves was improved and the high stakes media conflict declined.

\subsubsection{Hunters \& agriculturalists}

While there can be no doubt that wolf predation was costly and harmful to individual farmers, and was sometimes blamed for the loss of small-scale animal agriculture in the region, it is equally likely that restructuring of the industry and the lack of competitive advantage for animal agriculture in the region also played a role. 
Hunters were alarmed about proposed changes in the 1990 s both from the perspective of the perceived irrationality of protecting wolves when they often did not see the canines as wolves nor as endangered, and by their apprehended impact on the deer population. The deer hunt in the region is important socially, culturally and economically (personal communication Informants $\mathrm{H}, \mathrm{J}$ and $\mathrm{K}$ ) and a perceived threat to the hunt was taken very seriously (personal communication Informant I). Since the wolf-killing moratorium was introduced the deer hunt has been up and down, but apparently within the range of variability that had been the case before the moratorium. The major pro-hunting voices in the debate were the Ontario Federation of Anglers and Hunters and the Pembroke Outdoor Sportsmen Club.

\subsubsection{Environmentalists}

There were several organizations that took a leadership role in promoting wolf protection in the debate. World Wildlife Fund, Earthroots, the Ottawa Valley Chapter of the Canadian Parks and Wilderness Society were among the most prominent. Earthroots facilitated speaking tours by John Theberge in which he lectured on his research and on the plight of the wolves, and engaged in polling and media relations to put political pressure on the government to enshrine the ban on killing Algonquin wolves ("Events (Ontario Edition)," 2001). WWF substantially funded the research (Theberge \& Theberge, 2004). Earthroots and CPAWS maintained a strong media effort to push for wolf protection, particularly in the 1998 to 2000 period (Brooks, 2001; Tkachyk, 2001).

These organizations were very prominent on the communications and lobbying side of shifting discourse to action. Ultimately they were trying to influence the MNR and particularly the Minister to implement protection measures. Their efforts raised the profile of 
the issue to the level at which it became a political issue at a provincial level, which probably facilitated the protection-oriented decisions that were ultimately made in this case.

\subsection{Key Events}

\subsubsection{Science goes public}

Prior to the Pimlott study in 1958, there was little scientific information available on Ontario's wolves. There had been four major wolf studies in North America and the longterm, single species research effort was just evolving. The advent of Pimlott's research study both brought the killing of the wolves into focus and provided the wolves with a new image. As Pimlott publicized his research, for example, he was featured in the Globe and Mail with photographs of wolves that he raised from captured Algonquin pups at his home in Toronto, and he gave testimony to Ontario Provincial Parliament committees. The media coverage, which was generally favourable to wolves, was among the first voices to promote wolves as a positive element of the ecosystem.

The research project also discovered the evocation of wolf howls which became the basis of the Algonquin Public Wolf Howl in 1962 and subsequent public howls, including the Bonnechere Provincial Park wolf howl which caters to the area which includes the Round Lake Centre Deer Yards, the epicenter of the 1993 controversy. This elevated awareness and positive sentiment toward Algonquin wolves since the hunting ban was made permanent.

The publication of early research results from the Theberge study in 1993 set the stage for the first hunting moratorium in the region. This led to the most dramatic eras of conflict related to this issue. 


\subsubsection{McDonald Four speaks}

In the spring of 1993 strong local resistance to the ban was covered extensively in local papers in Barry's Bay and Eganville, close to the affected townships. In winter 1993 a group called "Friends of the Wolf" posted flyers on bulletin boards and telephone poles in the area that featured a picture of a wolf, a headline stating "HOW DARE YOU!!" and the following text"
"On behalf of this and other citizens of the Wolf Nation, Friends of the Wolf hereby order human citizens to immediately cease and desist on all attacks and plans of attack on the Algonquin and all other Wolves. Any further violence against wolves in these areas will be met with prolonged and diverse resistance" (Theberge \& Theberge, 1998, p. 201).

On March 12, 1993 one of these posters, the severed head of an Algonquin wolf called "McDonald 4", the radio collar it was wearing at the time of its death, and a handmade cardboard sign stating, "DO NOT DARE US ? !!! $\checkmark$ " were found attached to a telephone pole in Round Lake Centre, a small community in the ban-affected townships. Figure 8 is a photograph of the decapitated wolf and the sign. 


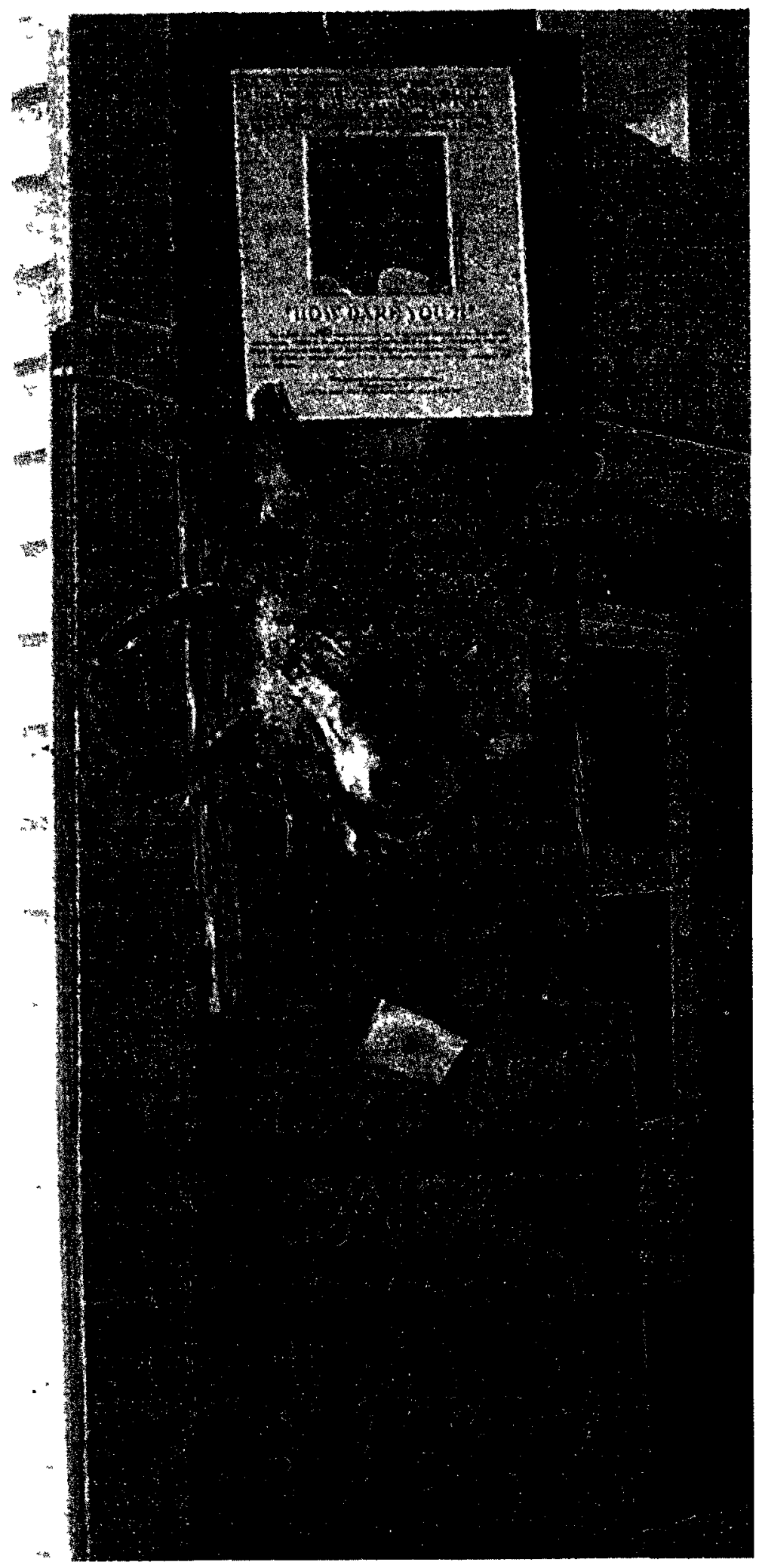

Figure 8: McDonald 4 after the decapitation

From Wolf Country (Theberge \& Theberge, 1998, p. 180) 
Theberge claims that this event was a turning point in the perception of wolves by community members. The brutality of the attack and the imagery of decapitation were so shocking to the community that a great deal of hostility toward the researchers and the regulation drained away. Furthermore, the feared attacks on livestock and humans and expected collapse of deer populations did not materialize, which probably influenced community perceptions as well. Local hunting advocates who agitated against the moratorium lost credibility and support and formal opposition declined within the region (Theberge \& Theberge, 1998 personal communication Informant L).

\subsubsection{Government intervention}

The establishment of AWAG in 1998, the implementation of protection measures beyond what AWAG recommended in 2000 and the subsequent confirmation of those measures in 2005 were also key events in the case. With a protection regime installed surrounding Algonquin Park and a further management regime in the rest of the province, the open hostility and later quiet neglect of wolves had been repudiated and the 2005 policy was a positive outcome for Ontario wolves.

\subsection{Outcomes}

As of 2010 , wolf populations in the area appear stable. Increased pup survival and a stable population indicate that the area's wolf population is exporting members to elsewhere in the region, which is a change from the 1999 PHVA which surmised that it was likely that wolf in-migration was maintaining the protected area's population. As well, with the introduction of a permanent moratorium on wolf hunting in the area, the family structures and territoriality practices of wolves returned to the predicted norms of high rates of kinship (Rutledge, Patterson, et al., 2010). Human-wolf conflict in the area is present but low - some 
informants called it an uneasy truce. However, it seems that the human population has accepted the ban and shifted focus to other issues.

\section{Data analysis}

\subsection{Data sources}

I analyzed a collection of 114 articles, letters, editorials and opinion pieces collected from the Toronto Globe and Mail, the Pembroke Observer, the North Bay Nugget and the Algonquin Park Raven published between 1987 and 2008, along with supplemental information not published in these papers but available from Theberge and Theberge (1998). The Globe and Mail, arguably Canada's national newspaper of record, was chosen to represent a province-wide and cosmopolitan representation of issues surrounding the wolves of Algonquin Park. North Bay and Pembroke, with populations of 53,000 and 13,000 respectively, are important regional centres located within $50 \mathrm{~km}$ of the park boundary that offer local representations of the issues. The Algonquin Park Raven is a visitor newsletter published by the Park, and might be considered the "official" view of park managers and naturalists. Wolf Country (Theberge \& Theberge, 1998) provides supplemental "behind the scenes" information and correspondence, as well as references to newspaper articles other than those I used in this study. These were collected from the Canadian Newstand database, formatted as 'rtf files and named with case, date and source identifiers, and loaded into TAMSAnalyzer for coding and presentation.

I conducted 11 interviews with officials, AWAG members, local residents and anonymous respondents to my toll-free phone line. The transcripts of these interviews were loaded into TAMSAnalyzer. I interviewed one researcher who focuses on wolves in the 
study area and reviewed the literature on area wolves throughout the study period to both examine the co-existence context and the changing knowledge of wolves in the region.

\subsection{Analytical procedures}

The transcripts were coded following the constant comparative method of examining statements in the text and assigning them codes that are reflective of their meaning. The focus was on identifying actors and actions in the situation of co-existence, as well as what Carvalho (2000) calls 'objects', discursive elements that extend the action items into narratives. These constructs are often called themes in qualitative research. Carvalho recommends the term object in order to emphasize the constructedness of narrative elements. These objects were used to help document the timeline and narrative above. The action and actors codes were used to assemble tables of action and discourse by actor so that a better sense could be drawn of the actual processes of co-existence documented in media reports and informant interviews. The interview transcripts were analyzed with the same set of codes to examine the insights and provide deeper analysis of individuals than available through the media reports.

\subsection{Action themes}

In the research the processes contain the myriad of daily actions undertaken by people and wolves, as well as the grand scale of policy development and change which loop back to the 'ground level' through enforcement practices. In order to distil these actions from the scores of files in the database, the following action themes were identified: adaptive, protective, compromise, destructive, defensive, landscape change, policy change and research. Table 8 shows a matrix of actors and actions in the case, and in the paragraphs that follow each action theme is described in further detail. 
Table 8: Wolf case actor/action matrix

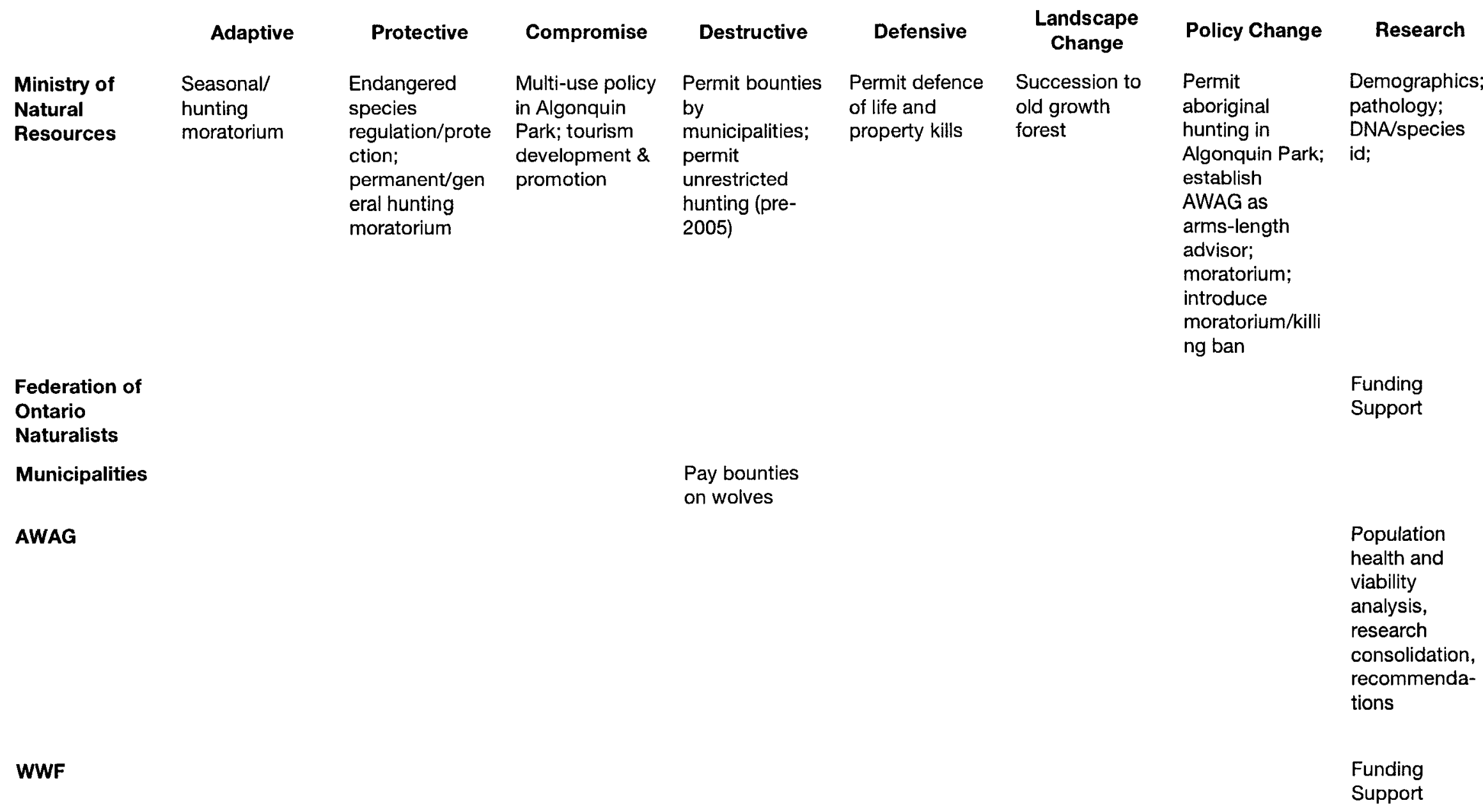




\subsubsection{Adaptive action}

Adaptive action is that which alters behaviour or activity to accommodate coexistence with the other. In this case the introduction of the first seasonal hunting moratorium in 1993 was a recognition of the wolves' feeding behaviour that lead them out of the park, and a protection measure to ensure that the population was not destroyed when it was most vulnerable. Here the underlying dynamics of protection within or outside of the park remained unaddressed, and the overall scheme of protection outside the park remained the same - wolves outside the park, ordinarily, had very little protection. In the particular case of the 'Algonquin Park wolves', however, protection was extended. Human concerns about risks arising from wolves' presence were not alleviated but at least considered in not extending protection to broader reaches.

\subsubsection{Protective action}

Protective action in this case is the realm of the province - its legal jurisdiction to manage the park, promote agriculture, and protect species-at-risk was at the root of its immediate actions, public consultations, and ultimate decision to ban hunting wolves in the 39 townships surrounding Algonquin Park. The listing of the species as falling under the jurisdiction of the Furbearers Act of 1977 meant that wolves also had some limited protection throughout the province as well. This may seem like a small step but it marked a departure for the government in terms of the historic treatment of wolves, and it defused much of the southern-based concern about the Algonquin wolves at the expense of angering northern voters.

\subsubsection{Compromise}

Compromise, as defined by this study as an adaptive action that takes a middle ground in human-wildlife issues that may not meet basic needs, is inherent in the 
establishment and management of Algonquin Park. The park's history is rooted in protecting the area from settlement for forestry, not for wildlife protection. The current park policy system, established in the 1970 s, is explicit about the multi-use nature of the park, the inherent conflicts arising there from being mitigated by land use planning. The high degree of tourism engendered by the park increases traffic and the risk of collisions and potentially disturbance that can interfere with wolves. At the same time, interpretation events like the public wolf howl generate interest and political support for wolf conservation, and the negative effects on wolves appear to be transient and minor, so this compromise does not appear overly harmful.

\subsubsection{Destructive action}

Hunting and snaring of wolves were the prime destructive aspects up until the early 1990s. There was also human-caused mortality from vehicle collisions. Outside the park area trapping for fur was practiced in certain reaches, and culling to support the deer population was part of the motivation for wolf killing. After the provincial bounty was lifted in 1972 some municipalities began paying a local area bounty, which was permitted by the Ministry until the policy was changed in 2005 .

\subsubsection{Defensive action}

Parks staff, MNR staff and individual citizens are authorized and known to kill wolves in defence of life and property. In 2008 a Whitney woman was reported to have killed a wolf at her home outside the park boundary after it killed her dog and returned the following day (Drake, 2008). There was some (unfounded) concern among farmers within the 39 townships that the wolf-kill ban would prevent them from protecting their livestock from wolf attacks. Mortality information since the 2005 policy shows that this is not a very common issue (Rutledge, Patterson, et al., 2010). 


\subsubsection{Landscape change}

One of the major areas of concern in the wolf protection debate was the role of forestry practices in reducing habitat for beavers and deer, resulting in reduced food sources and prosperity for wolves. The mainstream narrative on this topic is that the deer and wolf population exploded in the region in the 1880 s as forestry operations opened up stretches of dense forest, left a considerable number of tree tops and branches on the ground which was advantageous for deer, and that this led to a deer (and wolf) population explosion (Quinn, 2005). Nineteenth century logging practices were notoriously profligate. With the advance of modern forestry techniques, the forest cover is less advantageous for deer and the process of forest succession (toward old growth) is leading to reduced success for deer and wolves. The remedy here could be to disturb the forest and try to manage the landscape for increased deer and beaver production, contributing to wolf success. The environmental organizations see this as a Trojan horse to increase logging in the park and is opposed to this proposal.

\subsubsection{Policy change}

There were several important policy changes during the study period, including opening the eastern part of Algonquin Park for aboriginal hunting, introducing the various moratoria and establishing AWAG as an arms-length advisor to the Ministry. The net result was the Wolf Conservation Policy of 2005 which enshrined the 39 township killing ban and brought the wolves into the wildlife management system province-wide.

\subsubsection{Research}

The predator-prey ecology, wolf demographics and DNA testing were the three areas of research action that had the most bearing on this case. The disconnections between the Theberge study, partially funded by MNR but largely funded by NGOs, and the interests of MNR led to political conflict over the results of the research, as well as scientific debate 
about its substance. Since then, Dr. Brent Patterson of MNR, and adjunct professor at Trent University, has led a vigorous research program for wolves in the province, especially in and around Algonquin Park and has contributed to papers that address some of the questions that remained open after the Theberge study (Rutledge, Garoway, et al., 2010; Rutledge, Patterson, et al., 2010; Wheeldon, et al., 2010).

One of the key contributions of the AWAG was the convening of the Population Health and Viability Analysis under the auspices of the IUCN Species Survival Commission in 1999. These workshops bring together species experts to analyze data and develop consensus recommendations. The Algonquin PHVA differed with some points of interpretation of the Theberge data but identified the risk of the regional population being dependent on immigration from outside the park to maintain the population numbers. This helped point out the need for measures to support the regional population, which AWAG recommended, but which were later exceeded by the province.

\subsection{Discourse themes}

Discourse and action are intimately connected, particularly when discourse is defined in the Foucauldian sense of including meanings, values and systems as opposed to strictly linguistic content. Initially I attempted to combine action and discourse themes in the belief that discursive acts and physical acts are largely unified. However, the adversarial communication in the study and the means which by actors attempted to influence the Ministry of Natural Resources led me to reconsider this strategy and to create a separate set of discourse themes. Table 9 summarizes these themes, which are elucidated in the subsequent paragraphs. 
Table 9: Wolf case actor/discourse matrix

\section{Obfuscation}

Ministry of Natural Resources

Interfere with

Theberge study

\section{Wildlands League}

\section{Ontario Federation of Anglers} and Hunters

\section{Federation of Ontario \\ Naturalists}

\section{Earthroots}

\section{Canadian Parks and Wilderness}

Society

\section{Municipalities}

\section{Ontario Cattlemen's}

\section{Association}

\section{Ontario Trapper's}

Association/Fur Harvesters

Auction

AWAG
Pro-protection Advocacy

Anti-protection Advocacy

Enforce hunting regulations on all - including aboriginals; protect landscapes from conversion

Enforce hunting regulations on all - including aboriginals; protect landscapes from conversion;

Buffer zone around park

Lobby for conservation strategy; support buffer zone; polling on public support for wolf protection; lobby for ESA listing

Buffer zone around park; release environmental registry info showing vast support for additional protection; lobby for ESA listing

Lobby for changes to livestock insurance regime

Oppose kill restrictions

Oppose kill restrictions

No such thing as Algonquin wolf; landscape disturbance required
Oppose killing ban; encourage landscape change to reverse succession

Recommend closed seasons and hunting restrictions 
As mentioned in Section 6 of the introduction (Procedures), media coverage represents events in the world by setting up identities for those involved in the story and by taking a stance in the reporter-audience relationship (Fairclough, 1995). The understandings of wolves and people engendered by scientific research and by human-wolf interactions were covered by media outlets and this coverage expressed and fed a public debate about the proper management of wolves, which in turn influenced a process of policy making that changed the wolf management/protection regime in the province. Coherent sets of interpretations represented in media coverage are known as storylines, and people and groups that cohere on a storyline (accept and communicate the same arguments and narrative) are known as discourse coalitions (Hajer, 1993)

The three active storylines related to the wolves of Algonquin Park during the study period were: that critical prey was not available to the wolves, that they were not sufficiently protected from human killing, and that they were a tiny remnant population of a near-extinct species. Conflict over these interpretations ignited a war of words that radically re-shaped government policy toward the wolves.

These strands emerged and were meaningfully supported by science by the late 1990s. An earlier extirpationist coalition had effectively dissolved by this point. In the postBruntland Commission, post-Earth Summit era of sustainable development, to promote the intentional destruction of a species was to invite marginalization. This stance also ran counter to the provincial government's artfully stated but consistently held position that wolves would only be intentionally destroyed in specific instances where they were proven to harm local wildlife or livestock populations. In 1966, Department of Lands and Forest representative Jack Shannon had defended the government from an attack by trapping and farming representatives complaining that increasing wolf populations were harming their 
industry, saying, " "we are doing more in this work [of reducing wolf populations] than ever has been done before. There has been an impression that we are protecting wolves. We are not protecting wolves.' But he said that the department's policy is to carry out control where needed only" ("Wolf numbers prompt requests for provincial action," 1966).

Two discourse coalitions remained, a protection coalition made up of environmental non-govemmental organizations, most notably Toronto-based Earthroots and the Ottawa Valley Chapter of the Canadian Parks and Wilderness Society, and a management coalition that included the Ontario Federation of Anglers and Hunters, the Ontario Trappers Association and their successor, Fur Harvesters Auction Inc., several county agricultural organizations, and representatives of Algonquin Park. The Ministry of Natural Resources (successor to the Ontario Department of Forests and Lands) played a curious dual role, responsive to vocal public support for greater protection for Algonquin wolves while not abandoning the scientific management approach that marks Ontario's approach to the use of natural resources. While Park staff, who are employed by Ontario Parks, an arms-length agency of the provincial government, wrote about the discoveries of the Algonquin wolves' unusual genetic heritage (Strickland, 1999), they also downplayed aspects of uniqueness and endangerment (Strickland, 2001). The biological argument here was that due to fertility mechanisms that respond to population change and prey abundance, human killing of the wolves and did not impact the wolf population because pup production increased in years following high adult mortality. Speaking about the population's long-term resilience Park Naturalist Dan Strickland told a Globe and Mail reporter, 'It's pretty good evidence that killing all those wolves (during the years of culling before 1958) didn't matter', (Honey, 1998b).

The two discourse coalitions engaged in an ongoing campaign from about 1998 to implement their preferred action responses to claims of endangerment for the Algonquin 
wolves. Their respective storylines were in many ways diametrically opposed and are summarized in Table 10.

Table 10: Wolf case discourse coalitions and storylines, c. 1998

\begin{tabular}{|c|c|c|}
\hline & Protection & Management \\
\hline Species & Endangered red wolf & Common eastern Canadian wolf \\
\hline Range & $\begin{array}{l}\text { Unknown, perhaps limited to } \\
\text { Algonquin Park }\end{array}$ & Ranging from Quebec to Manitoba \\
\hline Numbers & $100-300$ & 10,000 or more \\
\hline Ecology & Threatened by trapping, logging & $\begin{array}{l}\text { High mortality due to the mature } \\
\text { forest of Algonquin Park }\end{array}$ \\
\hline $\begin{array}{l}\text { Proposed } \\
\text { Action }\end{array}$ & $\begin{array}{l}\text { Ban on hunting or trapping wolves } \\
\text { in Algonquin Park and in a } 10 \mathrm{~km} \\
\text { buffer zone around the Park }\end{array}$ & $\begin{array}{l}\text { Forest thinning/disturbance along } \\
\text { waterways in the park to increase } \\
\text { the beaver population; limited } \\
\text { hunting seasons and reporting of } \\
\text { kills; ban on hunting or trapping in } \\
\text { the winter deer yards }\end{array}$ \\
\hline
\end{tabular}

The key development in the critical discourse moment that galvanized the two discourse coalitions was the publication of results of the Theberge study. John Theberge had published extensively on the Algonquin wolves, and the Algonquin Park Wildlife Research Station had supported numerous research projects that touched on wolves and their ecology over the years. 'This longer-term study, however, would provide points of comparison with the 1957-1965 research project and answer new questions about predator-prey relationships, pack behaviour and park ecology (Theberge \& Theberge, 2004). This study was one of the first to raise the issue of Algonquin wolves leaving the park in large numbers to follow wintering deer, and to publicize the killing of the supposedly protected wolves outside the Park. In $199355 \%$ of the wolves collared for radio tracking in the study (considered representative of the Park's eastern population as a whole) were killed, all but one by humans (Honey, 1998b; Theberge \& Theberge, 1998). 
Media coverage and pressure for political action began to grow as these findings were publicized. In Theberge's 1998 Wolf Country he outlined the results of the research and put the plight of the wolves in empathetic language, exposed the extirpationist tendencies of the humans living around the Park, and presented in detail the reluctance of provincial officials to take action (Theberge \& Theberge, 1998). In the face of government responses ranging from reluctance to active harassment, Theberge "went public" and began releasing research results and commentary to the media. In 1993 the Ministry of Natural Resources agreed to a hunting ban in the townships containing the Round Lake deeryards during the winter season.

This moved triggered a strong response from the local communities, represented and reinforced by reporting in the community newspapers. The fears of wolves destroying the deer population and harming agriculture were escalated to include fears of attacks against humans and incursions in the area's towns and villages. As environmental organizations like Earthroots and the Canadian Parks and Wilderness Society pressured the govemment to commit more firmly to wolf protection, local tensions and political pressure within the Ministry of Natural Resources and in the broader political scene led to changes in action in the region.

\section{Processes of co-existence}

\subsection{Shared space}

A stereotypical view of wilderness or national parks in the North American context is that they correspond to what has been called 'fortress conservation', physical or regulatory enclosure of landscapes that have particular ecological significance. These are landscapes managed for natural heritage values, and this approach is often criticized today as one that 
undermines the knowledge, use and values of human communities that are excluded from the park boundaries (Brockington, 2002). This is certainly a point of view that featured in the wolf protection debates of the 1990s and 2000s when the prospect of 'park' wolves being killed outside the boundary was a focal point of conflict.

The situation in Algonquin Park is more complex than this, however. The park itself is a 'Category IV' protected area or a habitat/species management area. This is defined as a protected area managed mainly for conservation through management intervention, "an area of land and/or sea subject to active intervention for management purposes so as to ensure the maintenance of habitats and/or to meet the requirements of specific species" (Dudley, 2009, p. 19). The park is an active and shared landscape with Aboriginal hunting, industrial logging and massive tourism taking place within and around it, and porous boundaries that enable wildlife migration in both directions. Park-based forestry is an important economic driver in the region and there is tension in the region related to balancing the environmental demands of the park and environmental advocates and the local economic advantages of the park for rural residents. The park is an advantage and an irritation in local eyes.

The park is wolf habitat, from one point of view, and logging reserve from another. The deeryards are deer habitat, but border farms where wolves might be killed in defence of livestock. Further down the valley agriculture increases and threats of livestock predation are more real, but the prevalence of wolves' declines and that of coyotes increases over that distance. Some residents reported occasional sightings around their property or crossing the Ottawa River in winter, but there are no 'wolf jams' as one sees with moose-watchers in Algonquin Park and grizzly bears in Alberta. Many residents report hearing wolves howl, but for most people a sense of sharing space is an abstraction. 
For the wolves, sharing space is generally threatening. Before the moratorium, mortality was high, the population was stable, and the social structure highly disrupted. After the moratorium there was a population spike for one year, after which it returned to average levels, but the social structure began to revert to one more typical of other wolf populations. A key observation is that wolves and deer respond to human changes in the landscape, shaping subsequent events. The 1980s and 90s research found there was low kinship (Grewal, et al., 2004) and high rates of adoption (Theberge \& Theberge, 2004) among the wolf packs on the eastern part of Algonquin Park. Not only were packs often made up of unrelated wolves, but also they engaged in strategies that reduced aggression between packs (Theberge \& Theberge, 2004). One of the concerns about wolf protection was that it would reduce the deer population. However, both the deer presence and the predator-prey relationships are illustrative of the relational nature of human-other adaptation. The deer that congregated in the Round Lake Centre deeryards did not arrive there by chance. Although the topography and land cover are favourable, the same is true of numerous regions within the park. Also, deer have been successful in regions with far worse conditions than Round Lake Centre (Strickland, 2009).

The concentration of deer in the deeryards that became a focal point of controversy in the 1990 s was more than happenstance. Starting in the 1960 s, supplemental feeding was undertaken in the area to help the deer survive the harsh winters that had begun to take a toll on the population around that time (personal communication Informants $\mathrm{H} \& \mathrm{I}$ ). Although this has long ceased to be part of regular government management practices, it is still widely practiced by private individuals (personal communication, Informants I \& $\mathrm{M}$ ). This feeding practice helped shape deer tradition over decades (personal communication, Informants H \& $\mathrm{N})$. 
The prime determinant of deeryarding location is not favourable topographical conditions, but what is called deeryarding tradition. The prime determinant of where an adult deer will winter is where its mother took it to winter in its first year of life (Nelson \& Mech, 1981). Many observations have been made of deer relocating from one area for the winter, only to have their abandoned range taken over by a different group of wintering deer, and locations that according to traditional models should not be able to support wintering deer actually do (Nelson \& Mech, 1981; Strickland, 2009).

In the winters of 1960 and 61 there was significant winterkill of deer who were badly affected by a series of harsh winters. There was a public outcry that the government intervene to protect the deer. Supplemental feeding began in an area just outside the park. One informant indicated that the equivalent of ten to twenty large round bales of hay were placed in the "Round Lake Centre Deer Yards". This enticed deer outside the park and protected them from the harsh winter and deep snow inside the park.

Not surprisingly, wolves followed the deer to the newly enhanced deeryards. One of the survival strategies in 'yarding up' is that the deer are more highly concentrated, but that they are concentrated in the territory of fewer wolves (Halls, 1984). In the case of Round Lake Centre in 1991, there were two resident packs whose territory overlapped the deeryard. If they remained dispersed or even yarded up in Algonquin Park, more than 100 wolves would be feeding on them. In the deeryard, only ten or so wolves would be expected to be resident. Given the wolves' supposed territoriality, this should have provided a strong defence.

This did not actually turn out to be the way it works. As the wolves concentrated to prey on the deer, they were killed in large numbers by snaring (Theberge \& Theberge, 2004). 
This changed the composition of the packs and appears to have changed the structure of the packs, with packs including a large number of 'immigrants' and unrelated wolves (Grewal, et al., 2004; Rutledge, Patterson, et al., 2010; Theberge \& Theberge, 2004). For this reason, or due to the abundance of food in the deer yard, or a combination of reasons, the resident wolf packs did not aggressively defend their territory, but permitted a much higher rate of "pack trespass" than was observed in comparable situations in other study areas (Theberge \& Theberge, 2004). This resulted in more wolves preying on the deer and less inter-pack aggression than would have been expected. Furthermore, radio collar tracking shows that the invading wolves were furtive, using rapid transits to the feeding area and back to their pack territory to further minimize aggression. This tactic indicates an awareness of wolf territorial etiquette (predictably adaptive behaviour, given the risks attendant to inter-pack aggression) but a willingness to transgress that etiquette. The tolerance and risk taking activity may well have resulted from the pack instability and loss of older wolves who would reinforce wolf social norms. Alternatively, the concentration of deer by artificial supplemental feeding may have reduced the need for aggression and increased cooperation between packs.

Furthermore it likely increased pup production as the population dipped below optimum density (although this coincided with high pup mortality as well). Since the wolf-killing moratorium in the region, pup survival has increased and wolf density has been much more stable than in previous years (indicating that wolves are dispersing into other areas) (Rutledge, Patterson, et al., 2010).

The irony, of course, is that by feeding deer and killing wolves to support the deer population, the human community increased predation on deer and reduced the inter-pack pressures on the wolf population. This was ultimately counterproductive. When scientists documented the wolf killing behaviour, the public outcry led to a loss of local control over 
the situation and imposition of a governmental solution, which increased the local sense of loss of power and marginalization of the resource periphery.

The wolves' behaviour changed over time, often in response to human interventions. Typically, these interventions were counterproductive because the wolves adapted to the changes either biologically, behaviourally or both. Furthermore, they attracted an urban constituency to themselves in their own voices through the Algonquin and later the Bonnechere Public Wolf Howls. This made the situation qualitatively different that in eras past when the management discourse coalition (and earlier, the extirpation coalition) did not see wolf killing as problematic, and the general public was indifferent - the pro-protection coalition was tiny. The wolf howl likely shifted the 'silent majority' toward the protection coalition, which would help explain why the new protection regime extends only to the wolves of Algonquin Park and surrounding areas - wolves in the rest of the province are not protected, but managed as fur-bearers.

\subsection{Interactions and relationships}

During the 1957-63 Pimlott study, it was discovered that wolves could be induced to respond to recorded wolf howls and to human imitations. This technique was used to locate wolves and wolf packs, and to estimate their numbers (Theberge \& Falls, 1967). In 1962, park naturalists and interpreters decided to try to use this discovery to pilot a new educational program. An effort was made to create a public wolf howl - which might be repeated if there was enough interest on the part of visitors (Strickland, 2000). To the surprise of the park staff, hundreds of people showed up on the first night. This required an impromptu feat of organization and traffic control that has been polished to high art in the 50 years since - and public wolf howls can now accommodate more than 2,000 visitors in a 
open air amphitheatre for a slide show and talk about wolves and howling, followed by more than 800 vehicles departing the theatre to park, evenly spaced and centred on a pre-located wolf pack along the Park's major corridor. Once there park naturalists howl and hope for a response from the wolves - the events have had a more than $70 \%$ success rate over the decades. More than 120,000 people have shared this experience, and thus encounteredcognitively through the talk and viscerally through the actual wolves' howls - the Algonquin wolf in a personal way. Perhaps this experience has displaced earlier generations' fear and aversion of wolves. If so, it helps explain the intense interest aroused by the evidence of human killing of wolves outside the park that came to light in the early 1990s. Figures 9 and 10 are photographs from a wolf howl in 2009 which give a flavour of the sense of group engagement as well as the format of the two parts of the event (public talk followed by the howling event along the highway). 


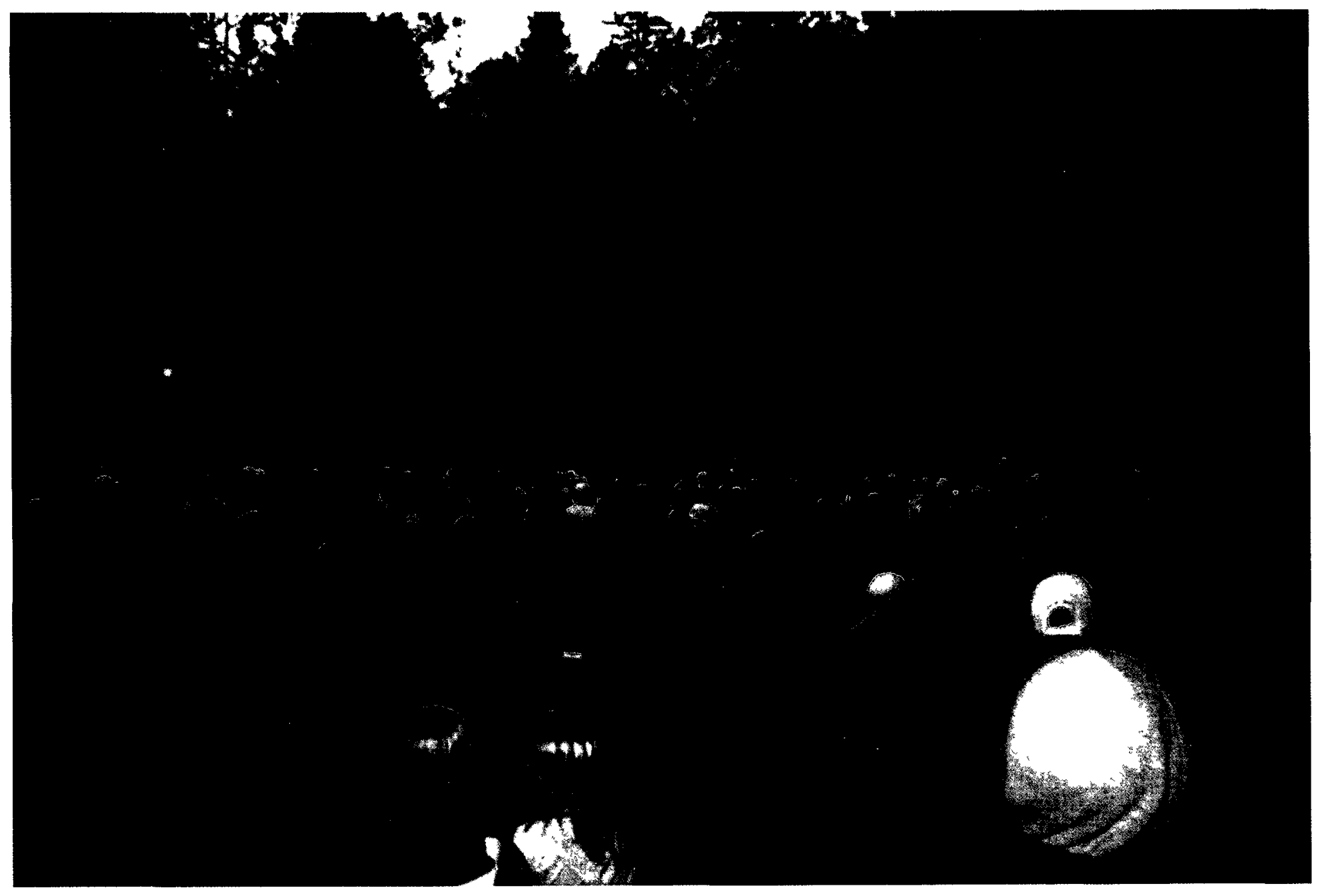

Figure 9: Visitors of all ages preparing for interpretive talk, Algonquin Park Public Wolf Howl, August 20, 2009. Photograph by John Wall 


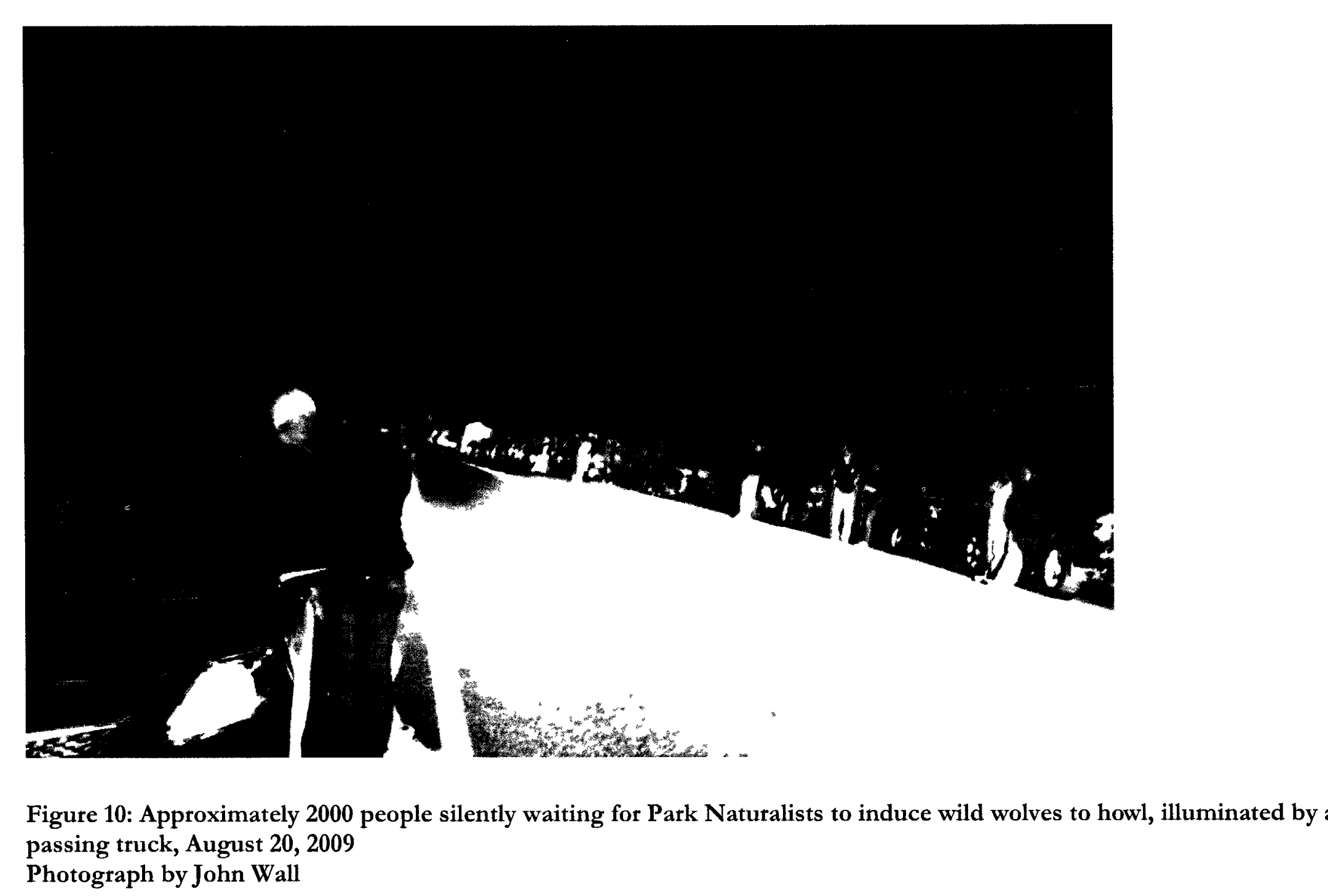


In 2000 a new wolf howl began based in Bonnechere Provincial Park, about $20 \mathrm{~km}$ east of Algonquin Park, very close the Round Lake Deer Yards, the focal point of the 1990s controversy. This was an important development in political and economic terms in the region. It also helps illustrate how this interpretative activity can help re-shape the relationship between people and wolves, and form a wolf constituency in the human population.

An official who was involved in the creation of the wolf howl reported an economic and relational change that emerged from this activity:

Informant I: one of the ways we were trying to offset (the loss of economic activity related to deer hunting that might occur due to the moratorium) was to look at what positive opportunities we could develop, and the wolf howl was part of that.... We also saw a bit of amazement from the outfitters, the lodgers, the people who provide accommodation, the local stores were kind of amazed, we were too, by the number of people that we would draw into the area... and drive to the middle of nowhere... to hear a wolf howl.... They actually saw some benefit as all these people were buying water and gas and all that neat stuff at the stores.

Interviewer: Do you have a sense of people's reaction... what did people come away from the event with? Informant I: It's actually quite impressive. I've never heard someone who's attended a wolf howl, and we have people from a really broad section of Ontario, I've never had anyone go away even if the wolves didn't howl...they still had a moving experience... To go into what they perceive to be the ultimate wilderness experience... to stand quietly in the pitch dark and listen to the sounds of night, whether we hear the wolf, or even the barn owl, it's still a moving experience. That's the feedback we've gotten from people. More importantly they go back and tell it to their friends and family...

Interviewer: Either through the passage of time or activities like the wolf howl, have you found attitudes shifting? What would you say is the state of public opinion or people's approach to wolves? 
Informant I: A couple of things have changed. The research ... was completed and they moved on, so the in-your-face irritant wasn't as much. Other issues have come up, downsizing, political and economic issues that have taken place in the community, and although I still think the diehard hunters would always complain about the reduction of hunting opportunities, overall in the community that's not a big issue any more and in many instances through the efforts of wolf howls and even some of the new initiatives around endangered species, the community is starting to create more of an awareness that we have wonderful resources in the community, but they're valued. So there's a little bit of a change in terms of seeing the landscape - it's not just a piece of property with some trees that we do forestry on, but there's other values that other people cherish, and there's economic opportunities out of that.

Asked about how the people reacted to the fears that emerged in the 1990s about the risk of increasing wolf populations, the informant reported that, "Overall people are comfortable with where things are. There are so many other issues on people's mind."

\subsection{Lifeways and livelihoods}

White-tailed deer are the major prey of eastern wolves in Algonquin Park and a combination of deer yarding tradition outside the park, conditioned by supplemental feeding, has influenced deer and wolf behaviour on a long term basis, and this is more evident on the east side than west side of the park.

OFAH's position on the wolf population in the early 2000 s was that the problem with wolf populations was forest succession toward old growth, and the declining quality of habitat for beaver and deer depressed their food sources. Increased logging near waterways would create better browse for deer and more suitable habitat for beavers, increasing the prey base. At the same time, the Algonquin Forestry Authority was under pressure by environmental groups (some of which were also active in the wolf debate) to reduce logging in the park, and the 2010-2020 management plan did reduce the area of the park to be 
logged and emphasized logging approaches that mimic natural forest processes. Given that the wolf population is holding steady after the moratorium, using forestry as a means to generate wolf habitat and prey does not appear to be a serious consideration.

Outside the park, insurance records do not suggest that livestock predation is on the increase since the end of hunting in townships outside the park. Some positive economic benefits have been seen from the Bonnechere Wolf Howl. Current research shows that young wolves are dispersing from natal packs elsewhere the region (personal communication, Informant $\mathrm{N}$ ), but it is not clear whether these populations are having an effect on human communities or economies - there is no reported spike in human-wildlife conflict that would suggest that this is the case, however.

\section{Prospects of co-existence}

The tensions that rode high in the early 1990s and led to residents' support of 'wolf shoot days' to counter protectionist efforts have passed. There is a simmering sense of rural alienation directed at the provincial government more so than at the wolves. There are still incidents of conflict but not at the scale predicted in 1993.

The hunting ban appears to have shifted wolf mortality on the eastem side of the park from mostly human caused to mostly natural. Only two prosecutions have been attempted for violations of the ban in the last five years. Most of the human-caused mortality now comes from automotive collisions.

In short, the situation appears to be moving toward more successful co-existence. Recent research disputes elements of the fears on both sides from the early 1990s, and the population structure and ecological integrity of the wolves appears to be improving. Human livelihoods appear not to be negatively affected, so future prospects appear positive. 


\section{People and right whales in the Bay of Fundy}

Many of the theories about the causes of ... reproductive failure (of North Atlantic right whales) bave to do with the proximity of right whales to the industrialized east coast of North America. Indeed, between shipping, fishing, ocean noise, (and) pollution... the coastal zone of eastern North America is one of the most urbanized pieces of ocean in the world. And right whales, many of which live within that rone for most of their lives, are thus a new phenomenon in the marine world - a truly urban whale. Scott Kraus and Rosalind Rolland, The Urban Whale, p. 4

\section{Introduction}

North Atlantic right whales (Eubalaena glacialis) are not creatures that thrive in human space. They mature and reproduce slowly, and are highly susceptible to noise, chemical and other disturbance. Yet their feeding and migration patterns require them to move slowly through busy shipping and fishing areas (Krauss \& Rolland, 2007). With a population of approximately 400 , they are one of the most endangered great whales. Given the fragile state of the right whale ${ }^{6}$ population, there is little debate on the need for protection. Thought and action on how that protection is to be effected, however, proceeds from a reductive and unidirectional view of human interference with right whale lives.

\footnotetext{
'I use the term 'right whale' to refer to North Atlantic right whales.
} 


\section{Case study}

\subsection{Context}

The Bay of Fundy is a dramatic region that features some of the world's highest tides and a unique ocean ecosystem. The bay's islands and surrounding watershed are home to more than 100,000 people and the bay supports a major fishing industry, an important port, industrial and petro-chemical centre at Saint John, and a significant tourist industry. The same richness and variety that supports commercially important marine species attracts thirteen species of marine mammal.

\subsubsection{A brief history}

The Bay of Fundy (figure 11) boasts an abundance of marine mammals and a rich and long-standing maritime culture, and a history of adaptation and renewal in the face of changing fisheries. The historical record of whaling as an industry thought to have reduced the whale population in the North Atlantic by as much as $90 \%$ from the period before European contact (Roman \& Palumbi, 2003), but there is remarkably little evidence of a whaling history in the Bay of Fundy. Reeves and Barto (1985) studied archival, government

and journalistic accounts of whaling in the Bay of Fundy beginning in the early $1700 \mathrm{~s}$. These included historic regional newspapers and records from the New Brunswick Museum, the Provincial Archives of New Brunswick, The Maine State Library in Augusta and libraries in Calais and Eastport, Maine. They also consulted area residents for observations and recollections. 


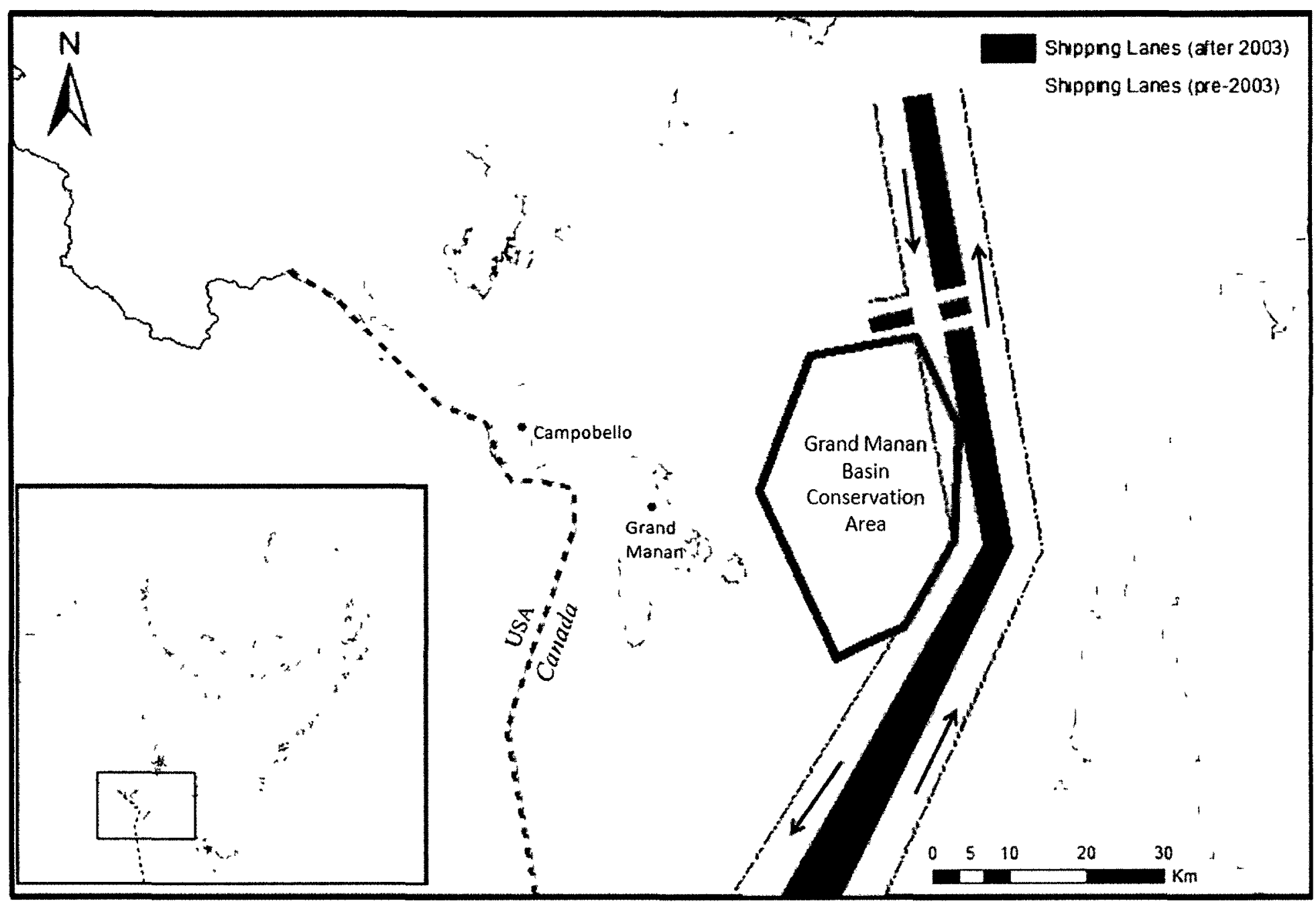

Figure 11: Bay of Fundy

Map by Christopher J. Czerwinski/John Wall. Shipping lane and conservation area data courtesy of the New England Aquarium. 
Reeves and Barto found numerous observations of whales present in the Bay and a record from 1859 of at least one whale (a humpback) that had returned to the area around Grand Manan every summer for more than twenty years. On industrial hunting, however, they found, "some hints that colonial whalers from New England visited the Bay of Fundy, at least occasionally, and that they caught right whales there" (p.15). An interview with an early settler recorded a right whale kill between 1771 and 1797 by 'Captain Folger of Nantucket'. They record that "on at least one occasion" in the 1760 s traders from Massachusetts "purchased a whale from local natives and tried out the oil" (p.15). Shipping, journalistic, and export records from the 1830 s to 1850 s show several ships 'fitting out' for long distance cruises exports of whale oil and whalebone (baleen) between 1839 and 1846 . The voyages were similar to the practice of industry leaders in Nantucket and New Bedford, who were whaling extensively in the South Pacific by this time. New England whaling, however, evolved from drift whaling (rendering washed up whales), to shore whaling, and only gradually became focused on deep sea voyaging. The fitting out of multi-year voyages from the Bay of Fundy when there were still local whales to exploit seems unusual. There is evidence that whales were still plentiful into the late $19^{\text {th }}$ century, with an attempt to start a shore whale fishery on Grand Manan in 1878, and media reports of whales and porpoises "sporting around the harbour nearly every day" (Eastport Sentinel, 1881, cited in Reeves and Barto, 1985, p.17). That this Grand Manan whale fishery failed is less likely due to lack of whales than the decline of whale oil as an industrial and household product.

By way of comparison, Nantucket had 151 whaling vessels before the start of the American revolution (Davis, Gallman, \& Gleiter, 1997a). While New Brunswick customs records show the export of 'small amounts' of whale oil, in New England 3.5 million gallons 
of sperm oil alone was entering US markets during the same pertod (1840s-50s) (Davis, et al , 1997a, p 346) Reeves and Barto's evidence shows that whule whaling was known to the region, it was a minor component of the regional economy, particularly in comparison to the herring fishery and sardine industry

In the historic records, species identification is extremely spotty Reeves and Barto often judge the species of whale mentioned in records by the amount of o1l it produced (a 70 barrel whale probably being a right whale) So whıle whales remained plentıful in the Bay into the 1880 s and beyond, it is entırely possible that night whales were very few This could be because of overhunting off the eastern seaboard Right whales were one of the first whales to recerve protection from commercial whalıng, in 1937, but by the 1950 s they were thought to be functionally extunct It could not be proven, but the thinking was that there might be a few individuals surviving in the North Atlantic that hadn't been spotted for some years (Krauss \& Rolland, 2007) By the mud-1950s Fundy residents reported whale sightings, including a pod of fifteen right whales spotted by a ferry crew, this report was "greeted with scepticism by certain members of the scientific community Right whales were so scarce at the time that a sighting of 15 seemed unlikely, especially in the Bay of Fundy, which was not one of the better-known former whaling grounds in the western North Atlantı" (Reeves \& Barto, 1985, p 14)

In The Urban Whale Kraus and Rolland state that the discovery of whales in the Bay of Fundy was an outcome of periodic research by the Woods Hole Oceanographic Institution that led to an aerial survey of the Bay in 1980 (funded by the US National Marine Fishery Service [NMFS] and conducted by the New England Aquarium) The survey found, "finback whales, minke whales, humpback whales, harbour porpoise, white-sided dolphıns, pilot whales, and to everyone's surprise, at least twenty-five right whales, including four 
mothers with calves. Some writers likened finding right whales in the Bay of Fundy to discovering a brontosaurus in the backyard, but the truth is that fishermen had been seeing the whales for years and simply did not understand the significance of these sightings. NMFS managers immediately grasped their importance...." (Krauss \& Rolland, 2007, p. 6). It was not only the rustics of the Bay who noted the whales' presence, but noted marine biologist D.E. Gaskin who published evidence in the Journal of the Fisheries Research Board of Canada (Arnold \& Gaskin, 1972). Rather less surprising than brontosauruses, the official history shows a pattem of clashing local and scientific knowledge, a theme that recurs through the subsequent story of whale protection and management.

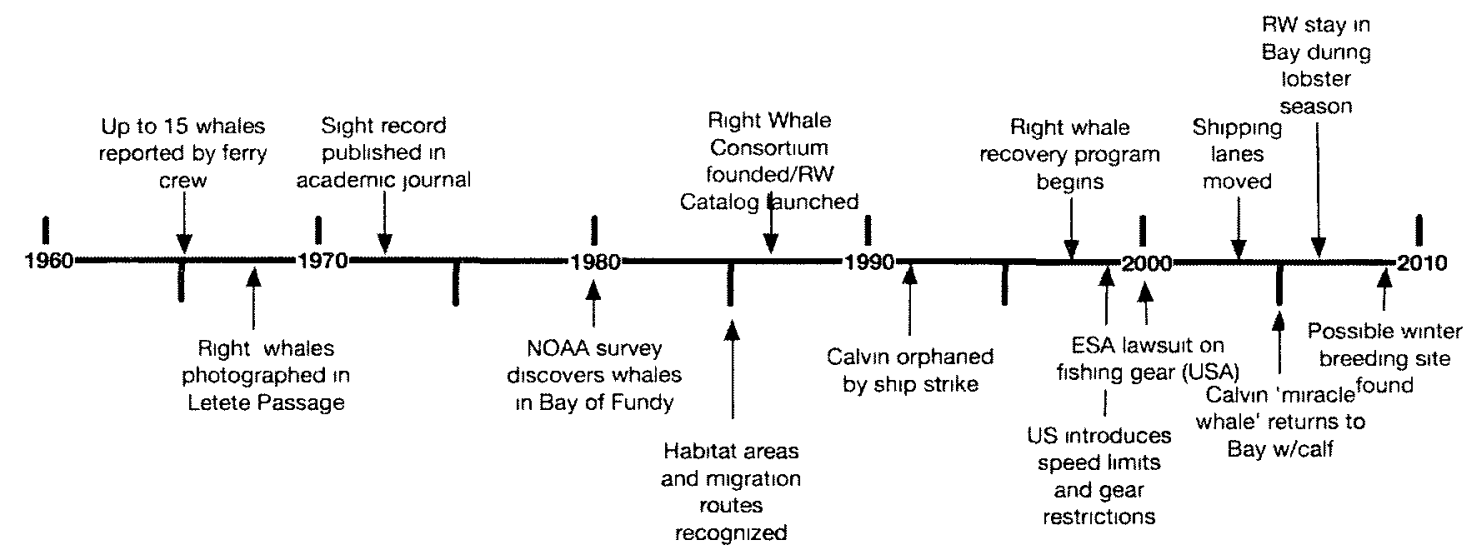

\section{Figure 12: Time line of right whale co-existence events 1960-2010}

Events moved rapidly in the 1980 s to establish a research program that would coordinate and share research, support decision-making in the NMFS and comply with the US Endangered Species Act. In 1991 NMFS published its first Right Whale Recovery Plan, which was followed by a voluntary Canadian recovery plan issued by the Right Whale Consortium in 2000. With the passage of the Species at Risk Act in 2003, the Government of Canada faced a series of requirements related to listing the species and preparing a recovery plan, which was completed in 2009 (M. Brown, et al., 2009). With the publication 
of this plan, the Department of Fisheries and Oceans took over responsibility for recovery from the previously existing and voluntary Right Whale Recovery Team, changing the relationships amongst fishers, conservationists, regulators and others who had been involved in the previous recovery process.

Citizen views of the whales and their protection within the study area (Campobello and Grand Manan Islands, Saint Andrews, Saint John) have been generally supportive, based on media reports and on interviews and site visits. The annual migration into the bay is typically covered by newspaper reports, including significant events noted earlier in the year, especially the number of new calves born each year, along with laudatory or alarming comments about baby booms and busts. The population estimates are tracked carefully in newspaper reports. A handful of regulators and scientists are reliable sources of quotes and current information, with some appearing several times each year.

In 2006 a change from the normal migration pattern brought co-existence tensions to a head. Typically right whales appear in Fundy waters around July and August, and they feed until mid- to late October when they begin their migration south. This is beneficial timing because the second Tuesday of November is "setting day", the beginning of lobster season in the bay. This period is thought to be significant in the timing of lobster migration from the shallow depths they frequent in summer and fall to the deeper water in which they winter. Missing this migration can be the difference between a profitable and unprofitable season. Most fishermen make the bulk of their lobster revenue in the first few weeks of the lobster season. The day has cultural significance and sees schools closed and all activity (particularly on Grand Manan) oriented toward launching the boats and setting lobster traps (Marshall, 2009). 
In 2006, the whales not only did not migrate out of the Bay in October, but also dispersed and were seen in regions in which they were not ordinarily noticed. While fishers from Campobello Island and especially Grand Manan were used to living with the whales and the attendant scientific and regulatory interest that attached to them, the mainland fishers were not and reacted strongly to suggestions that the season be moved or other changes be made to accommodate the whales. The Grand Manan Fisheries Association brokered a deal which introduced voluntary measures on the part of lobster fishers along with voluntary reporting of whale sightings, gear removal from areas where whales were sighted and aerial surveillance for whales, but maintained the traditional season. These events were significant because they illustrate the cooperative and voluntary approach to right whale management that contributes to recovery efforts. A similar dynamic can be seen among the members of the Right Whale Consortium, the former recovery team, and voluntary standards for whale watch operators in the Bay. It was an effort to head off significant change in the regulatory regime by voluntary means on the part of fishers. On the whales' part, it was said at the time that it was because of an abundance of food - "why leave when there's lots to eat?" as one regulator put it (Morris, 2006, p. A5). Also, local advocates argued that it was normal for some whales to be left in the area in November and that the government was over-reacting. Climate change and climactic fluctuations could also play a role however - the mid 2000s corresponded with a drop in the North Atlantic Oscillation Index (a climactic index of air pressure) which is thought to indicate change in upwelling and nutrient cycling in the North Atlantic, increasing food availability and reproductive capacity in right whales (Greene \& Pershing, 2004).

This event was significant because it expresses a signal concern of respondents in this study - not that whales are competitive or harmful beyond the level of a minor nuisance, 
but that regulatory action on the part of the government might have adverse effects on fishers without a corresponding benefit to whale conservation. This is arguably the case in the US, where the Endangered Species Act requires government officials to act to protect listed species. In 2000 there was a lawsuit against NMFS alleging that whale entanglement required a response from NMFS. The plaintiff won and NMFS introduced new regulations on whalesafe gear, even though it had not been proven that whalesafe gear (with sinking line, breakaway links) prevents entanglements. Since whales have been found trailing whalesafe gear, Canadian fishermen are worried that similar actions in order to 'do something' will cause them substantial costs, even though the costs of living with whales are minor overall. Figure 12 shows a timeline view of significant events in the case.

\subsection{Actors}

\subsubsection{North Atlantic right whale}

Whales capture the human imagination and crystallize questions of co-existence. Their size is part of the wonder (with average right whales weighing in at 60 tonnes and measuring 27 meters in length, see figure 13 for schematic diagram) but lying deeper is the intimate, intricate relationship between human society, cultures and industry and the fate of whale populations. Whales fuelled human enterprise for centuries. In Europe and North America their baleen filter plates, or whalebone, was an important industrial input in the $19^{\text {th }}$ century and earlier. Rendered blubber and other whale oil provided fuel, lighting and lubrication for enterprise and households and whales' usefulness and abundance shaped coastal whaling cultures as well as economic and social relations far from historic whaling grounds (Davis, Gallman, \& Gleiter, 1997b). As in other cases of commercially important wild resources, their contribution to human success correlated with their own decimation (Roman \& Palumbi, 2003). The recognition of this lopsided relationship and human 
culpability within it fostered the 'Save the Whales' campaigns of the 1960s and 70s, a harbinger of modern environmentalism (Cherfas, 1988).

\section{NORTH ATLANTIC RIGHT WHALE}
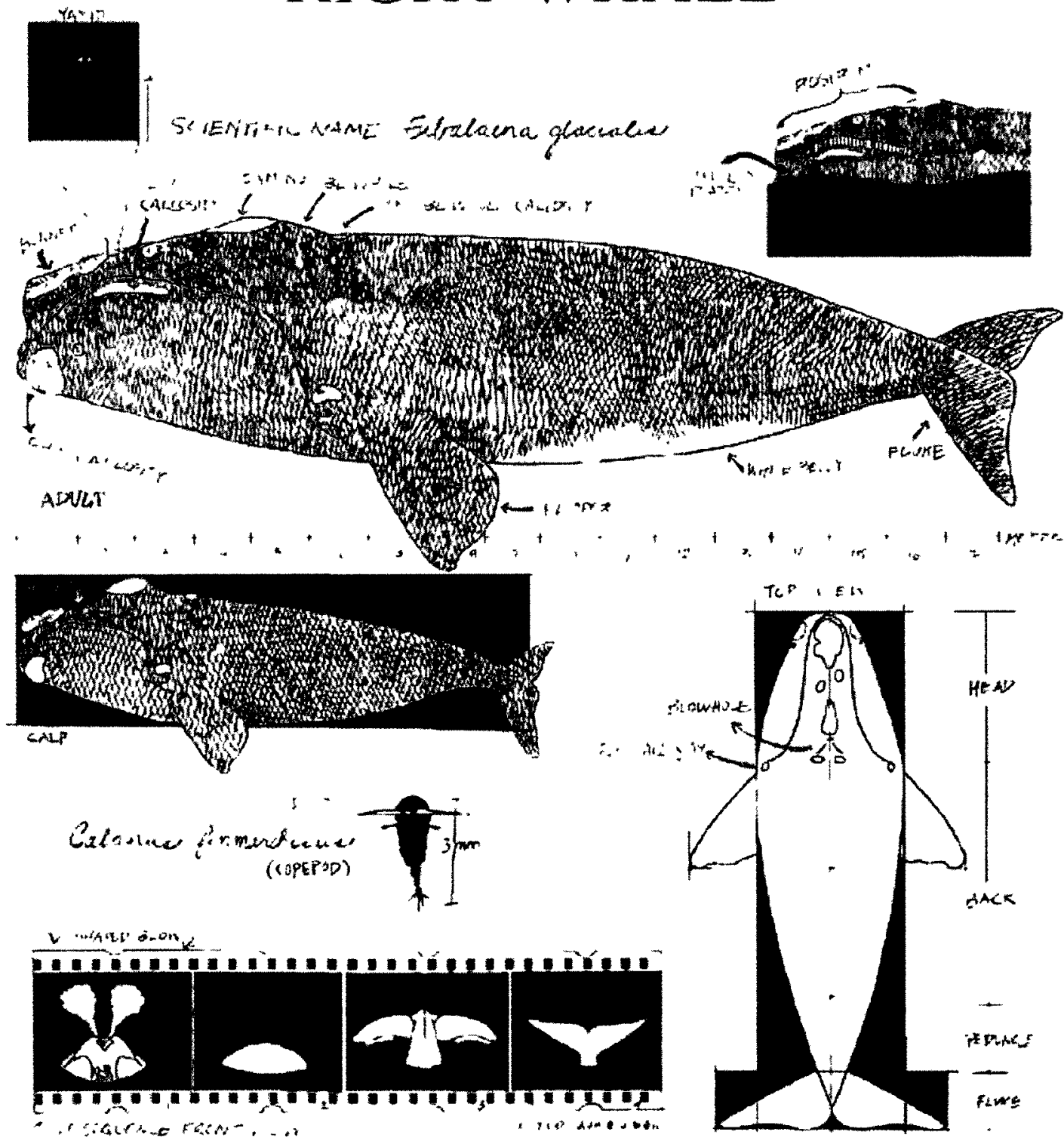

Figure 13: North Atlantic Right Whale Graphic courtesy of Daniela Weil 
Right whales are highly specialized to feed on copepods, they reproduce slowly and their range appears to be restricted to the eastern seaboard of North America. Whether all these traits are inherent and limited right whale populations since before human exploitation is questionable. Early estimates argued that right whales had large populations prior to Basque whaling in the North Atlantic, and the current low population is a remnant. Genetic research on whalebones recovered from ancient whaling sites suggests that right whales were not heavily hunted in the Basque era. Genetic analysis of living whales shows that they are descended from very few ancestors, perhaps 5 maternal lines and as few as 82 individuals. Was this 'bottleneck' prior to human exploitation or after? In either case, the species is rare there is a small population. This places it in danger of extinction. Canada's commitments to the Convention on Biological Diversity, Species at Risk legislation, and the expectation of citizens, is that biological rarity and political endangerment require a response, and as listed species under Canada's Species at Risk Act, a Recovery Plan (M. Brown, et al., 2009) and implementing action plans are required.

While the recovery plans review issues with fertility and biological limiting factors, there are two mechanisms of human-caused injury and mortality for right whales: ship strikes and entanglement in fishing gear (M. Brown, et al., 2009; NMFS, 2005). Diffuse human impacts like ocean noise and chemical contamination are harder to quantify and control, but direct action on the two direct problems could make a significant impact on species survival. Efforts are being made to reduce both entanglements and collisions. Up to $70 \%$ of the North Atlantic Right Whale population shows scarring from fishing gear.

Whether the whales learn to avoid fishing gear or to disentangle themselves is a difficult question to answer. The likely entanglement points include the mouth and around the fins and flippers. When the whale is feeding at depth, its wide set eyes, the darkness of 
the ocean and the high degree of ambient noise argues against the ability of the whale to see or otherwise perceive ropes floating in the water, either taut (as with sinking line) or floating (like standard polypropylene fishing ropes). Rather, it is most likely that they would take the rope into their mouths and it would catch on their baleen plates (personal communication, Informant B). Considering the length of the lines, up to 100 meters to connect a series of lobster pots, for example, and the excess length of buoy lines that must function over tides that rise and fall 20 meters, it is certain that a rope caught in the mouth would flow over the body and eventually around the extremities.

\subsubsection{Department of Fisheries and Oceans}

The Canadian Department of Fisheries and Oceans is a dominant presence in the lives of fishing families in the Bay of Fundy, with a mandate including fisheries management, marine habitat protection, aquaculture, and the coast guard. Like the state of the fishery itself, news of regulations, quotas, licensing changes, and works on public harbours are part of DFO's work and part of the daily discussion of fishers in all settings. The Minister of Fisheries and Oceans is also responsible under the Species at Risk Act for the recovery of marine species at risk, including the North Atlantic Right Whale.

Voluntary efforts to promote right whale conservation began in the 1980s when researchers from the New England Aquarium began routine work in the bay. This work evolved to include the Right Whale Consortium and the Right Whale Recovery Team, both of which include NGOs and research institutions, along with DFO and the US National Marine Fisheries Service. With the passage of SARA in 2003, DFO received legal responsibilities related to right whale protection and recovery and became more active in the area, ultimately dissolving the Right Whale Recovery Team (personal communication, Informant $\mathrm{B} \& \mathrm{O})$. 
Key activities of DFO in this research are commenting and interpreting sightings and events related to right whales, encouragement and provision of equipment to the Campobello Whale Rescue Team to ensure a disentanglement capability in Bay, research, and regulation/advice related to critical habitat areas for right whales which have helped with the establishment of marine protected areas in the Roseway Basin and Grand Manan Basin Conservation Area. DFO was consulted by Transport Canada and supported the eventual shift of shipping lanes to reduce the risk of ship strikes. The department has also taken on predominant responsibility for the Right Whale Recovery Plan, which had previously been more of a joint project with local interests, researchers and environmentalists.

In the 2006 case when right whales stayed in the bay into lobster season, DFO could have delayed the start of the lobster season and had to approve the fishers' voluntary plan to reduce the risk of entanglement. As it happened the department delayed the opening by one day due to bad weather, but this also gave the Grand Manan Fishermen's Association an extra day to prepare a mitigation plan. This dynamic goes to the heart of what fishers and other area residents fear in relation to right whale protection - not that the whales are dangerous in themselves, but that conservation action by DFO would disadvantage them, possibly for political or public image reasons, without necessarily helping whales.

\subsubsection{Fishermen}

Entanglement in fishing gear is one of the major threats to whales. With $70 \%$ of right whales showing scars, mostly from fishing gear, it is clear that individual whales are at risk. At the same time, an individual fisher is less likely to lose gear to an entanglement or to find a whale in his or her gear. As there many ways for a fisherman to lose gear, this is more of a theoretical risk and a cost of doing business that respondents in this study took in stride. 
In a December 2007 incident which was considered exemplary, a lobster fisherman saw a whale caught in his fishing gear and was concerned it was an endangered right whale. He called the Grand Manan's Fisherman's Association from his boat and the association staff notified DFO and the Campobello Whale Rescue Team. The whale was a humpback and not a right whale, and was safely released the following day. This was shown as an example of good communication, cooperation and rule-following that helped manage risks to whales (Gowan, 2007; personal communication, Informants P \& Q).

The Grand Manan Fishermen's Association took the lead in 2006 in making sure that the voluntary scheme for avoiding whale entanglements during the lobster season was accepted by DFO and it receives reports from fishermen on whale locations and problems. The Campobello Whale Rescue Team is made up of fishermen who volunteer to undertake the work and who receive training and equipment funded by DFO.

These organizations and other fishers and sailors that I spoke to in the research indicated that the presence of whales (and other mammals like dolphins and seals) indicate the Bay is healthy and clean and that it is important for everyone to do their part to keep the whales coming back. There is recognition that most of the endangered whales call the Bay home for part of the year and that this is a special attribute of the region.

\subsubsection{Shipping companies}

The Irving family and companies it controls are a dominant force in New Brunswick, with interests in media, forestry, agriculture, shipbuilding and shipping, and paper as well as oil (How \& Costello, 1993). Saint John is a major port and industrial city on the Bay of Fundy and many of the 800 ships that ply the bay each year are related to Irving's enterprises. 
As the dominant shipper in the region, Irving has a large stake in shipping regulations. However the company reports that in the 1990 s when they became aware of the plight of the whales they began to explore ways to decrease the threats their activities posed to the whales. This led to a partnership with the New England Aquarium, both to seek ways to minimize collision and help fund right whale research (Irving Oil, n.d.).

Early efforts to use audio monitors to track the whales or alarms to warn the whales away from ships proved unsuccessful - novel sounds like bells or alarms caused the whales to stop moving and to hover just below the surface to identify the sound. This would actually put the whales at greater risk of collision. By the early 2000 s, however, it was clear from analyzing whale sighting data that there was a high degree of overlap between the shipping lanes in the Bay and the area where whales feed most of the time (Taggart \& Vanderlaan, 2003). This led to a proposal ratified by the International Maritime Organization in 2003 that shifted the shipping lanes several kilometres toward Nova Scotia, away from the area of densest whale concentration. This change added four kilometres to the route that oil tankers take to reach the Saint John port and refinery. An Irving spokesman said, "they may get here a little later than they did before and they may miss the odd tide, but we look at this as a good thing to do for the whales and the right thing to do" (Trueman, 2002).

This proactive stance by Irving later helped them gain support from environmental organizations when they built a liquefied natural gas terminal in Saint John while the very same organizations were strongly opposing similar developments proposed by US industry in Passamaquoddy Bay (Brown, 2006).

\subsubsection{Researchers}

The researchers at New England Aquarium, Grand Manan Whale and Seabird Research Station, Center for Coastal Studies, and Dalhousie University are champions of 
human-right whale co-existence in the Bay of Fundy. These researchers fit Soulés (1985) concept of conservation biology as a crisis and mission-oriented discipline in applying their research to generate policy and practice change that promotes species survival. The shift of sea lanes is notable in that given the frequency of ship strikes in the Bay and the low number of whales extant, it was the long record of research, probabilistic analysis, and collaborative effort with industry, fishermen and regulators that enabled the shipping change. In today's combative public discourse of science, this statistics-based approach could easily have been criticized and undermined by industry (as was attempted by the Fraser Institute in the bear case); instead the various stakeholders met in a collaborative way. Media coverage was very positive.

Because of the low number of right whales and long history of continuous research, there is a remarkable research resource called the Right Whale Catalog, overseen by the Right Whale Consortium and managed by the New England Aquarium. Since right whales can be identified by the individual callosities on their heads, backs and chins, as well as other distinctive body parts, sightings of whales can be recorded in this catalogue and detailed life histories, including range, breeding and mortality can be developed and shared between researchers (New England Aquarium, 2011).

The researchers involved with right whales are frequently quoted in media articles and interpret sightings, birth and death rates and significant events each year. Articles about the whales typically include at least a paragraph of general information about the whales, their biology, status or other general information that promotes public awareness.

\subsubsection{Liquefied natural gas proponents}

Beginning in the mid-2000s three initiatives were launched to build liquefied natural gas (LNG) facilities in northern Maine. Downeast LNG, Quoddy Bay LNG and Calais LNG 
have all proposed receiving piers, holding tanks and pipeline works to permit the import of natural gas that has been cooled to $-160^{\circ} \mathrm{C}$ from the international market to the plant by ship. The liquid can then be stored, evaporated back into gaseous form, and piped to commercial and residential customers.

Many area residents are concemed about the industrial activity and especially shipping the product through the Head Harbour Passage, a narrow seaway from the Bay of Fundy to Passamaquoddy Bay and the St. Croix River. Whereas the approach to Saint John includes a direct route from the outer Bay of Fundy, and since 2003, avoids the Grand Manan Basin Conservation area, the Head Harbour route includes a whirlpool and extreme currents, and lacks the infrastructure and navigation systems of the Saint John harbour. Canada has indicated its intention to block LNG tankers from the passage over US objections that the route is through international waters.

While the project proponents argue that the initiatives are safe for people and whales, local fishing, tourism and aquaculture interests are working to stifle the efforts. The presence of the right whale and the critical habitat areas figure heavily in the debate.

\subsubsection{Environmentalists}

Environmental organizations that have been active in the area include World Wildlife Fund (WWF), Sierra Club, International Fund for Animal Welfare (IFAW), and the Conservation Council of New Brunswick. These organizations are active in some cases in doing or funding research, and in advocating for protective measures for the right whale. Several NGOs are members of the Right Whale Consortium and Right Whale Recovery Team, and thereby engaged in policy proposals. In this case the requirement for protection is consensual and although there is debate over the means of protection, the differences are 
limited. The positions of the environmental groups on proposed action therefore has a lot of common ground.

\subsection{Key events}

\subsubsection{SARA and recovery plan}

The first Right Whale Recovery Plan was issued in 1991 by NMFS, followed by a voluntary Canadian recovery plan issued by the Right Whale Consortium in 2000. With the passage of the Species at Risk Act in 2003, the Government of Canada through the Department of Fisheries and Oceans took over responsibility for recovery from the previously existing and voluntary Right Whale Recovery Team. This changed the relationships amongst fishers, conservationists, regulators and others who had been involved in the previous recovery process and shifted the situation from a voluntary one to a regulatory one. The results of this change and a possible shift of goodwill based on DFO's involvement (the fisheries regulator being a sometimes antagonist of local fishers) remain to be seen.

Media reports, my interviews and site visits indicate that area residents are supportive of the whales and their protection.

\subsubsection{The whalesafe gear lawsuit}

This event was significant because it expresses a signal concern of respondents in this study - not that whales are competitive or harmful beyond the level of a minor nuisance, but that regulatory action on the part of the government might have adverse effects on fishers without a corresponding benefit to whale conservation. This is arguably the case in the US, where the Endangered Species Act requires government officials to act to protect listed species. The 2000 lawsuit against NMFS alleging that whale entanglement required a 
response from NMFS was the case that led to new regulations in this area, which is causing "well-founded" concern among Canadian fishers that ineffective but expensive regulations might be imposed by DFO (personal communication, Informants B, P, \& R).

\subsection{Outcomes}

\subsubsection{Positive population trends}

Although right whales are still the most endangered great whale, their trajectory has shifted. In the 1950 s right whales were thought to be functionally extinct already. No one can know whether the whales were quietly travelling the eastern seaboard and into the Bay of Fundy throughout the twentieth century and were unnoticed until comprehensive surveying began or whether the population had grown over the decades from near extinction to observable densities during that period. The worst year on record for right whale births was 1999 when the calving interval for right whale mothers had lengthened from an average of three years to five; 2008 saw a baby boom, with more than 30 whales born, far above average births of 11 . Research is underway on food conditions, climate change and demographics that may affect the birth rate. Changes in shipping and fishing regulations may have likely made a difference and are positively affecting survival rates.

\section{Data analysis}

\subsection{Data sources}

This case was based on a review of 94 newspaper articles published in the New Brunswick Telegraph-Journal between 2001 and 2009, six long interviews with fishermen, scientists and NGO representatives, and four days of site visits, whale watching trips and informal discussions with fishermen and residents of Grand Manan and Campobello Island. 
The interviews were transcribed and, like the newspaper articles, entered into TAMSAnalyzer for coding and analysis. The informal discussions took place over several hours each day on wharves and boats and were not conducive to recording. For these sources I took detailed notes and referred to them in the process of analyzing and writing up the research.

\subsection{Action themes}

The action landscape in this case consists primarily of incidental harm from otherwise intended actions, and protective efforts to protect the right whales' population. There is a heavy research focus in the case, with new knowledge about the health, risks and demographics of the whale population relatively quickly finding its way into policy and regulatory change. Table 11 is an actor/action matrix that reviews the action themes in the case. 
Table 11: Whale case actor/action matrix

\section{Adaptive}

\section{Protective}

\section{Compromise}

New England Aquarium

Department of

Fisheries and Oceans

\section{Grand Manan Whale \\ and Seabird Research \\ Station \\ Center for Coastal \\ Studies}

Irving Oil

Reduce

speeds,

support

shipping

changes

\section{National Marine}

Fisheries Service

International Fund for

\section{Animal Welfare}

\section{Transport Canada}

\author{
Investigate harm to \\ whales/MMR violations; \\ fund and regulate \\ disentanglement; test \\ whalesafe gear; \\ implement recovery \\ strategy
}

Outreach to area

fishermen

\section{Disentangle whales}

Support shift of

shipping lanes

Disentangle whales;

recovery plan; regulate

shipping; require

whalesafe gear

Fund disentanglement
Regulate fishing

gear/fisheries; oversee

take reduction (2006

season)

Increase shipping
Destructive

Policy Change

apply for shipping changes; drafted recovery plan

Fail to monitor fishing gear impacts (grey zone)
Support shipping

changes
Sightings,

identification

Funding research

Funding

research/retracting

funding; monitoring mortality

Acoustic monitoring 


\section{Campobello Whale \\ Rescue Team}

\section{National Oceanic and}

Atmospheric

Administration

Woods Hole

Oceanographic

Institution

Canadian Coast Guard

\section{Sierra Club}

\section{Dalhousie University}

International Maritime

Organization

US Navy

Grand Manan

Fishermen's

Association

\section{Disentangle whales}

Regulate fishing gear; shipping restrictions

Monitor during incidents

landscape/seascape

change in region;

citizen whale

monitoring (NA-wide)

Population, ecology, avoid entanglements; ship strikes
Ocean

noise/destructive sonar
Encourage Hotline, voluntary take

reporting/disentangleme reduction efforts 
Separation between people and whales is not a factor in the case because of the nature of marine space. The effort is generally to moderate the influence of those actors that introduce the most risk to whales, namely ships through collisions and fishers through gear entanglements. These are areas in which there is little incentive for any individual to change, but a benefit if all the actors change, suggesting a regulatory role. Alternatively, a public and demonstrable volunteer effort can be effective. This can be seen in the voluntary acceptance of the Roseway Basin feeding area as an "Area to Avoid" for mariners; and in the Grand Manan Fisheries Association voluntary mitigation plan which they offered as an alternative to delaying the lobster season in 2006 . The key here is that even if the actions are voluntary, they are done collectively, maximizing the benefit and reducing the risk of 'free riders'.

\subsection{Discourse themes}

The discursive environment in this case is very simple. The endangered status of the whales is incontrovertible since there is a nearly complete record of each whale, a life history for most of them, and they can often be identified by sight by trained observers. This is very different from the wolf case, in which questions of species and endangerment made up a major thread in the discourse. The whales do not represent a danger to humans, and the range of direct interaction is very limited compared to the ways humans can connect with bears. The number of discursive voices is small compared to the other cases - organizations are informing the public, lobbying for protective action, and liaising or pressuring the Department of Fisheries and Oceans to act. Table 12 summarizes the actors and discourse themes in the case. 
Table 12: Whale case actor/discourse matrix

\section{Informing}

New England Aquarium

Department of Fisheries and Oceans

Grand Manan Whale and Seabird Research Station Irving Oil

International Fund for Animal Welfare

Conservation Council of New Brunswick

\section{Sierra Club}

Pro-protection Advocacy

Whale biology and demographics; Individual whale stories; mortality; interpret sightings/events; threats to whales; whale habitat; migration patterns

Interpret sightings and events

Interpret sightings and events

Public awareness/support museum events

Threats to whales
Restrict development Lobby against US LNG

Hajer's (1993) discourse coalitions are groups of actors that coalesce on a common storyline, and one storyline will become a hegemonic one - it will become the basis for policy and a frame through which events in question are seen. However, in the whale case there is only one storyline and only one discourse coalition. The status of the whale is accepted. There are differences of opinion about the utility of whalesafe gear. Sometimes the scientific community advocates protection measures that the fishermen do not accept (the overlap between whale presence and the lobster season in 2006 brought this to the fore) but the fishermen do not contradict the need for protection measures in general.

\section{Processes of co-existence}

\subsection{Shared space}

The interaction of area residents with whales operates in multiple types of space. In physical space, there is there is a situation of proximity - the whales are neighbours and 
transit fishing areas, shipping lanes and fishing gear In recent years changes in fish stocks and markets have seen inshore and mobile gear shift to offshore locations and fixed gear This has meant, on one hand, that gear is being set in deeper water that 1 more likely to be occupied by right whales At the same tume the amount and type of gear are less likely to entangle whales because they have fewer lines and less slack rope in the water Whale watchers seek proximity (within the bounds of a voluntary code of conduct for tourist boats) and the fishers practice avoidance

In social space, the avordance efforts produce and reproduce the sentiments of nuisance mentioned above However, many fishers and fishery associations invest time in voluntary activities (including the whale rescue team, federal consultations and voluntary mitigation measures)

Actual interactions between human and whale neighbours are through ship strikes and fishing gear entanglement I heard stories of whales drowned by ship captains who would not release them from nets in order to preserve the ratch, and of catches lost in order to save the whales (this latter is also recorded in two different instances by medıa reports in the 1990s) ${ }^{7}$ Media reports include experıments and competitıons to design gear, warning systems or introduce new technology that might reduce the risks of entanglement

This language of entanglement literally refers to the entanglement of the whales and the gear, but it could equally describe the ways in which the future of the fishers is intertwined with regulation, risk to whales, and the legal requirements of recovery actions by government

\footnotetext{
7 The examples cited in the media included lowering herring weirs to permit enclosed whales to escape This is a very significant act on the part of the fishers as one 'big haul' in a herring weir can "make a season" and the financial implications of missing a haul can be extremely serious
} 
The other notable interaction between humans and whales is through collisions. Seven ship-struck carcasses were documented between 2001 and 2005, and the record since 1991 has included one or two right whale deaths from ship-strike each year, but the number could be higher than documented (Knowlton \& Brown, 2007). As mentioned above, in 2003 the Bay of Fundy Traffic Separation Scheme was altered to move the shipping lanes about 4 nautical miles landward, keeping heavy shipping outside of the main area of whale feeding in the Grand Manan basin. There have been no collisions in the Bay since that time (which is not evidence of causation, but a positive development nonetheless) (personal communication, Informant R).

The creation of shipping lanes, like the creation of fishing areas and setting speed limits and quotas based on them, is a cogent example of the socialization of marine space. These impositions of mental or abstract space on the physical surface of the ocean represent both the rationalization of a lived space, typical of state efforts to make space legible and governable (Scott, 1998). The legal change accomplished by shifting the lanes had an impact on the behaviour of ships and most likely on the well-being of whales, an illustration of the mutual influence and interpenetrations of different types of space.

\subsection{Interactions}

The comings and goings of the whales in the Bay of Fundy, and right whales in particular, are in the regional news annually. For the people of Grand Manan in particular, these visitors are a seasonal marker, a tourist attraction and one of many elements that make the island unique. A fisher family outing by boat or a picnic at Swallowtail Head on the north end of the island to watch the whales is not at all unusual - the whales are an exciting and interesting aspect of the seascape, even for people who are often exposed to them. 
For visitors to the region, whale watching is possibly more special. Within the focal area of this study, there are eight whale watching companies and the right whale in particular is a draw for tourists. While humpbacks and fin whales are more numerous and in the area for longer than the right whales, the possibility of seeing the larger and more endangered right whale is a constant draw.

Other than this type of touring, the nature of marine space does not generate personal contacts or interaction the way that the other species in this research can (of course the contacts with artefacts - ships and fishing gear are very much part of the context).

\subsection{Relationships}

The human relationships among those interested right whales are very interesting in the often contentious world of wildlife management practices. In research, the Right Whale Consortium collects, analyses and shares data among the right whale research community. Whereas researchers are often proprietary about their research, the work of the consortium helps ensure that new research builds on existing work and answers questions that have been identified by practitioners (personal communication, Informant $\mathrm{R}$ ).

In the tourist field, the whale watch operators (who are less cooperative with each other than the researchers) (personal communication, Informant B) have created a voluntary code of conduct with regards to protecting the whales from harassment. Fishermen (under duress) prepared a risk mitigation plan to avoid unwanted regulatory change by DFO. All these elements suggest an unusual degree of cooperation in this case.

As far as relationships with whales go, there are individual connections mediated by expert commentators. For example, when Calvin, a whale that had been orphaned and was thought dead in 1992 returned to the Bay of Fundy in 2005 with a calf, it was a media feature 
for many weeks (Trueman, 2005a, 2005b, 2005c, 2005d). In 2001 the plight of Churchill, a heavily entangled male who was nearing death, and the efforts of rescuers to disentangle him similarly captured public attention ("Entangled right whale rescue fails, called off," 2001; Rescue of entangled right whale set for today," 2001; Urquhart, 2001; Whale rescue fogged in," 2001; Wheaton, 2001). This individuation helps focus and reify general concerns about the species.

At the same time, there is a strong sense of identification with the species and its status as highly endangered. While the whales are physically distant from most residents of the region, they are also an important part of the geographic imaginary of the region as a special marine space.

\subsection{Lifeways and liveliboods}

The specialization of the right whale in feeding on copepods brings the whale directly into contact and conflict with fishers and shipping on the eastern seaboard, some of the busiest waterways in the world. The efforts that it takes to protect the species have a real impact on human livelihoods. Moving shipping lanes and slowing ships for conservation reasons in the Bay of Fundy has been less problematic than elsewhere in the whale's range. For example, the whales ordinarily transit along the north-south axis, but shipping into the major Atlantic ports (such as Boston, Philadelphia, New York, Baltimore, Norfolk and others) travel on the east-west axis. A series of warning systems, areas to avoid and communications during migration periods attempts to mitigate the risks but they are continuing and real. In the USA fishermen have had to expensively refit their fishing gear, but there are still questions about the effectiveness of this strategy. Keeping fishing gear out 
of heavy feeding areas can lead to concentrations of gear outside those areas, which are a threat to whales when they are migrating.

The net result is a clash in which whale lifeways and human livelihoods are often in opposition.

\section{Prospects of co-existence}

What processes of space-making in the sense of creating possible futures prevail in the human-right whale relationship? For thirty years conservation-minded researchers have pursued a scientific and a protective mission, as one respondent put it, "everyone wants to see the right whale survive" (personal communication, Informant $\mathrm{R}$ ). This first principle has enabled a collaborative approach to sharing research that is not common in many areas of study. Researchers have directed their efforts to transportation authorities in their respective countries and multilaterally, shifting shipping lanes to reduce collisions. These are voluntary, institutionally innovative efforts that have increased knowledge and reduced threats to whales.

Fishermen have also made contributions to right whale survival. The Campobello Whale Rescue Team does, on a largely volunteer basis, dangerous disentanglement work that is government-financed in the USA. This takes a commitment of time, money and no small personal risk. What motivates this giving? As one respondent put it, "I spent my whole life making a living out of the sea. I see this as a way that I can give something back" (personal communication, Informant S). This is a profound statement of relationship that is instantiated on particular whales in particular spaces and times, when humans intervene to release and protect whales that have been entangled in human systems. 
One of the realities in this system is that DFO is mandated by law to develop and implement a recovery plan for the right whale. This plan has been written and is now awaiting a companion action plan. In fact the bulk of the plan was in place as a voluntary creation of conservationists and the Right Whale Consortium nearly a decade ago. Under the legislative framework of the Species at Risk Act, DFO published the Recovery Plan to meet the requirements of the act and took responsibility for it, dissolving the Right Whale Recovery Team that had been in place previously. This type of 'space invasion' by regulators is a central fear of fishermen and conservationists alike.

Canadian fishermen read the same media and in some cases fish immediately adjacent to US fishermen. They have a history of seeing fishery regulations that they believe are ill-thought-out or even counter-productive. They are concerned that they would be legislated to change their practices and particularly to shift to whalesafe gear primarily due to 'optics' the need for political leaders to be seen to act instead of sound principles. Voluntary efforts are made (as they were in 2006) in order to prevent regulations, but the spectre of arbitrary regulation hangs over individual relationships with the sea and with the whales. How this coercive power sits with the voluntary, relational action that preceded the publication of the Recovery Plan remains to be seen, but it is possible that coercion will be corrosive and actually reduce the space for alternative futures and positive co-existence, exactly counter-productive to the stated goal.

While Bruce Braun (2008) argues that the shift from studies of nature in geography as a distinct object has been supplanted by a subtler, more sophisticated understanding of relational ontologies, questions of how this understanding can be deployed in cases of ecological trauma remain. The multiplicity of space is evident in the story of North Atlantic right whales. Topology and hydrology, the biology of copepods and whales, the disciplining 
of space with fishing zones and shipping lanes and the social and economic spaces of humans do not sit here as layers, but co-create, interpenetrate and swirl. How does recognizing the agency of whales within a network of biological constraints, spatial abstractions, and the legal and economic systems help address possible futures for right whales and people on the Atlantic coast?

One way is the recognition that the scientific and legal frameworks that have been established by US and Canadian authorities are actually sub-systems of human-whale coexistence. The whale sighting information, statistical analysis, and proposals to shift the shipping lanes were facilitated and coordinated by extensive social networks of trust and accommodation developed over many years. Furthermore, the scientists involved recognize their own relationality - to study this species is also to protect them, a situation that does not necessarily prevail in other research settings on other species.

Beyond this, how fishermen and whale watchers relate to whales is an important factor. This is more than mere interaction, because the actors are transformed through their engagement - an example of relationality. Before 2003's passage of Species at Risk Act and 2009's official Recovery Plan, species recovery consultation and planning was underway funded by government and NGO contributions and voluntary participation by researchers, fishermen, fisheries associations and conservationists. This was not generally done because of legal coercion, but because people in these diverse organizations had adopted right whale survival as an interest and desire, and sometimes to forestall more drastic imposition of state authority. At some level, the moral community had been extended to right whales and the result was social process and action to protect them. That whale populations have swung upward instead of downward illustrates the presence of possibility within the whale survival scenario - space for a future of positive co-existence. 
As the right whale conservation context shifts and becomes fully incorporated in the Species at Risk Act process, what are the likely effects on these relations? 'The institutional processes of a bureaucracy favour the abstraction of space for legibility and control (Scott, 1998). The legal framework of SARA requires this abstraction for the definition of critical habitat and action to protect it. In the US, similar requirements have led to regulatory frameworks for shipping and fishing to reduce anthropogenic harm to whales. Canadian fishermen feel that this type of regulations can be ineffective and even counterproductive, opening the possibility that resentment toward the Department of Fisheries and Oceans could be directed toward conservation efforts including specific species that trigger higher levels of regulation (such as the right whale). This would undermine support for relationship and moral consideration. This resentment is present, although dispersed, based on general issues of living a regulated life, DFO's participation in reallocating boats and licenses from established fishers to aboriginal communities, and the loss of several species of commercial fish in recent decades. So while fishers have been supportive of whale conservation in principle, this good will, like the species itself, is at risk. 


\section{Moving toward spaces of co-existence}

We now know that there is not one space and one time only, but that there are as many spaces and times as there are subjects, as each subject is contained by its own environment which possesses its own space

and time.

Jacob von Uexkull, Theoretical Biology, 1920, cited in (Kohl \& Kohl, 1977, p. 11)

The concluding chapter revisits each of the cases in summary and develops a crosscase analysis of their significant elements. This provides the basis for a theory-building exercise to elaborate a theory of co-existence that can transcend the present cases and inform other situations of shared space.

\section{Summary of the study}

Humans have profoundly transformed the planet, and this transformation is reflected in a dramatic loss of biodiversity in recent years. Although extinction is part of the process of evolution and the planet has experienced major extinction episodes over geological time, the current extinction is being driven by habitat loss due to human conversion of landscapes, overexploitation of biotic resources, and habitat degradation as a side effect of human activity.

Over the past 150 years, the loss of species has been recognized as a threat and humans have taken action to try to protect species from extinction. Unfortunately, even as a consolidation of indices of biodiversity protection indicates that efforts have increased by 40 times in 40 years, the state of the earth's biodiversity has declined by $20 \%$ over the same period (Butchart, et al., 2010). Species that thrive in these conditions are synanthropes, those 
who benefit from human disturbances or who can use human habitats or food sources to improve their reproductive and survival success. The majority of species that come into contact with humans do not meet these conditions and so we are increasingly living in a world in which non-humans survive by human forbearance - only by consumptive restraint or human effort can most non-human species thrive.

This is likely to continue to be the case and to become even more prevalent in the face of growing human populations and increasing attention to meeting basic human needs. Therefore, an understanding of the processes of co-existence, the actions that people and other species take in order to adapt successfully to each other, is vital to stemming biodiversity loss. This study was designed to explore the processes of co-existence in three cases and so consider the prospects of co-existence in the future.

\subsection{People and grizzly bears}

The Bow Valley of Alberta is home to Canada's oldest national park and its most extensive network of parks. Early in its development, coal mining, logging and other extractive activities were included in the parks' management regime. Canmore, Alberta, was one of the communities outside the parks that developed a robust economy based on coal mining. It was also one of the few that succeeded after mining ceased to be profitable in the 1970s. Canmore supported a population of approximately 1,000 in 1979 when the last coal mine closed. In 2006 the permanent population was more than 11,000 with an additional estimated 5,000 seasonal residents. This population growth was spurred largely by recreational and lifestyle population growth in the closest community to Banff without restrictive land ownership and use policies. Combined with the explosive growth of income and economic activity in nearby Calgary, this led to a massive increase in property 
development in the region Furthermore, beginning in the 1980s, private developers and provincial authorities turned their sites to Kananaskis Country, south of the federal Rocky Mountains Parks chain of national parks, as a region for environmental protection and recreational development through the establishment of a set of provincial parks, including a region of commercial development to provide an alternative to the established centres at Banff and Lake Louse

In addition to the influx of residents, the Bow Valley region attracts large numbers of visitors (over 25 million per year) and is the only pass through the contunental divide for approximately 200 kilometres in either direction, which makes it an essential transit way for rail and road traffic, as well as wildlife migration It is an intensely used, multr-modal, linear space and supports human actrvity in place and elsewhere through the transportation network Similarly, wildlife depends on the valley bottom as habitat and a migration corridor It is a space of mixed meaning, uses, and pressures By the mid-1980s the Alberta government had approved developments on the north side of the Bow Ruver, in an area divided from the existing core of Canmore by the Trans-Canada Highway A wildlife study was done at the time and recommended a buffer zone that would protect migration routes and reduce human-wldlife conflict Subsequently similar developments were placed or recommended for the south side of the river Golf courses were included in the developments In conjunction with recreational trails, green space and open garbage collection in the town, the golf courses not only became a target area for bears, but the human settlement actually began to attract bears into areas that were not previously frequented This complicated the earlier recommendations for corridors that were more suitable for ungulates - bears were not much considered Even the planned corridors faced compromises Recreational space such as trails and golf courses were included in the 
corridors with the thought that these land uses would be compatible with wildlife habitat. However, bears that were habituated to human presence in these "human-spaces" tended to become problem bears by frequenting other (non-approved) human spaces. Therefore bears that lived on the golf courses tended to be killed as problem animals. Finally, bears that were challenged by co-existence with larger more dominant bears (which tend to avoid human settlements) tended to infiltrate the human spaces more frequently as a way of avoiding bearon-bear conflict. This was a combination of influences that exacerbated existing problems.

In 2005 a runner was killed on a trail above a golf course by a young, unpredictable bear that had been relocated the previous week after making unusual contacts with several people. The bear returned to the area, was hazed off of the golf course and attacked three runners who were running on a trail. This trail had been marked as closed for several months, but there was no context for the risk posed by the closure. The group encountered a wildlife official tracking the bear, but did not get any warning that a dangerous bear was in the area. This was in keeping with provincial practice of not publicizing bear locations to avoid attracting sightseers or spreading panic. However this led to the three runners encountering the bear that may have been confused or angry after being confronted with noisemakers and water hoses on the nearby golf course. Two of the runners turned back and the third, Isabelle Dubé, attempted to climb a tree to escape the bear. The bear climbed the tree after her (generally thought not be possible for an adult grizzly but documented in a few cases) and she may have been pulled or fallen from the tree during the attack.

As a well-known and well-liked teacher and outdoorsperson, Dubé's death caused an outpouring of grief and concern. The complicating factors of the bear's recent history, the uncertain status of the trail closure and the lack of information about the problem bear inflamed the concerns and heightened tensions between residents, environmentalists and 
development advocates. In time, this tension was partially resolved by roundtable meetings that brought these different interests together and led to the formation of Bow Valley WildSmart, a partnership of local organizations and municipalities, with federal and provincial project funding, to communicate about living with grizzly bears, cougars and elk, including information on reducing human-wildlife conflict. The municipality had also introduced a closed garbage collection system that prevented bear scavenging, and the provincial government's Sustainable Resource Development authority began strategically removing bear food (especially buffalo berry) from areas that are used by humans. Although these actions have reduced human-bear contact and conflict (although statistics for avoided conflict or harm to people are limited due to the low number of incidents), current real estate development plans on the south side of the river continue to contemplate development in what had been designated as a wildlife corridor.

\subsection{People and eastern wolves}

The wolves in eastern Ontario had been persecuted for many years, and fell under perhaps the loosest management arrangements for wolves in North America before a new provincial policy was implemented in 2005 (Hayes \& Gunson, 1995; Ontario, 2005). The largest industry in the Upper Ottawa Valley is logging and the sawmill industry. Algonquin Park is the primary source of high-value timber. At the same time, limitations and management placed on the park and the environmental lobbying related to the park are something of an irritant in the region. These tensions are amplifications of a more general and ongoing tension between Valley residents and what they perceive to be generic outsiders. Locally this is referred to as a rural-urban divide, with rural residents feeling maligned publicly and ignored politically. 
Deer hunting is an significant cultural and subsistence activity in the region. Some informants linked this to a cultural aversion toward wolves, who also depend on the deer for food. In addition to the logging, agriculture is important and the land is somewhat marginal for agriculture. This means that predation may be perceived as taking a relatively heavier toll than elsewhere in the province (even though numbers judged from predation insurance claims do not illustrate this in absolute terms) and heavily forested and protected regions like the park might be seen as a source of predation and a threat to culture and livelihood.

People intervene in the region, shaping the ecosystem to meet their needs. Feeding deer and snaring wolves to reduce predation were reasonable and self-interested means to boost the deer population. This was identified by researchers in the early 1990s (Theberge \& Theberge, 1998) and led to wolf protection in the 2005 provincial wolf strategy (Ontario, 2005). It appears that they also did not have the intended effects. As human-caused mortality increased, deaths from other causes probably decreased, increasing pup survival rates. This high mortality changed the way the packs interacted, making them more tolerant of strangers than they would otherwise be. At the same time, drawing the deer out of the park by supplemental feeding led to the dissolution of a yarding tradition inside the park, meaning that more wolves spent more time outside the park, increasing the risk of livestock predation and human-wolf contact and conflict (Rutledge, Patterson, et al., 2010; Theberge \& Theberge, 2004).

The presence of wolves and the chance of hearing them as part of an organized event, as an independent $\mathrm{cr}$, or as an area resident contributes to the region's wild character. Many respondents reported hearing the wolves as a distinctive (and generally positive) aspect of living in the region. Over the years, the Algonquin wolf migrated from the news and sports sections of metropolitan papers to the travel section, with the possibility of hearing a 
wolf howl as one of the major draws to the region. A high proportion of respondents to my surveys and requests for participation were not born in the region, but moved into the region between one and 40 years before this research. The wild character of the region, exemplified by the presence of wolves, was one of the main attractions.

The extension of wolf protection to the 39 townships surrounding the park was viewed as an unsound, undemocratic and unscientific move designed to appeal to distant others while harming the local human population. In spite of this, subsequent research shows that in most cases the ban is respected. A new public wolf howl in Bonnechere Provincial Park attracts considerable attention to the region east of Algonquin Provincial Park in the shoulder season between summer campers and fall deer hunters. It has drawn considerable support, including from hunting suppliers and outfitters that had otherwise expressed negative views of wolves. Fears over human safety have not been borne out, although stories about predation on house pets turned up during the study (these are serious claims, but may have related to events prior to the ban as well as subsequently). There have been few violations of the hunting ban reported or indicated by the tracking program that continues under MNR auspices in the region (personal communication Informant N). Radio tracking by collars and transponders has not indicated anything like the human-caused mortality that had been found in the 1987-1993 research period.

\subsection{People and right whales}

The North Atlantic right whale has been going through a baby boom since 2001, with the estimated population increasing to nearly 400 individuals. It is difficult to attribute the increasing population to changes in conservation practice because the numbers are so low. Statistical analysis showed that a reduction in mortality of fertile females of 1 to 2 
animals per year would be sufficient to change the population trend from negative to positive, and a later study showed that the risk of collisions had indeed decreased (Caswell, Fujiwara, \& Brault, 1999; Vanderlaan \& Taggart, 2009).

Entanglements with fishing gear appear to be down, but this is difficult to quantify for the same reasons. Furthermore, the nature of right whale entanglement is difficult to assess because while about $70 \%$ of whales have scarring from gear only a relative handful is trailing gear at any time (personal communication, Informant B). Right whales are so big that they pull up gear and take it with them, sometimes rolling out of it or otherwise being able to free themselves. Disentanglements have included epic stories of deep ocean transits and anaesthetics to try to catch and then free the whale. In the last decade, the entanglement risk has shifted because fishing gear has changed in response to changing gear and markets. Pelagic whitefish (like cod and haddock) have all but disappeared from the region, leaving herring and lobster as the major fisheries. The herring fishery is often conducted near shore in herring weirs (fixed gear) and lobster gear is being set more and more in the deep waters in the channels of the Bay. On one hand, this increases risk because this is the area that the whales feed in; on the other the gear is 'pot gear' which is set in long chains, with surface buoys on either end. Although this can mean a lot of loose rope in the water (considering the ropes must provide for about 20 meters of motion due to the Bay's high tides) there is typically less rope in the water and less risk to 'entanglement zones' around the baleen, flukes and flippers than with gill nets or other 'wide' gear. In the US the National Marine Fisheries Service has mandated 'whale-safe gear', which includes sinking lines and breakaway links that keep excess line out of the water (by falling to the bottom when not needed, and by releasing the gear when encountered by a whale). Some informants detailed at least anecdotal accounts of whales trailing whalesafe gear, which indicates that there are problems with the breakaway 
links. The NMFS has instituted wamings to mariners that are meant to slow traffic and steer ships away from likely whale locations during times of migration or feeding. There are many problems with this system. Fishers might be encouraged to set gear at all access points to 'an area to avoid', meaning the whales must run a deadly gauntlet to get to and from key feeding grounds. Changes in regulations require posting orders to mariners in the Federal Register- a process which takes at least a month, while whales transit significant portions of ocean in a single day.

In Canadian waters the response has been more organic. When right whales were sighted in unusual parts of the Bay of Fundy in 2006 for much longer than usual, potentially putting whales and lobster fishing gear in the same waters at the same time, a delay to the lobster season was proposed by some scientists and conservationists. Fishermen objected loudly but developed a voluntary whale sighting reporting mechanism and agreements to pull fishing gear from within one kilometre of whale sightings. This solution was imperfect considering the whales' capacity to travel quickly and without being sighted, but was adopted by regulators. Experiments with fishing gear that reduce the risk of entanglements have been conducted, but wholesale shifts of gear types or material appear unlikely. An active and recognized whale rescue team operates in the Bay with the support of DFO, conservation organizations, and volunteer fishermen-turned-rescuers. Two 'critical habitat areas' have been identified as key feeding grounds for the whales and have been established as voluntary areas to avoid by shipping companies.

The Canadian fishermen and fisheries organizations appear to take a pragmatic approach to right whale conservation. They have nothing against the whales, and seem willing to absorb (the rather small) risk of gear loss to entanglements as a cost of doing business (fishing gear is lost, damaged or worn out through use all the time). They are willing 
to make adaptive changes to promote conservation, especially if the actual and opportunity costs are not high. Some fishermen (the whale rescue team) make considerable sacrifices in terms of time, training and risk to release entangled whales. Most informants worried about the risk of arbitrary and possibly ineffective government regulation instead of direct costs of loss of gear or fisheries. In the highly regulated and controlled setting of the Atlantic fishery, people are concemed about the right whales becoming an agent of further regulation and control in a matrix of legal and administrative controls as opposed to some threat or need on the part of individual animals.

\section{Interpretation of the findings}

These cases share the basis of exploring spaces shared by people and others but differ in scale, the diversity of views of protagonists active in each case, the dynamics of interaction between people and the animal other, and the available range of political possibilities. The following section attempts a broader view of the lessons from the cases in order to develop a position on the key questions addressed by the research, the processes and prospects of co-existence.

\subsection{The processes of co-existence}

In Ontario, the southern publics have an attachment to the wolf as emblematic of the north, which forms a part of their Canadian identity. In Alberta, it is the local residents who have the attachment to the bear and the opposition to real estate and industrial development is localized. Investment and political decision making are coming from outside the habitat region, and the protectionist effort is largely coming from within it. This is different from the Ontario case where the protectionist effort is coming from outside and the hostility is local. 
In the case of the whales, there is both local and external attachment and the conservation effort is largely extemal, not because of lack of interest but because the action required is either of a transnational scale (moving shipping lanes) or communal in naturefishing gear regulations have to be pursued by everyone or else you have a motivation/free rider problem.

The positive or negative construction of the animal, the site of that construction (local or metropolitan), and the action required to mitigate conflict and protect species help determine the potential for political conflict, the possibility of legislative, regulatory and practical change, and the likelihood of peaceful co-existence. Table 13 analyzes these dimensions by case from the research. 
Table 13: Case summary of construction and impact on co-existence

\begin{tabular}{|c|c|c|c|c|c|}
\hline & Local construction & $\begin{array}{l}\text { Metropolitan } \\
\text { construction }\end{array}$ & Power situation & Action required & Scope of change \\
\hline Bears & $\begin{array}{l}\text { Representative of the } \\
\text { mountain town; } \\
\text { ecological health and } \\
\text { integrity; wild; the } \\
\text { frontier }\end{array}$ & $\begin{array}{l}\text { Representative of the } \\
\text { mountain town; } \\
\text { dangerous; impediment } \\
\text { to business }\end{array}$ & $\begin{array}{l}\text { Final authority with the } \\
\text { province; political power } \\
\text { is in Calgary in } \\
\text { Edmonton; } \\
\text { environmental } \\
\text { counterweight is in Bow } \\
\text { Valley }\end{array}$ & $\begin{array}{l}\text { Large scale relates to } \\
\text { land use policy and } \\
\text { prioritizing habitat } \\
\text { (government level); local } \\
\text { scale relates to bear } \\
\text { smart, attractant } \\
\text { reduction, following } \\
\text { advisories }\end{array}$ & $\begin{array}{l}\text { Province reluctant to } \\
\text { limit development; } \\
\text { legally obliged to } \\
\text { protect; general } \\
\text { reluctance around large } \\
\text { scale change; local } \\
\text { change more } \\
\text { enthusiastically } \\
\text { embraced and underway }\end{array}$ \\
\hline Wolves & $\begin{array}{l}\text { Dangerous; predatory; } \\
\text { savage; harmful to } \\
\text { humans }\end{array}$ & $\begin{array}{l}\text { Wild, northern, } \\
\text { ecological integrity, } \\
\text { beautiful, haunting }\end{array}$ & $\begin{array}{l}\text { Regulatory power rests } \\
\text { with the provincial } \\
\text { government; political } \\
\text { power generally in the } \\
\text { urban centres but } \\
\text { consideration of rural } \\
\text { ridings is necessary }\end{array}$ & $\begin{array}{l}\text { Generally large scale - } \\
\text { hunting regulation and } \\
\text { management practice; } \\
\text { individuals can make a } \\
\text { difference by protecting } \\
\text { farm animals and pets }\end{array}$ & $\begin{array}{l}\text { Province overruling rural } \\
\text { minority and general } \\
\text { position on wildlife to } \\
\text { protect these particular } \\
\text { wolves }\end{array}$ \\
\hline Whales & $\begin{array}{l}\text { Represent a healthy } \\
\text { ocean; awesome animal; } \\
\text { species at the brink }\end{array}$ & $\begin{array}{l}\text { Awesome animal; } \\
\text { species at the brink }\end{array}$ & $\begin{array}{l}\text { Regulatory and } \\
\text { enforcement power rests } \\
\text { with DFO; individual } \\
\text { action on gear or } \\
\text { shipping is ordinarily } \\
\text { regulated }\end{array}$ & $\begin{array}{l}\text { Large scale change - } \\
\text { shipping policy, fishing } \\
\text { regulations, little role for } \\
\text { individuals }\end{array}$ & $\begin{array}{l}\text { Federal government } \\
\text { pushed to act by SARA, } \\
\text { general consensus and } \\
\text { support for protective } \\
\text { action; concern about } \\
\text { over regulation and } \\
\text { 'political theatre' }\end{array}$ \\
\hline
\end{tabular}


These details illustrate difference but also commonality in how co-existence is created or negated. If we consider space as a bundle of possibilities, the elimination of possible futures for other species corresponds to an erasure of their space, the antithesis of a space of co-existence. Figure 14 represents a distillation of lessons from the research, conditioned by the literatures on animal geography, biology, and mutuality discussed in the sections below.

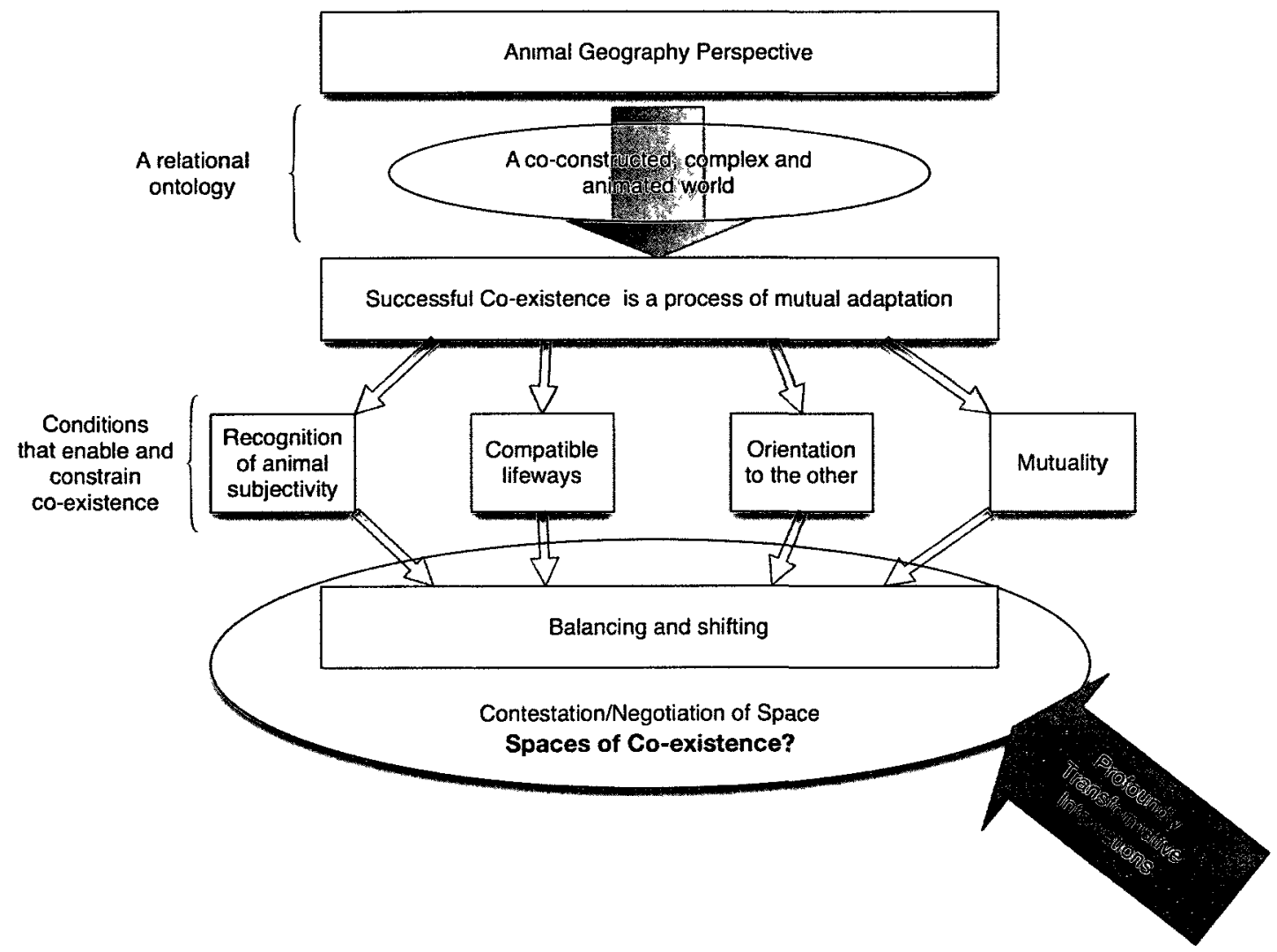

\section{Figure 14: A theory of co-existence}

Based on the research, I argue that there are four conditions that mediate the possibility of co-existence: recognition of animal subjectivity, compatibility of lifeways, orientation to the other, and mutuality. These conditions enable or constrain human action related to co-existence. Furthermore, the starting point of co-existence is mutual adaptation. 
The balancing and shifting that is the negotiation of space depends on the capacity of humans and non-humans to adapt. Those species whose evolutionary pattern or particular lifeways are too specific for adaptation in this context are not likely to succeed.

Synanthropes, whose lifeways benefit from human acts or interventions are the most likely candidates for successful co-existence.

Adaptation is itself a process and living together is a never-ending journey. For this reason, the state of co-existence (or its opposite) is never finished. The prospect of stochastic change is always present. In this research these changes came in the form of profoundly transformative interventions: dramatic incidents that emphasized, publicized, or symbolized issues at the core of human-animal relationships. The death of Isabelle Dubé in Alberta, the death of McDonald 4 in Ontario, the death of Delilah in the Bay of Fundy and the return of her daughter Calvin with a calf of her own twelve years later transformed the situation of co-existence and made a space for reconsideration and renegotiation of coconstructions of nature. Co-existence is a joint project of humans and others - whether we recognize it as such or not. In terms of discourse coalitions, there are long periods of stable hegemony, punctuated by critical discourse moments in which the hegemonic position can shift. These can be moments of tragedy or delight, but are instances of recognition. The character of this recognition will be dealt in section 2.2 .4 below, mutuality.

The following section considers the prospects of co-existence by examining the four conditions that enable and constrain it.

\subsection{The prospects of co-existence}

\subsubsection{Recognition of animal subjectivity}

The three cases are characterized by mutual influences. Where a straightforward reading of human agency would suggest that humans act on situations, systems and other 
creatures, the outcome in the cases describes a circumstance in which the effects are mutual and dynamic. Acts on the part of the animal trigger a human response; human action has consequences in return that may be unanticipated. This sense of dynamism comes into relief if animal agency is taken seriously; otherwise, unexpected or undesired outcomes are not read as unpredictable relationality, but a human failure to intervene correctly. The outcome of this misinterpretation is further action from the human side instead of a recognition of mutual change and adaptation.

In each case in this research the animal subjects learned, remembered, and generally adapted in the face of human change. The whales, because of the peculiarities of marine space and their lifeways learn and remember but do not appear to adapt in the same way as the others. The active and possibilist aspect of animal behaviour - and how it alters apparent reality - is marked in the wolf case. Human action to kill the wolves and support the deer had almost an opposite effect - wolf natality increased and pack aggression decreased, allowing more wolves to feed on the same deer population.

Seeing the active nature and possibility of acting otherwise on the part of the animal other carries a moral implication as well, which will be discussed further below under the heading of mutuality. Shifting our view of the other from object to subject opens a prospect of care that otherwise is, if not missing, at least highly discretionary.

\subsubsection{Compatible lifeways}

Economic interests are a factor in each of the three cases. The case with the most animosity toward the animal other, and the only one that featured intentional harm on the part of humans, is that of the wolves of eastem Ontario. The rationale for a wolf bounty, the media explanation of the anti-wolf sentiment and information from interviews all indicate that the economic costs of wolves as predators on livestock and as a check on the region's 
deer population, important both for subsistence and for profit from outfitting and otherwise supplying visiting hunters, was important. In fact, in the post-moratorium era, the creation of a public wolf howl in the post-camping, pre-hunting shoulder season helped reduce negativity about the moratorium, as the wolves provided a tourist draw with positive economic effects.

On the other hand, the whales do not have a direct economic impact on most fishermen. The risk of losing gear in a whale entanglement is real but remote, and is just one of many ways that a fisherman can lose gear. The costs of rigging, maintaining, repairing and replacing gear are a constant in the industry. Some of the costs are considerable and have led fishermen into novel ownership arrangements and cost-sharing with fish processors, but this has little to do with gear loss. Some fishermen and area entrepreneurs have sought to capitalize on whale tourism, and whale watching makes a contribution to the mix of attractions that supports a well-established tourist industry in the Bay of Fundy. For individuals outside the tourist industry, the whale is neither a direct threat nor a source of income, but part of the seascape. The whale-related cost that most fishermen fear is the cost of (what is perceived as) unfair or ineffective regulation, in which they would be required to make large capital expenditures on fishing gear that (they consider to be of) no great value, or that they would face large opportunity costs due to increased regulation (changing fishing seasons or closing prime fishing areas). Particularly galling is the idea that distant bureaucrats or politicians would enact crippling changes as a performance (being seen to act) when current practices are working well (as evidenced by the 'baby boom' of the late 2000s). This fear of excessive regulation fits well in the narrative of the life of the fishery as an excessively regulated one. 
The grizzly bears are the only 'other' in this study with real potential to harm humans - there is a physical danger of bear conflict that is not duplicated among the whales and the wolves. The sense of direct economic competition is absent in this case, and in fact, the presence of the bear is economically helpful inasmuch as their presence is part of the placemaking of Canmore. The Rockies wouldn't be the Rockies or Canmore without grizzly bears. Real estate developers do not want to sacrifice development opportunities OR the presence of bears, as the first action costs money in the form of potential profits, and the absence of bears (or other wildlife) undermines the wildness and wilderness character of the area. This is a case of good intentions or magical thinking - the bears are wanted but not wanted too close.

The reality of the economic costs is difficult to quantify. There is an estimate for wolf predation on livestock based on insurance claims that places the costs in the range of $\$ 20,000$ per year for all of Renfrew County. The actual costs of whales and bears are perceived as high (in lost revenue or additional costs due to whale regulations, and lost opportunities for real estate development in the case of bears) and any benefits that might accrue from bearing the risks appear remote.

\subsubsection{Orientation to the other}

What are the possible relationships between people and animals? Like, indifference or dislike seem to be three relational stances that could be exercised to various degrees - like could instantiate as respect, reverence, affection, or interest; indifference could be characterized as disinterest to dismissal (from the moral community) and dislike could range from distaste to hatred. In the case studies, aversion toward wolves and grizzlies was one of the themes that emerged, but with the whales the relationship ranged from indifference to liking. The situation that the media reported with regards to people's sentiments towards 
wolves, were primarily negative - people feared health and safety consequences of increased wolf population, as well as threats to pets, livestock, and white-tailed deer. However, in interviews, local residents who were aversive toward wolves presented a more nuanced view. One female respondent indicated that wolves or coyotes occasionally visited her property and she felt threatened by one that had approached the house closely, sat on her deck and sat in her driveway. She was worried that it could have been rabid, dangerous, or a threat to her $\operatorname{dog}$ (who was inside at the time). Later in the interview I asked if she disliked wolves and she said, "I wasn't crazy about the one in my driveway, but no, generally I like them" (personal communication, Informant T). This speaks to a willingness to co-exist combined with a fear of direct contact, which is not an unreasonable fear. The respondent (among others) commented that in building in a forested region, she was changing the wolf habitat and could only expect that she would be in contact with them.

One of the WildSmart volunteers in Canmore had a history that extended back into the coal-mining era (personal communication, Informant $G$ ). His sense was that people and bears are in competition and that co-existence was not a reasonable goal. Alternatively, an attractive town for people and healthy and abundant bear habitat outside the town would be the key - co-existence at a regional level. His sense was that people moving into the region as recreationalists and amenity-seekers "felt bad" about displacing the bears and that people must therefore make accommodations so the bears would not be displaced. On the contrary, he argued, you can't accommodate the bears where people are, instead people must act on their own property to pull up berry bushes, pick ripe fruit, adequately contain their garbage and otherwise remove attractants so that bears would "move right on by" the human settlement and seek food in the forest. He argued that we need "more Darwin and less Disney" when it comes to living with animals. On the affection - aversion scale, he was 
profoundly interested in bears - he likes them as bear, but dislikes them as neighbours (at least in the immediate neighbourhood). Yet he lives adjacent to a ravine that is a transit route for the bears, so he acts on his own property to keep the bears moving instead of troubling the human residents. He characterized his stance as neither liking or disliking the bears, but being rational about co-existence.

With the whales, there seemed to be a surprising amount of disinterest. While fishermen could easily distinguish body condition of herring in great detail, it was reported that many could not identify whale species. The fisheries association and the whale and bird research station have provided identification cards ("wheelhouse cards") to facilitate identification, but many people cannot identify the eight species of whales in the bay by sight. This was explained to me as the herring being commercially valuable and having a bearing on daily life, but the whales (and especially the whale conservationists and government) being a nuisance if relevant at all (personal communication, Informant B). On the other hand, the regional equivalent of a Sunday drive included boat trips in the bay, which included watching whales, birds and seals. It was difficult to attach an understanding of people's relationships with whales beyond their inclusion in a seascape that maintained their presence as important. Seals were another matter - seals have a tendency to swim into and out of herring weirs set close to shore, and due to the fickle economics and peregrinations of herring, a bad spate of predation could destroy a season's income. I met and heard of fishermen who would like to get rid of the seals.

On the flip side of aversion, many respondents expressed affection for the subject species. This could be because of the nature of the research - seeking comments on wolves, whales and bears from the general population, those who had expressed sentiment about them before or who were known to be interested, or who had affection for the other species 
would be willing to take the time to participate. Numerous people talked about feeling a connection with the other species. This ranged from an experience of connection related to seeing an animal in the wild and feeling a sense of kinship, or watching a wolf hunting and being impressed by its capacities, or a sense of the animal in place, that helped define and make the place. Seeing the animal as part of the land or seascape gave the animal, the place, and the watcher meaning. Sometimes this sense of affection was described as a transformative personal experience.

What the WildSmart volunteer above described as 'Disney-thinking', these people experienced as a connection with a morally significant other. The language of conservation biology is usually stripped of this kind of normative term (liking, loving) but does include mention of the wonder and intricacy of ecosystems, species and individuals. The overall thrust, however, is that in the maintenance of ecosystems the de-prioritization of individuals is unproblematic. Respondents to my interviews could hold both ideals of 'populations' and 'individuals' including welfare and survival simultaneously. This led people to take 'proanimal' positions in public debates, conversations with neighbours and to participate in coexistence measures like the WildSmart program.

One effect of affection toward the animal is pursuing experiences with that animal that may or may not be appropriate or healthful to the animal or the watchers. In Alberta, particularly in the Rocky Mountain Parks, Bear Guardians are employed to break up bear jams' on the highway, give an interpretation program that focuses on not harassing the bears, and make way for wildlife officers to 'haze' or 'condition' the bears away from human areas. In Yellowstone National Park, authorities have taken the opposite tack, and attempt to concentrate bear jams on areas of known sighting frequency, away from highway curves or other dangerous areas, and have park rangers spend extended periods with the viewers 
giving detailed interpretation of the scene and the animals. In some ways, this approach is like the Algonquin Park Wolf Howl which brings visitors into the scene and socializes the presumably natural behaviour of the animal other through a human engagement. Studies on the rates of habituation, creation of dangerous bears, or whether bears that have been watched at the highway behave unsoundly in the backcountry have found that the program does not have these effects (Matt, 2009).

\subsubsection{Mutuality}

There is a way of understanding relationship that goes beyond affection or aversion, and that can explain transformative experiences with other species and changes in sentiment and action toward those species. It has to do with feeling toward the other, but more importantly, with the recognition of the other. Martin Buber in his I and Thou (Buber, 1923/1970) explored several modes of being in relationship. In what he called the I-It moment, a person recognizes another as a means to an end, and an object of perception. The "It" here does not refer to a non-human or inanimate other - a person can see another person as an object and a tool, as they could a piece of furniture or a found object in nature. The It in his model refers to the essence of the perceived as utilitarian. In the I-Thou moment the dynamic is decidedly different. Buber says that what is sacred in the perceiver recognizes what is sacred in the perceived, and the I no longer sees the other as an instrument or an object, but as a part of one's greater self. Buber calls this moment of recognition the Encounter.

This philosophy of relationship, mutuality, provides profound insight into the objectification of the other, and the justification for inter-group conflict. I-It thinking is a prerequisite for dehumanization of the other in war or ethnic conflict, for example. One can consider the "re-cognition" of the other in which seeing the other as part of oneself makes 
you re-think your own position and how that position relates to the recognized. So where mere affection might not rationally explain concern and self-sacrifice for another person, or for an animal, or for the abstraction of an animal species, the sense of mutuality renders concern and action eminently reasonable. To understand why some people choose to alter their lifeways and accept personal danger in support of another species, one must engage this concept of fellowship.

To illustrate his the I-It and the I-Thou dichotomy and the mental processes that go into relationship, Buber wrote a section entitled, "I Contemplate a Tree". Having laid out the basic precepts of the multiple ways of knowing an other, he applies his approach to five different ways of seeing a tree - as a picture, as movement, as a member of a species, and as a number, "into a pure relation between numbers". He then writes, "but it can also happen, if will and grace are joined, that as I contemplate the tree I am drawn into a relation, and the tree ceases to be an It. The power of exclusiveness has seized me" (Buber, 1923/1970, p. 58). He illustrates that while mutuality is between beings, the recognition can work in one or both directions - a person can recognize the sacred in the tree without the tree recognizing anyone in return. Critics and scholars of Buber's work, placing him in the humanist tradition have often asked what this passage is doing in his key explanation of his philosophyvarious interpretations exist (Berry, 1985).

Buber's work figures lightly in geography, a remarkable oversight considering the potential links between recent work on relational ontologies and Buber's insights into transcending difference, object and subject. He has been pulled into the discipline under the umbrella of humanistic geography, with its focus on human awareness, agency and creativity (Hasson, 1984). This is consistent with the above-mentioned critiques of Buber's handling of nature. 
However, Donald Berry argues that Buber's philosophy extends to the more-thanhuman world and that while Buber addressed his commentaries and scholarly output to matters of human well-being, his basic philosophy applies to an extraordinarily wide moral community - extending to rocks as well as plants and animals. In this, Buber prefigures Aldo Leopold's land ethic, in which land, environments, plants and animals belong, and belong in place (Leopold, 1949/1966). Their mere existence entitles them to a place in the moral community. The rationale of protecting species because they might be lost, focusing on the species with the fewest number and greatest risk recognizes the significance and irreplacability of species, this is to recognize a part of what Leopold wrote about, the fabric of life and our ignorance of how the many parts of an environment work together. To be in I-Thou relationship with another animal, or with Buber's tree, is to care about the individual as well as the population, regardless of the capacity for reciprocation.

There were many instances in the research in which informants indicated an 'Encounter' had changed their ways of viewing and living with other species. A deer hunter who was surprised to notice a wolf quietly waiting for him to leave his deer's offal after a successful kill (personal communication, Informant $\mathrm{U}$ ); a budding environmentalist in a silent forest through which a wolf passed as she watched (personal communication, Informant V); a child's first sight of a bear that spawned a lifelong interest (personal communication, Informant H). These were moments in which the human/other dividing line was at least smudged and people's attitudes and actions changed in the process. The sense of mutuality or fellow-feeling is a key part of what determines whether humans are willing to act or to sacrifice some benefit to permit the persistence of the other. 


\section{Contributions to animal geography}

As outlined in the literature review, major themes in the current animal geography literature include the material well-being and cultural meaning of non-human animals, the politics of human-animal relations, animal agency, and animal subjectivity. To this list, I pulled in literature on human-environment relationships and values of nature, and addressed some of the scholarship on social nature and relational ontologies that underpin consideration of the moral and relational geographies that connect humans and non-humans in place.

This research provides empirical examples of relationality, in which "parties are reconfigured as they relate or engage with one another" (Hinchliffe, 2007, p. 51). This is notable with the grizzly bears and wolves, whose ecology and behaviour were changed by their proximity to humans and by human transformation of their landscapes. The whale ecology changed as well, but less visibly and less in the sense of individual transactions with whales, and this is related to the relatively lower ability of the whales to exist successfully in human space and the vast differences in our ability to comprehend and imagine the whales' experience - we have less in common with the marine and aural world of the right whale than the terrestrial.

As the animal other is transformed, so are the humans involved either materially through the need to negotiate and share space often through a complex and changing time geography; symbolically in that the animal others' existence takes on a meaning of wildness, northerliness or rarity that encourages changed relations and actions on the part of humans; or in terms of power - regulatory effects of state power condition and control human practice related to the species at risk. Making the link to observations and literature on 
animal behaviour answers a call to "those of us who seek a better understanding of the heterogeneous situations of animals" (Seymour \& Wolch, 2010, p. 313).

In terms of the political dimensions of human-animal relations, this work probes informal politics in terms of the power to include and exclude species from land or seascapes in organized and individual ways, and politics in the formal sense of execution of state power. In each case, the state intervened to implement a protectionist agenda, but reluctantly. Scientific consensus, popular demand, legal precedent or a combination both allowed and required policy change.

One of the contributions that I set out to make in the rescarch is an exploration of applying animal geographies in the context of biodiversity protection. How could a bridge be built between post-human geographers on one hand and wildlife managers and conservation biologists on the other, applying new understandings of nature to the business of coexistence? Animal subjectivity is gaining practical recognition in human dimensions of wildlife as the interplay between human activity and animal behaviour is better understood. The role of the encounter and orientation toward other species is also recognized under the rubric of environmental education. At the same time, these recognitions are underdeveloped and do not seriously engage with deeper conceptions of relational ontology. Effective bridge building must be undertaken in partnership with the biological and wildlife management communities, with interdisciplinary teams and a focus on practice. A new action-oriented 'conservation geography' could be a part of this effort, as could a fuller engagement for geography in groups like the Social Science Working Group of the Society for Conservation Biology.

The present work operationalizes some of the current conceptual frameworks extant in animal geography (notably relational ontologies and animal subjectivity) by applying them 
in empirical contexts, answering the call of authors like Seymour and Wolch (2010) to connect the geographic and biological traditions within the animal geography framework. While these are useful innovations, there are many options to extend and expand the research to address additional dimensions of animal geography and some of these are addressed in the following sections.

\section{Limitations}

This study was challenging both in addressing the science and social science dimensions of living with wildlife, the participatory and qualitative aspects of connecting with informants, the volume of textual material that needed processing, and the wide geographic range of the study sites. These complexities introduced logistic, disciplinary and methodological challenges that influenced the outcome of the project.

\subsubsection{The science side}

In attempting to build a bridge from the 'critical' neighbourhood of a social science, it was difficult to establish a bridgehead on the other, wildlife and biological side of the expanse. Trying to develop relationships with scientists active in three different regions on three different species required considerable outreach and, as a geographer, the disciplinary barriers of networks and language were real. The respondents were welcoming and open, and generally interested in my work, but on my part, there was certainly a sense of approaching gingerly from the outside.

In my research design, I had envisioned developing deeper connections with scientists from each study area and plumbing the depths of what they, as scientists but also as field workers who have spent a lot of time with the focal animals, could suggest as animal adaptations and responses to humans and to change. To follow the methods and understand 
how our knowledge is constructed would be a fascinating component of learning about mutual adaptation. This level of analysis and study was not really open to me, so I depended on relatively superficial interviews and published literature. This suggests that scope remains for greater efforts to locate science as the site of understanding the animal side of the human-animal relationship.

\subsubsection{Discourse analysis}

I became aware of critical discourse analysis as I was making preliminary efforts to understand the Ontario wolf case and the methods were a key to the lock of knowledge, communication and power that underpinned the changing state of relations between people and wolves. The method opened insights into knowledge and power that I was eager to apply to other cases.

As I studied the other cases in this project, discourse analysis remained relevant but there was no other in which the relationship between media discourse and the condition of co-existence was as fruitful as the wolf case. This was particularly so when it came to the whale case - the endangerment storyline and perception of needed response is so strong that there are no alternate discourse coalitions, and the power situation is not nearly as relevant as in the other two cases.

This meant that some of the richness of critical discourse analysis was left behind. The media accounts in the cases were examined thematically rather than from a strictly critical discourse methodology. This would indicate that discourse analysis as a method could better be applied in a more intensive and radical way in a more limited (i.e., single case) scenario where that case was rich in alternative views and public discourse. 


\subsubsection{Going deeper with fewer people}

There are two aspects of the study that offer rich veins for further research, mutuality and the discourse/policy interface. In the case of mutuality, relationship with animal others is a profoundly personal and intimate dimension. To understand how people come to view the other as a part of their extended self could be done in an ethnographic fashion. Extending from 'extreme cases' of which I met a few - people who have identified their connection with members of other species as a major aspect of their lives - could provide insight into commitment and change that could contribute to new approaches to coexistence.

Another option would be to develop the topic of this study as an explicitly political one and explore the relationship between biology, discourse and policy in a real world setting. This would involve connecting in the political realm to track localized conflicts and co-existence states. This would include an analysis the political decision making process and development of an animal political geography (see Hobson, 2007 for perspectives on this concept).

\subsubsection{Dealing more extensively with difference}

The focus of this research was to probe the human-animal divide in specific cases with a relational orientation. Other, more critical, approaches could also yield useful insights. The role of women in the cases varied, for instance. Many of the leading right whale researchers are women, while more wolf researchers are male, and bear researchers more male still. How gender dimensions shape or are reflected in research practice discourse and political outcomes is not considered here. There have been influential works on how masculinist narrative shapes production of knowledge in biology, notably Haraway's work on primatology (Haraway, 1989). On the contrary, in this research the importance of mothering 
in each case could offer an opening for feminist interpretation of both researchers and the researched in these and other cases.

In each of the cases in this study, Indigenous People were present. In Alberta, grizzly bear hunting by First Nations on reserve is permitted and unaffected by the recent hunting ban, and it was reported to me that research was underway to promote the extension of this right off-reserve (although I was unable to verify this). In Ontario the Algonquin First Nation and Bonnechere Métis have hunting rights in the region including in parts of Algonquin Park, but have voluntarily agreed to comply with the provincial regulations against wolf killing in the region. The PHVA analysis specified that its findings should have "no effect on the on-going land claim negotiation process between the Algonquin Nation and Canada and Ontario" (Ewins, et al., 2000, p. 13). In the Bay of Fundy, the Passamaquoddy Indians of Maine have had long-standing participation in the region's fisheries, which the Mi'kmaqs of New Brunswick have not shared. In 2000 the Supreme Court of Canada ruled that Mi'kmaq had treaty rights to the fishery and DFO began a buyback of existing licenses and boats for redistribution to First Nations communities in the province (and elsewhere). This caused a shift in the political economy of the regional fishery.

These circumstances appeared within the interviews and discourse analysis that I conducted, often tangentially to the main questions of co-existence that I was focused on. However, a more careful probing of the issues from a Native Studies or post-colonial pointof-view would elevate issues that were below the surface of the present research to permit a different type of analysis.

Therefore, while I identified issues of difference and justice within the research, it was beyond the present scope and scale to engage them fully. While this is a limitation in the research it also provides enticing directions for future research. 


\section{Suggestions for future research}

The limitations above point toward exciting opportunities for future research, particularly if the concepts of bridge building and boundary-erasing could be acted on in partnership with specialists from other disciplines.

For example selecting a single species and space of co-existence and approaching it in partnership with a biologist specializing in that place and species would permit a depth of examination of the animal side of the relationship that was not possible in this case. What this would particularly offer would be a social studies of science approach to how our understanding of the other species is constructed - a reflexivity that would add depth to the understanding of co-existence and how we know the other.

Similarly, selecting a study area and situation of co-existence for which the relationship between discourse and power is a key dynamic would facilitate a critical discourse analysis from a political point of view, permitting the application of what is often considered as a politics of nature and the connection of that politics with formal politics. This would permit a philosophical and practical assessment of power in relation to living with the other, a major contribution to promoting successful co-existence.

Finally, an empirical approach to mutuality by engaging with people who live routinely with wild animals would be a fascinating contribution. In this research I spoke with hunters, ranchers and fishermen who live in proximity with the focal species of the research, and their generosity and insight permitted me to make a connection to a philosophy of relationship that is relevant to but not seen in the geographic literature. Delving more deeply into how people see these animal others and how their sense of care and moral community 
develops from these views would make a contribution to our understanding of how humans can engage with animal subjectivity. 


\section{References}

Abner, W. L. (2005). Evidence of group learning does not add up to culture.

[Correspondence]. Nature, $438(24$ November), 422.

Al's Corner Store. (2010). What's New: Coyote Contest Winners. Retrieved August 1, 2010, from http://www.alscornerstore.ca/news.php

Alberta. (2009). Karelian Bear Dog Program. Retrieved March 13, 2011, from http://www.srd.alberta.ca/ManagingPrograms/FishWildlifeManagement/BearMana gement/KarelianBearDogProgram.aspx

Alberta. (2010a). Alberta designates grizzly bears a threatened species. Edmonton:

Government of Alberta. Retrieved March 11, 2011 from

http://alberta.ca/home/NewsFrame.cfm?ReleaseID =/acn/201006/28501FF40EE F0-D53C-C48F-6FF952CC62DDEF7C.html

Alberta. (2010b). Alberta grizzly bear mortality rates. Retrieved December 30, 2010, from http://srd.alberta.ca/ManagingPrograms/FishWildlifeManagement/BearManageme nt/GrizzlyBears/AlbertaGrizzlyBearMortalityRates.aspx

Alberta. (n.d.). Living with wildlife. Edmonton: Alberta Tourism, Parks and Recreation. Algonquin Wolf Advisory Group. (2000). The wolves of Algonquin Park. Retrieved from http://www.mnr.gov.on.ca/stdprodconsume/groups/lr/@)mnr/@,fw/documents/d ocument/mnr e001295.pdf

Anderson, K. (1997). A walk on the wild side: a critical geography of domestication. Progress in Human Geography, 21(4), 463-485.

Armstrong, P. (2004). " Leviathan Is A Skein Of Networks": Translations Of Nature And Culture In Moby-Dick. ELH, 71(4), 1039-1063.

Arnold, P. W., \& Gaskin, D. E. (1972). Sight records of right whales (Eubalaena glacialis) and finback whales (Balaenoptera physalus) from lower bay of fundy. Joumal of the Fisheries Research Board of Canada, 29(10), 1477-\&.

Aronson, J. (1994). A pragmatic view of thematic analysis. The Qualitative Report, 2(1). Retrieved from http://www.nova.edu/ssss/QR/BackIssues/QR2-1/aronson.html

Babin, T. (2000, December 20). Grizzly safety linked to park use, Calgary Herald.

Baker, J. (2002). Production and consumption of wilderness in Algonquin Park. Space and Culture, 5, 198-210.

Beck, A. (2001, November 17). Advisory group was ignored, Pembroke Observer, p. 4.

Beddard, F. E. (1895). A Text-book of Zoogeography. University press.

Benko, G., \& Strohmayer, U. (Eds.). (2004). Human geography: a bistory for the 21 st century. London \& New York: Arnold.

Bennett, C. F. (1960). Cultural animal geography: an inviting field of research. The Professional Geographer, 12(5), 12-14.

Berkes, F. (1993). Traditional ecological knowledge in perspective. In J. Inglis (Ed.), Traditional ecological knowledge: concepts and cases (pp. 1-10). Ottawa: International Development Research Centre.

Berry, D. L. (1985). Mutuality: the vision of Martin Buber. Albany, NY: State University of New York Press.

Bertch, B., \& Gibeau, M. (2009). Grizzly bear monitoring in and around the Mountain National Parks: mortalities and bear/human encounters 1990-2008. Lake Louise, AB: Parks Canada. 
Birke, L., \& Hubbard, R. (Eds.). (1995). Reinventing biology. Bloomington and Indianapolis: Indiana University Press.

Bordessa, R. (1993). Geography, postmodernism, and environmental concern. The Canadian Geographer, 37(2), 147-156.

Boulanger, J., \& Stenhouse, G. (2010). Demography of Alberta grizzly bears: 1999-2009. Edmonton: Alberta Sustainable Resource Development.

Bourdeau, P. (2004). The man-nature relationship and environmental ethics. Journal of environmental radioactivity, 72(1-2), 9-15.

Bovenkerk, B., Stafleu, F., TrAMPPEr, R., Vorstenbosch, J., \& Brom, F. W. A. (2003). To act or not to act? Sheltering animals from the wild: A pluralistic account of a conflict between animal and environmental ethics. Ethics, Place and Envinonment, 6(1), 13-26.

Bow Valley WildSmart. (n.d.). Waste Management in the Bow Valley. Retrieved March 3, 2011, from http://www.wildsmart.ca/programs/bowvalley waste-management.htm

Bow Valley WildSmart - Living with Bears, Cougars and Wildlife in the Bow Valley. (2011). Retrieved March 11, 2011, from http://www.wildsmart.ca/.

Braun, B. (2008). Environmental issues: inventive life. Progress in Human Geography, 32(5), 667-679.

Brink, J. (2008). Imagining Head-Smashed-In: Aboriginal buffalo bunting on the northern plains. Edmonton: AU Press.

Brockington, D. (2002). Fortress conservation: the preservation of the Mkomaqi Game Reserve, Tanqania. International African Institute in association with James Currey.

Brooks, R. (2001, January 10). Further steps needed to protect Algonquin wolves, Pembroke Observer, p. 4.

Brown, C. (2006). Right whale protection network launched, New Brunswick Telegraph Journal.

Brown, M., Fenton, D., Smedbol, K., Merriman, C., Robichaud-Leblanc, K., \& Conway, J. D. (2009). Recovery strategy for the North Atlantic Right Whale (Eubalaena glacialis) in Atlantic Canadian waters. Ottawa: Fisheries and Oceans Canada.

Buber, M. (1923/1970). I and Thou. New York: Charles Scribner's Sons.

Budiansky, S. (1995). The covenant of the wild: why animals chose domestication. London: Weidenfeld \& Nicolson.

Butchart, S. H. M., Walpole, M., Collen, B., van Strien, A., Scharleman, J. P. W., Almond, R. E. A., et al. (2010). Global biodiversity: indicators of recent declines. Science. doi: $10.1126 /$ science. 1187512

Campbell, L. M. (2000). Human need in rural developing areas: perceptions of wildlife conservation experts The Canadian Geographer, 44(2), 167-181.

Canada. (2007). Species at risk act: annual report for 2006 and 2007. Ottawa: Government of Canada.

Canadian Meat Council. (n.d.). Canadian Livestock and Meat Industry - 2008 Industry Statistics. Retrieved October 28, 2010, from http://www.cmccvc.com/english/industry statistic e.asp

Carvalho, A. (2000). Discourse analysis and media texts: a critical reading of analytical tools. Paper presented at the Intemational Conference on Logic and Methodology, Köln, Germany. http://repositorium.sdum.uminho.pt/dspace/handle/1822/3137

Carvalho, A. (2005). Representing the politics of the greenhouse effect: discursive strategies in the British media. Critical Discourse Studies, 2(1), 1-29.

Castree, N. (2003). Environmental issues: relational ontologies and hybrid politics. Progress in Human Geograpby, 27(2), 203-211.

Castree, N. (2005). Nature: London: Routledge. 
Caswell, H., Fujiwara, M., \& Brault, S. (1999). Declining survival probability threatens the North Atlantic right whale. Proceedings of the National Academy of Sciences, 96, 3308-3313.

Caughley, G. (1994). Directions in conservation biology. Journal of Animal Ecology, 62(2), 215244.

Caughley, G., \& Sinclair, A. R. E. (1994). Wildlife ecology and management. Blackwell Scientific Publications.

Chapin, M. (2004). A Challenge to Conservationists. World Watch, 17(6), 17-31.

Chapman, J. D. (1966). Presidential address: the status of geography. Canadian Geographer / Le GËographe canadien, 10(3), 133-145.

Cherfas, J. (1988). The hunting of the whale: a tragedy that must end. London: Bodley Head.

Clark, D. A., \& Slocombe, D. S. (2009). Respect for grizzly bears: an Aboriginal approach to co-existence and resilience. Ecology and Society, 13(1). Retrieved from http://www.ecologyandsociety.org/vol14/iss1/art42/

Clark, T. W. (1999). The living planet in crisis: biodiversity science and policy In J. Cracraft \& F. T. Grifo (Eds.), Averting extinction: reconstructing endangered species recovery. $\mathrm{New}$ York; New Haven, CT: Columbia University Press and Yale University Press.

Clutton-Brock, J. (1995). Origins of the dog. domestication and early history. In J. Serpell (Ed.), The domestic dog: its evolution, behaviour and interactions with people. Cambridge, UK: Cambridge University Press.

Cohen, C. (1986). The case for the use of animals in biomedical research. New England Journal of Medicine, 315(14), 865-870.

Connolly, S. M. (2005). St. Casimir's Church, 1930-2005: a tribute to the parish and its people. Ottawa: SM Connolly.

Cooper, B. (2005, March 16). Bear hunt allows brush with danger, Calgary Herald.

Cooper, B., Hayes, J., \& LeRoy, S. (2002). Science fiction or science fact? The grizzly biology behind Parks Canada management models Fraser Institute Critical Issues Bulletin. Vancouver: Fraser Institute.

CP Rail. (2010). Parks Canada and Canadian Pacific take action to further protect Grizzly Bears in Banff National Park. Retrieved March 4, 2011, from http://www8.cpr.ca/cms/english/media/news/general/2010/protect+grizzly +bear $\underline{\mathrm{s}+\text { in }+ \text { banff }+ \text { national }+ \text { park }+. \mathrm{htm}}$

Creswell, J. (2002). Research design: qualitative, quantitative and mixed method approaches. Thousand Oaks, CA: Sage.

Criminal Code, C-46\$445-447 (1985).

Cronon, W. (1996). The trouble with wilderness; or getting back to the wrong nature. In W. Cronon (Ed.), Uncommon ground: retbinking the human place in nature. New York: W. W. Norton \& Company.

D'Aliesio, R. (2006, March 4). Alberta suspends grizzly bear hunt: three-year ban meant to assess population size Calgary Herald.

D'Aliesio, R. (2007, May 13). Protecting people and grizzly bears: husband of mauling victim presses province, Calgary Herald.

Davis, L. E., Gallman, R. E., \& Gleiter, K. (1997a). In pursuit of leviathan: technology, productivity and profits in American whaling, 1816-1906. Chicago: University of Chicago Press.

Davis, L. E., Gallman, R. E., \& Gleiter, K. (1997b). Product markets. In L. E. Davis, R. E. Gallman \& K. Gleiter (Eds.), In pursuit of leviathan: technology, productivity and profits in American whaling, 1816-1906. Chicago: University of Chicago Press. 
Dawson, C. (1999, June 12). A park to die for: hundreds of large mammals - bears, elk, wolves and others - have died on the roads and railways of Banff National Park; now environmentalists have called for action to end the killing;, Calgary Herald.

Dayer, A., Stinchfield, H. M., \& Manfredo, M. J. (2007). Stories about wildlife: developing an instrument for identifying wildlife value orientations cross-culturally. Human Dimensions of Wildlife, 12, 307-315.

Demeritt, D. (2001a). Scientific forest conservation and the statistical picturing of nature's limits in the Progressive-era United States. Environment and Planning D, 19(4), 431-460.

Demeritt, D. (2001b). The construction of global warming and the politics of science. Annals of the Association of American Geographers, 91(2), 307-337.

Descartes, R. (1637/1993). Animals are machines. In S. J. Armstrong \& R. G. Botzler (Eds.), Environmental ethics: divergence and convergence (pp. 281-285). New York: McGraw-Hill.

Doyle, P. (2005, July 6). Upper Bench closure now permanent, Canmore Leader.

Drake, L. (2008, January 21). Whitney woman kills wolf that ate her pet beagle, Ottawa Citizen.

Dudley, N. (2009). Guidelines for applying protected area management categories: IUCN.

Dyke, F. V. (2008). Conservation biology: foundations, concepts, applications. Springer.

Ellis, C. (2005, July 7). Ten grizzlies killed in spring shootings: debate rages of elimination of bear hunt, Calgary Herald.

Entangled right whale rescue fails, called off. (2001, June 27). New Brunswick Telegraph-Journal.

Environment Canada. (1999). The importance of nature to Canadians: survey highlights. Ottawa: Public Works and Government Services Canada.

Environment Canada. (2009). Recovery Strategy for the grizaly bear (Ursus arctos), prairie population, in Canada. Ottawa: Environment Canada.

Events (Ontario Edition). (2001, November 1). Toronto Star.

Ewins, P., de Almeida, M., Miller, P., \& Byers, O. (Eds.). (2000). Population and babitat viability assessment workshop for the wolves of Algonquin Park: Final Report. Apple Valley, MN:

IUCN/SSC Conservation Breeding Specialist Group.

Fairclough, N. (1995). Media Discourse. London, UK, Sydney and Aukland, Australia: Arnold. Festa-Blanchet, M. (2010). Status of the grizzly bear (Ursos arctos) in Alberta: Update 2010 (pp. 56). Edmonton: Government of Alberta.

Fife, R. (1970, February 21). Influence of conservation authorities criticized, Globe and Mail, p. 40.

Fitzsimmons, M. (1989). The matter of nature. Antipode, 21(2), 106-120.

Forsyth, T. (2001). Critical realism and political ecology. In G. Potter \& J. Lopez (Eds.), After postmodernism: an introduction to critical realism (pp. 146-154). London \& New York: The Athlone Press.

Foss, S. K., \& Waters, W. (2007). Destination dissertation: a traveler's guide to a done dissertation. Lanham, MD: Rowman and Littlefield.

Frey, R. G. (1980). Interests and rights: the case against animals. Oxford: Clarendon Press.

Friends of Algonquin Park. (2005). Plants and Animals of Algonquin Provincial Park.

Retrieved March 11, 2011, from http://www.sbaa.ca/about.asp?cn=279

Friends of Algonquin Park. (n.d.). Wolf Howling in Algonquin Park Algonquin Park Technical Bulletin. Whitney, ON: Friends of Algonquin Park.

Gade, D. W. (2010). Shifting synanthropy of the crow in eastern North America. The Geographical Review, 100(2), 152-175.

Gailus, J. (2009, September 1). The Canmore crash, Alberta Venture. 
Gamson, W., Croteau, D., Hoynes, W., \& Sasson, T. (1992). Media images and the social construction of reality. Annual Review of Sociology, 18, 373-393.

Garshelis, D., Gibeau, M., \& Herrero, S. (2005). Grizzly bear demographics in and around Banff National Park and Kanaaskis Country, Alberta. In S. Herrero (Ed.), Final report of the Eastern Slopes Grizaly Bear Project (pp. 26-49). Calgary: Faculty of Environmental Design, University of Calgary.

Gaston, K. J. (1994). Rarity. London: Chapman \& Hall.

George, W. (1993). Appendix. In W. George \& R. Lavocat (Eds.), The Africa-South America connection. Oxford and New York: Clarendon Press and Oxford University Press.

Gibeau, M. (2000). A conservation biology approach to management of grizzly bears in Banff National Park, Alberta. Doctor of Philosophy, University of Calgary, Calgary.

Gibeau, M., \& Stevens, S. (2005). Grizzly bear response to human use. In S. Herrero (Ed.), Final Report of the Eastern Slopes Grizzly Bear Project (pp. 182-192). Calgary: Faculty of Environmental Design, University of Calgary.

Gibson-Graham, J. K. (2002). Poststructural interventions. In E. S. Sheppard \& T. Bannes (Eds.), A Companion to Economic Geography (pp. 95-110). Oxford, UK and Malden, MA: Blackwell Publishing.

Giddens, A. (1987). Social theory and modern sociology.

Glaser, B. G., \& Strauss, A. L. (1967). The discovery of grounded theory; strategies for qualitative research. Chicago,: Aldine Pub. Co.

Gowan, D. (2007, December 20). Rescuers free entangled humpback wale: Oceans 'It was one of the worst tangled up whales I'd ever seen', Telegraph-Journal.

Greene, C. H., \& Pershing, A. J. (2004). Climate and conservation biology of North Atlantic right whales: the right whale at the wrong time? Frontiers in Ecology and Environment, 2(1), 29-34.

Grewal, S., Wilson, P. J., Kung, T. K., Shami, K., Theberge, M. T., Theberge, J. B., et al. (2004). A genetic assessment of the eastern wolf (canis lycaon) in Algonquin Provincial Park. Journal of Mammology, 84(4), 625-632.

Groom, M. J., Meffe, G. K., \& Carroll, C. R. (2006). Principles of Conservation Biology (3rd ed.). Sunderland, MA: Sinauer Associates.

Gullo, A., Lassiter, U., \& Wolch, J. (1998). The Cougar's Tale. In J. Wolch \& J. Emel (Eds.), Animal Geographies: place, politics and identity in the nature-culture borderlands (pp. 139-161).

Hajer, M. (1993). Discourse coalitions and the institutionalization of practice: the case of acid rain in Great Britain. In F. Fischer \& J. Forester (Eds.), The argumentative turn in policy analysis and planning. Durham and London: Duke University Pres.

Halls, L. K. (1984). White-tailed deer: ecology and management. Harrisburg, PA: Stackpole Books. Hambler, C. (2004). Conservation. Cambridge: Cambridge University Press.

Hames, R. (2007). The ecologically noble savage debate. Annual Review of Anthropology, 26, 177-190. doi: 10.1146/annurev.anthro.35.081705.123321

Haraway, D. J. (1989). Primate visions: gender, race, and nature in the world of modern science. New York: Routledge.

Hare, B., \& Tomasello, M. (2005). Human-like social skills in dogs? Trends in Cognitive Science, 9(9), 439-444.

Hartshorne, R. (1939). The nature of geography: a critical survey of current thought in light of the past. Lancaster, PA: The Science Press Printing Company.

Hasson, S. (1984). Humanistic geography from the perspective of Martin Buber's philosophy. Professional Geographer, 36(1), 11-18. 
Hauser, M. D. (2001). Wild minds: what animals really think. New York: Henry Holt and Company.

Hayes, R. D., \& Gunson, J. R. (1995). Status and management of wolves in Canada. In L. N. Carbyn, S. H. Fritts \& D. R. Seip (Eds.), Ecology and conservation of wolves in a changing world. Edmonton: Canadian Circumpolar Institute.

Heilprin, A. (1887). The geographical and geological distribution of animals.

Henton, D. (2009, February 22). Anecdotes about grizzlies not on par with science, groups say; Minister Ted Morton to weigh both sides in decision on hunt, Edmonton Journal.

Herrero, S. (Ed.). (2005). Biology, demography, ecology and management of grizely bears in and around Banff National Park and Kananaskis Country: the final report of the Eastern Slopes Grizily Bear Project. Calgary: Faculty of Environmental Design, University of Calgary.

Heuer, K. (2009). The big squeeze: can wildlife and hyperdevelopment coexist in the Bow Valley. Alberta Views, 32-37.

Hillary, C. (2005, June 9). Your Space - Your Time, Calgary Herald.

Hilton-Taylor, C., Pollock, C. M., Chanson, J. S., Butchart, S. H. M., Oldfield, T. E. E., \& Katariya, V. (2009). State of the world's species. In J.-C. Vié, C. Hilton-Taylor \& S. N. Stuart (Eds.), Wildlife in a changing world: an analysis of the 2008 IUCN Red List of Threatened Species. Gland, Switzerland: IUCN.

Hinchliffe, S. (2007). Geographies of nature: societies, environments, ecologies. London: Sage Publications.

Hobson, K. (2007). Political animals? On animals as subjects in an enlarged political geography. Political Geograpby, 26(3), 250-267.

Holstein, J. A., \& Gubrum, J. F. (1995). The active interview. Thousand Oaks, CA: Sage Publications.

Honey, K. (1998a, November 12). Revealed: Algonquin wolf's true colour, Globe and Mail. Honey, K. (1998b, November 12). Will the call of the wild be silenced?, Globe and Mail, p. A13.

Honey, K. (1999, March 11). Charges pulled against research of park wolves, Globe and Mail, p. A10.

How, D., \& Costello, R. (1993). K.C.: the biography of K.C. Ining. Toronto: Key Porter Books. Hughes, R., \& Flintan, F. (2001). Integrating conservation and development experience: $A$ review and biblography of the ICDP Literature. London: International Institute for Environment and Development.

Hunter, C., Caswell, H., Runge, M., Regehr, E., Amstrup, S., \& Stirling, I. (2010). Climate change threatens polar bear populations: a stochastic demographic analysis. Ecology, in press. doi: 10.1890/09-1641

Hunter, M. L. (1996). Fundamentals of Conservation Biology. Cambridge, MA: Blackwell Science.

Illical, M., \& Harrison, K. (2007). Protecting endangered species in the US and Canada: the role of negative lesson drawing. Canadian Journal of Political Science, 40(2), 367-394.

Industry Canada. (2010). Fishing, Hunting and Trapping (NAICS 114). Retrieved October 27, 2010, from Industry Canada

Irving Oil. (n.d.). Right place for the right whale. Retrieved March 19, 2011, from http://www.irvingoil.com/who we are/our stories/right place for the right wha $\underline{\text { lel }}$

IUCN. (1980). World Conservation Strategy. Gland, Switzerland: IUCN.

Jacob Herrero Environmental Consulting. (2000). Wildlife corridors in the south Canmore region: assessing the design and functionality of wildlife movement corridors in the southern Canmore region. Calgary: BowCORD Bow Valley Naturalists. 
Jacobson, S. K., \& McDuff, M. D. (1998). Training Idiot Savants: The Lack of Human Dimensions in Conservation Biology. Conservation Biology, 12(2), 263 - 267.

Jepson, J. (2008). A linguistic analysis of discourse on the killing of nonhuman animals. Society and Animals, 16, 127-148.

Johnson, E. A., \& Klemens, M. W. (2005). Nature in fragments: the legacy of sprawl. New York: Columbia University Press.

Kellert, S. R. (1996). The value of life: biological diversity and human society. Washington, D.C.: Island Press/Shearwater Books.

Kellert, S. R., \& Wilson, E. O. (Eds.). (1993). The biophilia hypothesis. Washington, D.C.: Island Press.

Kelly, B. T., Beyer, A., \& Philips, M. K. (2004). Canis rufus. 2007 IUCN Red List of Threatened Species. Retrieved from http://www.iucnredlist.org/search/details.php/3747/summ

Killing of wolves must stop, warns wilderness group. (2001, January 19). Pembroke Observer, p. 3.

Kluckhohn, F., \& Strodtbeck, F. L. (1961). Variations in value orientation. Westport, CT: Greenwood Press.

Knight, J. (2000). Natural enemies: people-zvildlife conflicts in anthropological perspective. New York: Routledge.

Knowlton, A. R., \& Brown, M. (2007). Running the gauntlet: right whales and vessel strikes. In S. D. Krauss \& R. M. Rolland (Eds.), The urban whale: North Atlantic right whals at the crossroads. Cambridge, MA and London, UK: Harvard University Press.

Kohl, J., \& Kohl, H. (1977). The view from the oak: the private worlds of other creatures. San Francisco; Boston: Sierra Club Books/Little, Brown.

Kolenosky, G. B., \& Standfield, R. (1975). Morphological and ecological variation among gray wolves (Canis lupus) of Ontario, Canada. In M. W. Fox (Ed.), The wild canids: their systematics, behavioural ecology and evolution (pp. 62-72). New York: Van Nostrand Reinhold.

Krauss, S. D., \& Rolland, R. M. (2007). Right whales in the urban ocean. In S. D. Krauss \& R. M. Rolland (Eds.), The urban whale: North Atlantic right whales at the crossroads. Cambridge, MA and London, UK: Harvard University Press.

Kwan, K. M., \& Tsang, E. W. K. (2001). Realism and constructivism in strategy research: a critical realist response to Mir and Watson. Strategic Management Journal, 22(12), 11631168.

Larson, J. (1986). Not without a plan: Geography and natural history in the late eighteenth century. Journal of the History of Biology, 19(3), 447-488.

Leopold, A. (1949/1966). A Sand County almanac. New York: Random House.

Lincoln, S., \& Guba, E. (1985). Naturalistic Inquiry London: Sage Publications.

Locke, C. (1999, September 8). Bureaucratic decisions threaten national parks ideal: plan to close Lake Louise gondola bows to extreme environmental factions, argues ski area operator Charlie Locke, Calgary Herald.

Lomolino, M. V., Riddle, B. R., \& Brown, J. H. (2006a). Biogeography (3rd ed.). Sunderland, MA: Sinauer Associates.

Lomolino, M. V., Riddle, B. R., \& Brown, J. H. (2006b). Conservation biogeography and the biogeography of humanity. In M. V. Lomolino, B. R. Riddle \& J. H. Brown (Eds.), Biogeography (3rd ed., pp. 709-744). Sunderland, CA: Sinauer Associates.

Lorimer, J. (2006). What about the nematodes? Taxonomic partialities in the scope of UK biodiversity conservation. Social \& Cultural Geography, 7(4), 539-558. 
Luke, T. (2002). On the political economy of Clayoquot Sound: the uneasy transition from extractive to attractive models of development. In W. Magnusson \& K. Shaw (Eds.), A political space: reading the global through Clayoquot Sound. Montreal: McGill - Queen's University Press.

Madden, F. (2004). Creating Co-existence between Humans and Wildlife: Global Perspectives on Local Efforts to Address Human-Wildlife Conflict. Human Dimensions of Wildlife, 9(4), 247-257.

Manfredo, M. J. (2008). Who cares about wildlife? Social science concepts for exploring human-wildlife relationships and conservation issues. New York: Springer.

Marr, K. (2005, August 24). Bear death probed, Canmore Leader.

Marshall, J. (2009). Tides of change on Grand Manan Island: culture and belonging in a fishing community. Montréal: McGill-Queen's University Press.

Matt, C. (2009). 3rd International Bear-People Conflicts Workshop Summary. Canmore, Alberta: Red Deer College.

Mattson, D. J., \& Merrill, T. (2002). Extirpations of grizzly bears in the contiguous United States, 1850-2000. Conservation Biology, 16(4), 1123-1136.

McCracken, G. (1988). The long interview. Thousand Oaks, CA: Sage Publications.

McKinney, M. L., \& Lockwood, J. L. (1999). Biotic homogenization: a few winners replacing many losers in the next mass extinction. Trends in Ecology and Evolution, 14, 450-453.

Merriam, S. B. (1998). Qualitative research and case study applications in education (2nd ed.). San Francisco: Jossey-Bass Publishers.

Michel, S. M. (2000). Golden eagles and the environmental politics of care. In J. Wolch \& J. Emel (Eds.), Animal geographies: place, politics and identity in the nature-culture borderlands (pp. 162-190). London: Verso.

Midgley, M. (1983). Animals and why they matter. Harmondsworth, Middlesex, UK: Penguin. Miles, M. B., \& Huberman, A. M. (1994). Qualitative data analysis: an expanded source book. Thousand Oaks, CA: Sage Publications.

Mol, A. (2002). The body multiple: ontology in medical practice. Durham, NC: Duke University Press.

Moore, L. (2009). Beware the elephant in the bush: myths, memory and indigenous traditional knowledge in north-eastern Namibia. Cultural Geographies, 16, 329-349.

Morris, C. (2006, November 11). Right whales in Bay of Fundy may postpone lobster season; fisheries officials fear whales will become entangled in fishing gear, New Brunswick Telegraph Journal, p. A5.

Muscovici, S. (1984). The phenomenon of social representation. In R. Farr \& S. Muscovici (Eds.), Social Representations (pp. 3-69). Cambridge: Cambridge University Press.

Nash, R. F. (1989). The rights of nature: a bistory of environmental ethics. Madison, WI: University of Wisconsin Press.

Nelson, M. E., \& Mech, L. D. (1981). Deer social organization and wolf predation in northeastern Minnesota. The Wildlife Society.

New England Aquarium. (2011). North Atlantic right whale catalog from New England Aquarium for the Right Whale Consortium http://rwcatalog.neaq.org/

Newbigin, M. I. (1913). Animal Geography: The Faunas of the Natural Regions of the Globe. Oxford: Clarendon.

Nietschmann, B. (1973). Between land and water; the subsistence ecology of the Miskito Indians, eastern Nicaragua. New York: Seminar Press.

NMFS. (2005). Recovery plan for the North Atlantic right whale (Eubalaena glacialis). Silver Spring, MD: National Marine Fisheries Service. 
Nussbaum, M. C. (2006). Frontiers of justice : disability, nationality, species membership. Cambridge, MA: Harvard University Press.

O'Connor, T. (1997). Working at relationships: another look at animal domestication. Antiquity, 71, 149-156.

O'Neill, I. (2000, April 13). Skinning the myth of the coydog, Globe and Mail, p. R11.

O'Riordan, T. (1989). The challenge for environmentalism. In R. Peet \& N. Thrift (Eds.), New models in geography (Vol. 1, pp. 82-109). Florence, KY: Routledge.

Offenberg, J. (2001). Balancing between mutualism and exploitation: the symbolic interaction between Lasius ants and aphids. Behavioral Ecology and Sociobiology, 49(4), 304-310. doi: $10.1007 / \mathrm{s} 002650000303$

Ontario. (2005). Strategy for wolf conservation in Ontario. Toronto: Ontario Ministry of Natural Resources.

Ontario Ministry of Agriculture Food and Rural Affairs. (2009). Wolf-Coyote Predation Program - 3 year stats. Unpublished data. Ontario Ministry of Agriculture, Food and Rural Affairs. Guelph.

Pauktuutit Inuit Women of Canada. (2006). The Inuit way. Ottawa: Pauktuutit Inuit Women of Canada.

Perrin, T. (2009). The business of urban animals survey: the facts and statistics on companion animals in Canada. Canadian Veterinary Journal, 50(January), 48-52.

Philbrick, N. (2000). In the heart of the sea : the tragedy of the whaleship Essex. New York: Viking.

Philo, C., \& Wilbert, C. (2000). Animal spaces, beastly places: new geographies of human-animal relations. London; New York: Routledge.

Pissot, J. (2005, June 16). How with province solve Canmore's wildlife concerns? Calgary Herald.

Pluhar, E. B. (1995). Beyond prejudice: the moral significance of human and nonbuman animals. Durham: Duke University Press.

Proctor, J. D. (2000). The spotted owl and the contested moral landscape of the Pacific northwest. In J. Wolch \& J. Emel (Eds.), Animal geographies: place, politics and identity in the nature-culture borderlands (pp. 191-217). London: Verso.

Quinn, N. W. S. (2005). Reconstructing changes in abundance of white-tailed deer, Odocoileus virginianus, moose, Alces alces, and beaver, Castor canadensis, in Algonquin Park, Ontario, 1860-2004. Canadian Field-Naturalist, 119(3), 330-342.

Raup, D. M. (1986). Biological extinction in Earth history. Science, 231, 1528-1533.

Reeves, R. R., \& Barto, M. F. (1985). Whaling in the Bay of Fundy. Whalewatcher (Winter 1985), 13-18.

Regan, T. (1983). The case for animal rights. Berkeley: University of California Press.

Remington, R. (2005, June 8). No guarantees in a mountain town, Calgary Herald, p. B1.

Remington, R. (2006, May 16). Every shadow menaces on trail where Banff worker was mauled, Calgary Herald.

Remington, R. (2010, October 24). Bridging the killing field in Banff: Banff's controversial wildlife overpasses have become runaway success in reducing wildlife deaths on the Trans-Canada Highway, Calgary Herald.

Rescue of entanged right whale set for today. (2001, June 25). New Brunswick Telegraph-Journal. Residents asked to do their part against crows. (2010, December). Chatham Daily News.

Rodrigue, C. (1992). Can religion account for early domestication? Professional Geographer, 44(4), 417-430.

Roman, J., \& Palumbi, S. R. (2003). Whales before whaling in the North Atlantic. Science, 301, 508-510. 
Rutledge, L. Y., Garoway, C. J., Loveless, K. M., \& Patterson, B. R. (2010). Genetic differentiation of eastern wolves in Algonquin Park despite bridging gene flow between coyotes and grey wolves. Heredity, 1-12. doi: 10.1038/hdy.2010.6

Rutledge, L. Y., Patterson, B. R., Mills, K. J., Loveless, K. M., Murray, D. L., \& White, B. N. (2010). Protection from harvesting restores the natural social structure of eastern wolf packs. Biological Conservation, 143, 332-339.

Sandford, R. (2008). The weekender effect: byperdevelopment in mountain towns. Vancouver: Rocky Mountain Books.

Sandilands, C. (2002). Between the local and the global: Clayoquot Sound and simalacrul politics. In W. Magnusson \& K. Shaw (Eds.), A political space: reading the global through Clayoquot Sound (pp. 139-168). Montreal: McGill - Queen's University Press.

Sauer, C. O. (1952a). Agricultural origins and dispersals. New York: American Geographical Society.

Sauer, C. O. (1952b). Seeds, spades, hearths and herds. New York: American Geographical Society.

Sayer, R. A. (1992). Method in social science: a realist approach (Vol. 2nd ed.). London \& New York: Routledge.

Sayer, R. A. (2000). Realism and social science. London and Thousand Oaks, CA: Sage Publications.

Scott, J. C. (1998). Seeing like a state: why certain schemes for the improvement of humanity bave failed. New Haven: Yale University Press.

Scully, M. (2002). Dominion: the power of man, the suffering of animals, and the call to mercy: St. Martins Press.

Seger, J. D., \& Van Beek, G. W. (1996). Retrieving the past: essays on archaeologocial research and methodology in bonor of Gus Willard V an Beek. Winona Lake, IN: Eisenbrauns.

Semmens, G. (2004, October 6). Plan 'nail in coffin' for wildlife, Calgary Herald.

Semmens, G. (2005, February 2). Minister refuses to cancel grizzly hunt, Calgary Herald.

Seymour, M., \& Wolch, J. (2010). "A little bird told me": approaching animals through qualitative methods. In D. DeLyser, S. Herbert, S. C. Aitken, M. Crang \& L. McDowell (Eds.), The Sage Handbook of Qualitative Geography. Los Angeles and London: Sage.

Shepard, P. (1996). The others: how animals made us human. Washington, DC: Island Press. Shutiak, L. (1999, August 22). Parks become battlegrounds: the right to a fair trail, Calgary Herald.

Sillero-Zubiri, C., \& Switzer, D. (2001). Crop raiding primates: searching for alternative, humane ways to resolve conflict with farmers in Africa. In C. Sillero-Zubiri \& D. Switzer (Eds.), People and Wildlife Initiative (Vol. 1, pp. 19). Oxford, UK: Conservation Research Unit, Oxford University.

Singer, P. (2002). Animal liberation (1st Ecco paperback ed.). New York: Ecco.

Singh, J. S. (2002). The biodiversity crisis: a multifaceted review. Current Science, 82(6), 638647.

Smith, N. (1984). Uneven development: nature, capital and the production of space. New York: Blackwell.

Smith, N. (2001). Are indigenous people conservationists? Rationality and Society, 13(4), 429461.

Social structure. (2002). In C. Calhoun (Ed.), Dictionary of the Social Sciences. Oxford: Oxford University Press. 
Soja, E. W. (1999). Thirdspace: expanding the scope of the geographical imagination. In D. Massey, J. Allen \& P. Sarre (Eds.), Human Geography Today (pp. 260-278). Malden, MA: Polity Press.

Soule, M. E. (1985). What is conservation biology? Bioscience, 35(13), 727-734.

Soulé, M. E., \& Lease, G. (1995). Reinventing nature?: responses to postmodern deconstruction. Island Press.

Species at Risk Public Registry. (2001). Species profile: eastern wolf. Retrieved June 4, 2010 http://www.sararegistry.gc.ca/species/speciesDetails_e.cfm?sid $=608$

Statistics Canada. (1996). Community profiles: Canmore, Alberta (Town). Retrieved September 5, 2008, from http://www12.statcan.ca/english/profil/Details/details1.cfm?SEARCH=BEGINS $\& I D=12184 \& P S G C=48 \& S G C=4815023 \& D$ ata Type $=1 \& \mathrm{LANG}=$ E\&Province $=48$ $\&$ PlaceName $=$ Canmore $\& C M A=0 \& C S D N A M E=$ Canmore $\& A=\&$ TypeNameE $={ }^{\prime}{ }_{0}$ wn

Statistics Canada. (2006). Community profiles: Canmore, Alberta (Town). Retrieved September 5, 2008, from http://www12.statcan.ca/english/census06/data/profiles/community/Details/Page .cfm?Lang $=\mathrm{E} \& \mathrm{Geo} 1=\mathrm{CSD} \&$ Code $1=4815023 \& \mathrm{Geo} 2=\mathrm{PR} \&$ Code $2=48 \& \mathrm{Data}=\mathrm{Cou}$ nt $\&$ Search Text $=$ canmore $\&$ Search Type $=$ Begins $\&$ SearchPR $=01 \& B 1=$ All $\&$ Custom $=$

Statistics Canada. (2010). Food available, by major food groups (Animal Products) (Table 002-0029). Retrieved October 28, 2010, from Statistics Canada http://www40.statcan.gc.ca/101/cst01/famil102d-eng.htm

Steed, J. (1988, October 15). The oldman of the woods, Globe and Mail, p. D5.

Stibbe, A. (2001). Language, power and the social construction of animals. Society and Animals, 9(2), 145-161.

Stolte, E. (2005, July 12). Report calls for grizzly management: humans still greatest threat to bears, Calgary Herald.

Stork, N. E. (2010). Re-assessing current extinction rates. Biodiversity and Conservation, 19(2), $357-371$.

Strickland, D. (1999, July 29). A wolfian trilogy part 3: you red it here first, The Raven.

Strickland, D. (2000, August 3). We've come a long way, Raven.

Strickland, D. (2001, August 2). Wolves through the time warp, The Raven.

Strickland, D. (2009). What prevented, and later allowed, the expansion of the white-tailed deer. Oxtongue Lake, ON.

Taggart, C. T., \& Vanderlaan, A. (2003). Regional time/space conflicts in vessel traffic and fishing effort with right whales in the Bay of Fundy. Halifax: Dalhousie University.

Theberge, J. B., \& Falls, J. B. (1967). Howling as a means of communication in timber wolves. American Zoologist, 7, 331-338.

Theberge, J. B., \& Theberge, M. T. (1998). Wolf country. Toronto: McLellan and Stewart.

Theberge, J. B., \& Theberge, M. T. (2004). The wolves of Algonquin Park: a 12 year ecological study. Waterloo: University of Waterloo.

Tkachyk, M. (2001, November 15). The wolves howl, the government listens, Guelph Mercury.

Treves, A., Wallace, R. B., Naughton-Treves, L., \& Morales, A. (2006). Co-managing humanwildlife conflicts: a review. Human Dimensions of Wildlife, 11, 383-396.

Trueman, M. (2002, December 23). Biologist praises decision to give whales right-of-way, New Brunswick Telegraph Journal. 
Trueman, M. (2005a, August 27). Biologists celebrate return of miracle whale; Calvin, the right whale, spotted and photographed in the Grand Manan Basin, New Brunswick Telegraph-Journal.

Trueman, M. (2005b, August 6). Biologists file in for annual right whale passage, New Brunswick Telegraph-Journal.

Trueman, M. (2005c, August 30). Calvin, calf make it safely to Bay of Fundy, New Brunswick Telegraph Journal.

Trueman, M. (2005d, July 18). Special right whale is offspring of NB Museum's Delilah, New Brunswick Telegraph Herald.

Trut, L. N. (1999). Early canid domestication: the farm-fox experiment. American Scientist, 87, 160-169.

Tuan, Y.-f. (1984). Dominance \&o affection: the making of pets. New Haven: Yale University Press.

Urquhart, M. (2001, June 13). Scientists preparing for a whale of a rescue, New Brunswick. Telegraph-Journal.

van Dijk, T. (1980). Macrostructures: an interdisciplinary study of global structures in discourse, interaction and cognition. Hillside, NJ: Laurence Erlbaum.

van Dijk, T. (1988a). News analysis: case studies of international and national news in the press. Hillside, NJ: Laurence Erlbaum.

van Dijk, T. (1988b). News as discourse. Hillsdale, NJ: Laurence Erlbaum.

van Dijk, T. (Ed.). (1985). Handbook of discourse analysis. London: Academic Press.

Vanderlaan, A., \& Taggart, C. T. (2009). Efficacy of a voluntary area to be avoided to reduce risk of lethal vessel strikes to endangered whales. Conservation Biology, 23(6), 14671474.

Vidal de la Blache, P. (1956). Principles of human geography. London: Constable.

von Uexküll, J. (1926). Theoretical biology. New York: Harcourt, Brace \& Company.

Wallace, A. R. (1876). The geographical distribution of animals. Macmillan.

Whale rescue fogged in. (2001, June 30). New Brunswick Telegraph-Journal.

Whatmore, S. (2000). Geography of animals. In R. J. Johnston, D. Gregory, G. Pratt \& M. Watts (Eds.), The Dictionary of Human Geograpby (Fourth Edition ed., pp. 25-26).

Malden, MA; Oxford, UK; Victoria, Australia: Blackwell Publishing Ltd.

Whatmore, S. (2002). Hybrid geographies: natures, cultures, spaces. London and Thousand Oaks, CA: Sage.

Whatmore, S., \& Thorne, L. (1998). Wild(er)ness: reconfiguring the geographies of wildlife. Transactions of the Institute of British Geographers, 23(4), 435-454.

Wheaton, A. (2001, September 21). Entangled whale may be dead, New Brunswick Telegraph Journal.

Wheeldon, T., Patterson, B. R., \& White, B. N. (2010). Colonization history and ancestry of northeastern coyotes. Biology Letters, 6, 246-247. doi: 10.1098/rsbl.2009.0822

Whiten, A., Goodall, J., McGrew, W. C., Nishida, T., Reynolds, V., Sugiyama, Y., et al. (1999). Cultures in chimpanzees. Nature, 399(17 June), 682-685.

Williams, J. (1999, April 8). Group says injured bear first of many, Calgary Herald.

Williamson, K. (2005, August 28). Bears, humans in turf war, Calgary Herald.

Wilson, P. J., Grewal, S., Lawford, I. D., Heal, J. N. M., Granacki, A. G., Pennock, D., et al. (2000). DNA profiles of the eastern Canadian wolf and the red wolf provide evidence for a common evolutionary history independent of the gray wolf Canadian Journal of Zoology, 78, 2156-2166. 
Wilson, P. J., Grewal, S., McFadden, T., Chambers, R., \& White, B. N. (2003). Mitochondrial DNA extracted from eastern North American wolves killed 1800s is not of gray wolf origin. Canadian Journal of Zoology, 81, 936-940.

Wolch, J., \& Emel, J. (1998). Preface. In J. Wolch \& J. Emel (Eds.), Animal geographies: place, politics, and identity in the nature-culture borderlands. London and New York: Verso.

Wolch, J., \& Emel, J. (Eds.). (1998). Animal geographies : place, politics, and identity in the natureculture borderlands. London and New York: Verso.

Wolch, J., Emel, J., \& Wilbert, C. (2003). Reanimating Cultural Geography. In K. Anderson (Ed.), Handbook of Cultural Geography. Sage Publications.

Wolf hunting ban now in effect. (2002, January 2). Pembroke Observer, p. 1.

Wolf numbers prompt requests for provincial action. (1966, March 18). Globe and Mail, p. 8.

Woods, M. (2000). Fantastic Mr Fox? Representing animals in the hunting debate. In C.

Philo \& C. Wilbert (Eds.), Animal spaces, beastly places: new geographies of animal-human relations (pp. 182-202). London: Routledge.

Yarwood, R., \& Evans, N. (2000). Taking stock of farm animals and rurality. In C. Philo \& C. Wilbert (Eds.), Animal spaces, beastly places: new geographies of animal-buman relations (pp. 98-114). London: Routledge.

Yarwood, R., \& Evans, N. (2003). Livestock, locality and landscape: EU regulations and the new geography of Welsh farm animals. Applied Geography, 23(2-3), 137-157. doi: 10.1016/j.apgeog.2003.08.003

Yin, R. K. (2009). Case study research: design and methods (4th ed.). Thousand Oaks, CA: Sage.

Young, S. P., \& Goldman, E. A. (1944). The wolves of North America. New York: Dover Publications.

Zeuner, F. E. (1963). A history of domesticated animals. Englewood Cliffs, NJ: Prentice-Hall. 


\section{Appendix A: Informed consent documentation}

This research was conducted with the clearance of Carleton University's Research Ethics Committee and conducted in accordance with the Tri-Council Policy Statement: Ethical Conduct for Research Involving Humans and the Carleton University Policies and Procedures for the Ethical Conduct of Research. The following statement was delivered to each interviewee in the research program:

\section{Spaces of Co-existence: Processes and Prospects of Living With Endangered Species}

\section{Informed Consent}

This interview is part of a research project by myself, John Wall, which will lead to a doctoral dissertation in the Department of Geography and Environmental Studies at Carleton University. My credentials with Carleton University can be established by contacting Professor lain Wallace, Carleton University at (613) 520-2600 extension 2575 or by e-mail at iain_wallace@carleton.ca.

This document constitutes a voluntary agreement to take part in the research program, the purpose of which is to learn about how people adapt to the presence of animals thought to be at risk, and how those animals adapt to changing human land use. This interview is intended to gather information on (animal in location), human-wildlife conflict, conservation and management issues, and public perceptions of (animal). The interview is planned to take 90 minutes or less.

If you agree to participate in an interview, you may refuse to answer any question, and you may withdraw from the interview at any time. If you withdraw from the interview you can decide if I can use any information that you have given me prior to that withdrawal, or if you wish to have any notes or recordings of the interview destroyed.

For the purpose of accurate record keeping and analysis, it is my preference to record and transcribe our interview. If you consent to an audio recording, the audio file, transcription and any personal information gathered in the research will be destroyed once it is no longer needed (approximately December 2011).

I consent to the audio recording of my interview

Yes No

(initials) (initials)

Quotations from our interview that are published or otherwise made public will not be attributable to you, and you may not any comments that you wish to remain private so that I can avoid publicizing them at all. 
There is no compensation for participating in the study. However, if you incur any costs by participating (lost wages, child care or transportation, for example), I would be pleased to reimburse you for your expenses. If you expect to incur any expenses in participating in the research, please note the amount and type of expense here:

Type of expense:

Amount of expense:

If you are interested in following the research and its outcome, I will be pleased to provide you with a summary copy of the research results and a digital copy of the complete dissertation at the end of the research (approximately December 2010. Between now and then, you can see interim results and information as it develops at the website www.spacesofco-existence.net.

By signing below, you give your free and informed consent to participating in this project. 


\section{Appendix B: Interview guide - bears}

The following was an interview guide that was prepared after (Holstein \& Gubrum, 1995; McCracken, 1988) and adapted according to the knowledge and interest of respondents in the bear case.

\section{Biographic Information:}

Name:

Occupation:

Interest in topic/possible roles:

Residence:

\section{Context}

Tell me about grizzly bears in the Bow Valley.

What are your experiences with bears?

What do you see as the place of bears in the area?

\section{Change over time}

Do you find anything different today about grizzly bears than in years past?

What about people's attitudes toward bears, have they changed?

\section{How bears react to change}

(If a change on the bears' part has been noticed) Why do you think (name aspect from previous part of interview) has changed?

(If appropriate) Are bears more common or less common than they were in the past? Why do you think this is?

Do you think there is more human-bear contact now or less? More or less conflict?

\section{Conservation and management policy}

Grizzly bears in Alberta are listed by the federal government as 'a species of special concern' and by the province as a 'species that may be at risk' - what does this mean to you?

What do you think of current grizzly bear conservation and management policy?

Is there anything else that we haven't talked about that you would like to add? 


\section{Appendix C: Interview guide - wolves}

The following was an interview guide that was prepared after (Holstein \& Gubrum, 1995; McCracken, 1988) and adapted according to the knowledge and interest of respondents in the wolf case.

\section{Biographic Information:}

Name:

Occupation:

Interest in topic/possible roles:

Residence:

\section{Context}

Tell me about wolves in the Ottawa Valley.

Tell me about your experiences with wolves and how you learned about them.

What do you see as the place of wolves in the area?

\section{Change over time}

Do you find anything different today about wolves than in years past?

What about people's attitudes toward wolves, have they changed?

How wolves react to change

(If a change on the wolf's part has been noticed) Why do you think (name aspect from previous part of interview) has changed?

(If appropriate) Do you see or hear wolves now in more or fewer places than in the past? More or less often?

Do you think there is more human-wolf contact now or less? More or less conflict?

\section{Conservation and management policy}

The wolves in the Ottawa Valley are listed as 'a species of special concern' by the provincial and federal governments - what does this idea that they may be at risk mean to you?

What do you think of the current wolf management policy in Ontario? In the Ottawa Valley?

Is there anything else that we haven't talked about that you would like to add? 


\section{Appendix D: Interview guide - whales}

The following was an interview guide that was prepared after (Holstein \& Gubrum, 1995; McCracken, 1988) and adapted according to the knowledge and interest of respondents in the whale case.

\section{Biographic Information:}

Name:

Occupation:

Interest in topic/possible roles:

Residence:

\section{Context}

Tell me about right whales in the Bay of Fundy.

What are your experiences with whales? How do they affect your life?

What do you see as the place of whales in the area?

\section{Change over time}

Do you find anything different today about whales than in years past?

What about people's attitudes toward whales, have they changed?

How whales react to change

(If a change on the whales' part has been noticed) Why do you think (name aspect from previous part of interview) has changed?

(If appropriate) Do you see whales now in more or fewer places than in the past? More or less often?

Do you think there is more human-whale contact now or less? More or less conflict?

\section{Conservation and management policy}

The right whales in the Bay of Fundy are listed as 'critically endangered' - what does this idea that they are endangered mean to you?

What do you think of the current whale conservation and management policy?

Is there anything else that we haven't talked about that you would like to add? 


\section{Appendix E: Informants context/reference sheet}

Under the ethics guidelines of the research, participants were promised that their statements would not be attributable, and that their identities would be held in confidence. The following information is provided to readers to provide context to dissertation readers on who and where the informants were.

Informant A: Rancher and Retired Biologist, $A B$

Informant B: Biologist, NB

Informant $C$ : Naturalist, Canmore, $A B$

Informant D: Manager, Sustainable Resources Development, $\mathrm{AB}$

Informant E: Educator, Canmore, $\mathrm{AB}$

Informant F: Environmental Advocate, Canmore, $\mathrm{AB}$

Informant G: Community Volunteer, Canmore, $\mathrm{AB}$

Informant $\mathrm{H}$ : Rural Resident, Canmore, $\mathrm{AB}$

Informant I: Manager, Ministry of Natural Resources, ON

Informant J: Hunting Representative, $\mathrm{ON}$

Informant K: Rural Resident, Renfrew County, $\mathrm{AB}$

Informant L: Environmental Advocate, Ottawa, ON

Infomant M: Rural Resident, Renfrew County, AB

Informant $\mathrm{N}$ : Biologist, $\mathrm{ON}$

Informant $O$ : Environmental Advocate, $O N$

Informant P: Fisheries Advocate, NB

Informant Q: Whalewatch Operator, NB

Informant R: Biologist, MA

Informant $\mathrm{S}$ : Fisherman, NB

Informant T: Rural Resident, Renfrew County, ON

Informant U: Rural Resident, Renfrew County, ON

Informant V: Environmental Advocate, ON

Informant W: Naturalist, ON 